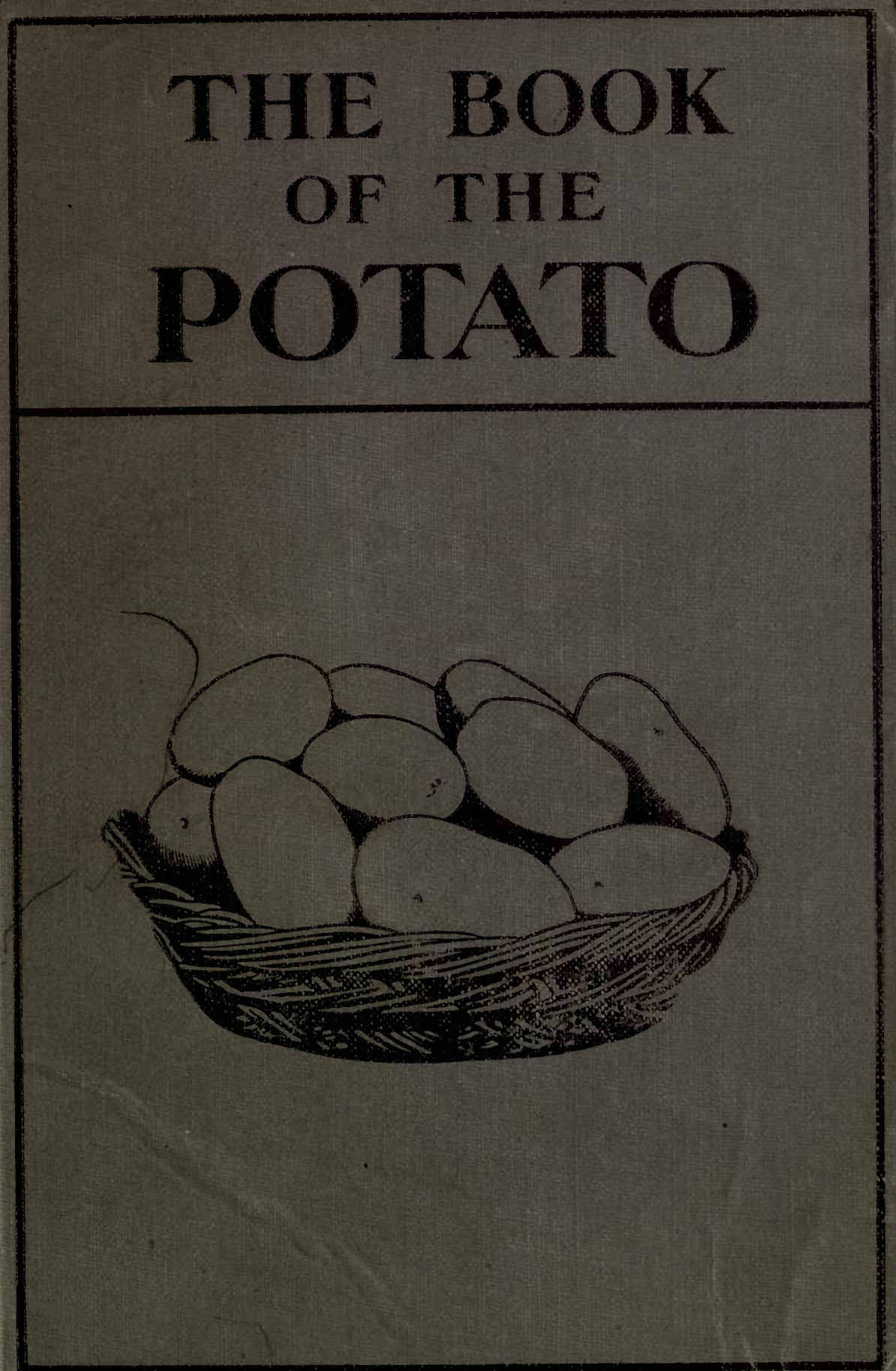




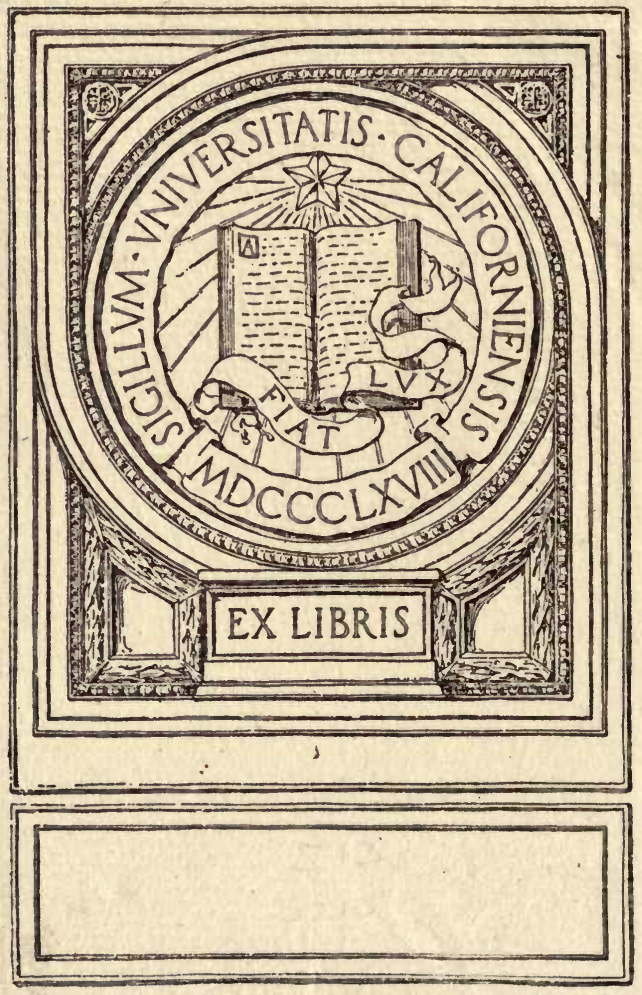






\section{THE BOOK OF THE}

\section{POTATO.}

A Practical Handbook dealing with the Cultivation of the Potato in Allotment, Garden and Field, for Home Consumption; also the Pests and Diseases thereof; together with Selections and Descriptions of the most Productive, best Cooking, and Disease-Resisting Varieties, etc.

ILLUSTRATED.

BY

T. W. SANDERS, F.L.S., F.R.H.S.

(Editor of "Amateur Gardening"; Author of "Allotment and Kitchen Gardens," "Vegetables and their Cultivation," etc.).

LONDON :

W. H. \& L. COLLINGRIDGE, $148 \& 149$, Aldersgate Street, E.C. 


\section{HOO8 314}

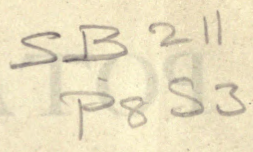

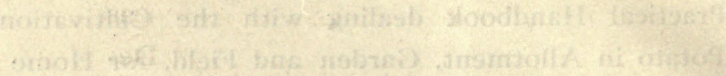

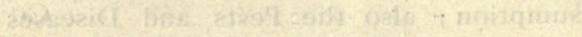

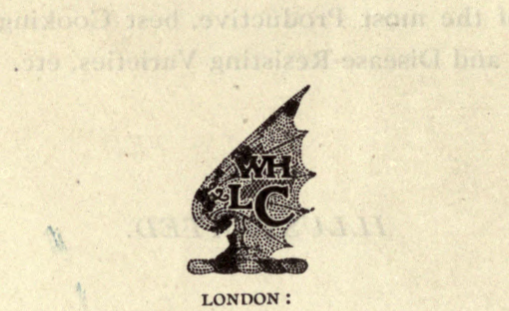

PRINTED BY W. H. AND L. COLLINGRIDGE,

148 AND 149, ALDERSGATE STREET, E.C.

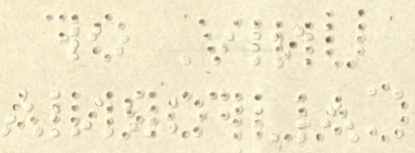




\section{FOREWORDS.}

FEw people recognised prior to 1914 that the British folk would later on have to face the problem of a possible shortage of potatoes for food. Until then we were able to produce, with the exception of the very earliest supplies, which were imported in large quantities from the Canary and Channel Islands, sufficient to meet the then requirements of the population of this country. But since the advent of the great European War, such immense quantities have had to be exported to the front to feed our great army that the supply for home consumption has necessarily been considerably curtailed. Another difficulty in production, too, has arisen in consequence of the military authorities having taken so many of the workers on the land to serve in the forces, that it has not been possible for farmers and market gardeners to plant so large an acreage with potatoes as in former years. It is, therefore, no wonder that our supplies should not be abundant, or that these should increase in value.

In face of these facts, it becomes the imperative duty of occupiers of gardens and allotments to cultivate their own supplies, and not rely, as in the past, on obtaining them from the shop or market. Happily, this fact has already been seriously recognized by country and suburban dwellers, and a greater area of land has been laid under tribute for potato culture than was previously the case. Allotments especially have increased a hundredfold throughout the country, and these have been wisely 
utilised for growing so important a food crop. In the future everyone who possibly can should grow potatoes as the staple crop, and thus render himself independent of market supplies.

To grow potatoes of good quality and in abundance more attention must be paid to the tillage of the soil, as well as to the selection of varieties of sterling merit, than is often done. Potatoes require a deeply-dug, rich and generous soil. To attempt to grow them in hungry, shallowdug soils can only end in light crops of poor quality. There must be no waiting until the planting time before attempting to prepare the soil ; this work should be carried out in autumn and winter, so that the soil is rendered sweet and wholesome for the roots when the growing season begins. This being accomplished, the next important point is to select varieties suitable to the soil, whether heavy or light, and the climatic conditions of the district.

The reader who desires to obtain the most authoritative information on the cultivation of the noble tuber on allotments, in the garden, or on the farm, should " read, mark, learn, and inwardly digest " the contents of the following pages. Therein he will find everything there is to be said about the cultivation of so valuable a vegetable, and a vast deal of other interesting facts on the subject. The lists of varieties have been carefully drawn up and supervised by leading experts. No attempt has been made to give a complete list of all the sorts in cultivation, but only those modern and older well-tried sorts that can be relied upon to give entire satisfaction as regards productiveness, first-rate cooking qualities, and more or less complete immunity from disease. 
A note of warning must be given here about that muchdreaded disease, the Black Scab or Wart Disease, which, during the last few years, has seriously threatened to annihilate the potato in this country. It is illustrated on pp. 167 and 168. Since the first appearance of this work, the Board of Agriculture and Fisheries, 4, Whitehall Place, London, S.W., have taken the disease in hand, with a view to exterminating it. Persons who find their crop attacked like the specimens illustrated, must at once notify the Secretary of the above Board of its presence, or run the risk of incurring a penalty of ten pounds in default. The Board will then send an expert to deal with the crop so as to prevent the disease spreading. Elsewhere a list of varieties recommended by the Board as likely to resist an attack of the disease is given.

T. W. S. 


\section{THE MOST POPULAR GARDENING PAPER. AMATEUR GARDENING. ONE PENNY WEEKLY.}

Coloured Plate with Every Number.

Subscription: 12 months, $6 / 6$; 6 months, $3 / 3$; 3 months. 18 . Sold Everywhere. Offices : 148 and 149, Aldersgate St., London. 


\section{ILLUSTRATIONS.}

Bacterial Disease

Marine Animal Mimic... .. 203

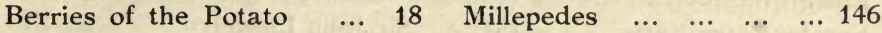

Black Scab or Wart Disease

Monarch of the Mould ... 204

167, 168 Potato Bug ... $\quad \ldots \quad$...

Potato Gnat and Larva ... 156

Cave, Potatoes Grown in 113, 114

Propagation, Mode of... ... 54

Centipedes ... $\quad \ldots . \quad \ldots \quad \ldots 146$

Clamp, Mode of Ventilat-

Ridging Soil, Mode of $\quad \ldots \quad 32$

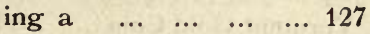

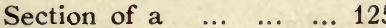

Colorado Beetle and Larva 148 and its Mimics... ... ... 147

Cottage Loaf Tuber ... ... 202

Crop of Evergood Potatoes 85

Dart Moth and Larva ... 150

Scab Diseases $\quad \ldots \quad \ldots \quad \ldots 174$

Seed or Sets, Sizes of 60,61, 62, 63 Tubers, Mode of Boxing 64

$\begin{array}{lllllll}\text { Slugs } & \ldots & \ldots & \ldots & \ldots & \ldots & 159\end{array}$

Snail, Garden $\quad$... $\quad \ldots \quad \ldots 159$

Spindle Disease $\quad \ldots \quad \ldots \quad \ldots 176$

Death's Head Moth and

Sprouting Buxes, Forms of 71, 72 $\begin{array}{llllll}\text { Larva } & \ldots & \ldots & \ldots & \ldots & 153\end{array}$

Storing, Faulty Practice in... 123

Storing S:ed Tubers ... $\quad \ldots 131$

Doggie Tuber $\quad \ldots \quad \ldots \quad \ldots 203$

Dresser ...

Eyes, Propagation by $\quad \ldots \quad 58$

Trenching Soil, Mode of ... 30

Tuber, Improperly Sprouted 66

Pierced by Twitch ... ... 206

Properly Sprouted ... ... 68

Flowers of the Potato $\quad \ldots \quad 15$ Tuber-in Tuber Freak... ... 205

Section of ... $\quad \ldots \quad 138,139$

Frog Fly $\quad \ldots \quad \ldots \quad \ldots \quad \ldots 154$

Heart and Dart Moth and

$\begin{array}{lllllll}\text { Larva } & \ldots & \ldots & \ldots & \ldots & 152\end{array}$

Hotbed and Frame $\quad \ldots \quad \ldots \quad 107$

Varieties, Arran Chief $\quad . .217$

Beauty of Hebron ... ... 9

British Queen $\quad \ldots \quad \ldots \quad \ldots \quad 11$

Chapman, The $\ldots . . . \quad \ldots 210$

Dalmeny Jewel ... $\quad \ldots \quad \ldots \quad 99$ 


\section{PAGE}

Varieties, Dalmeny Regent 95

$\begin{array}{llllll}\text { Discovery } & \ldots & \ldots & \ldots & \ldots & 17\end{array}$

Duchess of Cornwall _.. 57

Duchess of Norfolk ... _. 81

$\begin{array}{lllll}\text { Duke of York } & \ldots & \ldots & \ldots & 25\end{array}$

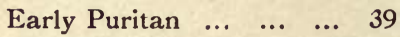

$\begin{array}{lllll}\text { Early Queen } & \ldots & \ldots & \ldots & 3\end{array}$

$\begin{array}{llllll}\text { Eldorado } & \ldots & \ldots & \ldots & \ldots & 65\end{array}$

Ensign Bagley ... $\quad \ldots \quad \ldots \quad 105$

Eureka Extra Early... ... 151

$\begin{array}{llllll}\text { Evergood } & \ldots & \ldots & \ldots & \ldots & 155\end{array}$

Extra Early $\quad \ldots \quad \ldots \quad \ldots \quad 117$

$\begin{array}{llllll}\text { Gold Reef } & \ldots & \ldots & \ldots & \ldots & 77\end{array}$

Goodfellow $\quad \ldots \quad \ldots \quad \ldots 185$

Highlander $\quad \ldots . \quad \ldots \quad \ldots 141$

$\begin{array}{lllllll}\text { Ideal } & \ldots & \ldots & \ldots & \ldots & \ldots & 165\end{array}$

$\begin{array}{lllll}\text { John Austen } & \ldots & \ldots & \ldots & 73\end{array}$

King Edward VII. $\ldots . \quad \ldots \quad 21$

$\begin{array}{llllll}\text { Knockout } & \ldots & \ldots & \ldots & \ldots & 109\end{array}$

$\begin{array}{llllll}\text { Leader } & \ldots & \ldots & \ldots & \ldots & 137\end{array}$

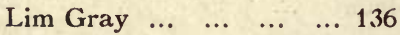

$\begin{array}{llllll}\text { Ninetyfold } & . . & \ldots & \ldots & \ldots & 43\end{array}$

Nobleman, The ... $\quad \ldots \quad \ldots \quad 67$

$\begin{array}{lllll}\text { Northern Star } & \ldots & \ldots & \ldots & 51\end{array}$

Pearl, The ... $\quad \ldots . \quad \ldots \quad \ldots \quad 145$

$\begin{array}{llllll}\text { Peckover } & \ldots & \ldots & \ldots & \ldots & \ldots \\ \end{array}$

Provost, The $\quad \ldots \quad \ldots \quad \ldots \quad 67$
PAGE

Varieties, Rajah, The ... $\quad \ldots \quad 3$

$\begin{array}{llllll}\text { Recorder } & \ldots & \ldots & \ldots & \ldots & 47\end{array}$

Ringleader $\quad \ldots . \quad \ldots \quad \ldots 151$

Ruby Queen $\quad \ldots \quad \ldots \quad \ldots \quad 155$

$\begin{array}{lllll}\text { Sacisfaction } & \ldots & \ldots & \ldots & 35\end{array}$

Scot, The $\quad \ldots \quad$...

Sharpe's Express $\quad \ldots \quad \ldots 173$

Sharpe's Victor... $\quad \ldots \quad$... 5

Sir John Franklin $\quad . . \quad \ldots \quad 133$

Sir John Llewelyn $\ldots . \quad \ldots \quad 21$

$\begin{array}{llllll}\text { Snowdrop } & \ldots & \ldots & \ldots & \ldots & 35\end{array}$

Southern Star $\quad \ldots \quad \ldots \quad 169$

Sutton's Gordon Castle ... 213

Superlative $\quad \ldots . \quad \ldots \quad \ldots 121$

Syon House Prolific... ... 144

Up-to-date $\quad \ldots \quad \ldots \quad \ldots \quad 43$

Vermont Gold Coin ... ... 133

$\begin{array}{llllll}\text { Warrior } & \ldots & \ldots & \ldots & \ldots & 129\end{array}$

Webb's New Colonist ... 209

Westmere Forester ... 161

Windsor Castle $\quad \ldots \quad$... 5

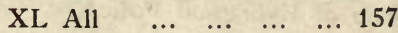

Yorkshire Glory $\quad \ldots \quad \ldots 179$

Wireworm and Click Beetle 142

Yellow Under-wing Moth ... 158 


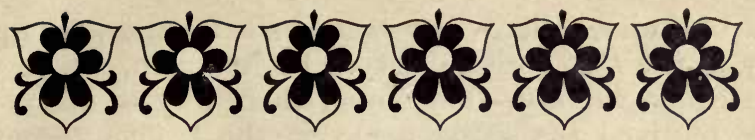

\section{The Book of the Potato.}

: 0 :

\section{CHAPTER I.}

\section{HISTORY OF THE POTATO.}

THE early history of any popular flower, fruit, or vegetable grown in British gardens is always interesting alike to the student or grower. And so any historical facts about the tuber which has commanded so much notoriety among gardeners and farmers, the last year or so, will be sure to meet with ready acceptance. In compiling histories, however, legend is often so much bound up with fact that it becomes no easy task to write a really truthful narrative, and especially when the subject thereof has been more or less under notice for several centuries, as in the case of the potato, for instance. However, we have consulted the best authorities, and we give the story, based upon such information as we have been able to obtain.

An Early Nineteenth Century Account.- - The best historical account of the potato we have come across appears in Loudon's " Encyclopædia of Gardening," published in 1836. Therein we read: "It appears probable that the potato was first brought into Europe from the mountainous parts of South America, in the neighbour. 
THE POTATO.

hood of Quito, where they were called papas, to Spain, early in the sixteenth century. From Spain, where they were called battatas, they found their way to Italy, and there received the same name as the truffle, taratoufil. From Italy they went to Vienna, through the Governor of Mons in Hainhault, who sent some to Clusius in 1598. To England the potato found its way from North America, being brought from Virginia by the colonists sent out by Sir Walter Raleigh in 1584, and who returned in July, 1586, and 'probably,' says Sir Joseph Banks, 'brought with them the potato.' Gerarde, in his Herbal, published in 1597, gives a figure of the potato under the name of Potato of Virginia, whence, he says, he received the roots; and this appellation it appears to have retained, in order to distinguish it from the battatas or sweet potato (Convolvulus battatas) till the year 1640 , if not longer.

Gough says the potato was first planted by Sir Walter Raleigh on his estate of Youghal, near Cork, and that they were soon after carried into Lancashire. Gerarde and Parkinson, however, mention them as delicacies for the confectioner, and not as common food. Even so late as Bradley's time (1716, in his 'Historia Plantarum Succulentarum ') they are spoken of as inferior to skirrets and radishes.

"The use of potatoes, however, became more and more known after the middle of the eighteerth century, and has greatly increased in all parts of Britain within the last thirty years. It is also very general in Holland and many parts of France and Germany, and is increasing rapidly in Russia. In Spain and the East and West Indies they are not much cultivated, owing to the heat of the climate; but in all the temperate parts of North America, Australasia, and South America, they are grown by the colonists. In China they are cultivated, but not extensively, owing to the slow progress which everything new makes in that country. Indeed, no root hitherto discovered is so well adapted for universal use as the tubers of the potato; for, having no peculiarity of taste, and consisting chiefly of 
starch, their farina is nearly the same as that of grain. Hence, with the flower [flour] of potatoes, puddings and

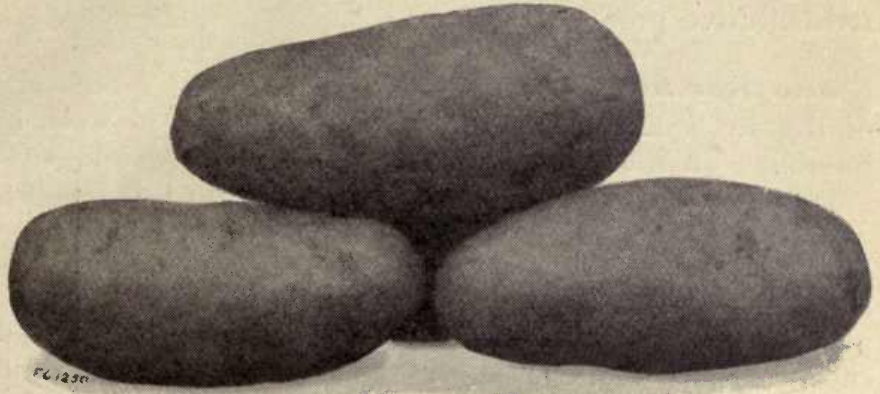

First Early Putalo-The Rajah.

such like preparations as do not call the gluten of wheatflower [sic] into action may be made equal to those of millet or rice, and excellent bread, with a moderate proportion of

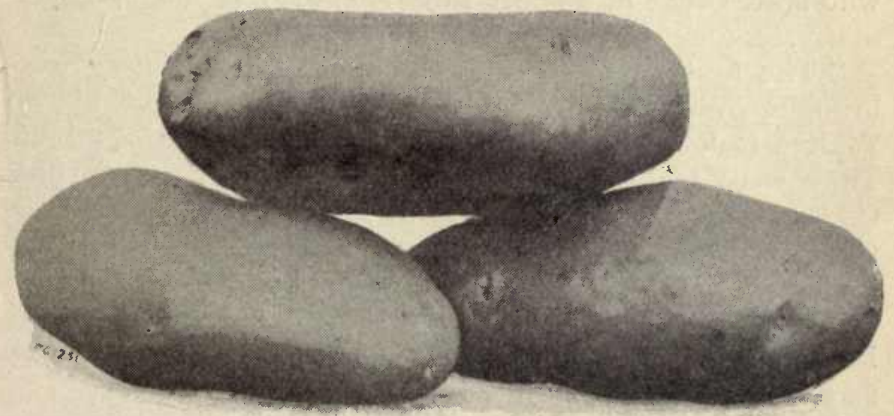

Finst liarly futato-EakLy QueEx.

good wheat-flour. Potato starch, independently of its use in the laundry and as a hair-powder, is considered an equally delicate food as sago and arrowroot. As starch B 2 
and sugar are so nearly the same that the former is easily converted into the latter, the potato yields a spirit equal to that of malt by distillation, and a wine or beer by the fermentative process."

Another Account.-We next turn to the " Treasury of Botany," dated 1884, an invaluable standard work of reference on matters botanical, where we are told that "The native country of the potato (Solanum tuberosum), and the date of its introduction into Britain, have been subjects of much discussion. There can be no doubt of its being indigenous to various parts of South Americaplants in a wild state having been found on the Peruvian coast, as well as on the sterile mountains of Central Chili and Buenos Ayres. The Spaniards are believed to have first brought it to Europe, from Quito, in the early part of the sixteenth century. It afterwards found its way into Italy, and from thence it was carried to Mons, in Belgium, by one of the attendants of the Pope's legate. In 1598 it was sent from Mons to the celebrated Clusius at Vienna, who states that in a short time it spread throughout Germany.

"The first potatoes that reached this country were brought from Virginia by the colonists sent out by Sir Walter Raleigh in A.D. 1584, and who returned in 1586. They were planted on Sir Walter Raleigh's estate near Cork, and were used for food in Ireland long before they were even known or cultivated in England. Gerarde had a plant in his garden in Holborn, and has given a figure of it in his Herbal, published in 1597, under the name of Batata virginiana. He recommends the tubers to be eaten as a delicate dish, and not as common food.

"In the time of James the First, they were so rare as to cost two shillings a pound, and are mentioned in 1619 among the articles provided for the royal household. In 1633, when their valuable properties had become more generally known, they were deemed worthy of notice by the Royal Society, which took measures to encourage their 


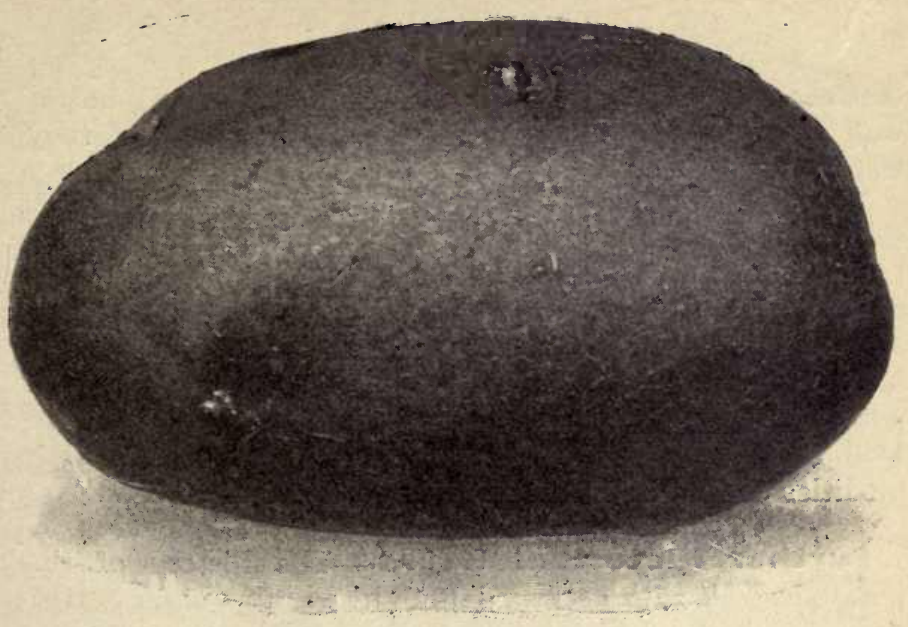

First Early Kidney Potato-Sharpe's Victor.

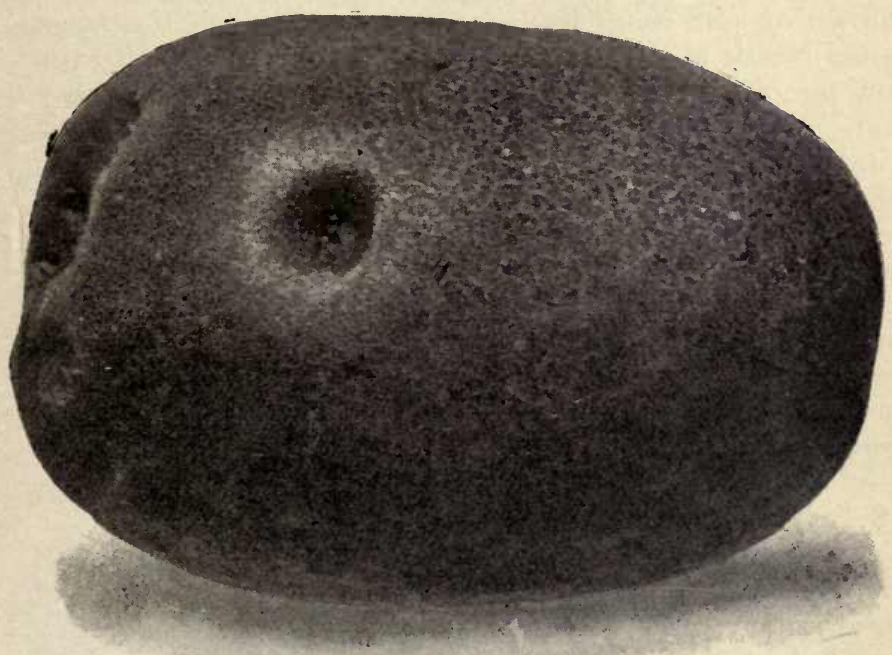

Second Early Oval Potato-Windsor Castle. 
cultivation, with the view of preventing famine; but it was not until a century after the above date that they were grown to any extent in England.

" In 1725 they were introduced into Scotland, and cultivated with much success, first in gardens, and afterwards (about 1760), when they had become plentiful, in the fields. Since that period the prejudices which so long existed against their use, both in England and Scotland, have gradually vanished, and for many years past, the potato crop has been regarded throughout the British Dominions as a most valuable addition to the staple commodities of life, only sacond in importance to cereals."

Further Historical Notes.-The history of the potato is dealt with at some length by Phillips in his " History of Cultivated Vegetables," dated 1822. He remarks: "We are informed that it [the potato] was accidentally thrown on our shore by a vessel wrecked on the coast called North Meols, in Lancashire; a place and soil even now famous for producing this vegetable in great perfection." We learn from the same source, too, that " the potato first became an object of national importance in 1662-3, as appears by the record of a meeting of the Royal Society, held March 18 th in that year; when a letter was read from Mr. Buckland, a Somersetshire gentleman, recommending the planting of potatoes in all parts of the kingdom, to prevent famine. This was referred to a committee, and, in consequence of their report, Mr. Buckland had the thanks of the Society; such members as had lands were entreated to plant them; and Mr. Evelyn was desired to mention the proposals at the close of his 'Sylva.'

"In Shropshire," says the same author, "Lord Clive found it an excellent practice to permit the planting of potatoes [by, presumably, his poor tenants] in his young [tree] plantations, the season after the young trees are put in the ground. The potatoes were continued for three years." 
Phillips further remarks: "Mr. Coke, of Holkham, in Norfolk, permitted the poor to plant potatoes in his young. plantations, and found the cultivation beneficial to the trees. . . Mr. Abdy, of Essex, grubbed a wood, and planted potatoes, which answered well. It would be highly profitable to allow the poor to plant baulks and headlands in cornfields with potatoes."

John Evelyn's Advice.-John Evelyn, in his "Kalendarium Hortense; or, the Gard'ner's Almanac; Directing what $\mathrm{He}$ is to do Monthly, throughout the Year," published in 1664, evidently does not hold the potato in very high estimation, for in his directions for the month of February, he briafly says, "And plant your potatoes in your worst ground." In the November instructions, he further remarks: "Take up you potatoes for winter spending, there will be enough remain for stocks, though never so exactly gather'd."

Lord Bacon on Potatoes.-The celebrated philosopher has the following quaint reference to the potato in his " Natural History ": "If," says he, " potado [sic] roots be set in a pot filled with earth, and then the pot with earth be set likewise within the ground, some two or three inches, the roots will grow greater than ordinary. The cause may be, for that having earth enough within the pot to nourish them, and then being stopped by the bottome of the pot from putting strings downward, they must needs grow greater in breadth and thicknesse. And it may be that all seed roots, potted and so set into the earth, will prosper the better."

Potatoes in Puritan Times.-In "Donaldson's British Agriculture," the author states that "The Puritans condemned the use of the potato, as the plant was not mentioned in the Bible, and as that gloomy enthusiasm ruled for some time, it may have hindered the commodities of life from a general diffusion., 
Introduction of the Potato into scotland.In the excerpt culled from the " Treasury of Botany," it is stated that the potato was first grown in Scotland in 1725 . The " Scottish Field," however, in reviewing our " Vegetables and their Cultivation," wherein we repeated this fact, controverts our statement. It says: "The potato is here stated not to have been introduced into Scotland prior to 1725 , when there are several known instances of its having been grown earlier, the Duchess of Buccleugh having paid 2s. 6d. to a neighbour for a peck in 1701, and in 1683, Sir George Mackenzie's gardener published details of its cultivation and treatment generally." We are glad to be able to rectify the error, and to record the additional facts supplied by the " Scottish Field." Phillips, in his "History of Cultivated Vegetables," records that "Thomas Prentice, a day labourer, first planted potatoes in the open fields, in Kilsyth; the success was such, that every farmer and cottager followed his example."

Market Culture of the Potato.-The first account we can find of the potato being extensively grown for market appears in the writings of the late Arthur Young, the agricultural writer and traveller. He mentions that in 1807, a farmer, named Puttman, of Barking, in Essex, grew 300 acres of potatoes, and sent to market, washed ready for sale, no less than 3,000 tons.

\section{Varieties Grown Sixty to Seventy Years Ago.}

-In Johnson's “Farmers' Encyclopxedia," published in 1842 , we learn that the potato was then grown extensively in field and garden, and considerable space is, consequently, devoted to the subject in that volume. The varieties then grown for field culture were the Ox-Noble, Champion, Purple Red, Rough Red, Hundred Eyes, Kidney, and Moulton White; while for garden culture Broughton's Dwarf, Early Warwick, Ash-leaved Kidney, Fox's Seedling, Early Manly, Early Mule, Early Kidney, Nonsuch, Early Shaw, and Goldfinder, are sorts advised for the ear- 


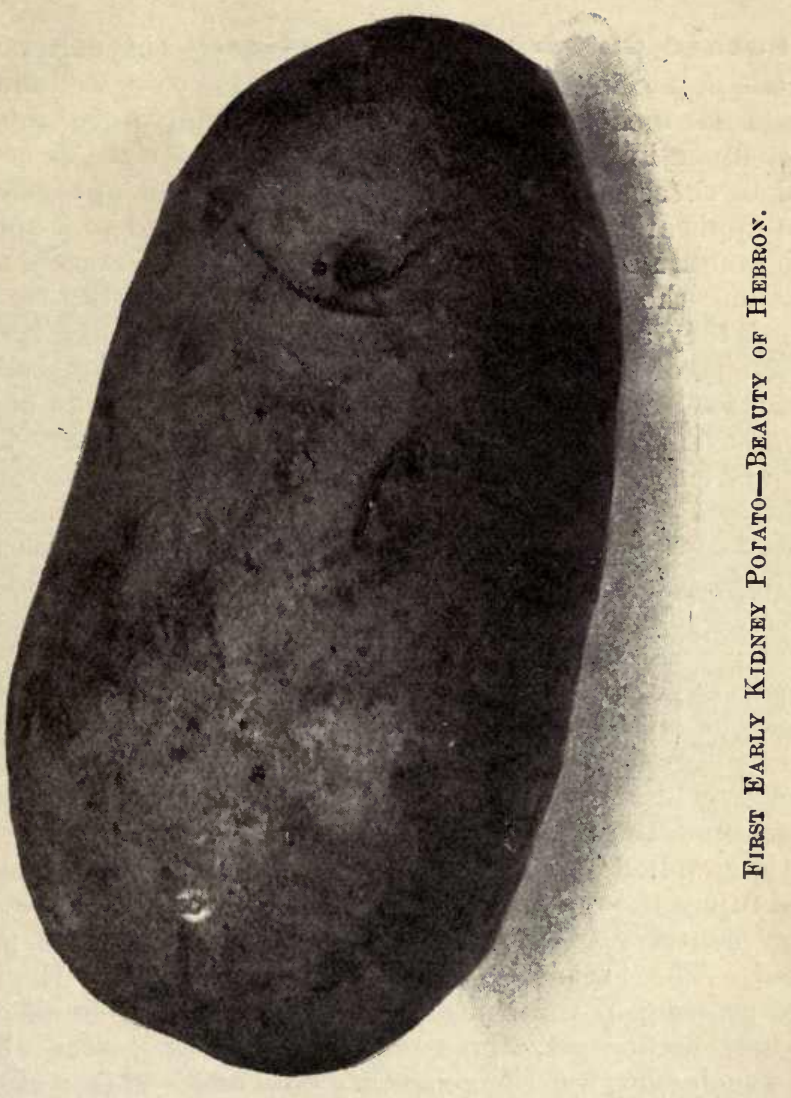


liest crops ; and Early Champion, Red-nose Kidney, Large Kidney, Bread Fruit, Red Streak, or Lancashire Pink-eye, Black Skin, and Red Apple for main crops.

Potato Culture in the Forties. - The cultivation of the potato in the forties appears to have been well understood, for most of the cultural details which are considered of so much importance to-day were strongly urged as essential to success at that period. For instance, in regard to the application of stable manure, it is advised to " spread the manure over the surface previous to digging, rather than put into the holes with the sets, or spread in the trench, when they are so planted." There seems to have been a diversity of opinion with regard to the size of the " sets " used for planting. Some growers were in favour of the largest and finest tubers planted whole; others, large tubers cut into portions, with one or two eyes to each; others, again, large tubers cut in halves; while some believed in using the shoots only, or in employing the parings as sets. The author of the last-mentioned volume expressed his opinion, as the result of experiment, " that moderate-sized sets, having two healthy buds or eyes, are most advantageously employed; middling-sized whole potatoes are the best, from which all but the above number of eyes have been removed, but especially having the crown, which is a congeries of small eyes always present, first removed; for from these proceed an equal number of little spindled stalks, which are comparatively worthless, and injure the main stem. For the early crops, almost the very contrary to the above is advantageous to be practised. The 'set' should have the crown eye, which is one growing in the cuntre of the congeries of small ones above mentioned, preserved. Some potatoes have two such eyes, but the generality only one. This is always the most prompt to vegetate." The same author also remarks that "Cuttings of the stalks, five or six inches in length, or rooted suckers, will be productive, if planted during showery weather in May or June; and during this 
last month, or early in July, it may be propagated by layers, which are formed by pegging down the young stalks, when about twelve inches long, they being covered three inches thick with mould at a joint."

In Holland's "Agricultural Survey of Cheshire " reference is made to the system adopted in that county of growing early crops of potatues. Says the author: "These [the ' sets'] should be prepared in November, by removing

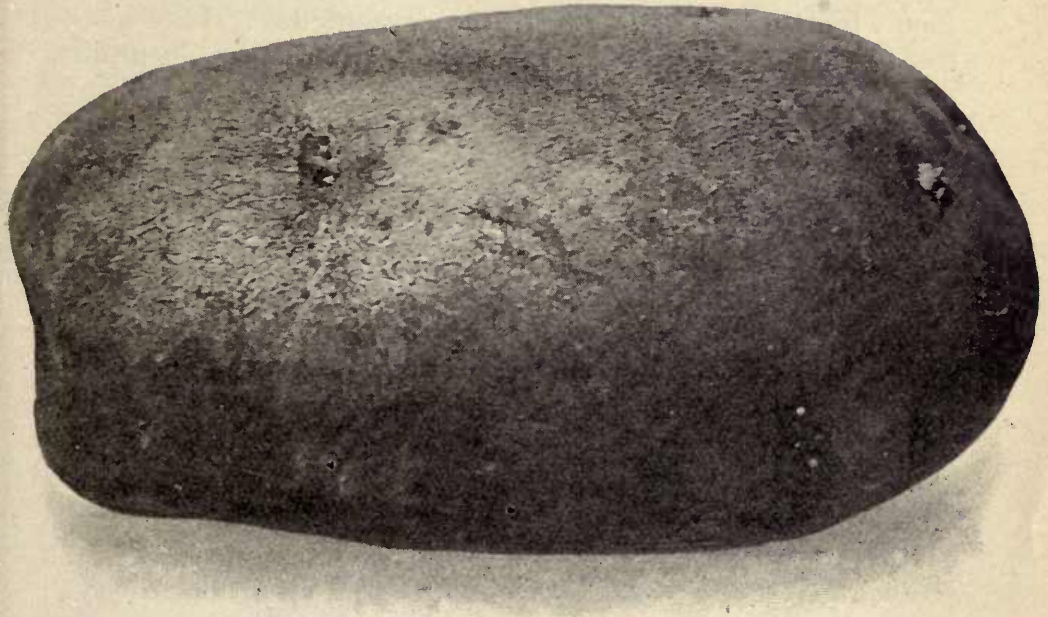

Second EarLy Kidney Putato-British Queen.

every eye but one or two; and being placed in a layer, in a warn room, where air and light can be freely admitted, with a covering of chaff or sand, they soon emit shoots, which must be strengthened by exposure to the light and air as much as possible, by taking off the covering without injuring them. The leaves soon become green and tolerably hardy. In early spring they are planted out, the 
leaves being left just above the surface, and a covering of litter afforded every night until the danger of frost is past."

\section{Rearing New Varieties Seventy Years Ago.} -In the "Transactions of the Horticultural Society of London,"' Vol. II., p. 64, very full information is given on the subject of rearing new varieties from seed. The gardener is advised to keep the tubers of each seedling separate, as scarcely two will be alike in shape or quality, while many will be worthless, and but few of any excellence, a fact which still holds good at the present day. It is also remarked that "Seldom or never does a seedling resemble exactly the original stock."

Potato Culture in the Seventies.-In that excellent little volume, "British Industries, Horticulture," by Mr. F. W. Burbidge, M.A., F.L.S., published in 1877, we gather that potatoes were extensively grown as a market garden crop at that period. There was an enormous demand for tubers for eating, as well as for the manufacture of starch and gum. It appears that large areas were devoted to potato culture at Deptford and Chiswick, near London, while in Lancashire, the district of Ormskirk was at that time a famous one for early crops. Cottagers and small farmers planted the tubers on beds of light, rich earth, protected by walls of turf, and reed or straw screens or frames, which were used in frosty weather only. The crops were lifted in May, packed in hampers, containing 20lbs. each of tubers, and sold in the Manchester, Blackburn, and Bolton markets, the produce realizing as much as $1 \mathrm{~s}$. per pound. Mr. Burbidge informs his readers that "as much as $£ 70$ had been offered by local dealers for the produce of a little cottage garden, not large enough for the support of a cow."

Potato Culture in the Channel Islands.-According to the last-named source of information, the cul- 
tivation of early potatoes for the English markets commenced somewhere about the seventies. Mr. Burbidge says : "During the last few years, a remunerative industry has made rapid progress in the Channel Islands, where, owing to the difference in the climate, the potato crop reaches maturity earlier in the season than is the case in many parts of England; and, consequently, a ready market is found in London, where the Channel Island produce competes successfully with that from Southern Cornwall, the Scilly Islands, and Normandy. Every year the quantity of early potatoes from Guernsey and Jersey increases, so much, indeed, that these islands are likely to become potato gardens ere many years elaps". Most of the people who possess a patch of ground make a point of cultivating this crop, either in the open air or under glass, as the case may be. Many acres of pits, frames, and glass-houses are devoted to potatoes during the winter and spring months. In these houses the potatoes are ready for digging very early in the spring, when they are sold for as much as 1s., or more, per pound to the Covent Garden dealers. Some idea of the extent already reached by this new industry may be formed from the fact that during two months of the potato season of $1876,22,623$ tons were exported from Jersey alone, the value of this quantity being $£ 215,000$. From trustworthy data, it has been calculated that the cultivation of this vegetable alone yields annually a return of $£ 710$ s. for each acre in ths island of Jersey.'

The Potato in Modern Times.-We have collated together in the foregoing paragraphs as many fragments of the history and progress of the potato as we have been able to discover, and such as we deemed of sufficient interest to the potato enthusiast. So far as the history of the potato, during the last twenty years, is concerned, there is nothing very startling to add beyond the fact that very considerable progress has been made in the improvement of the potato by rearing new varieties, superior in form and quality, and with greater powers of resisting disease. Ex- 
perts, like the late Mr. Paterson, Robert Fenn, Messrs. Sutton and Sons, A. Findlay, etc., have, indeed, effected quite a revolution in the potato industry, and put on the market really first-class varieties that have made themselves famous, and will continue to do so for years to come. So prominent has the potato become that we now have its interests looked after by a special society, the National Potato Society, whilst there is also an annual exhibition, solely devoted to displaying the merits of the countless varieties now in commerce.

The years 1903 and 1904 will be memorable in the future annals of the potat.). In these years the noble tuber was " boomed" as it had never been before, and the extraordinary prices obtained were far and away without parallel in the history of the potato. It may safely be asserted that such extraordinarily high values will never again be obtained. Certainly, not in this generation.

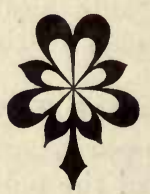




\section{CHAPTER II. \\ BOTANY OF THE POTATO.}

IT is the business of every Handbook devoted to a special subject, or crop, to give the fullest details thereon, and so

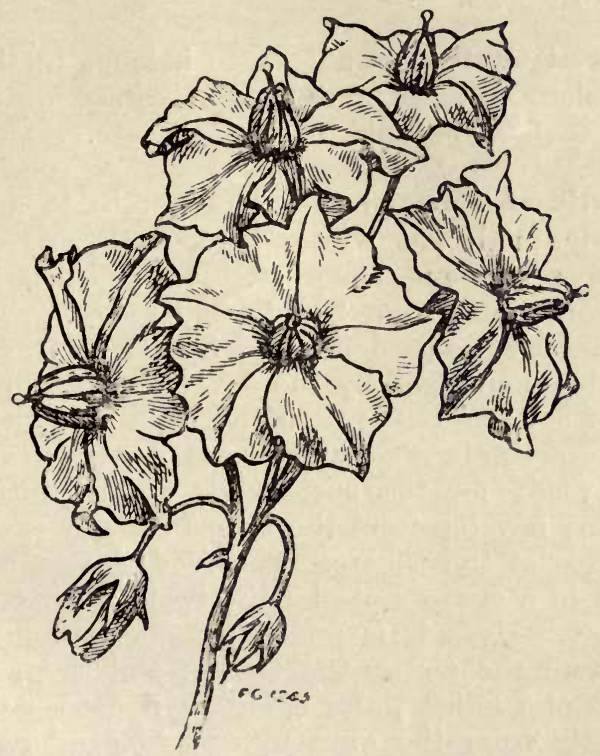

'The Flowers of a Potato.

we shall supply a few facts about the botany and physiology of the potato, so that the information imparted herein about the latter is as full and complete as possible. 
Botanical and Common Names.-First of all, the botanical name of the potato is Solanum tuberosum, pronounced So-la'-num tu-ber-o'-sum. The first, or generic, name is an old Latin word used by Pliny, the great Roman naturalist; and the specific name means tuberous-rooted. The common, or English, name, potato, is derived from the Spanish narne patatas. The latter is also the Portuguese name of the potato, while an almost similar name, patata, is used by the Italians. The French call the potato pomme de terre; the Germans, kartoffel; the Flemish and Dutch, aardaffle; the Danish, jordepeeren; and the South American, the papas.

Natural Order.-The potato belongs to the natural order Solanacex, a family of plants embracing the tobacco, tomato, petunia, nightshade, etc.

Botanical Features.-The potato is a tuberousrooted perennial, has white, lilac, or lavender coloured petals, five stamens, one stigma, and bears globular berries containing from 200 to 300 seeds. The tubers which concern the gardener and farmer most, are subterranean stems enlarged by the development to an unusual degree of cellular tissue. In the cells nutriment, in the form of starch, is gradually stored during the season of growth, ready for the sustenance of any future shoots which may develop from the latent buds or eyes, sunk in the surface of the tubers. The food thus stored is first absorbed in a crude state by the roots, then conveyed to the leaves. Here it is joined by the carbonic acid absorbed from the air by the leaves, and then, under the influence of sunlight, the chlorophyll causes the carbon to separate from the oxygen, and to combine with the hydrogen and oxygen of the crude sap, and thus form the starch, which is gradually conveyed down to the enlarged portions of the root, called the tubers. The eyes of a potato tuber are really leaf buds and analogous to those formed on the stems of a plant. 


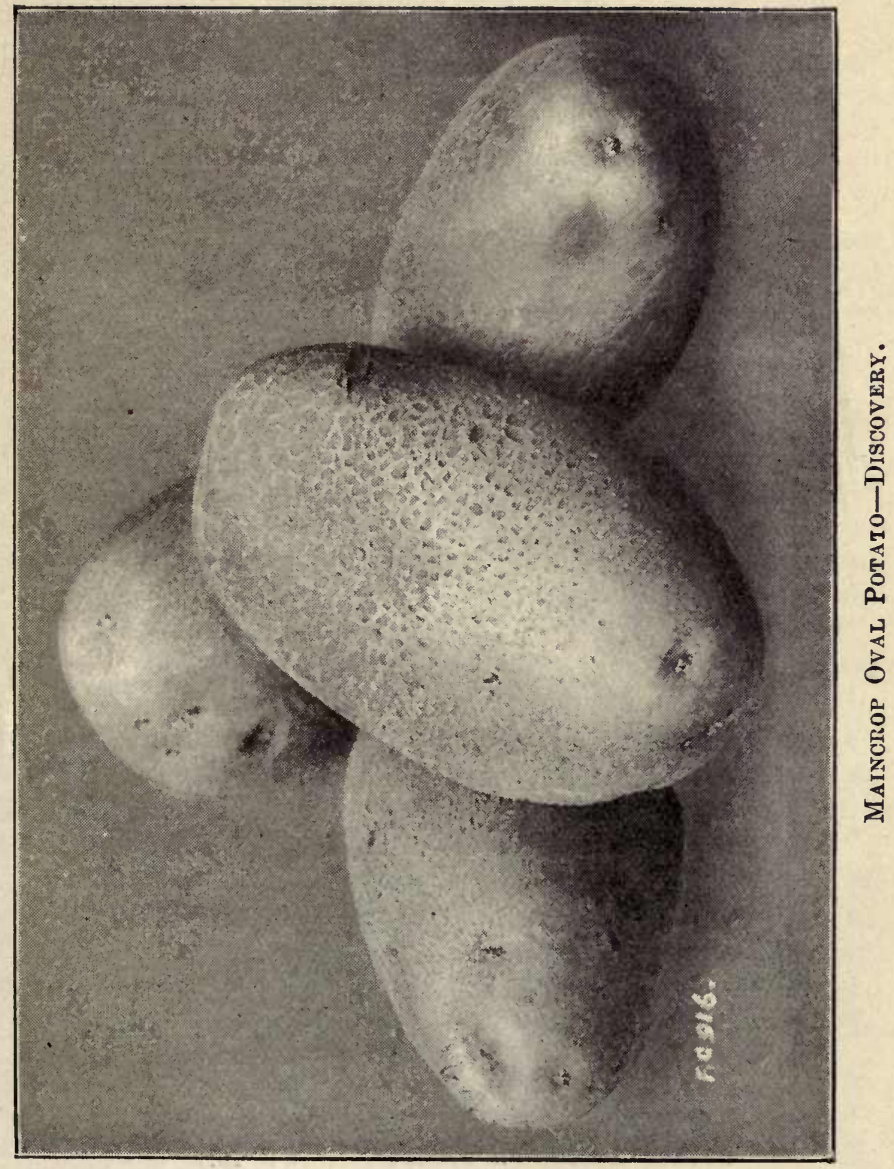


Offices of Tubers and seeds.-In this way Nature has made provision for two methods of reproduc-

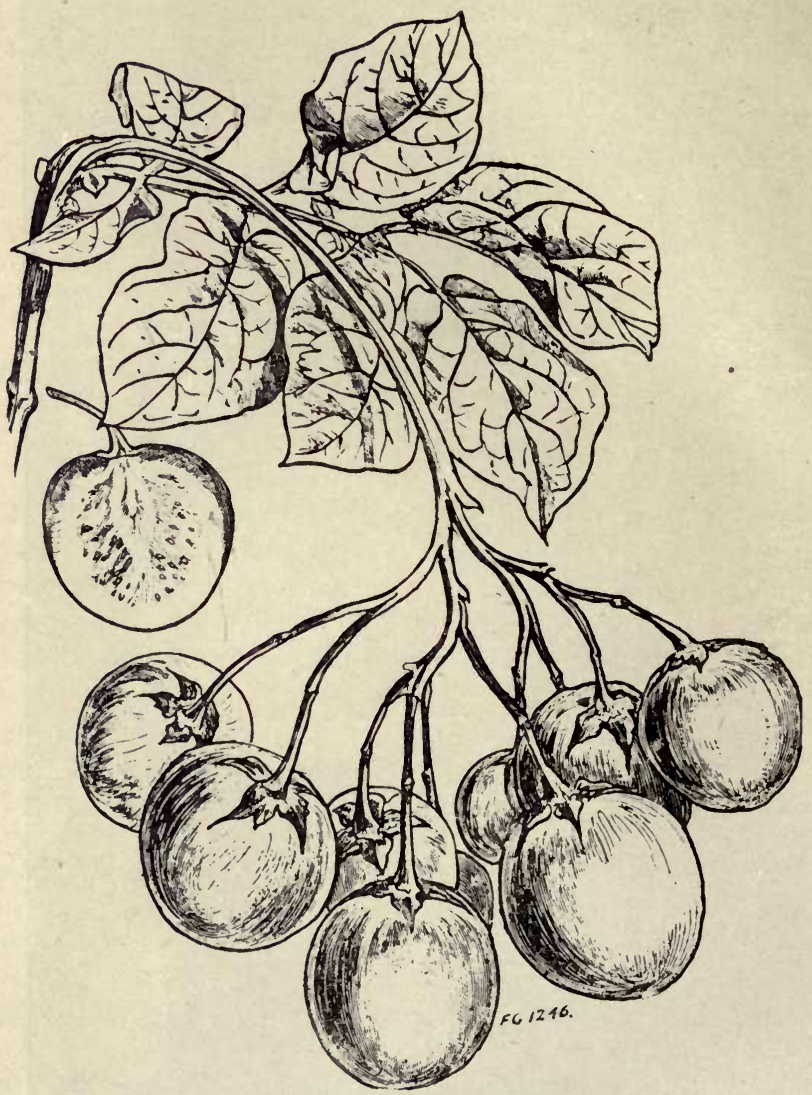

Potato Apples or Berries. (See p. 16.)

tion of the species-by tubers and by seeds. It should be understood that a potato plant also stores up a similar kind 
of food in the cells of the seeds. Hence, it frequently happens that early potatoes concentrate their energies so fully in storing up food in the tubers that they fail to produce flowers or perfect seeds. The main object of cultivating the potato is to secure an abundance of large tubers, and so we feed the plant liberally with that object in view; in other words, we encourage it to devote all its energies to tuber production. If we wanted a potato plant to yield flowers and berries in preference to tubers, we should attempt to discourage the formation of too many tubers, and so divert the manufactured food to the formation of seeds, by growing the plant in a poorer soil.

So far as the perpetuation of a potato is concerned, a tuber is as good as a seed. The tuber, as previously explained, contains reserve food for supporting the young growth till it can begin to put forth roots of its own, and collect its own soil-food. Directly it is placed in the moist earth, or if it is stored in a warm place, heat and moisture penetrate the skin of the tuber, oxygen is absorbed, and this, combining with the cell nutriments, chemically changes the starch into sugar, and provides the special form of food which the bud or eye requires to induce it to begin to grow. Precisely the same thing occurs in the case of a seed. When leaves are formed, as well as roots, the former collect food from the air, called air-food, and the latter food from the soil, called soil-food.

The story of the office and development of a tuber or seed has been told in as simple language as possible, in order that the novice in botany and plant physiology may understand the matter with ease. To the scientific reader, the facts we have set forth are well known and understood in a fuller degree than we have described.

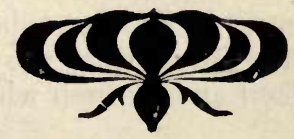


CHAPTER III.

\section{POTATOES AS A PROFITABLE CROP.}

The statistics of the potato acreage in Great Britain, given in Chapter IX., convey the impression that the growing of the crop is profitable, for otherwise the area would not have remained as great as it was twenty years ago, while the arable acreage, as a whole, has greatly decreased. One partial explanation of this satisfactory state of affairs is that in respect of soil, skill, enterprise, and varieties of potatoes in cultivation, taken together, this country is preeminent in potato production; while another is that the crop is such a bulky one that only very early produce will pay for transporting over great distances, except when the main crop is particularly dear, and then home growers get large returus.

Yield. - The average yield of potatoes in Great Britain for the ten years ending with 1904 was 5.83 tons per acre, and if the exceptionally bad crop of 1900 were omitted, it would come out within a very small fraction of 6 tons. Few foreign countries cari show such an average. That of France is only about $3 \frac{1}{4}$ tons pèr acre, that of Denmark about 4 tons, and that of the United States only a little over 2 tons. Germany and Belgium, so far as can be judged from the returns of a few recent years, are close or equal to Great Britain; but then they grow a large quantity of coarse tubers for distillation. Averages, of course, are brought down by the inferior crops grown on unsuitable soil and by men who spend very little 
upon them. Enterprising growers in the best potato districts of Great Britain would not be satisfied with much

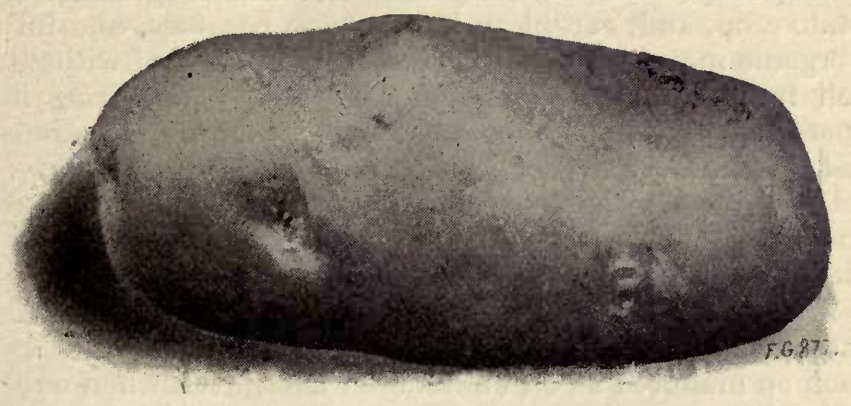

Maincrop Kidney Potato-King Edward VII.

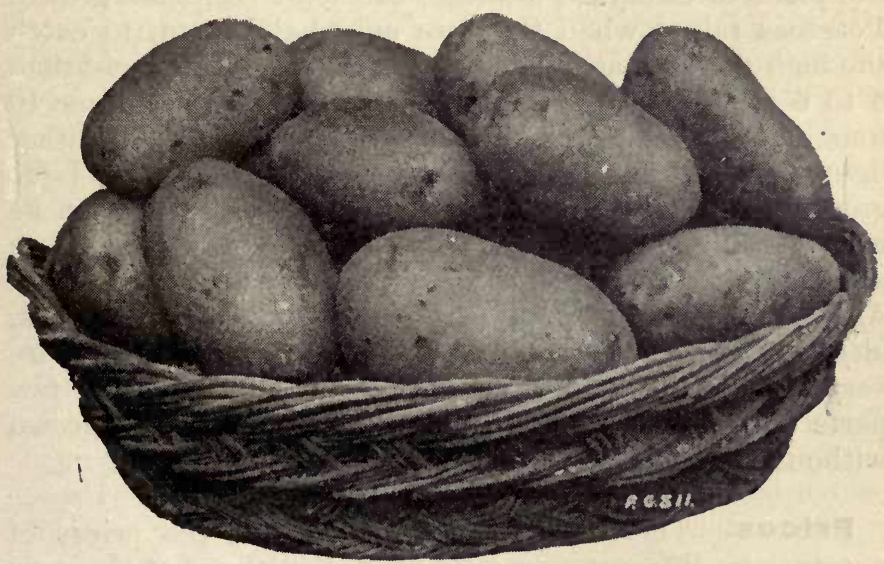

First_Early Kidney P'otato-Sir John Llewelyn.

less than double the average for the whole country. a competition in Scotland last autumn three of the com- 
petitors were declared by the judge to have produced over 18 tons per acre, the highest yield being 18 tons $13 \frac{1}{2}$ cwt. No crop responds more freely to liberal manuring than the potato crop, and, excent on land new to potatoes, and full of organic matter, great crops cannot be produced without such treatment. In Jersey very heavy manuring is general, and, although potatoes are grown on the same land year after year, while the crop is raised very early, and much before it has grown to its utmost bulk, 6 to 8 tons per acre are produced. In the parts of this country where yields of 10 to 12 tons per acre are often produced on a large acreage, the manuring is also on a very liberal scale. In many experiments the yield has been twice as much on manured as on unmanured land, even when only artificials have been used. In Ayrshire, as in Jersey, early potatoes are grown on the same land year after year, and yet, by means of heavy manuring, seaweed often taking the place of farmyard manure, excellent crops are grown. Potatoes raised when they are only half-grown, to catch the high-priced markets, do not commonly yield more than 3 to 6 tons per acre; but later liftings run up to 8 or 10 tons; and occasionally as high as 14 tons. These and other figures relating to the Ayrshire crop were supplied by large growers to Mr. Arthur Sutton a few years ago, when he was visiting the district, and they were published in an article which he contributed to the Journal of the Royal Agricultural Society. Such crops of early potatoes, although not early enough to sell at the highest rates, are very profitable. But the district is one of the very few parts of Great Britain in which first earlies can be grown without serious risk of damage by frost.

Prices:-There are great variations in the prices of potatoes in different years, as well as in those of the very early and the late tubers in the same season. With respect to the main crop, it would not be very easy to find a greater variation than there is in the prices of the present season, 1904-5, and those of the preceding one, as the rates have 
rarely been lower than those of this season, or higher than those of 1903-4. On the last Monday in 1903 the range of prices in London, taking the quotations of three markets, was $75 \mathrm{~s}$. to $130 \mathrm{~s}$. per ton; and on the corresponding day of 1904 it was 50s. to 80s. Prices in both seasons, of course, were much lower on farms, and particularly in parts of the country distant from the great markets. For example, at Crieff, an important Scottish market for potatoes, British Queens were quoted early in 1904 at $75 \mathrm{~s}$. to 80 s. per ton; while this year at about the same period they were only $32 \mathrm{~s} .6 \mathrm{~d}$. to $35 \mathrm{~s}$. Up-to-Dates were sold at about the same prices as British Queens in each season. Again, in the planting season of 1904 one of the most extensive Lincolnshire dealers in sead potatoes quoted 102s. 6d. per ton for British Queens, and sold a large quantity at that price; while this year he has offered the same variety at $65 \mathrm{~s}$. The most complete statistics of prices for early potatoes are those of Jersey, the quotations representing prices at the port of St. Heliers. In 1904 the start in shipments other than the small lots from hothouses was a low one, and the average for May 2-14 was $£ 28$ 12s. per ton. No doubt some hothouse produce was included. By the first week of June the price had fallen to $£ 61 \mathrm{~s} .4 \mathrm{~d}$., and before the end of the month there was a drop to $£ 25$ s. 6d., which was followed by a rise to $£ 39$ s. 4 d., at which the season ended, on July 23. The starting price is usually $£ 30$ to $£ 32$, and in one year, on May 5, it was $£ 45$ per ton for 25 tons. There is always a great drop in the course of a few weeks, but prices have seldom been as low as those of 1904. In Ayrshire, where raising usually begins from the middle to the end of June, the crops are mostly sold by the acre to dealers, who raise and market them. Very early pieces sometimes make $£ 35$ to $£ 40$ per acre, but $£ 26$ to $£ 32$ are more nearly average rates.

Expenses and Returns. - The cost of growing an acre of potatoes varies enormously, with rent, wages, manuring, and methods of raising. Here is an account 
of the estimated expense in a district where wages are 2s. 6d. per day at ordinary times, and $3 \mathrm{~s}$. 6d. for potato raising:

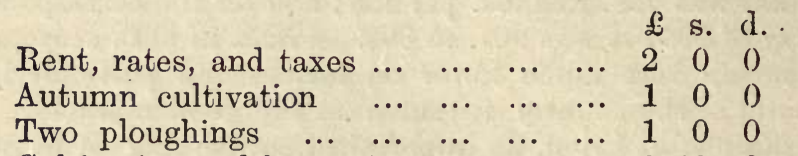

Cultivating and harrowing in spring $\quad \ldots \quad 0 \quad 0 \quad 10 \quad 0$

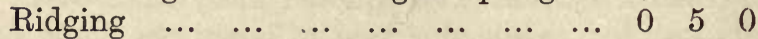

Ten tons farmyard manure and spread-

$\begin{array}{lllllllllll}\text { ing } & \ldots & \ldots & \ldots & \ldots & \ldots & \ldots & \ldots & 2 & 10 & 0\end{array}$

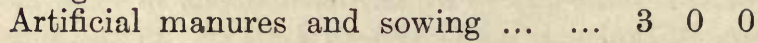

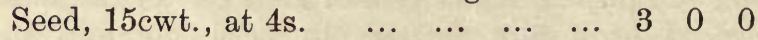

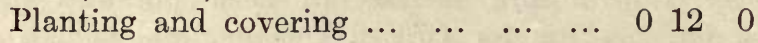

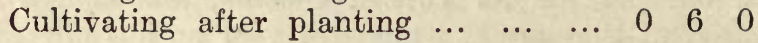

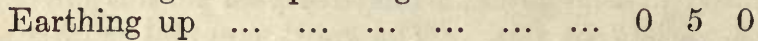

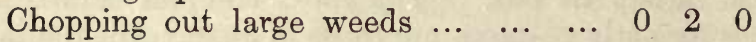

Raising with plough, picking, and cart-

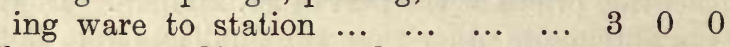

Clamping, riddling, and marketing

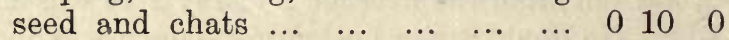

Share of miscellaneous expenses of \begin{tabular}{lllllllllll} 
farm & $\ldots$ & $\ldots$ & $\ldots$ & $\ldots$ & $\ldots$ & $\ldots$ & $\ldots$ & 0 & 10 & 0 \\
\hline 18 & & 10 & 0
\end{tabular}

If London dung carted from station used instead of farmyard manure, extra

$\begin{array}{lll}1 & 10 \quad 0 \\ £ 20 \quad 0 \quad 0\end{array}$

This is an account of the estimated expense of what may be termed moderate farming for potatoes. The rent is higher than the average on the farm, the best land being used for potatoes. Seed from Lincolnshire or Scotland would cost more in some seasons, and seldom less, including rail carriage. The expense of raising is heavy, as the 


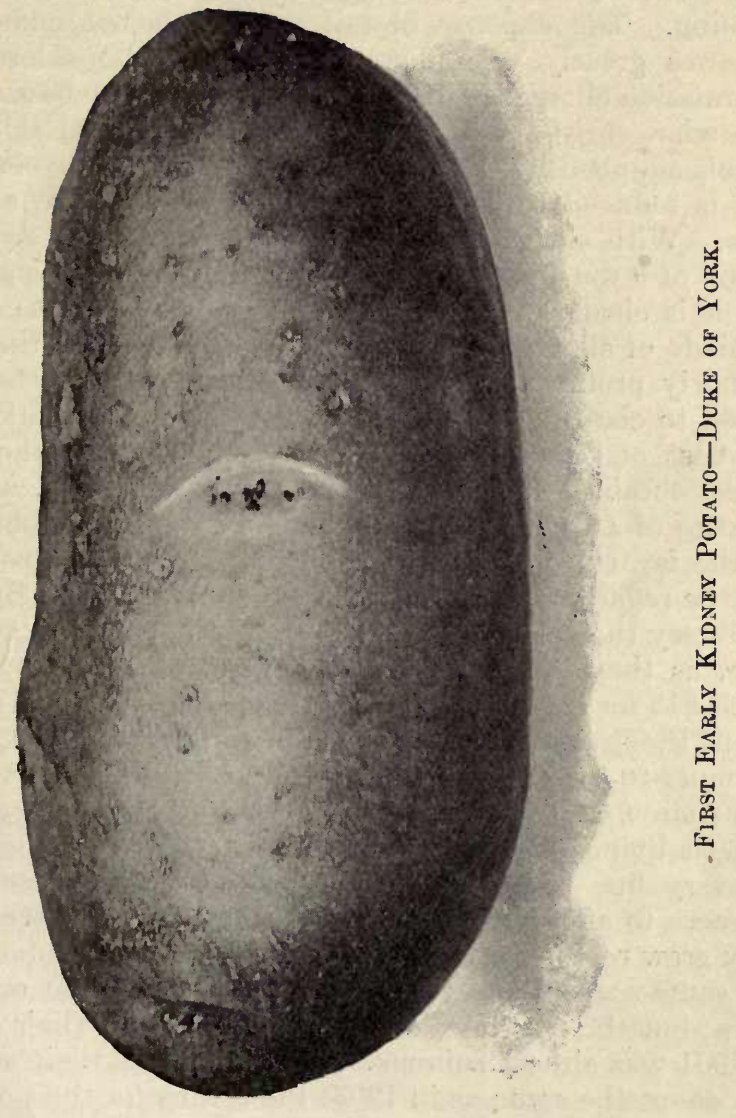


ware is picked up separately and carted direct from field to station, while the seed and chats are clamped, and afterwards sifted, the seed being re-clamped or stored in a building. The expense of rail carriage is not added, as it varies greatly with distance. Nor is the salesman's commission charged. It is $10 \mathrm{~s}$. per ton for potatoes raised somewhat early and consigned in sieves (bushel skips) or barrels supplied by the salesman. In London the commission is reduced to 5s. per ton when potatoes are sent in bags. With such farming as is indicated by the account, a crop of 8 tons one season with another shculd be grown, and it is clear that, unless an average of over £3 per ton be made of all sizes together, no less a crop than that will be fairly profitable. Where the potatoes are carted unsorted to clamps, to be dealt with later on for marketing, the cost of raising the crop is much less; but then the prices obtained for the ware are lower as a rule, and an average of $£ 3$ per ton for all sizes would not be obtained on the farm in most seasons. From $£ 15$ to $£ 30$ per acre may be regarded as the range of expens ss in Great Britain. In Jersey the growers put their expenses at $£ 35$ to $£ 40$ per acre, as they often pay $£ 10$ por acre for rent, and even up to $£ 15$ for choice bits of land sloping tow ards the south. Then they spend up to $£ 15$ for manure, and labour amounts to a good deal. They do not consider a return of less than $£ 40$ per acre fairly remunerative, as they have to get a living off a few acres. Those who pay $£ 15$ an acre for very fine spots for the earliest production need $£ 50$ per acre to afford them a moderate profit. It is true that they grow roots or some other forage crop after potatoes in the same season, and that they make some profit on their cows; but the potato crop is their mainstay. Their return in 1904 was almost ruinous. Assuming that their acreage was about the same as in 1903, the return for the potatoes shipped was not much over $£ 29$ per acre, and the extra money received for potatoes consumed in their island would not be much. In 1903 the " record " return of $£ 60$ per acre was made, and it has been over $£ 50$ in a few 
other seasons, and over $£ 40$ often. As no notice has been taken of the prices of new varieties of potatoes, " boomed " extravagantly as they have been, so no reference to the returns obtained by fortunate speculators has been deemed desirable. Potato growers who are distant from a good market make more money in a season when the crop in the country generally is small, and prices are high, than when a great yield has to be sold at low rates, because the rail carriage and marketing expenses are much heavier on the great crop, being the same per ton when prices are low as when they are high.

\section{CHAPTER IV.}

\section{SOILS AND THEIR TREATMENT.}

The potato will succeed in almost any soil, provided it be properly cultivated. But experience demonstrates the important fact that while good crops may be grown in any soil, it does not follow that the produce thereof will be of equally good flavour and quality. Crops grown on heavy clay land, for example, are inclined to be waxy and wanting in flavour. The same remarks apply to those grown on peat or bog lands. Those grown on the deep, rich, silicious, or gravelly loams of the Old Red Sandstone formation invariably turn out of better flavour and also cook more floury than those grown on other soils. We have also observed that.crops grown on the greensand and marls of the New Red Sandstone formation yield produce of first- 
rate quality. In the fen and warp lands of Lincolnshire potatoes do remarkably well, especially in those of peaty origin, known locally as “ Black Lands." In Essex, on the London clay, and in Sussex, on the Wealden clay, good potatoes are likewise grown.

If we turn to the annual official statistics, giving the acreage of potatoes grown in Great Britain and Ireland, we shall find that there are few counties in which potatoes are not extensively grown, and on a great diversity of soil formations too. In Cambridgeshire, for instance, 24,024 acres were grown in 1904 . The northern part and the centre are mostly fen land, and the remainder the Upper and Lower Chalk formation. Cheshire grew 24,167 acres, the soil being a reddish loam or marl overlying the New Red Sandstone. In Lancashire no less than 44,665 acres of potatoes were grown, and here there are a variety of soils, clays, marls, and peat beds overlying the Coal Measures, New Red Sandstone, and Millstone Grit. Lincolnshire, as might be expected, grew 76,249 acres. The chief crops were grown on the fen or warp lands, already alluded to, as well as probably on the Lias, Marl, and Greensand formations. The East, West, and North Ridings of Yorlsshire collectively grew 52,563 acres on a diversity of soils overlying the New Red Sandstone, Millstone Grit, Magnesian Limestone, etc. Then, in Wales, Cardiganshire, which possesses a by no means favourable soil, on the Silurian formation, grew 5,450 acres, or nearly double the acreage of any other county in the Principality. In Scotland, the biggest acreage grown last year was in Perthshire, this being 13,678 acres. The geological formation here is Silurian and Old Red Sandstone. Fifeshire comes next with 15,831 acres, Forfarshire with 13,305 acres, and Ayrshire with 9,457 acres. Here, again, the chief geological formations are Old Red Sandstone, Silurian, and Coal Measures. In Ireland the largest acreage devoted to potatoes in 1904 occurred in Co. Cork. Here 44,665 acres were grown, and these chiefly on the marly soils overlying the Old Red Sandstone formation. The next highest acreage 
$(41,855)$ was grown in Co. Down, on the Clay Slate formation, a very poor type of soil. - In Limerick and Tipperary, where the richest soil prevails, potatoes do not appear to be grown so extensively. Still, the soils of Ireland are, as a whole, richer than those of England and better adapted for potato culture than ours. They have no strong retentive clays, but, on the other hand, there are a large proportion of peat lands. The main drawback to successful potato culture in Ireland is the excessively moist climate. We mention the foregoing facts to show that, although the best results are obtained from certain soils, yet large crops are grown on soils of a very diversified character.

Garden Soils. - Those of the ordinary garden type that have been well manured for years only require an cccasional application of lime (see chapter on Manures) to put them in good order for successful potato culture. There are some garden soils, however, that, while rich as regards manure, are often wanting in depth of tillage. Such soils have probably been dug over the orthodox one spit deep generation after generation, and consequently there is just about one foot or less of tilled soil on the surface, the subsoil being hard and impervious to moisture. Soils of this character are bad for successful potato culture. The potato loves a deep soil, and dislikes having its roots brought in contact with an impervious subsoil, covered with stagnant water. Such a soil should therefore be trenched fully two feet deep, taking care not to bring the sour subsoil to the surface, but merely to turn it over. This work should always be done in the autumn, if possible. Soils that have been properly trenched from time to time ought to be thrown into ridges in the autumn, and left thus all the winter. The action of the frost and air upon soils thus exposed will be most beneficial from a chemical and mechanical point of view, as well as assisting to reduce the numerous pests that have sought refuge therein. Soils of a heavy nature, required for growing 
early crops, would be all the better for having plenty of decayed vegetable refuse, leaf-mould, and grit mixed with them at the time of digging. You cannot make a soil too friable, nor render it too free from stagnant moisture. Deep tilth drains a soil, and enables its interstices to be filled with air instead of water, renders it drier and warmer, and promotes the development of nitrifying organisms.

How to Deepen Soil by Trenching.-In trenching a piece of land we should avoid the erroneous and bad system of burying the top and good soil, and bringing the
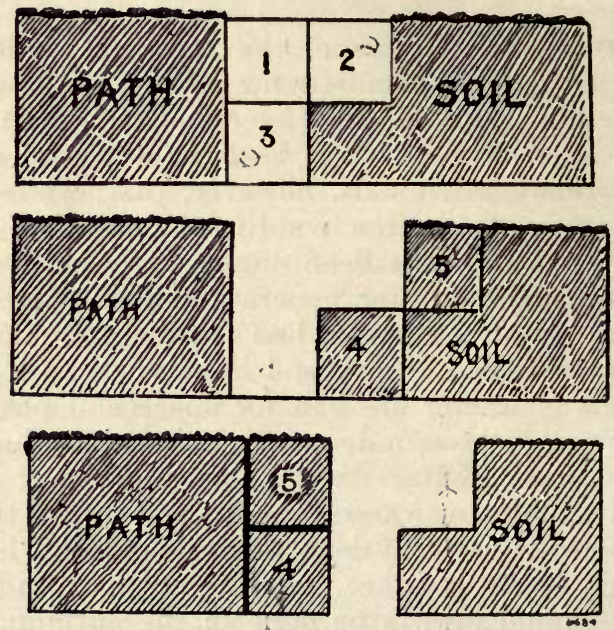

Mode of Bastard-Trenching Soll.

bottom and bad soil to the top. Some people say that soil so treated is improved in time, which is correct; but the cost of such improvement is conducive to loss rather than profit. We desire to obtain at once the most profitable crops possible; and we can, and do, obtain such crops by the process of bastard-trenching. By this pro- 
cess we obtain all the benefits attending such deep culture, and none of the disad vantages of the other system of trenching. Let us, in imagination, prepare for bastardtrenching by first showing such a trench in section: We commence by removing spit number 1 in the diagram, next the path, or elsewhere; then spit number 2 ; and finally spit number 3 , and the whole is wheeled to the other end where we propose to finish the operation, and where it will be required for the purpose of filling up the last trench. We now proceed to throw forward the spit number 4 , placing it where number 3 has been. Then the top spit, number 5 , is thrown forward and fills up where number 1 was; and so on, until the whole of the ground has been bastard-trenched. It is advisable to bastard-trench a fourth or fifth of the entire area under spade culture each year, thus trenching the whole of the ground every four or five years. Whether that quantity is trenched or not, the whole of the ground required for carrots, parsnips, and beet should be so prepared, and no manure should be given to these tap-rooted crops.

Improving a Soil by Ridging.-By this process a larger volume and surface of soil is exposed to the air, the elements, and the friends of the cultivator-the birdsthan by the process of ordinary digging. Frost penetrates, sweetens, fertilises, and pulverises a larger amount of soil, and birds more easily obtain the larvæ of insect pests which naturally exist, or shelter, in the soil ; two distinctly important gains to the gardener. Ridging is not so often carried out as it deserves; and this is chiefly because few people have heard of the operation, and fewer understand the modus operandi, simple as it is. The work is commenced exactly as in single digging; that is by first excavating a trench a spit wide and a spit deep across the plot to be ridged, and taking the soil to where it is proposed to finish. Then we proceed to dig in the ordinary manner, by inserting the spade as deeply as possible, and lifting the spadeful of soil by a sharp downward pressure of the handle, 
and a simultaneous lifting of the lower part of the spade. The spadeful of soil is projected forward and turned over at the same time, and deposited in the trench, and so on right across the plot. Although the method of taking up the spit of soil, projecting it forward, and turning it over, is identically the same as in single digging, the manner of placing each spit of soil is rather different. We wish to have the soil in ridges, and in a rough condition, and in order to obtain that result special means must be adopted, and they are exceedingly simple. Now let us see how it is done. We dig the first spit of soil, and project and turn it over in front of us. We take a second spit, and serve it the same, placing it by the side of the first. We now take a third spit, and place that on the top of the first two, and we have formed the commencement of a ridge, thus:

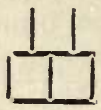

We proceed as before, by taking two more spits and throwing them forward; then add another third spit to the top of them; but instead of placing the first of each three spits of soil in contact with the second spit of each preceding three, we leave the space of a spit of soil, thus:

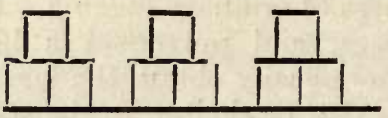

and so on across the plot. This process is repeated again and again, forwards and backwards across the plot, until the whole is completed, and we have a piece of ground in ridges and furrows like the annexed diagram.

Farm Soils. - In the treatment of farm soils deep tillage is equally important. Trenching, of course, is out of the question, but deep ploughing should certainly be done, and this as early in the autumn as possible, so that the turned-up furrows may be thoroughly "weathered" dur- 
leather-jacket grubs; and hence it is needful to take precautionary measures against injury by such pests before planting the potatoes. Where expense is a secondary consideration, it is undoubtedly a good plan to pare and burn the turf before ploughing. The paring shourd be done to the depth of almost three inches. Start a fire with straw, sticks, and other dry rubbish, then add some of the driest of the turves, and when the fire has got a good hold keep adding turves until the whole are charred. Several fires inay be formed thus. The burning converts the vegetable matter into valuable plant foods, and destroys injurious grubs. The ashes should be spread evenly over the land. The cost of paring will amount to about $£ 1$ per acre, the burning to $£ 15 \mathrm{~s}$. or $£ 110 \mathrm{~s}$. per acre, and the distribution of the ashes to $5 \mathrm{~s}$. per acre, or a total of $£ 210$ s. to $£ 215$ s. per acre.

Where this cannot be done on the score of expense, then apply quicklime, at the rate of ten tons per acre, before breaking up the pasture. Gas-lime may be used instead, at the rate of ten cwt. per acre, if the ploughing be done in autumn. Some growers have used salt at the rate of ten ewt. per acre before ploughing in autumn, and found this an excellent preventive against wireworm attack. In breaking up the pasture, it is advisable to follow the ordinary plough with a subsoiling plough, in order to get a good depth of workable soil.

Best Soils for Early Crops.-It is important to bear in mind the fact that light-coloured soils are colder than darker ones. The former reflect the sun's rays, whereas the latter absorb them. Soils, therefore, that overlie chalk or limestone are apt to be light-coloure.l and less warm than dark soils heavily charged with humus, the result of many years of manuring. The latter type of soils is best for early crops ; that is, if well drained and free from stagnant water. They are warmer and in other respects better suited for promoting that genial growth which is so essential in the case of early crops. 


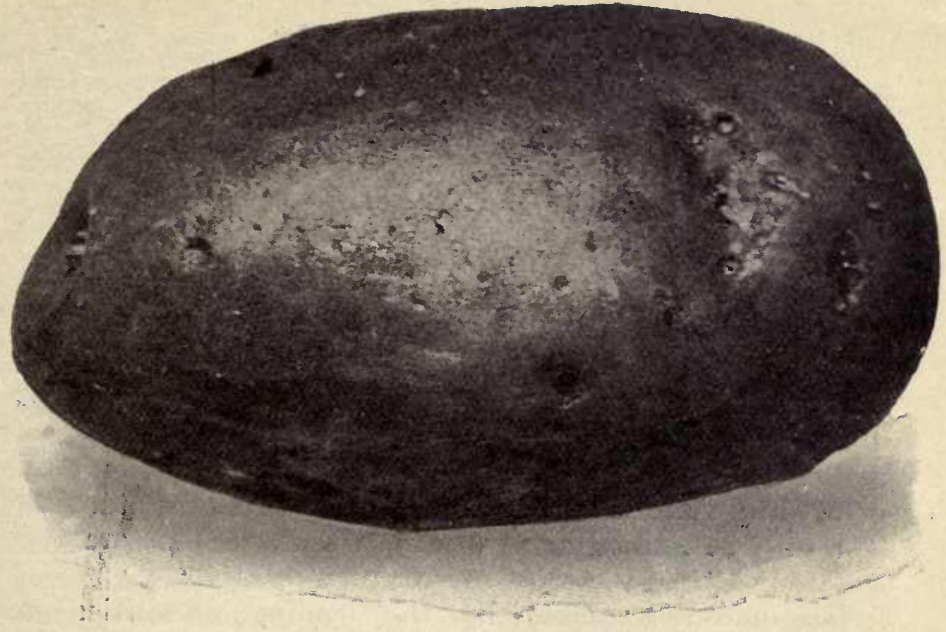

Maincrop Oval_Potato-Satisfaction.

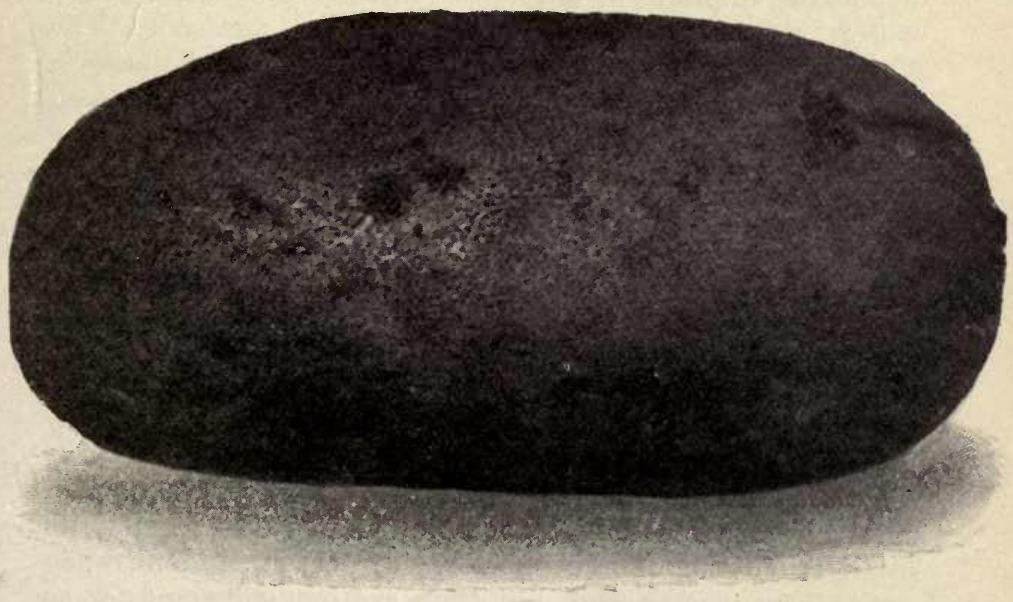

First Early Kidney Potato-Snowdrop.

D 2 


\section{CHAPTER, V.}

\section{MANURES AND MANURING.}

THe subject of manuring land for potato cultivation is one of considerable interest to potato growers, and we propose in the following notes to give a digest of the opinions expressed by various authorities, in order that some tangible idea may be formed as to what kinds of manures are best adapted to yield the most satisfactory results.

The manures advised by the leading authorities are farmyard dung, superphosphate, basic slag, bone-meal, phosphatic Peruvian guano, kainit, muriate and sulphate of potash, sulphate of ammonia, nitrate of soda, sulphate of iron, sulphate of lime, magnesium salts, and soot. The farmyard dung may be said to be an all-round manure, because it contains small quanties of phosphates, potash, and nitrogen, the three chief elements required as food by the potato. Superphosphates, basic slag, bone-meal, and phosphatic guano are phosphatic manures; kainit, sulphate, and muriate or chloride of potash are potash manures; while sulphate of ammonia and nitrate of soda are purely nitrogenous manures. We will now deal briefly with the merits of each manure, so far as they apply to the potato.

Farmyard Manure.-This is generally agreed to be an indispensable manure, partly from a chemical, and partly from a mechanical point of view. Chemically, its small quantities of phosphoric acid, potash, and nitrogen are helpful to the crop, but they are not sufficient, or so readily accessible, to aid materially in the development of 
a heavy crop. It is more from a mechanical standpoint that farmyard manure is a valuable aid to potato culture. In this capacity horse dung increases the porosity and the temperature of heavy soils, and sow or pig dung serves to bind light or sandy sjils together, conserve the moisture in dry seasons, and, consequently, provide a congenial pabulum for the surface roots. Thus, in the case of heavy soils, by rendering them porous and warmer, healthy root action is encouraged, and they are in a better condition to receive such artificial manures, and to facilitate their assimilation by the roots. Then on the lighter soils the conservation of moisture, and their greater compactibility, enable the artificials to be held in reserve till the roots can assimilate them, instead of being washed into the subsoil. All authorities are agreed, however, that it is unwise to use farmyard dung too liberally. It has a tendency to produce over-luxuriance, and to subject a crop to disease in wet seasons. It is clear, therefore, that farmyard dung should only be used in moderate quantities, and for a mechanical, rather than a chemical reason.

Phosphatic Manures.-Experiments have already demonstrated that phosphates in some form are absolutely necessary for the successful culture of the potato; in fact, all the special compound manures prepared for potatoes contain superphosphate. As previously pointed out, there are several forms of phosphatic manures, and the question to be decided here is, which is the best form of phosphate to use. Well, on soils that are known to contain a fair quantity of lime, the acid phosphates-superphosphate and dissolved bones-are best; while on those that contain no lime, such as peats and clays, non-acid phosphatesbasic slag, bone-meal, or Peruvian guano-are more suitable. The two first act more rapidly, however, than the latter.

Potash Manures.-There seems to be a difference of opinion among experts as to the value of potash as a 
potato manure. It is, however, universally agreed that potash manures should not be used indiscriminately for the purpose. Clay soils, for instance, usually contain sufficient potash to meet the requirements of the potato. On such a soil it would be well to experiment with its use, and ascertain if it be wise economy to apply it to any extent. We advise this course because, although a clay soil may contain potash, the latter is not always available for the crop. On light, chalky, and peaty soils, potash is indispensable. Three forms of potash are availablekainit, muriate (chloride), and sulphate of potash. The former is the cheapest form of potash, and, as it contains a small proportion of magnesium salts, it supplies what little may be required of the latter. It is, however, slow in action, and requires to be applied either in winter or in early spring to be of the greatest value to the crop. Muriate or chloride of potash is often advised as a good potato manure. It is richer in potash than kainit, one ton being equal to four of the latter, and the price is correspondingly higher. Sulphate of potash is also richer in potash than kainit, and dearer. The muriate is similar in action to kainit, but, owing to its liability to form calcium chloride in the soil, a substance harmful to plant life, it is not altogether a safe form of potash to use. Then again, it is said to have a tendency to cause waxiness in the tubers. Sulphate of potash, on the other hand, is a perfectly safe form of potash, and, unlike kainit, it may be applied at the time of planting.

Sulphate of Iron.-Dr. A. B. Griffiths is the authority who so firmly believes in, and so strenuously advocates, the use of sulphate of iron as an ingredient in potato manure formulas. In his "Treatise on Manures" (Whitaker and Co.), he plainly demonstrates its value, not only as an aid to obtaining a greater yield of tubers, but also as a preventative of the potato disease. According to his statements, an application of iron sulphate will give a greater yield than one of kainit. He asserts, moreover, 


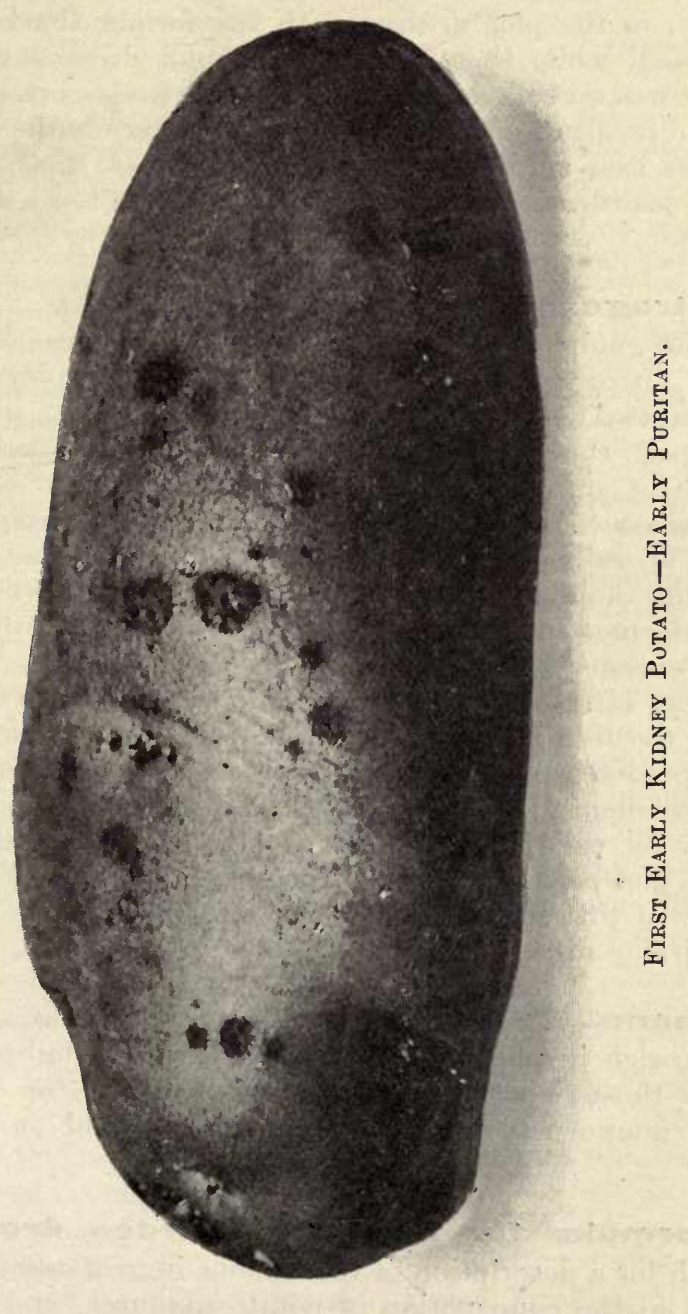


that in the experiments made with kainit and iron sulphate, in the plot dressed with the former the crop was diseased, while that grown in the plot dressed with the latter was quite free from disease. We must certainly say, as the result of our own and others' experiments with the use of iron sulphate on crops and plants, that there is some justification for Dr. Griffiths' claim as to its manurial value.

Nitrogenous Manures.-Apart from farmyard manure, sulphate of ammonia and nitrate of soda are the chief nitrogenous manures required for the potato crop. Of the two, nitrate of soda is the one generally used. In any case, this is best in dry seasons and on dry soils. Sulphate of ammonia is more suitable for damp soils and wet seasons. It is said that when farmyard manure has been liberally used, sulphate of ammonia has the effect of causing the plants to make smaller tubers. On the whole, it is deemed best to apply the latter only on damp soils in wet seasons, or where farmyard manure has been used. Neither nitrate of soda nor sulphate of ammonia must be used too freely, as they promote a too luxuriant growth, and predispose the plants to disease. Soot and malt dust are excellent nitrogenous manures for potato culture, especially for early crops. Both should be applied along the drills just before planting. From eight to ten cwt. of malt dust, of fifty to eighty bushels of soot per acre, will be a suitable dressing.

Guano.-The various forms of Peruvian guano, such as those rich in phosphates, may be used at planting time, while those richer in nitrogen are valuable for top-dressing. Fish guano acts more slowly, but is useful at planting time.

Formulse for Field and Garden Crops.-So much for a description of the various ingredients generally used in the composition of potato manures, and now we 
will give a number of formula recommended as ideal potato manures:-

$\begin{array}{lll}\text { Quantity } & \text { Per } & \text { When to } \\ \text { Formula. Mannre. } & \text { per Acre. } & \text { Square Rod. Apply. }\end{array}$

No. 1. Farmyard Manure ... 12 tons ... $1 \frac{1}{2}$ cwt. ... Autumn.

Nitrate of Soda $\quad \ldots \quad 1 \frac{1}{2} \mathrm{ewt} . \quad \ldots \quad 1$ lb. $\quad .$. Late Spring.

superphosphate $\ldots . .3$ cwt. ... 3 lbs. ... Planting Time.

$\begin{array}{lllllllll}\text { Muriate of Potash ... } & \text { l } & \text { cwt. } & \text {... } & \text { l } & \text { lb. } & \ldots & \text { Autumn. } \\ \text { No. 2. Kainit } & \text { Autumn }\end{array}$

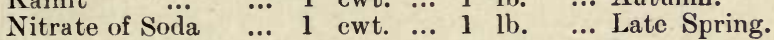

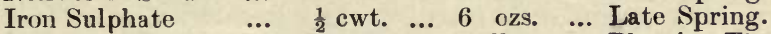

Superphosphate ... 3 cwt. ... $1 \frac{1}{2}$ lbs. ... Planting Time.

No. 3. Superphosphato ... 2 cwt... .3 lbs. ... Planting Time.

Sulphate of Ammonia 1 cwt. ... 1 lb. ... Late Spring.

Kainit... ... ... 2 cwt. ... ] $\frac{1}{2}$ lbs. ... Autumn.

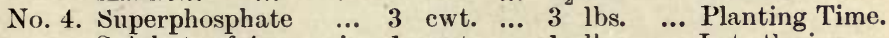

Sulphate of Ammonia 1 cwt. ... 1 l lb. ... Late Spring.

Kainit $\quad . . \quad \ldots .1$ cwt. $\ldots .1$ lb. ... Autumn.

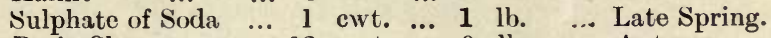

No. 5. Basic Slag ... $\quad \ldots .12$ cwt. $\ldots .99$ lbs. ... Autumn.

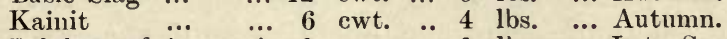

Sulphate of Ammon $\ldots$ a 1 cwt. ... 1 l lb. ... Late Spring.

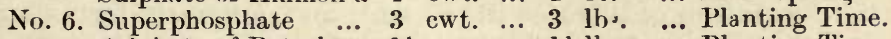

Sulphate of Potas $1 . . . \quad 1 \frac{1}{2}$ ewt. ... $1 \frac{1}{2} \mathrm{lbs}$. ... Planting Time.

Nitrate of Soda $\quad \ldots \quad 1$ cwt. ... 1 l lb. ... Late Spring.

Remarks re Formula. - It will be observed that farmyard manure is included in the first formula only. The others may be used with or without farmyard manure. If a soil is well supplied with manures, farmyard manure is not essential. For general purposes, No. 1 or No. 2 may have the preference. Nos. 3 and 4 come in useful in damp seasons, as the ammonia is then the best form of nitrogen to use. No. 5 is especially suitable for heavy soils, and No. 6 is an excellent mixture to use where the phosphates and potash can only be applied at planting time.

\section{How and When to Apply Manures.-Farmyard} manure should be ploughed or dug in during autumn or winter, not put in the rows, as is sometimes done at the time of planting. Kainit takes a long time to dissolve, therefore should be applied at the time of ploughing. The same remarks apply to muriate of potash. Sulphate of potash may be applied at planting time, sprinkling it along 
the drills. Superphosphate should be applied at planting time, applying as advised for the sulphate of potash. Nitrate of soda and sulphate of ammonia are best used as top-dressings when the shaws are a few inches high.

Lime.-There is no doubt that lime is an excellent material to apply to land about to be cropped with potatoes. It is a valuable substance for mechanically improving the condition of soils. Mechanically it renders clay soil more pliable and less plastic, and, in the case of light soils, hélps to bind the particles together, and thus render them less susceptible to drought. Chemically, lime sweetens sour soils, such as those of a peaty nature, or that have been heavily manured generation after generation. Moreover, it unlocks the inert fertility of a soil, and sets free potash for the food of the crops. Further, it acts upon vegetable acids and liberates ammonia, encourages the formation of nitrates in the soil, and generally forms an excellent plant food. Then again, lime in its caustic condition destroys the various insect and fungoid pests in the soil, and is, therefore, of great value all round. Lime is best applied in its caustic or "quick" form to heavy clay and sour soils, and in the form of fine chalk to light soils. As it quickly sinks in the soil it should be applied in smail doses at frequent intervals, rather than large doses at long intervals. Quicklime may be applied in winter or early spring, at the rate of one to two tons per acre; and chalk at the rate of three to five tons per acre in winter. The former dose should be repeated every five or six years, and the latter every eight or nine years. Quicklime should be slaked and immediately ploughed or harrowed in, not left on the surface of the soil, otherwise its caustic properties and chemical and mechanical value will be lost, or weakened.

Seaweed. -This is an excellent manure for potatoes where it can be easily and cheaply obtained. It contains from four to twenty per cent. of potash, and about three 


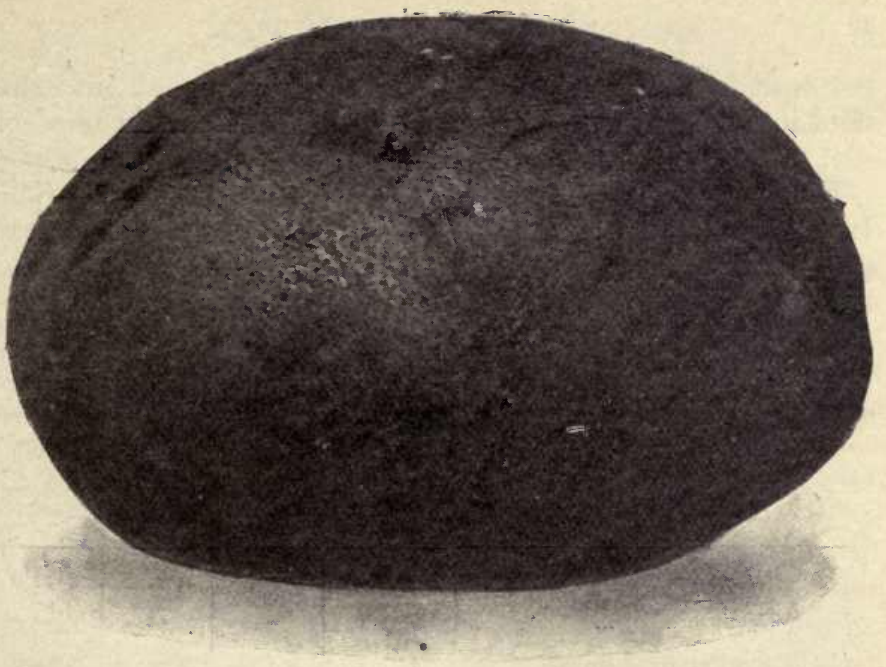

Maincrop Oval Potato-Up-to-Date. t.

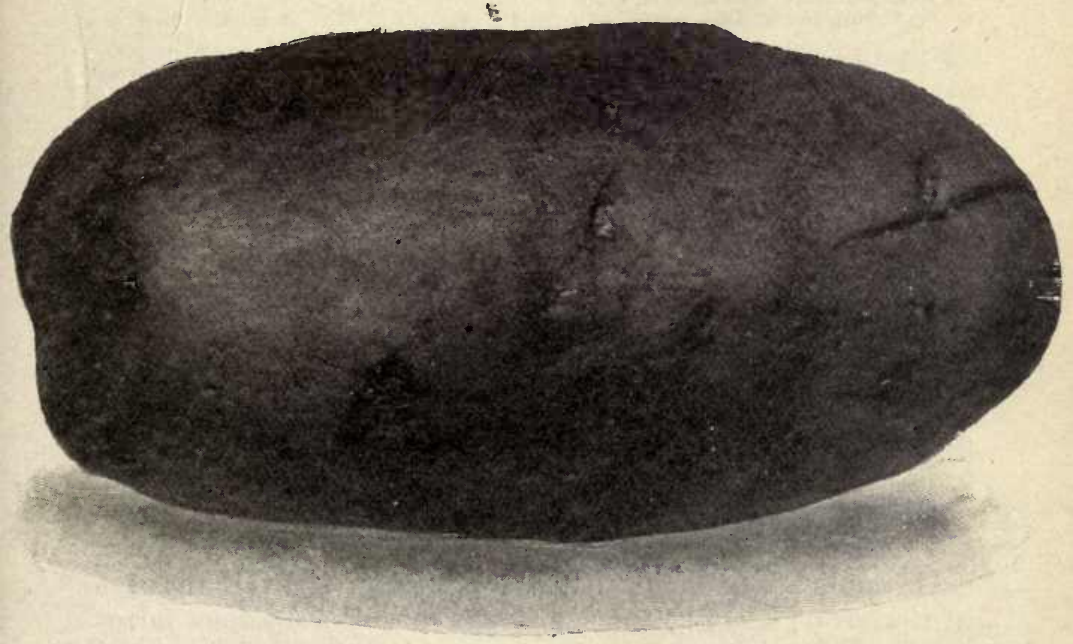

First Early Kidney Potato-Ninetłfotyd, 
per cent of nitrogen. It is best dug or ploughed into the land in autumn, at the rate of 40 to 50 tons per acre.

\section{Some Interesting Irish Experiments.-The} Irish Department of Agriculture made some interesting ex. periments at various centres in 1901, 1902, and 1903, to test the values of artificial and farmyard manures in relation to the yield of potatoes. These we reproduce, as follows :-

\begin{tabular}{|c|c|c|c|c|c|c|c|c|c|c|}
\hline \multirow[t]{2}{*}{ Plot. } & $\begin{array}{l}\text { Manure applied per Statute } \\
\text { Acre. }\end{array}$ & \multicolumn{2}{|c|}{$\begin{array}{c}\text { Average } \\
\text { Total Yield } \\
\text { of Potatoes } \\
\text { per Strtute } \\
\text { Acre. }\end{array}$} & \multicolumn{2}{|c|}{$\begin{array}{l}\text { Increase } \\
\text { dne to } \\
\text { Manures. }\end{array}$} & \multicolumn{2}{|c|}{$\begin{array}{l}\text { Ccst of } \\
\text { Mannures. }\end{array}$} & \multicolumn{3}{|c|}{$\begin{array}{l}\text { Estimated } \\
\text { Profi: per } \\
\text { Statute } \\
\text { Acre.* }\end{array}$} \\
\hline & & Tuns & Owt. & Tons & Cwt. & $£$ s. & d. & $£$ & & d. \\
\hline 1 & No Manure ... $\quad \ldots \quad$... & 3 & 1 & & & - & & & - & \\
\hline 2 & ¿) tons Farmyard Manure & 8 & 2 & 5 & 1 & 40 & 0 & & 14 & 0 \\
\hline 3 & 15 tons Farmyard Manure & 7 & 9 & 4 & 8 & 30 & 0 & 5 & 9 & 0 \\
\hline 4 & $\begin{array}{l}15 \text { tnns Farmyard Mannre, } 1 \text { ewt. } \\
\text { Sulphate of Ammonia }\end{array}$ & 8 & 6 & 5 & 5 & 312 & 6 & 6 & 8 & 6 \\
\hline 5 & $\begin{array}{l}15 \text { tona Frarmyard Manure, } 1 \mathrm{cwt} \text {. } \\
\text { Sulphate of Ammonia, } 4 \mathrm{cwt} \\
\text { Superpbosphate } \quad . .\end{array}$ & 9 & 10 & 6 & 9 & 45 & 6 & 8 & 2 & 6 \\
\hline 6 & $\begin{array}{l}15 \text { tons Farmyard Manure, } 1 \mathrm{cwt} \text {. } \\
\text { Sulphate of Ammonia, } 4 \mathrm{cwt} \text {. } \\
\text { Superphosphate, } 1 \mathrm{cwt} \text {. Muri- } \\
\text { ate of } 1 \text { otash } \ldots\end{array}$ & 10 & 5 & 7 & 4 & 4. 16 & 0 & 9 & 3 & 0 \\
\hline 7 & 15 tons Farmyard Manure & 7 & 6 & 4 & 5 & 30 & 0 & 5 & 4 & 0 \\
\hline
\end{tabular}

* The value of saleable pctatoes is taken at $£ 2$ per ton, and of the small potatoes $£ 1$ per ton.

"In calculating the profits obtained the following prices have been assigned to the different manures:-Farmyard manure, 4s. per ton; sulphate of ammonia, £12 10s. per ton; superphosphate, £3 $5 \mathrm{~s}$. per ton; and muriate of potash, £10 10 s. per ton.

"The figures in the above table indicate-first, that each application of manure has produced a large increase in the crop; second, that the application of 15 tons farmyard manure has produced a crop which is not three-quar- 
ters of a ton less than that pioduced by the application of 20 tons farmyard manure; and third, that on each of the plots 4,5 , and 6 , the addition of artificial manures to the lighter dressing of durg has yielded a larger crop than the heavier dressing of dung yielded.

"It may be urged, and justly so, that it is a mistake to charge the potato crop with the full value of the farmyard manure. But whether the full value, or oniy nalt of the value, of the farmyard manure is charged to the potato crop, the result is the same, viz., the use of artificial manures along with 15 tons farmyard manure has in each case left a greater profit per acre than the use of 20 tons farmyard manure alone. These experiments, therefore, seem to justify the conclusion that, as a general rule, and particularly where farmyard manure is limited in amount, farmers would be well advised to apply the latter in more moderate quantities, and to supplement it with suitable artificial manures.

"That leads to the further question arising out of the experiments :-What artificial manures should be used in supplementing a moderate drıssing of farmyard manure? An answer is furnished from the figures contained in the following table:-

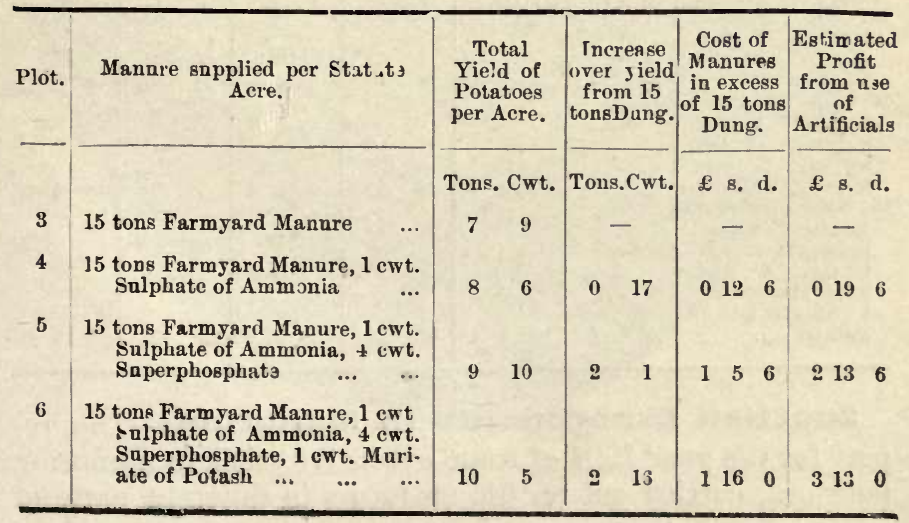


"These figures show that the mixture of artificial manures required to supplement a moderate application of dung should be complete, i.e., it should contain nitrogen, phosphorus, and potassium. The omission of muriate of potash caused a reduction in the profit obtained of almost $£ 1$ per acre, while the further omission of the superphosphate reduced the profit by $34 \mathrm{~s}$. more.

"The foregoing conclusions are very considerably strengthened when the results of last year's experiments are compared with those of similar experiments conducted during the two previous years. This comparison can be made from the following table:-

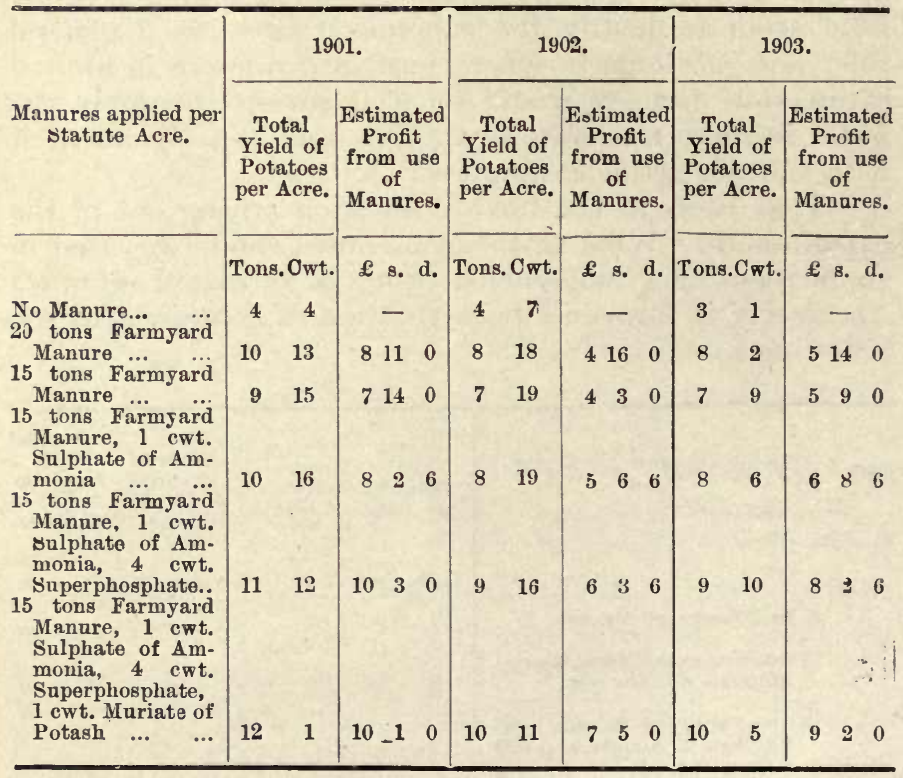

Scottish Experiments in Manuring:-The report for the year 1901 of some extensive trials in manuring potatoes, carried out on fifteen farms in different parts of 


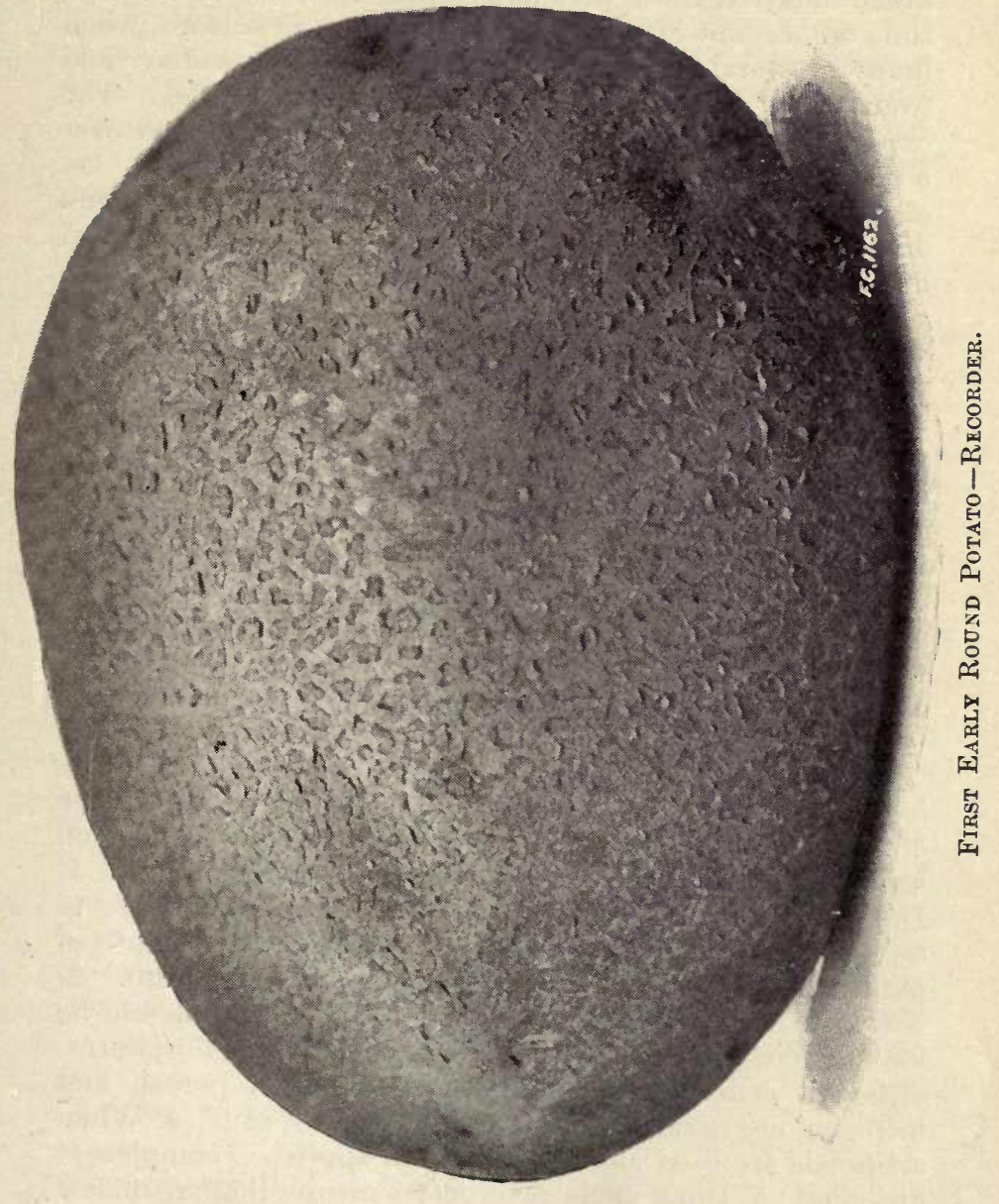


Scotland, was recently issued by Professor Wright, of the West of Scotland Agricultural College. Although very much delayed, the report has considerable interest at this time on account of the great boom in potato culture, when many growers are trying to get the largest possible yield from small quantities of the seed of new varieties. The experiments have, for the most part, been carried out over a period of four years, and on a great variety of soils. On each of the farms the same set of twelve different manurial dressings was tried, the plots receiving some farmyard manure alone, some artificials alone, and others various combinations of the two. The general results show that the best dressing was one consisting of 10 tons of farmyard manure, 4 cwt. of superphosphate of lime, $1 \mathrm{cwt}$. of sulphate of ammonia, and $1 \frac{1}{2}$ cwt. of sulphate of potash per acre. The use of an extra 10 tons of farmyard manure instead of the artificials produced a smaller yield at a greater cost. When artificial manures alone were used the best combination was one of $6 \mathrm{cwt}$. of superphosphate, 2 cwt. of sulphate of ammonia, 2 cwt. of sulphate of potash, and $1 \mathrm{cwt}$. of nitrate of soda. The last-named was applied as a top-dressing after the growth appeared above the ground, just before earthing up was done.

Some English Experiments.-Experiments in the manuring of potatoes, carried out by the Durham College of Science, have led to the following conclusions, which form a useful summary of this important subject: 1 . During 1903 potash proved, in the majority of cases, to be the most important ingredient for potatoes, muriate of potash proving the most satisfactory potash manure. 2 . Nitrogen in all cases proved of great value, and should be included in all mixtures for this crop. 3. Phosphates, although generally of less importance than potash and nitrogen, are necessary on certain classes of soils. 4 . When artificials are used alone it is best to apply a " complete" dressing. 5. Dung alone gave better results than artificials alone, but their relative effects depend largely upon cir- 
cumstances. 6. As a rule, it is profitable to use dung and artificials together in moderate quantities, and, on the whole, this may ba regarded as the moct economical way of manuring the potato crop. 7. As dung varies so much in composition, it is safest in the majority of cases to use " complete" artificials with it, although nitrogen appears to be more important in this connection than the other ingredients.

\section{CHAPTER VI. \\ PROPAGATION.}

A Goop deal of attention has been paid to the subject of propagating potatoes by cuttings and eyes, during the last year or two, more especially in regard to new varieties, which raisers and purchasers desired to obtain a large stock of as speedily as possible. There is nothing new in the method of propagation of the potato by cuttings; it has been practised by our forebears in generations past, as we have pointed out in the opening chapter of this Handbook. But the system has never met with popular favour among grower; till the "boom" recently set in, and then it was revived with a considerable amount of energy by raisers and growers of recently introduced sorts. There seems, however, to be a great diversity of opinion among potato experts as to whether the system is a wise one or not. Some assert that it has a deteriorating effect upon the stock, weakening both the stamina of the tubers and their yielding properties. Others, again, assert that the system 
does not affect the stamina or the yield of the crop; but, as sufficient time has not yet elapsed to clearly demonstrate its good or bad effects, it would be premature, perhaps, to express a decided opinion upon it, one way or the other. Physiologically, we hold the opinion that the yield from a cutting cannot be as perfect in stamina or quality as that from a properly prepared tuber or set. Each tuber or set is composed of cells, containing food stored up for the sustenance and support of the shoot or shoots it may in due course put forth, and when the tuber is placed in the earth, and growth begins, such shoot or shoots have a supply of food to enable them to make vigorous, healthy growth, until they are able, by means of their own roots, to collect food on their own account. Now, a plant which has been thus nourished in its early stage of growth must naturally be more vigorous and fruitful than one which has been reared from a cutting, which is deprived at an early stage from deriving support from its parent, and has to put forth roots of its own to maintain its existence. However, the matter is one which requires to be put to a series of practical tests to determine whether the produce of cuttings is really inferior to that obtained from sets.

Since writing the foregoing we find, from the following facts published in the "Gardeners' Magazine," that experiments have been made with potatoes grown from cuttings, cut, and whole tubers:- " The very high prices paid for the newer varieties of potatoes have resulted in their rapid propagation from cuttings. This is thought by many cultivators to be harmful to the variety and likely to materially impair its vigour of growth. In order to determine the effect of intensive propagation on the vigour and productiveness of varieties, an experiment was commenced at the Harper-Adams' Agricultural College under the auspices of the Education Committee of the Staffordshire and Shropshire County Councils last year. In carrying out the experiment three plots of ground were planted with: 1 , whole sets; 2 , cut sets; 3 , plants from cuttings. The 


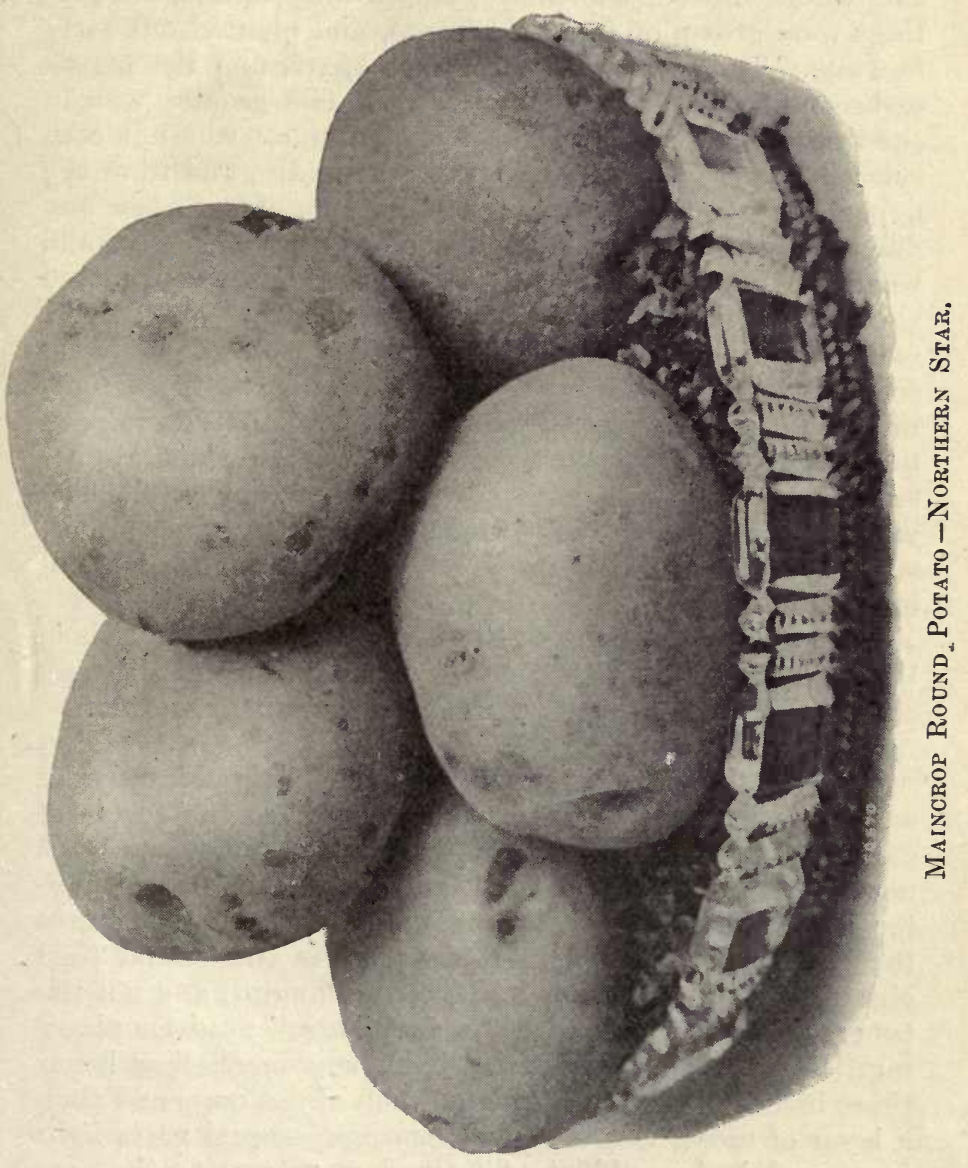

E 2 
variety selected was Northern Star, which it is stated had already been subjected to considerable propagation. The whole and cut sets were planted May 6, and the cuttings were grown on in a cold frame, and planted out early in June. The rows were three feet apart, and the plants eighteen inches apart in the rows. The ground was in good condition, and the addition of manure was not considered necessary. The plants grew rapidly, and from the appearance of the haulm it was not possible to see any difference in the plots. The rhizomes grew strongly, and when the crop was lifted in October the ridges were matted with rhizomes. The following is the yield per acre: No. 1 (whole sets) 18 tons 2cwts. Oqrs. 11lbs.; No. 2 (cut sets, single eyes), 16 tons 1cwt. 2qrs. 12lbs.; and No. 3 (cuttings), 17 tons 10cwts. 2qurs. 19lbs. It will thus be seen that the total yield from the cuttings was intermediate between the produce from the whole and cut sets. The yield of tubers of ware size from the cuttings was largnr, while the yields of "seed" and chats were correspond. ingly smaller."

According to this, the potato is more fruitful from whoie " sets" than from cut "sets" or cuttings, thus bearing out the views expressed by us in our opening remarks.

By seed.-This is a method which should only be adopted when new varieties are desired, as the result of careful cross-fertilisation. With the latter subject we shall not concern ourselves, as that will be dealt with in Chapter XVI. Here we shall simply deal with the sowing of the seed. The seed here referred to is the actual seed obtained from the berries borne on the haulm, and not the tubers or sets, often called " seed-tubers," used for planting. The seeds should be sown in pans or shallow boxes three inches deep, containing an inch of drainage and then a layer of moss, and sufficient compost-equal parts light loam and leaf-mould-to fill the box or pan to the top. Press the compost down firmly with a flat piece of board, and sprinkle some fine sand over it. Sow the seeds thinly, 
and then cover with an eighth of an inch of finely sifted mould. Lightly press the surface again, and cover the box or pan with a pane of glass. The pans or boxes may be placed in a sunny, cold frame, or in a cool greenhouse. Shade from sun with a sheet of paper. Watch the surface of the mould daily, and directly it shows signs of getting in the least degree dry, give it a gentle watering. The soil must not be allowed to get too dry or too wet, and this is why it is better not to give water at the time of sowing. Too much moisture, moreover, will cause the seeds to rot. In ten days to a fortnight the seedlings will begin to appear, and then the glass must be tilted a little to admit air. As soon as the seedlings show themselves freely, remove the glass. When the third leaf forms, carefully transplant each one into a thumb pot. The compost for this purpose should consist of equal parts of good soil and leaf-mould, with a fair amount of sand. Do not press the soil too closely in the pot. Stand the seedlings not far from the glass, and attend carefully to watering and airing during the day. As soon as the seedlings are nicely rooted, shift them into three-inch pots, and keep in the frame till all danger of frost is past; then plant out in ? good and properly prepared plot of ground to produce their first crop of tubers. When the crop has reached maturity, lift the roots, and keep each one separate. Examine them carefully, selecting only those of great promise to grow again, and discarding the remainder. Probably two-thirds of the roots will be useless. Store the selected tubers, and plant these out in the ordinary way the following spring. In due course, lift and examine the produce, selecting the best as before and rejecting the remainder. Proceed thus year after year, for four or five years, until you may perhaps get one, or, at the most, two, varieties that promise to be distinct improvements on existing linds. The best time to sow is in March or April. It is a good plan also to balke the soil used for covering the seeds, in order to prevent the " damping off " fungus from developing and destroying the young seedlings. 
By Eyes.-This method is, like that of cuttings, practised where new and choice varieties are required to be increased in quantity. Fig. 1 is a good and suitable set for any purpose. It has been properly treated during the winter by being exposed to light and air. It has also been
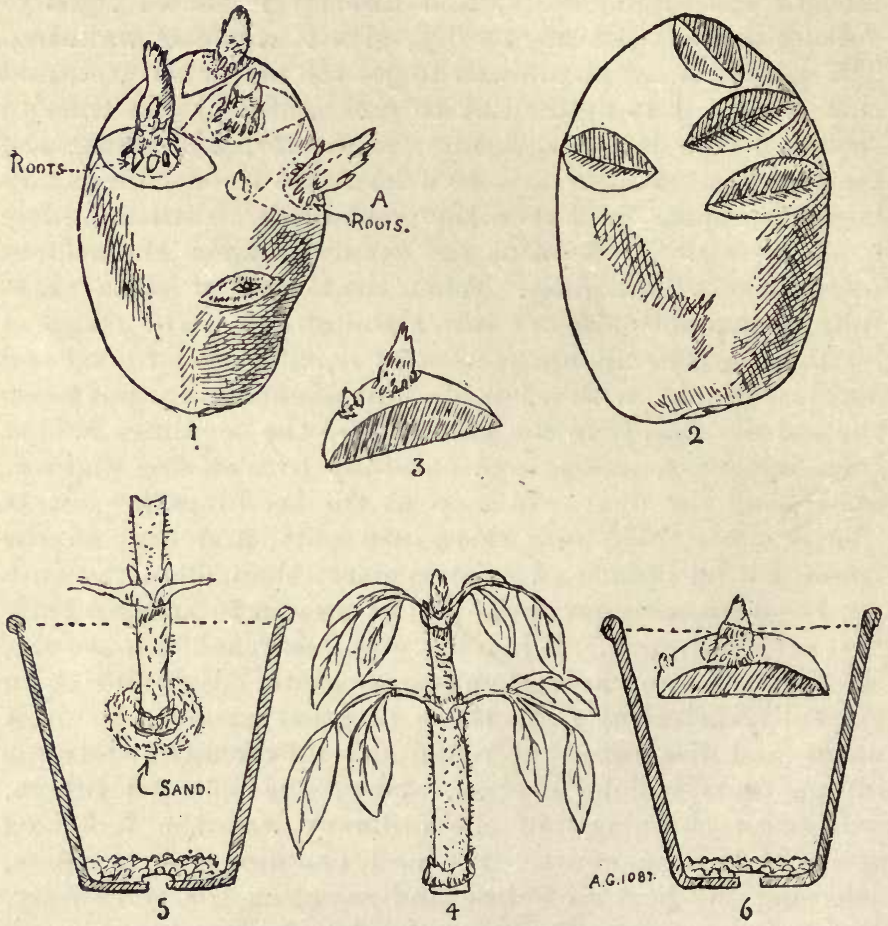

How to Propagate the Potato.

REFERENCES. - Fig. 1, A good set for any purpose. Fig. 2, How to take the eyes onto Fig. 3, Eye removed and ready to pot. Fig. 4, Cutting ready to pot. Fig. 5, How to pot a cutting. Fig. 6 , How to pot an eye.

keep from sprouting too early. February is quite soon enough for seed potatoes to begin to sprout, unless required for forcing. About the beginning of February the 
boxes containing the sets-for they should have been placed in boxes at the time of lifting - should be placed in a light and somewhat warm house or room, where they will soon begin to sprout, and when the sprouts (Fig. 1A) are three-quarters of an inch in length, each shoot should be taken out as shown at Figs. 2 and 3 , and be potted as at Fig. 6. Use finely sifted soil, but before these eyes are potted the cut parts should have been allowed to dry for a few hours, in order to prevent decay. If, however, the eyes are potted as soon as cut out, dip the cut parts in powdered charcoal and lime, this will do something towards preventing decay. These eyes will soon form roots, and make sturdy plants, filling the little pots with roots, when they should be transferred to larger sizes, using good soil. The pots should be placed in a greenhouse or warm frame near the glass, and be carefully watered. Every endeavour should be made to keep the plants sturdy. Do not allow them to become drawn and weakly. As soon as the danger of severe frost is over for the season, they should be placed in cool frames and kept near the glass, but the light must be covered securely against frost, as they will not stand a single degree. Air must be given freely when the weather is favourable, and also on warm nights to cause a sturdy growth. Watering must be very carefully attended to, using tepid water for the purpose.

By Cuttings.-This is an old method, but it has come into fashion lately, owing to the advent of the high-priced varieties, and the desire to make as many plants as possible from a tuber. It is a plan which should only be adopted in the case of new or rare sorts. There is no difficulty in propagating potatoes thus; yet a few important points require consideration. The tubers may be laid out singly and exposed to the light and air as early as convenient, and at any time in February they may be put into a warm house. A temperature of from 55 degrees to 65 degrees will be quite warm enough to promote growth. We have found them do well when laid out on a border in a 
vinery or peach-house that was shut up for starting. We have seen the tubers covered with light soil; but they are better laid on the ground, as when covered they make roots too freely. The shoots (Fig. 4) should be taken off when they are about two and a-half inches long. It is a mistake to take them to's soon. Potted singly, in threeinch or four-inch pots (Fig. 5) they will soon make a new start, and should be removed to a cooler house or a pit, before they begin to draw up. It should be added that the shoots must be taken off quite close to the tubers; this ensures a greater number of roots starting from the stem, and may make some difference in the number of tubers that will be produced from the roots. 'The stock tubers will soon start again, and a good many cuttings may be had from each one before planting time. A great point is to avoid getting the shoots drawn up weakly; so, if there is any sign of this, they may be removed to a cooler position or to where they can get more light. After they are potted they require a little care in watering, as the roots must be kept perfectly healthy. Those started early may require larger pots.

By Cut Tubors. This is a method often adopted in the case of large tubers used as " sets." It is, however, far wiser to use medium-sized whole sets than to cut larger ones. In the first place, it is wasteful to use tubers as " sets" that are fit for food; and secondly, the resultant yield is never so good from cut as whole sets. These remarks apply to English potatoes. In Scotland cut tubers have been found to do as well as whole tubers. Still, if a grower has plenty of "ware" tubers that he cannot consume or dispose of, and medium-sized whole " sets" are scarce, there is no reason why he should not divide the large tubers into two or more portions. Each portion should contain at least two " eyes," in case one should get injured. The cutting should be done just before planting, and the wounded surfaces immediately rubbed in powdered lime to seal up the cells and prevent loss of sap. 


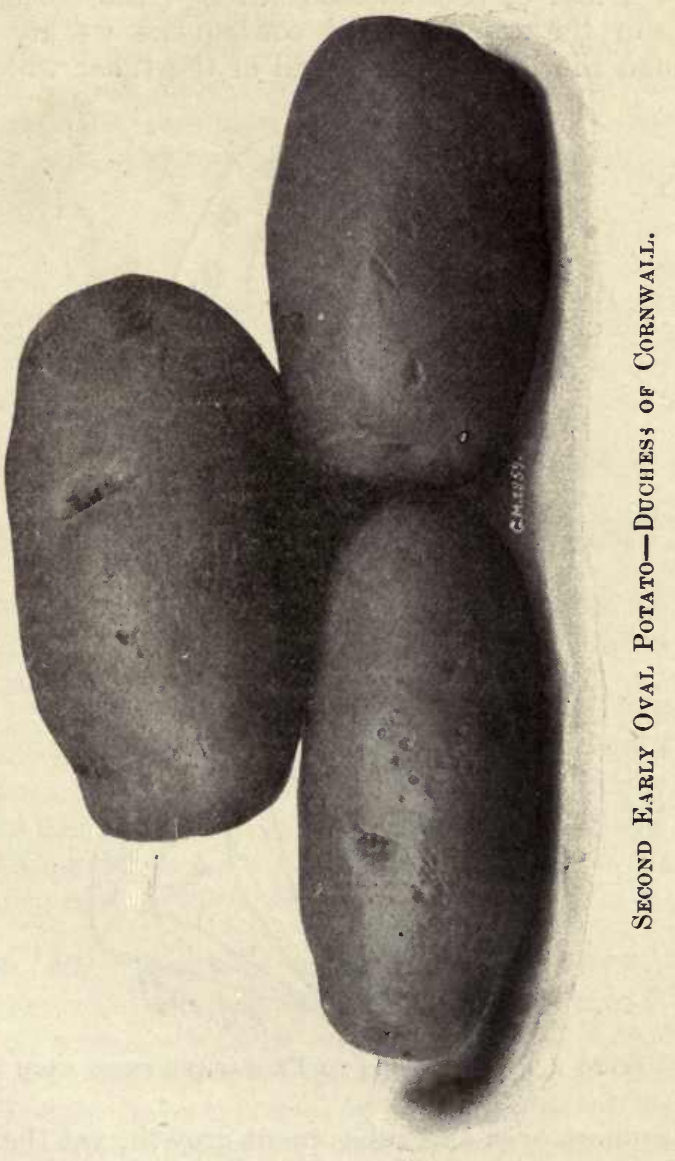


Those who cut the tubers a long time in advance, and let them remain in a heap, make a great mistake, as this means a loss of reserve food through the oozing out of sap from the wounds, and consequent weakly growth. Although the broad or rose end of the tuber will produce

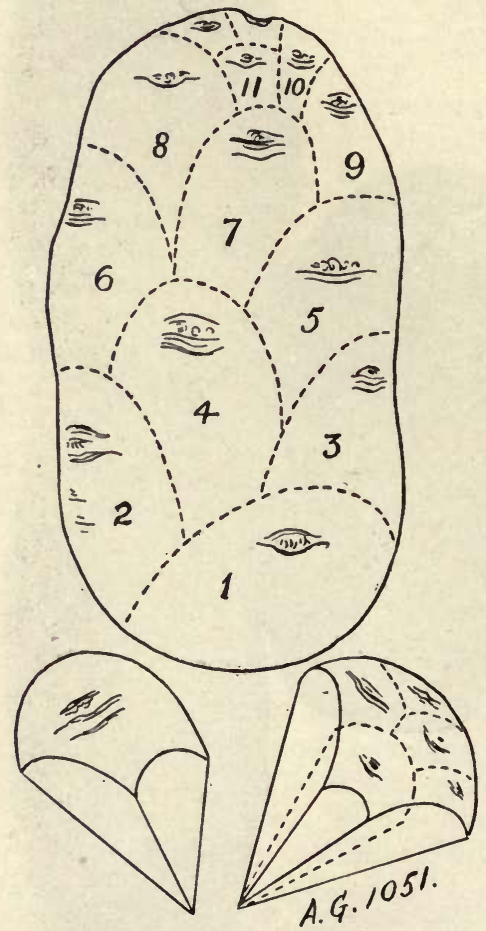

Cetifing a Potato so as to Propagate from each Eye.

the strongest eyes and subsequent growth, yet the narrow, or " heel " end should not be despised if the stock of "sets" be limited. Where specially good results are required, it will be well to allow only two shoots to develop 
on each cut "set," removing the others. The accompanying sketch shows a method of cutting up a tuber into as many " sets " as possible. In this case, every eye is used, and consequently many of them are very small indeed. The dotted lines show how each set is cut from the tuber. We only advise this plan in the case of a very choice sort which it is desired to make as many of as possible.

CHAPTER VII.

\section{TUBERS OR "SETS" FOR PLANTING.}

The subject of size of " sets " for planting, and their treatment previous to planting, is of sufficient importance to be considered in a separate chapter. There is, among growers, a diversity of opinion as to whether small, medium, or large tubers are best to use as " sets," but there are no two opinions about the wisdom of paying proper attention to the "boxing" and "sprouting" of the tubers intended to be used as " sets." However, we will deal fully with both matters.

\section{Size of "Sets" or "Seed Tubers."-Some} growers use the smallest type of tubers known as " chats." This, of course, is done from motives of economy, the largest tubers being used for cooking or sold. Now, such small tubers have necessarily weak eyes, which will in turn give birth to weakly shoots and a poor crop of inferior tubers. Unless, therefore, the variety be a scarce or expensive one, it is an unwise policy to use tubers of the smaller or "chat" size as "sets." Such tubers are far 
more profitably utilised for stock or poultry feeding. We now come to the relative advantages of medium-sized and large tubers. In practice, we always found the former to yield the most satisfactory results. The same opinion, too, is shared by other growers. Tubers that average between $1 \frac{1}{2}$ and $2 \mathrm{in}$. in width, and weigh 2 to $3 \mathrm{oz}$. each, are undoubtedly the best for " sets." These contain sufficiently strong eyes to give birth to vigorous shoots, and

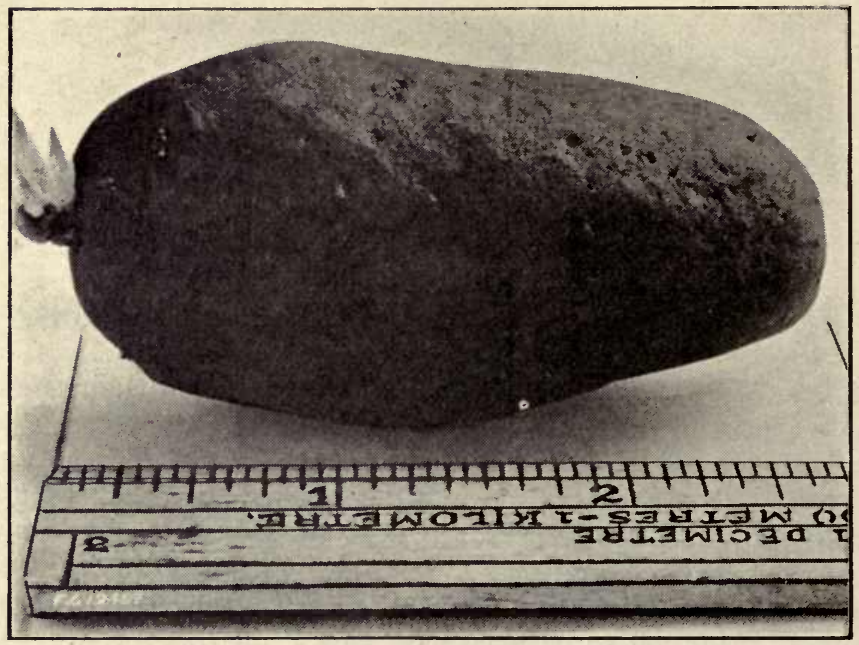

Maximum-sized Kidney Seed Tuber.

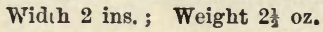

the tuber contains an ample supply of reserve food to support the shoot till it is able to forage for itself. As to larger tubers we regard it as a waste of valuable food to use them as "sets." A large tuber will not give a proportionately larger yield of tubers than a medium-sized one. It must be remembered also, that in using large tubers a greater quantity will be required to plant a given area of land than of the medium-sized " sets." It is more profitable to use the large tubers for food or to dispose of 
them. Nor is it a vise plan to cut up large tubers for "sets," unless the grower is short of the proper size. Our advice to growers is, therefore, use medium-sized whole tubers that will pass through a 2in. mesh, but not less than a $1 \frac{1}{2}$ in. mesh. A trifle larger will not matter, but on no account let is smaller size be used. The weight of the right sized tuber should be 2 to $3 \mathrm{oz}$, not more. We give illustrations of four tubers of approximately actual size, to afford an idea of the minimum and maximum size of tuber to select.

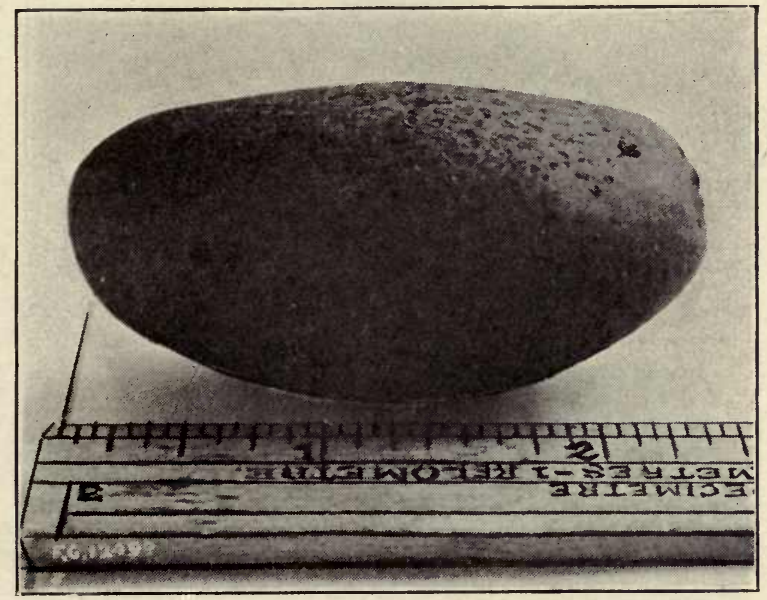

Minimum-sized Kidney Seed Tuber.

Width $1 \frac{1}{2}$ ins.; Weight $1 \frac{1}{2}$ oz.

Change of Seed.-Every gardener and farmer knows that if he uses home-saved tubers for " sets " for several years in succession his crop deteriorates in yield and quality annually. Forty years ago this fact was known even to the cottager. "A change of seed " is indispensable. The Scotch farmers who came south years ago and obtained their supply of "seed tubers" from their native land, were able to grow much finer crops than the English 
farmer, who relisd upon his " change of seed" from a neighbour only. Hence of late years, it has become a recognised fact that it is wise to get fresh "seed tubers" from another county, or even from Scotland, to ensure success. What is wanted is "seed" from an entirely different soil and climate. As to how long it is profitable to continue to grow home-saved " seed" depends a good deal upon the variety and the soil it is grown in. There

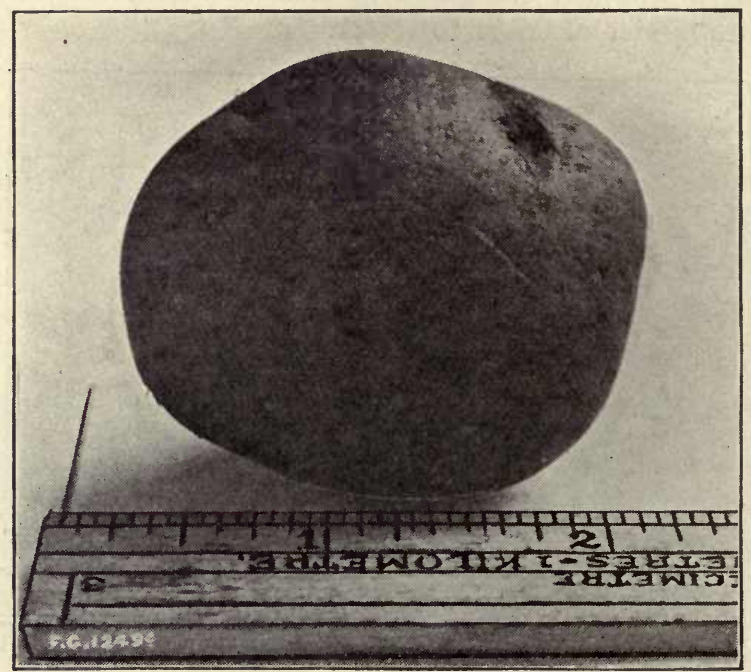

Maximum-Sized Round Seed Tuber.!

Width 2 ins.; Weight 2 oz. (See pp. 60 and 61.)

is no doubt, however, that a change should be made every third year at least.

Boxing the Tubers.-We come to the important subject of boxing and sprouting the tubers intended for "sets." As previously remarked, there is no question about the wisdom of the practice. The old-time practice of placing the tubers in a heap, and allowing them to be- 
come sprouted into a tangled mass of shoots no longer obtains, except where ignorance of the proper method prevails. The up-to-date method is to place the seed tubers, after they are lifted and become dry, direct into shallow boxes, like the one figured. The kidney tubers are placed on their narrow or " heel " ends in rows across the box till it is full. The round ones, with the parts containing the most eyes upwards, in a similar fashion. These boxes are then stored in a cool, airy loft or shed, where

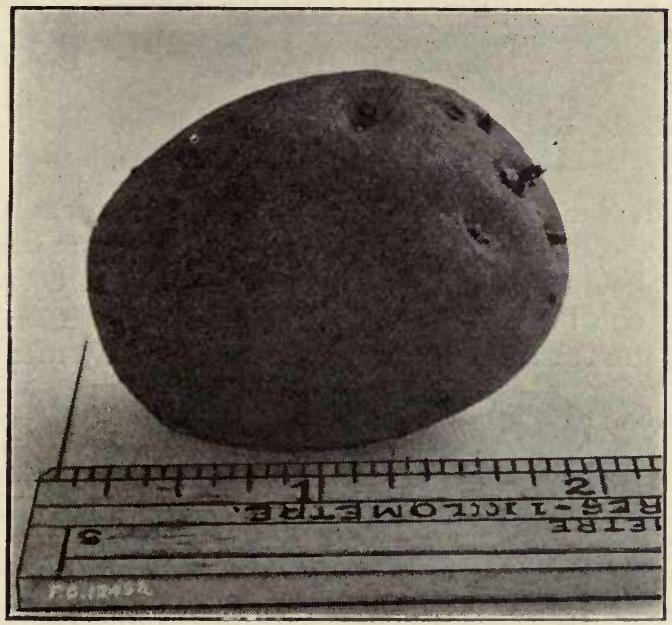

iMinimum-sized Round Seed Tuber.

Width $1 \frac{1}{2}$ ine.; Weight $1 \frac{1}{4}$ oz. (See pp. 60 and 61.)

frost can be kept from them. Plenty of light is admitted at all times, and when the turn of the year arrives, the boxes may be placed in a still lighter position; in fact, stood outdoors in fine weather. This plan ensures the tubers getting plenty of air, prevents premature growth, and ensures, when February and March arrives, plump, healthy tubers, with one or two dark green sturdy shoots. There is no exhaustion of the tubers by the production of 
weakly shoots; all its energies are reserved for the fulfiment of its proper mission, supplying food to the shoot which is to form the future plant, and in due course yield a crop of tubers.

The plan is often practised of spreading the tubers in a layer on the floor of a loft or room. Even if light be

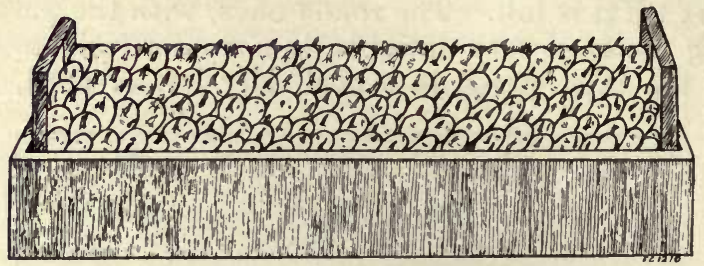

Mode of Boxing "Seed" Tubers.

admitted, the close contiguity of the tubers promotes premature sprouting, and each tuber is often producing several shoots like the example figured on p. 66. Boxes like the one figured are so easily made that it is unwise to store the tubers in the rough and ready way mentioned.

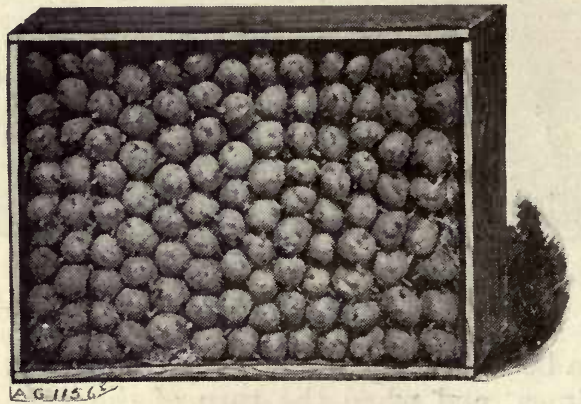

Sprodting Tubers in an ordinary Shallow box.

There is another great advantage in the use of boxes, and that is, as the tubers are placed in them at the time of lifting, they require no further handling till they are planted in the rows. Then, there is a still further advantage in sprouting the tubers in boxes. You get the one 


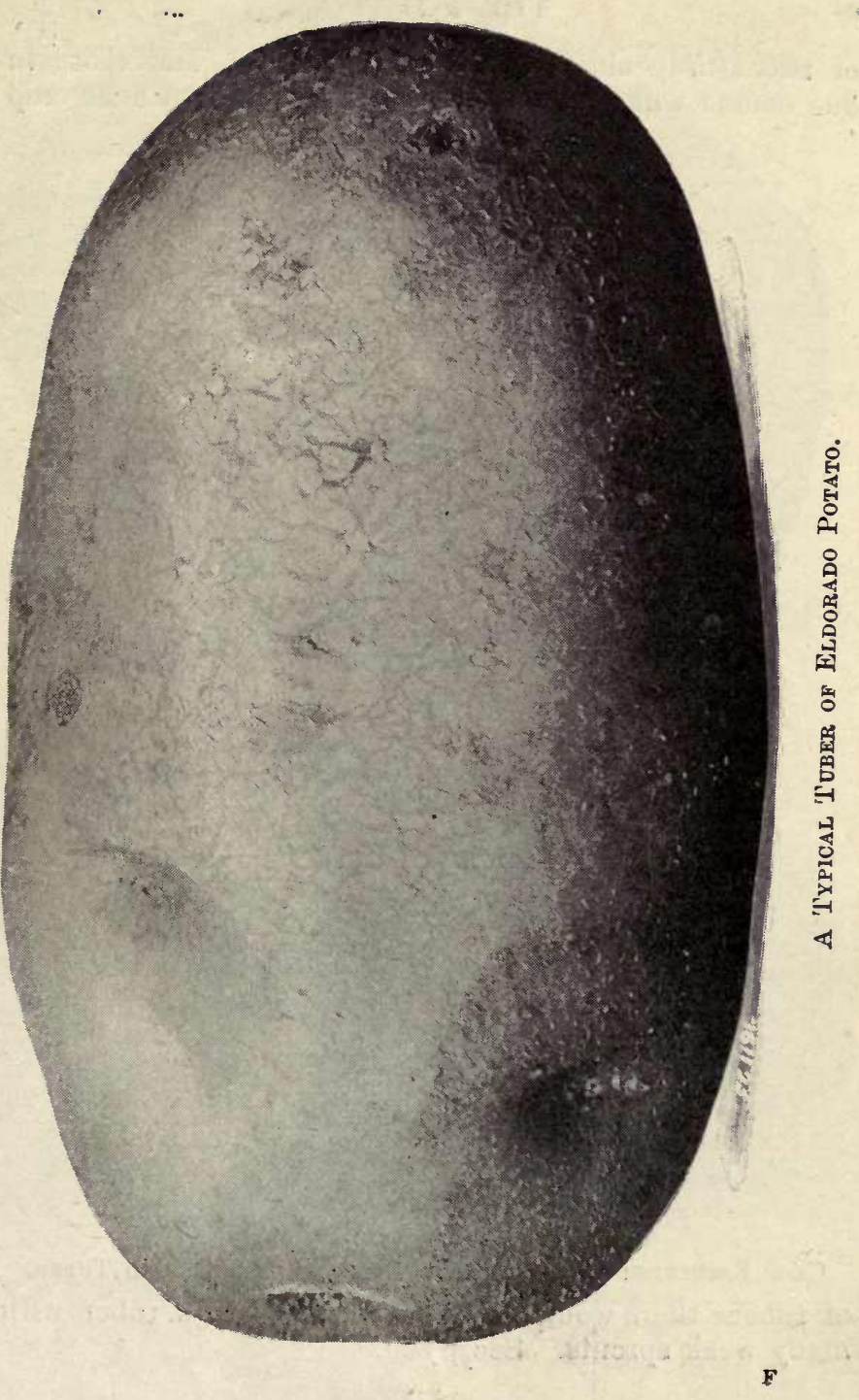


or two sturdy shoots as shown on p. 68, and these in due course will give not only a heavier, but a finer crop

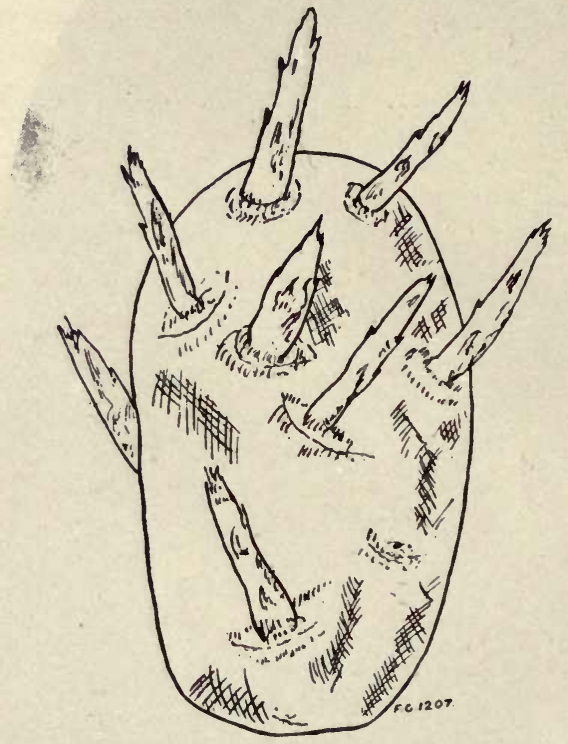

Potato Tuber Improperly Sprodted.

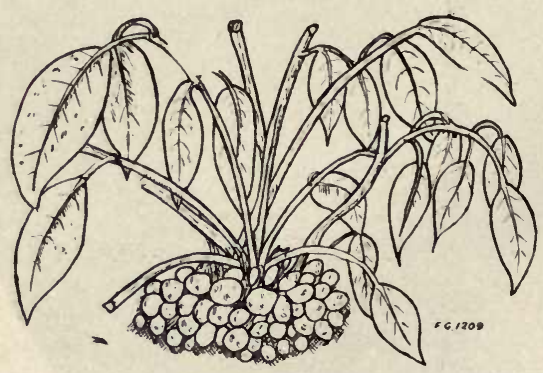

Crop Resulting from Planting Improperly Sprodted Tuber. of tubers than would a plant reared from a tuber with many weak sprouts. See \& 69. 


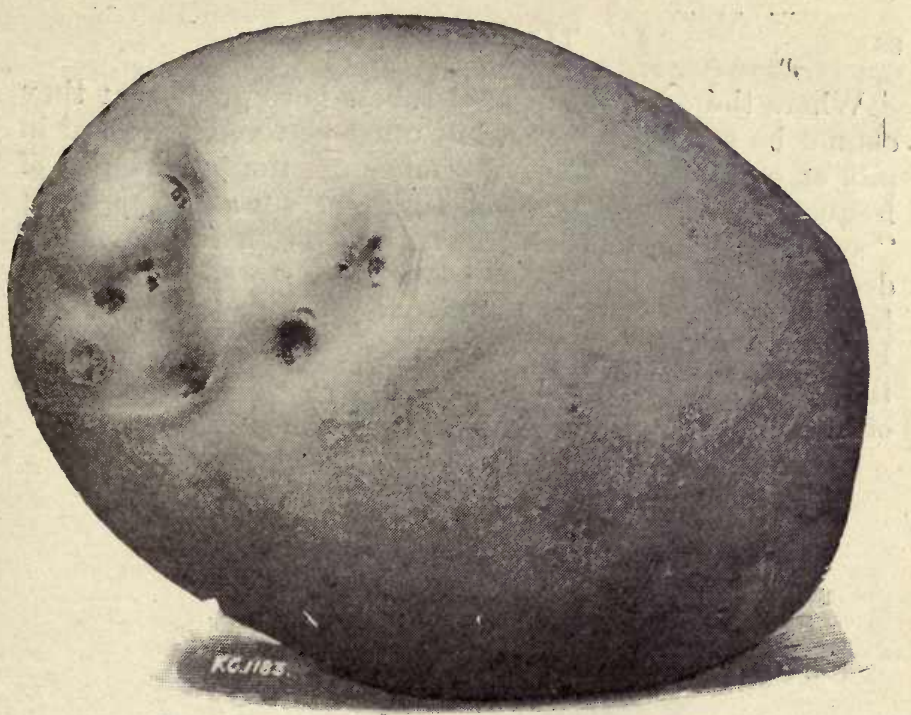

Maincrop Round Potato-'The Provost.

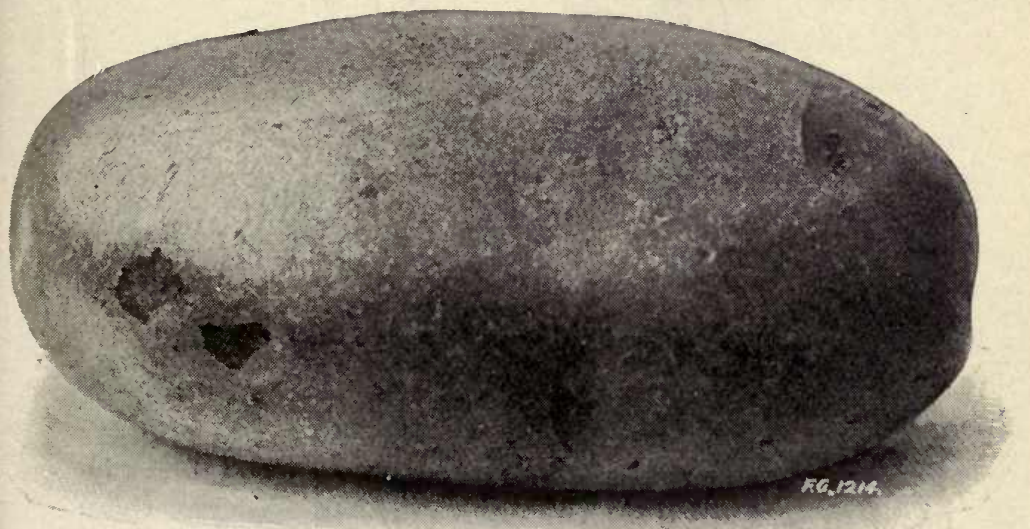

Maincrop Kidney Yotato-The Nubleman. 
Where the quantity of seed tubers is so great that they cannot be stored in boxes, but must perforce be stored in pits or outhouses, then we would urge the importance of frequently turning the tubers over, so as to prevent "sweating," premature growth, and often the spread of decay and disease. Even when thus stored it is manifestly advantageous to remove the tubers into boxes in February, if not earlier, and expose them to the light, so that they make the sturdy, dark green shoots that are so eminently desirable for securing first-class crops.

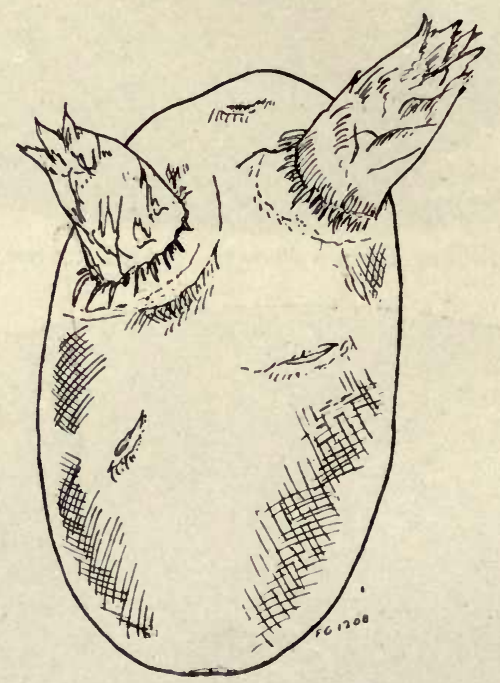

Potato Tuber Properly Sprouted.

In the management of tubers in boxes care should be taken to look over them occasionally, to see that there are no diseased tubers. If the tubers show an inclination to sprout too rapidly, let them have all the light and air possible. If they are backward, keep them dark and warm. 
Irish Experiments in Boxing and Sprouting. -The Irish Department of Agriculture, a body which looks keenly after the interests of agriculturists in the Emerald Isle, conducted a series of valuable experiments last year with a view of ascertaining what advantages, if any, were

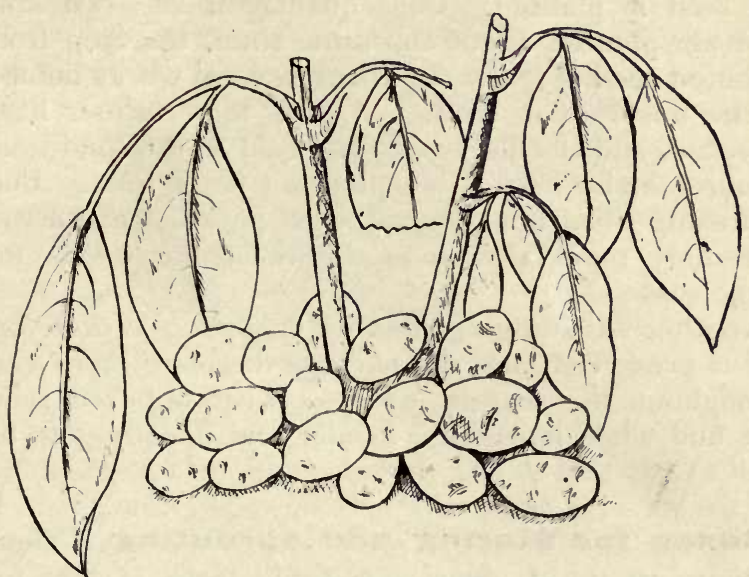

Crop Resulting from Planting Properly Sprodted Tuber.

to be gainad in the yield of potatoes by boxing and sprouting the "sets" before planting. The experiments were carried out with late or maincr $p$ varieties, and the average yields per acre at the thirty-four experimental stations were as follows:

From "boxed" seed-

Saleable ware $\quad \ldots . \quad \ldots \quad \ldots .99$ tons 15 cwt.

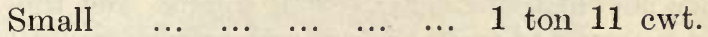

From unsprouted seed-

Saleable ware $\quad \ldots \quad \ldots \quad \ldots \quad 7$ tons 3 cwt.

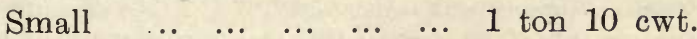

Average increase per acre due to sprouting, 2 tons

13 cwt.

These figures show that the yield from the boxed tubers 
amounted to 25 per cent. over that from the unboxed and unsprouted tubers. Some of the tubers were boxed in the autumn and others in February and March. The Department remarlis: "The chief advantage of sprouting is that a few weeks' growth is secured in the boxes before the seed is planted. Consequently if the two kinds of seed are planted about the same time, the crop from the sprouted seed is ready for lifting several weeks before that of the unsprouted seed. Again, if a farmer has seed sprouted, and the soil is wet and cold or the conditions unfavourable, he may delay planting for a time. Further, on freshly-tilled land the sprouted potatoes make such an extremely rapid growth as smothers the weeds for the whole season.

Another advantage gained by sprouting is that the first bud is preserved, and the plant is therefore more vigorous throughout the season, whereas with unboxed seed the first bud when it exists is tender and usually gets broken off."

Boxes for Storing and sprouting.-The illustrations on p. 71 show a suitable form of box for the above purpose. The box is handy for lifting about, and, as a considerable number can be piled upon each other, large quantities of potatoes can be stored in a comparatively small space. The most useful size is 27 inches long, 18 inches wide, and $3 \frac{1}{2}$ inches deep. The sides and ends should be formed with deal $\frac{5}{5}$-inch in thickness, and the bottom with $\frac{3}{4}$-inch deal 2 inches wide, and fixed 1 inch apart. The uprights and the crosspieces forming the handles should be of deal, 1 inch square, and the former should be screwed to the sides, and screws should be used in fastening the crosspieces. As shown, the boxes can be stood one upon the other without excluding the light, or interfering with the free circulation of the air, a point of great importance in the case of potatoes for planting. On page 72 is represented another form of box, which may be made as follows: The measurements are $2 \mathrm{ft}$. long, 
1ft. wide, and 7in. high. The wood used is as follows: Sides and bottom-pieces, 3 in. by $\frac{3}{8}$ in., and end-pieces, 3 in. by $\frac{1}{2} \mathrm{in}$. The corner-pieces are $1 \frac{1}{4}$ in. square. The handle

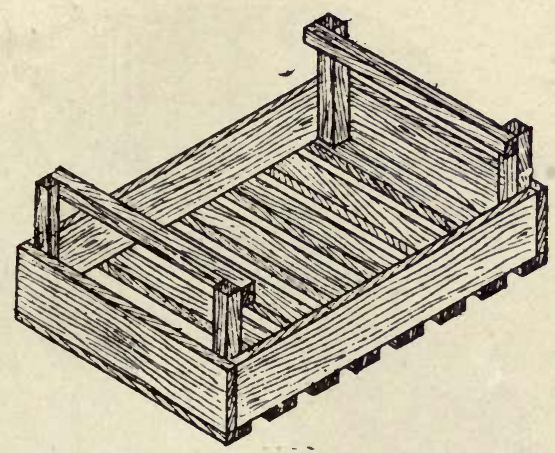

A Handy Potato Sprouting Box.

is also made of $1 \frac{1}{4} \mathrm{in}$. square stuff, and is inserted in holes bored in the end-pieces, and kept in place by a nail driven into each end. $\Lambda$ s will be seen, the bottom-pieces do not

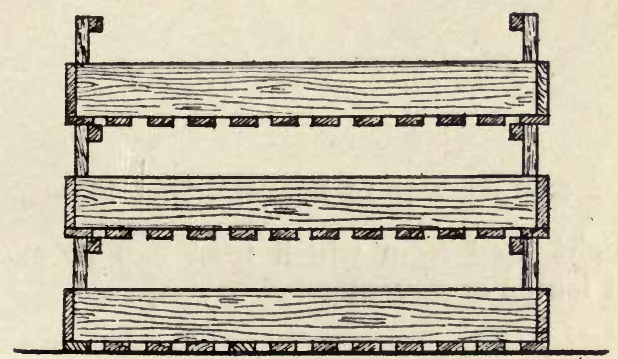

Boxes for Storing and Sprouting Potatoes.

Fig. 1. A Single Box. Fig. 2. A Nest of three Boxes stored one on the other.

touch each other, but a small space is left between for ventilation. Three strips will be required if the bottom is put on, as in the illustration, lengthways, or six if put on 
crossways. The wood can now be obtained from most box-makers ready cut into lengths. These trays are filled with a layer of seed tubers, and stacked one above another

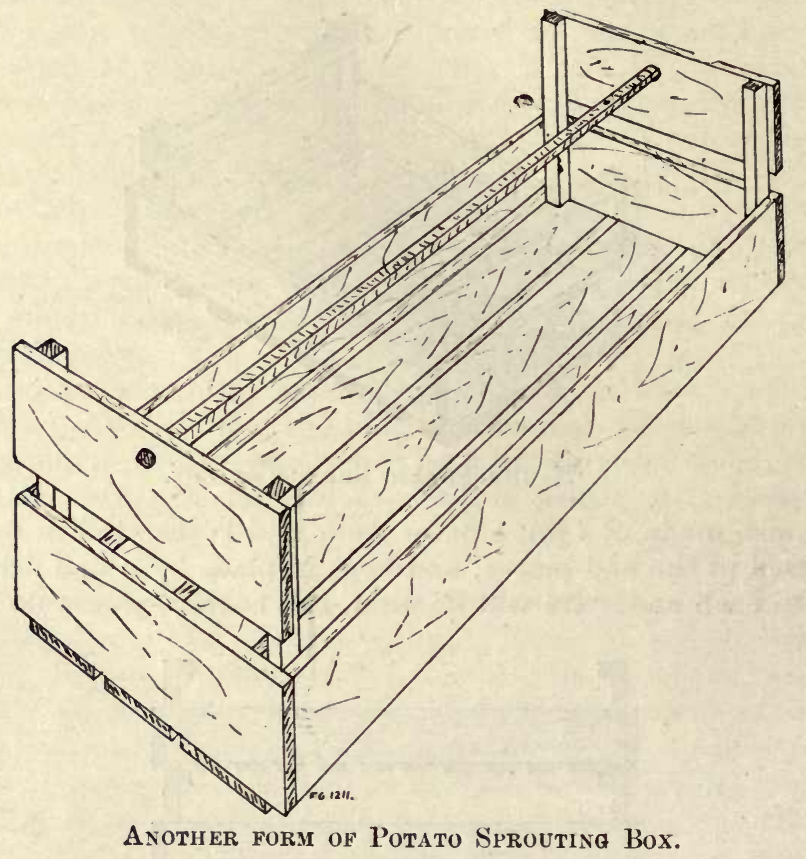

in any light shed from which frost can be excluded by means of lamps or coverings.

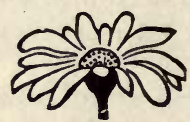




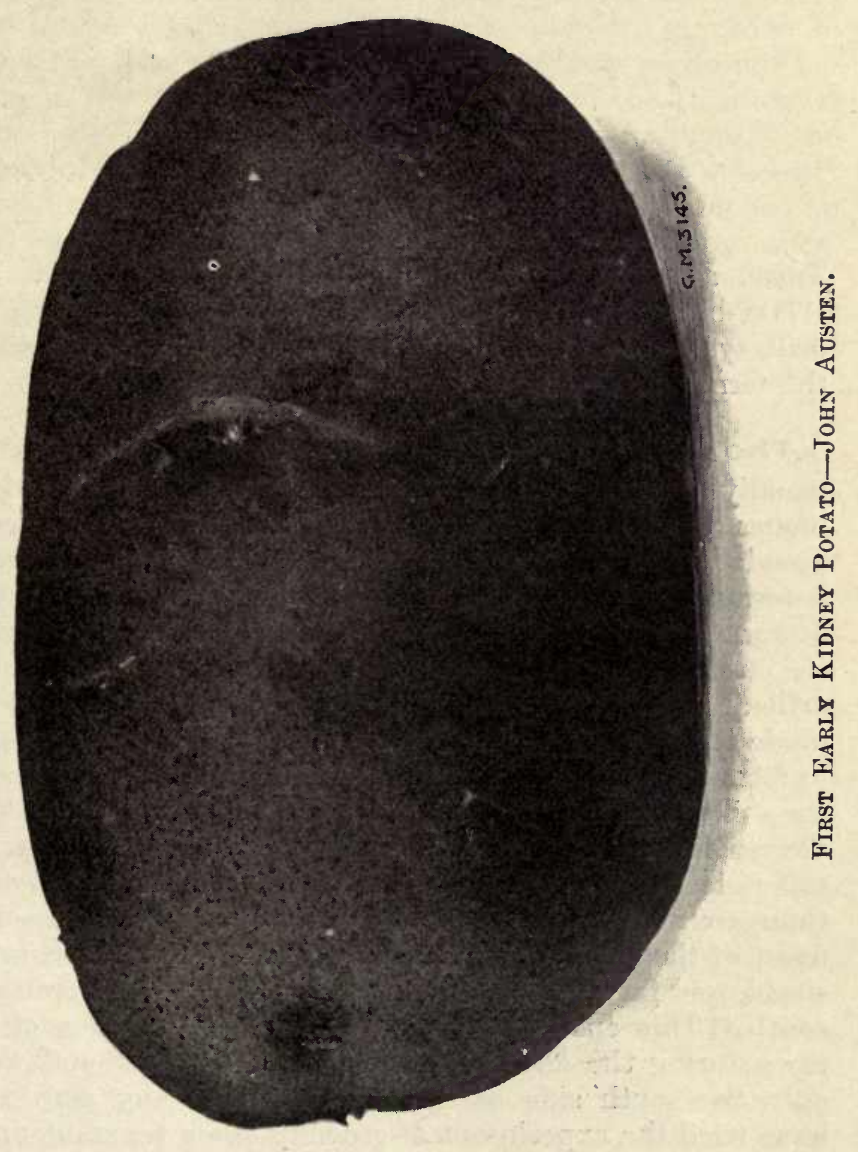




\section{CHAPTER VIII. \\ SYSTEMS OF PLANTING.}

There are three systems in vogue, the drill, flat, and "lazy-bed," the latter a method peculiar to Ireland. The drill system is the one most generally adopted, both on the farm and in the garden.

The Drill System.-In the garden the drills are usually drawn four to five inches deep on heavy, and six inches on light soils. Shallower drills are, however, recommended. See Chapter X. Sometimes the drills are drawn before planting, and this answers all right when the soil is dry and not likely to be rendered too close and compact by the treading incidental to planting and covering in the drills. Where the soil is heavy and pasty and liable to be made too close and compact by treading, it is a good plan to form the drills one at a time, plant the tubers, turn over the soil with a fork or spade till a sufficient width has been dug to form a second drill, and so on. In this way the soil is left uniformly light, and when rooting commences there are no compressed lumps of earth to restrict development of the roots. In forming the rows or drills, it is desirable, as far as possible, to let them run due north and south. This enables the sun to reach both sides of the rows during the day; whereas, if running east and west, only the south side of the rows will get any sun. We have tried the experiment of growing other vegetables, besides potatoes, in rows running east and west, and north and south, and have found the best results by following the latter rule. On the farm the drills or rows are usually 
drawn by a double-breasted plough, an alternate ridge and furrow being formed. Manure is then placed along the bottom of the furrows, the potatoes planted on top, and the ridges afterwards split by the plough, in order to cover the "sets." As remarked elsewhere we do not believe in the practice of placing manure in the furrows; it is better to apply it in autumn or winter. As regards the depth of the drills in field culture, it is pretty generally agreed that it is unwise to go deeper than three inches on the heavier soils and four inches on the lighter ones. For this shallow planting the soil must be in good tilth, otherwise the "sets" will not grow satisfactorily. 'The nearer the young shoots and roots are to the sunshine and air, the better will growth and yield be.

The Flat System.-In this case, the land is manured and got into good tilth beforehand. The position of the rows is indicated by means of a line, or by means of a shallow furrow marked out by a marking or setting-out machine. The workman then, by means of a spade or dibber, makes the holes three to four inches deep, and is followed by another person who drops in the " sets," and yet another who covers them with soil. This is not a commendable plan to follow when choice and sprouted tubers have to be planted, as there is always a risk of the sprouts being broken off. A modification of this plan is for a workman to take out a shallow spitful of soil at the required distances in the rows, another person dropping a "set" into each hole. When the end of the row is reached, the workman works back on a second row, and each spadeful of soil taken out is thrown by him into a hole in the previous row, containing a "set." He thus forms holes in one row, and covers in the "sets" in the preceding one as he works along the field. This is really a much better and more expeditious way than dibbling in the "sets."

Lazy-bed System.-This system is followed in many 
parts of Ireland, especially on damp soils. The soil is marked off into beds 4 to $6 \mathrm{ft}$. in width, and trenches 1 to $2 \mathrm{ft}$. wide and $1 \mathrm{ft}$. deep are taken out on each side, the soil being thrown on the top of the bed. The potatoes are then planted on the surface, more soil being dug out to cover them. When the shoots are six inches high, still further soil is dug out of the trenches to earth them up. This system is too laborious and expensive to adopt except in wet districts.

Distances for Planting.-The distance apart at which it is best to plant, of course, varies with circumstances. Very early light-cropping varieties to be dug when very young may be planted in drills 20 in. apart, with the sets a foot apart. Medium early may be put 27 in. (the narrowest at which moulding-up can be done by the plough), with sets 12-16in. apart. For heavy growing maincrops $30 \mathrm{in}$. ridges and sets 14 -16in. is near enough; and for very big-haulmed potatoes $32 \mathrm{in}$. is not too wide, with sets 14 to $18 \mathrm{in}$. apart.

Ploughing-in System.-This consists of ploughing the land and planting potatoes at the same time. It is, however, not a commendable plan to adopt generally. The furrows are formed in the ordinary way, and in every third one the sets have to be planted by a number of hands. When the fourth furrow is turned this covers the "sets." The system is bad, because the tubers are laid up upon the hard, smooth subsoil or "pan" formed by the passage of the plough, and the " set" has consequently very poor encouragement in the way of friable soil to put forth healthy roots and shoots. Where a digging plough is used in piace of the ordinary plough there is less objection. We regard this system as a rough and ready one, only fit for adoption in the case of foul land which it is desirous to clean by taking a haphazard crop of potatoes from it. 


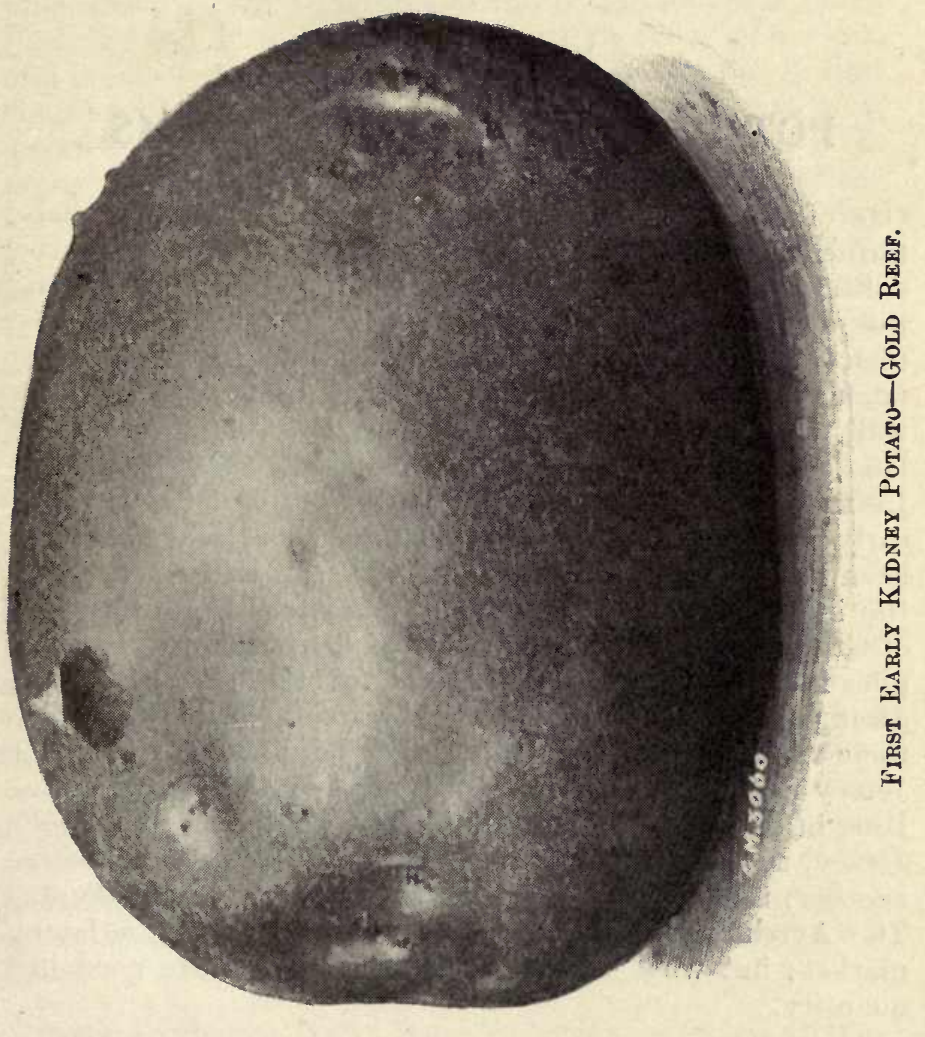




\section{CHAPTER IX.}

\section{POTATO CULTURE ON FARMS.}

() of the few branches of agriculture in which British farmers can hold their own in these times of severe agricultural competition is that of potato growing. Even in the production of early tubers, to be sold as " new " potatoes, this is the case in relation to districts specially favoured in respect of climate, such as the south of Cornwall, the Scilly Isles, and the west coast-lands of Scotland, particularly of Ayrshire. Recently, the South of Ireland has been added to the number of districts in which early potatoes are grown, and none too soon, as it has long been known that the climate there is admirably suited to the industry. Of course, we do not produce in any part of Great Britain or Ireland potatoes to compete with supplies from tropical or semi-tropical countries, which arrive during the winter. Nor do our growers deem it worth their while to produce potatoes in glasshouses, after the Jersey fashion, or at least not to any considerable extent. But, in open-air production, the Scilly Isles are ahead of Jersey, and the south of Cornwall, taking one season with another, is about on a level with the great potato island. The Ayrshire growers have to be content with a later market; but what they lack in price they make good in quantity.

Acreage on Farms. - The potato crop is one of the few crops which have not been reduced in area in Great Britain during the last twenty years. In 1884 the area was 565,048 acres, and in 1904 it was 570,209 acres. Bear- 
ing in mind the fact that, during that period, the arable land in Great Britain has decreased by nearly two million acres, these figures bear out the statement that our growers of potatoes can defy outside competition. It is true that in Ireland the area of the potato crop has fallen fronc 798,942 acres in 1884 to 618,540 in 1904 , as a result of a great conversion of arable land to pasture, but in that country a large proportion of the produce has always been grown for consumption on farms, and the increased prosperity of the people has rendered them less dependent upon potatoes as food than they were formerly. The five greatest potato-growing counties in England, with the acreages for 1904, are: Lincoln, 76,249; Yorkshire, 52,733; Lancashire, 44,665; Cheshire, 24,167; and Cambridge, 24,024. Kent, Norfolk, Devon, Durham, and Stafford grow severally from 10,000 to over 13,000 acres. Among Scottish counties Fife stands highest, with over 15,000 acres; Perth and Forfar growing over 12,000; Ayr nearly 9,000; Haddington over 8,000; and Aberdeen over 7,000 acres.

Soilc-A good loam, light, rather than heavy, such as the soils over the Old Red Sandstone or the Greensand, or alluvial soil, is the best for potatoes. Peaty soils, such as those of the Lincolnshire fens, produce great crops, but the tubers, known in the market as "blackland " potatoes, are of comparatively low quality, and sell accordingly. Neither clays nor their soils over the chalk are well suited to the crop. In the former the potatoes are particularly liable to disease in rainy seasons, and in the latter they suffer from drought in dry seasons. See also chapter on Soils.

Cultivation.-When potatoes are to be grown after a corn crop, the stubble should be thoroughly cultivated as early as possible. Nothing beats steam cultivation, but where this is not available, the land should be well worked with the plough, the cultivator, and the harrows, being 
stirred repeatedly to cleanse it from weeds. After this it should be ploughed deeply for the winter. The ploughing depends partly upon the method of planting. Some growers, who adopt the ridge system, ridge the land up with a double-breasted plough in the autumn, in which case it lies well for the winter, and is easily worked in the spring. Others plough it on the flat, cross-plough it in February if dry enough, and cultivate thoroughly and ridge it just before planting it. Those who grow on the flat pursue the like course, except that, after cultivating and harrowing, they plough or dibble the potatoes in without ridging. If the land be at all heavy, the plan of ploughing in February or later is a questionable one. It cuts thistles, no doubt, but, unless hard frost follows, the land is not in as finely divided a condition at planting time as it would have been if not ploughed a second time, and consequently it is not so well suited to the ramification of the potato root fibres, while it does not resist drought so well in a season subject to that infliction. Whatever method of cultivation and planting is adopted, it is of the utmost importance to obtain a good depth of fine mould, and when the land is cloddy, heavy rolling and harrowing should be perseveringly pursued until a fine tilth is secured. The ridge system is probably the best for the main crop, and certainly it has many conveniences; but early potatoes are grown on the flat in Jersey and in some parts of Great Britain, shallow planting being desirable for them.

Manuring.-Most of the great growers rely largely, and some entirely, upon farmyard manure or town dung. Where no artificials are used, twenty to thirty tons of the natural manure, and sometimes forty, are applied by those who grow heavy crops. This manure is put on the land before the first or second ploughing where the crop is to be grown on the flat, and in some cases where it is to be grown on the ridge system. Most of the Scottish growers, who generally pursue the ridge system, however, 


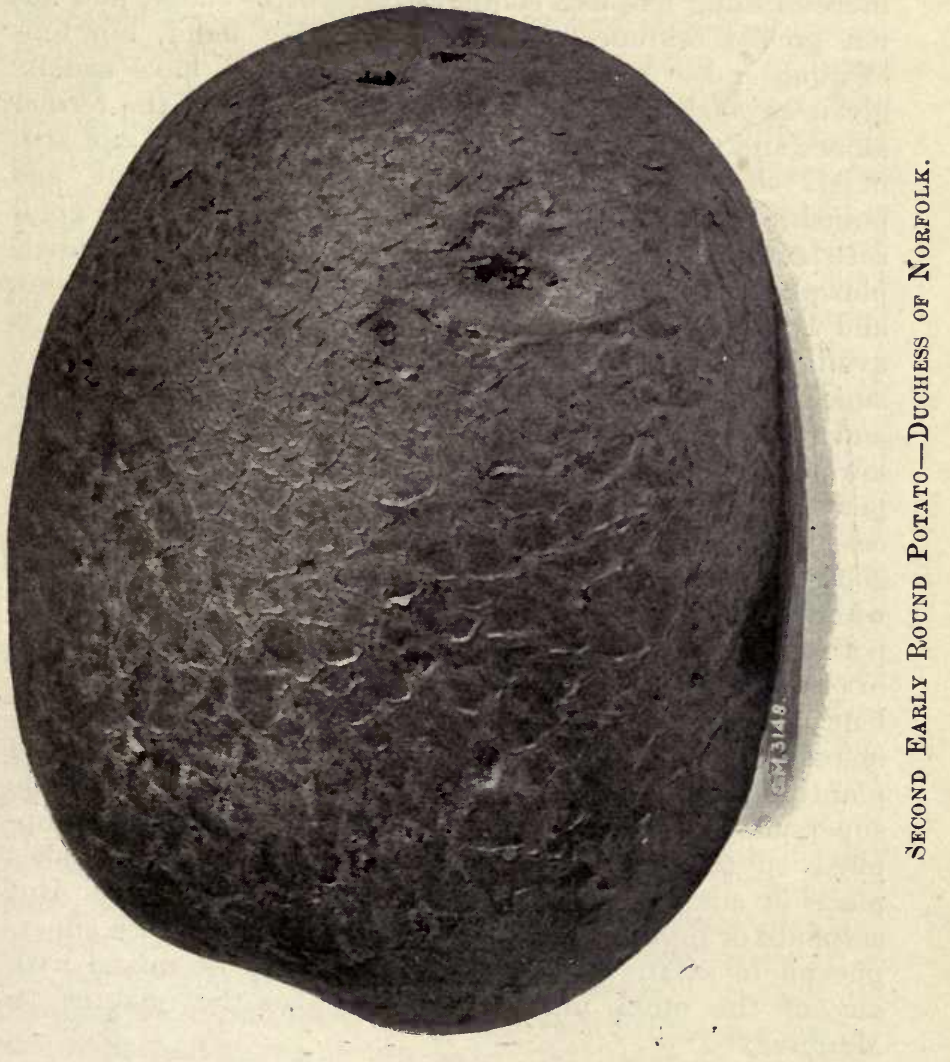


apply the farmyard manure in the drills, just before planting. Experiments, as a rule, have shown that nothing beats a very heavy dressing of natural manure, and in many cases the addition of artificials to twenty tons or more of dung has had comparatively little effect, and has not proved remunerative. On the other liand, ten tons of dung and a dressing of artificial manures have usually given as good results as double the quantity of the former alone, and sometimes better crops. In all cases, the artificials should contain nitrogen, phosphoric acid, and potash. A dressing that has almost invariably given great satisfaction consists of 10 tons of dung, 4 cwt. of superphosphate, 1 to 2 cwt. of sulphate or muriate of ammonia, and 1 to 2 cwt. of sulphate of potash. When no dung is available, a successful dressing is made up of 4 ewt. of superphosphate and 2 ewt. each of sulphate of ammonia and sulphate of potash, applied at planting time, and followed, just before the potatoes are earthed up, with 1 cwt. per acre of nitrate of soda as a top dressing. In some cases, such liberal artificial manuiring has given crops as good as where dung has been used, and at a smaller cost when town dung has been purchased. As a source of potash sulphate has done best in some cases, and muriate in others, each having almost invariably beaten an equivalent quantity of kainit. When nitrate of soda is used instead of sulphate of ammonia, partly at the time of planting, and partly later, it should not be mixed with the supersphosphate, unless the mixture is certain to be supplied on the same day, because chemical action takes place in such a mixture, causing loss of nitrogen. But sulphate or muriate of ammonia may be mixed with superphosphate at any time. The potash may be mixed with any of the other manures. See also the chapter on Manures.

Planting.-Very early crops are commonly planted in February, or occasionally, in Jersey, Cornwall, and the Scilly Isles, in the latter part of January, if the lant be 
dry enough, which is not often the case. But in districts more liable than these favoured ones to spring frosts, it is not safe to plant before the last week of February or early in March. In Jersey the very earliest open-air crops are grown on slopes facing the south, and small pieces are sometimes planted by hand, as in a garden. On larger pieces of land, the tubers are usually ploughed in, a small one-horse plough being used. The seed, invariably sprouted, is planted in rows $14 \mathrm{in}$. to $20 \mathrm{in}$. apart, the sets being about 12in. apart in the rows. They are dropped in every second furrow after the plough, which covers them with only three or four inches of soil-usually not more than three inches. In Ayrshire early potatoes are planted in drills, on the ridge system, these being often drawn by a combined drill-plough and artificial manure sower, which forms two drills at the same time, and sows the manure within. The sets are covered up with a double-breasted plough. The drills are usually 25in. apart, and sprouted seed is used. As to the size of the seed tubers, in Jersey they are as they are raised, unless very small ones are sifted out. In Ayrshire sets of fair size are now generally used. Wholé sets are always used, and women generally do the dropping. In the case of the main crop of potatoes the ridges in Great Britain generally are made about $27 \mathrm{in}$. apart, and the sets vary in distance in the rows, from $12 \mathrm{in}$. to $18 \mathrm{in}$., partly according to the size of the tubers, and partly in relation to the richness of the soil. Some growers use seconds for seed, others large tubers cut or uncut, and yet others a mixture known as " seed and ware," consisting of the potatoes as grown sifted over sieves of $1 \frac{1}{4} \mathrm{in}$. to $1 \frac{1}{2} \mathrm{in}$. mesh, very large tubers being sometimes picked out during the sifting. The most common method of planting where the ridge system prevails is that of drawing the drills and covering the seed alike with the doublebreasted plough. When grown on the flat, the potatoes are most commonly ploughed in with ploughs which will draw furrows wide enough to make two furrows $27 \mathrm{in}$. wide, so that the seed can be dropped in every second 
furrow. Some growers plant heavy-cropping varieties in rows $30 \mathrm{in}$. apart, and in that case the sets are dropped in every third furrow. In some cases, however, the land is marked out with a drill, and the seed is dibbled or "spaded" in. Potato-planting machines are used to a small extent.

Varieties.-These are so exceedingly numerous that a complete list of all those used in field culture would occupy much space. Among first earlies, the Royal Jersey Fluke is the favourite in the Channel Islands, Ashleaf, formerly the prevailing variety, being much less grown. The former is preferred on account of its superior yield, the tubers being much larger than those of the latter. The quality of the Royal Jersey Fluke is very poor; but as consumers in England prefer large size to fine quality, and will actually pay more for the big and handsome Fluke than for the Ashleaf, the growers are glad to suit their taste. The old Jersey Fluke, a superior variety, is very little grown now. Prince of Wales is planted to some extent. Myatt's Ashleaf and Dulie of York are most grown in Cornwall, the former variety and Royal Jersey Fluke in the Scilly Isles. Other more or less early kinds grown as field crops in England are Puritan, Sharpe's Victor, Snowdrop, Early Rose, Market Favourite, and Beauty of Hebron. In Scotland the favourite first early is Puritan. Sir John Llewelyn has gained much favour in all parts of Great Britain, but has only just become cheap enough for planting on a large scale. Among second earlies British Queen is probably grown mure extensively than any other, though some of the newer kinds may be gradually replacing it. Royal Kidney, Sutton's Windsor Castle, and Early Regent have come much into use in some parts of the kingdom. Of the late varieties Up-todate is still most extensively planted in Great Britain as a whole. Maincrop, Langworthy, Bruce, and other sorts are also extensively grown in Scotland; while Abundance, Magnum Bonum, the Factor, and other kinds are much in 


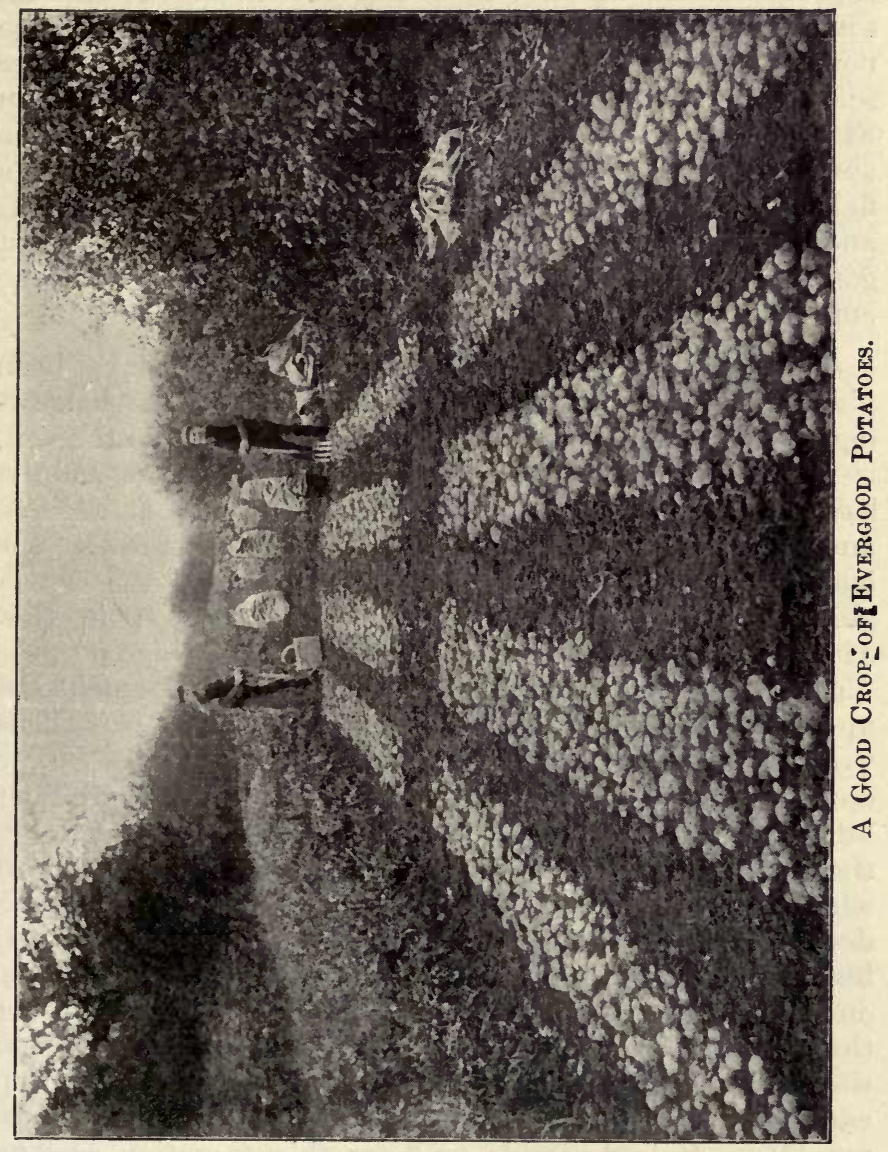


use in England. Ireland still stands by the Champion to a great extent, but not so nearly exclusively as she did some years ago. Among the new varieties which have now become cheap enough for culture on a fairly large scale, are Evergood, King Edward VII., and Northérn Star. Eldorado has dropped tremendously from the absurdly "boomed" price of 1904, but is still dear for a field crop. The old Regent, one of the best of potatoes, and formerly grown extensively in Scotland, has almost gone out of cultivation, its constitution having become enfeebled by age.

After-Cultivation.-After the potatces have been planted, and shortly before they come up, light harrowing, to kill annual weeds, and to break any cap in the soil, is carried on. For ridges what are known as saddleback harrows are used. They do two ridges at a time, and are easily drawn by one horse. There is one handle to each pair of harrows, by which the driver guides the implement. The next operation is that of cultivation between the rows. For this purpose "grubbers" are made with curved tines, which stir up the soil deeply, and close, to the potatoes. This work is done two or three times, as a rule. The double-breasted plough, without its breasts, and with hoes attached to it, is extensively used for cultivation between the rows. The ordinary horse-hoe is commonly used where potatoes are grown on the flat. Hand-hoeing is desirable in the rows, especially where thistles come up; but some growers do but little of this work, as they rely on the tops to smother small weeds, while large ones other than thistles are frequently pulled up by women. When the tops are sufficiently advanced, they are earthed up with the double-breasted plough, or by a three-row moulder. It is desirable to defer this operation as long as possible, short of waiting till the tops hang down towards the spaces between the rows.

Spraying.-The practice of spraying potatoes with 
Bordeaux mixture is extending rapidly. It is not only a valuable preventive to disease, but also a means of prolonging the life of the haulm, and thus increasing the yield. It does not give absolute immunity from disease, but greatly reduces the injury. The mixture consists of $20 \mathrm{lb}$. of sulphate of copper, and either 10lb. or 20lb. of quicklime in 100 gallons of water. The larger quantity of lime is preferable, as it insures the neutralizing of the acidity in the sulphate of copper, and does away with the necessity of testing. When the smaller quantity of lime is used, the testing of the mixture with a piece of litmus paper is of importance. If the paper turns red when dipped in the solution more lime must be added until it is found to retain its blue colour on dipping it. The copper sulphate is dissolved with hot water in a wooden vessel, and the lime is slaked in another. When the lime has been sufficiently liquefied, it is strained through a sieve of the finest brass wire gauze into the other solution. After further dilution to make up 100 gallons, the mixture is strained into the spraying machine. Bordeaux mixture should not be made until it is required, as it deteriorates by keeping. Some authorities state that it should not be kept for over forty-eight hours. A readymade dry mixture, known as Strawsonite, which will keep for any time in its dry state, is manufactured by Messrs. Strawson, of Queen Victoria Street, London. It is dearer than the sulphate of copper and lime, but saves much disagreeable work. Messrs. Strawson make excellent spraying machines for potatoes. One is an independent machine, which sprays seven rows of potatoes at a time, and gets over 25 acres in a day. It contains 100 gallons, and is drawn by two horses. Another, which contains 60 gallons, sprays five rows at a time. A third is a five-row sprayer, which can be worked from an ordinary farm cart, and costs much less than an independent machine. This machine is either worked by a man standing in the cart, or by gearing attached to one of the cart wheels. Twelve to fifteen acres a day can be sprayed with this 
machine, which is drawn by one horse. Very early potatoes are not often sprayed, as the operation retards maturity, and the crop is usually got off the land before disease becomes widely prevalent. This, however, is not always the case, the early crop in 1904, particularly in Jersey, being very badly diseased. Late crops should be sprayed twice, the first time soon after the potatoes have been earthed up, and the second time about three or four weeks later. A dry day, when there are no signs of rain, should be chosen for the work. Further information on the potato disease and the remedies for its prevention will be found in a separate chapter.

\section{CHAPTER $\mathrm{x}$. \\ CULTURE IN GARDENS.}

Most people who have gardens of any size, or, failing them, allotments, like to grow their own potatoes. This is especially true of the early and second early sorts, that can be lifted as required from the garden. Home-grown tubers taste ever so much sweeter and nicer than those half-shrivelled, waxy things one gets from the Canary Islands, or those only a trifle better that hail from the Channel Islands and Cornwall, and which have been exposed in the market or on the greengrocer's stall for days before one gets them. To dig up one's own kidney potatoes fresh from the soil in June and July, when their skins are tender and easily rub off, then cook and serve them with melted butter, flavoured with mint, is, indeed, a source of delight. We certainly think that all who can 


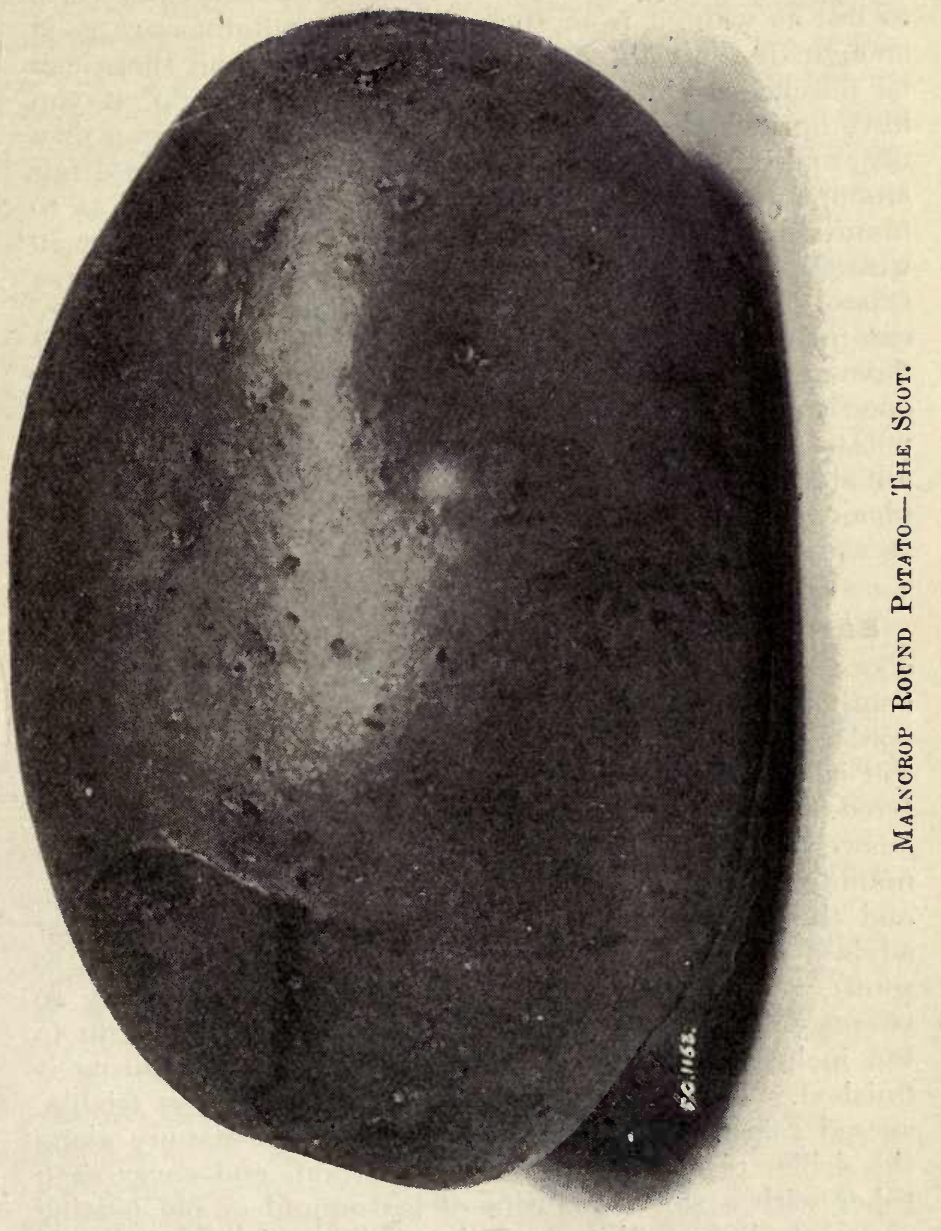


find room for a few potatoes should grow the early sorts to use as wanted from the soil. Late potatoes are good enough, if the right sort, wherever grown, and these can be purchased cheap enough when required. So, if you have limited room, by all means grow earlies for your own use, and buy late ones in due season. If you have a fair amount of room grow earlies and second earlies, so as to maintain a supply till autumn, and buy late potatoes in winter. But, if you have plenty of room, grow all three types; it will pay you to do so, and, moreover, if you are careful in the selection of sorts, you will get much better flavoured potatoes than you coild probably buy in the open market. In order, then, that you may grow your potato crops successfully we will now proceed to tell you all about the business, reserving no special secrets, but placing all our knowledge and experience fully and freely at your servize.

Early Crops.- Here we mean early crops grown outdoors, not those reared in pits or frames, as referred to in another chapter. To have tubers fit to lift in June a south border at the foot of a wall, and a rich, deep, well-drained soil is preferable; but an open plot, provided it be sheltered from north and east, and slope to the south, will answer almost as well. The soil should be prepared and manured as advised in the chapters on Soils and Manures, and the "sets" got ready for planting in the manner advised in Chapter VII. Draw the drills from north to south, and three to four inches deep, and twenty to twenty-four inches apart. In these place the sets eight to ten inches apart, cover with mould, and the planting is finished. In the event of the soil not being over friable, spread some decayed refuse or well rotted manure along the drills, place the "sets" in position, and cover each tuber with a small quantity of leaf-mould or old potting compost, before filling up the drills with the ordinary mould. In warm districts from the end of February to the first week in March will be a good time to plant. When 
the shaws appear above the ground protect with a little dry litter laid on at night only. Use the hoe or fork freely between the rows a little later, and as soon as the shaws get fairly strong mould up th $\rightarrow$ rows. Lifting for use as required may begin in June, and the remainder of the crop as soon as the haulm begins to turn yellow and the skin on the tubers becomes "set" or firm.

Second Early Crops.-The second early varieties should be planted from the middle to the end of March, the earlier period being best on light, warm soils, and the latter on those of a less genial nature. Here, again, the soil should be properly prepared and manured in accordance with the advice given in Chapters IV. and V. The drills on the lighter soils may be four inches, and cn the heavier ones three inches deep, and they should run north and south. Do not be in too great a hurry to plant if the soil is at all wet and pasty; better by far wait a week, even, and plant when the soil will work pleasantly. Due consideration, too, must be paid to the habit of growth of the variety, giving those that are of robust growth plenty of width between the drills. In the event of frosty weather supervening when the shoots are pushing through, draw a little fine mould over them from time to time as a protection. In fine weather stir the mould between the rows. This operation will be of immense benefit to the crops, checking the growth of weeds and aerating and ameliorating the soil. As soon as the shoots are the requisite height mould up the rows, and then there will be nothing more to see to till the lifting time occurs-when the haulm turns yellow and the skin has set on the tubers.

Main Crops. - The best time to plant maincrop potatoes is from the end of March to the middle of April. As this is the chief crop, special pains ought to be taken to get the land in really good condition the previous autumn or winter. The importance of this subject has been fully discussed in Chapter IV., and we strongly counsel the 
reader to read, mark, learn, and inwardly digest every line of the advice given therein. Given a good soil and fine weather, so that the soil can be comfortably and easily worked without trampling it into a pasty mass, the planting may proseed in earnest between any of the dates mentioned. Do not overlook the importance of selecting medium-sized whole tubers as " sets," getting these boxed and properly sprouted, and then allowing ample space between the "sets" and the rows. Give each plant good soil to supply food, and plenty of room to develop, and it will reward you a hundredfold for all your pains. The drills in this case may be three to four inches deep, according to the state of the soil. Directly the shoots appear through the soil use the hoe occasionally to keep down weeds and aerate the soil. At this period it will be opportune to apply guano or one of the nitrogenous manures advised in Chapter V. When the shoots or "shaws" are high enough, mould up the rows, choosing a fine day for the work. Draw the earth up well to the stems, and take care in doing so not to injure or expose the young tubers. In damp seasons favourable to the potato disease the Jensen system of giving a second earthing up might well be practised. This, however, can only be properly practised where there is a good width between the rows in order to get the necessary mould. The system is to draw the mould up flatly on one side of the row and to depress the stems over on to it, and then to earth up freely with a fork on the opposite side, this causing the potato stems to heel over on their sides. This plan prevents the spores of the fungus being washed on to the tubers. The lifting of the crop should be done on fine days. As the lifting proceeds throw the haulm into one row, the cooking tubers into another, the seed tubers in another row, and the "chats" by themselves. Diseased tubers, if any, should, if discovered, be thrown into a basket or box, and burnt at the earliest opportunity. Tubers for cooking purposes should not be exposed longer than necessary to the light, but stored away. Fuller 
details on storing cooking "and "seed" tubers will be found elsewhere.

Catch Crops. - In small gardenis the most has to be made of the limited space at command, and hence it is frequently the practice to plan's green crops between the rows of potatoes. There is no serious objection to this being done if plenty of width is allowed between the rows. When such is not done, both crops suffer, and the potato crop more especially. Those, therefore, who wish to grow kale, sprouts, broccoli, savoys, or eabbages between potatoes should allow a width of not less than thirty inches, or, better still, three feet. There is then no chance of the potato haulm smothering the plants, or of the latter interfering with the growth of the potatoes. These catch crops should, of course, be planted after the final moulding is completed. In the Midlands cottagers often drop broad bean seeds in the rows of their potatoes at planting time. The seeds are placed about a foot apart. Here, again, if plenty of space is allowed between the "sets" no great harm is done, and many a dish of broad beans to accompany the inevitable piece of bacon is assured. When the potato crop is lifted, the soil is usually levelled between the green crops, and the latter then have the plot to themselves. This double cropping business, to be success, depends upon the thorough preparation of the land for the potato crop. The more thoroughly the land is tilled and enriched the preceding autumn and winter, the better will the dual crops be.

Varieties.-There are so many varieties in cultivation, and so many of them possessing high merit, that it becomes no easy task to make a selection. As we are giving a descriptive list of the chief varieties grown in this country at the end of this book, we shall content ourselves with naming twenty-four of what we consider the best flavoured, good cooking, and free cropping sorts for garden culture. 
First Earlice.-Myatt's Ashleaf, an old variety, with white kidney-shaped tubers, a strong grower and heavy cropper. Snowdrop, a white kidney, free cropper, and good cooker. Sutton's May Queen, a white kidney, very early, and well adapted for warm border, frame, or hotbed culture; free cropper and good cooker. Early Puritan, an early oval round, with large tubers, which cook well. Sir John Llewelyn, a white lidney, with handsome shalloweyed tubers, which cook well, and are of excellent flavour; free cropper; resists disease; good for light soils. Sharpe's Victor, white flesh, a white round, suitable for very early crops in warm borders, frames, or pots; excellent cooker; flavour first rate. Sutton's lingleader, a white lidney, with white flesh, well suited for the earliest crop; good for a light soil ; of excellent flavour, and a first-rate cooker; planted in February, the crop will be ready to lift early in June. The Pearl, a white lidney, with handsome tubers; crops splendidly, cooks well, and is of excellent flavour; will do well on a light soil.

Second Earlies.-Sutton's Windsor Castle, a white round, with oval, flattish tubers, having a netted skin; heavy cropper; cooks splendidly, and is of excellent flavour. British Queen, a white kidney, and very free cropper and disease resister; tubers cook very dry and floury, and the flavour is first class; good keeper. Cigarette, a white round, an enormous cropper, high flavoured and good cooking variety; resists disease well. Sutton's Supreme, a white kidney, with pebble-shaped tubers; crops heavily, resists disease well, cooks exceedingly well, and is of tirst-rate flavour. General Roberts, a white round, with flattish tubers; is a heavy cropper, cooks nice and floury, and is of excellent flavour; has white flesh; will do well on a light soil. General French, a white round, with flattish tubers, shallow eyes, and white flesh; flavour first rate; cooking qualities excellent. Beauty of Hebron, a coloured round, with rosy-tinted, oval-shaped tubers, well suited for light or chalky soils; 


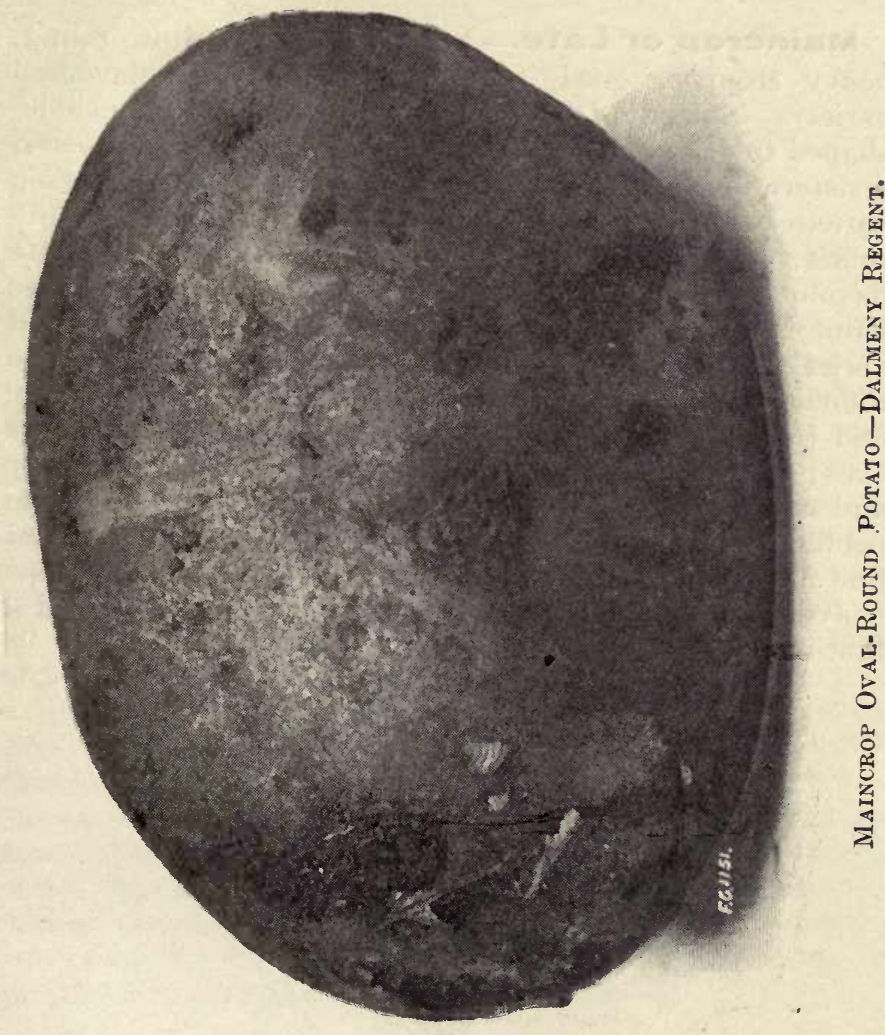


has white flesh, a very fine flavour, and cooks dry and floury. King Edward VII., a coloured kidney, with white skin and deep pink eyes; a heavy cropper, good cooker, and fairly good flavoured variety.

Maincrop or Late.-Northern Star, a white round, heavy cropper, good cooker, and first-rate flavoured variety. Sutton's Discovery, a white round, with pebbleshaped tubers; is not only a splendid cropper and diseaseresister, but also one of the best flavoured and cooking varieties in cultivation. Webb's Goldfinder, a white round, with flattish tubers; crops heavily, is of first-rate flavour, and a grand cooker. Charles Fidler, a white kidney, heavy cropper, good cooker, and fine flavoured variety; excellent keeper. Lim or Sim Gray, a white round, with oval-shaped, fairly large tubers; crops heavily and cooks well. Eldorado, a white kidney, with shallow eyes; heavy cropper and disease-resister; first-rate cooker and of excellent flavour. Sutton's Satisfaction, a white pebble-shaped round, heavy (ropper, excellent cooker, and fine flavoured variety. The Fartor, a white round; crops heavily, has a grand constitution; is of fine flavour and a first-rate cooker.

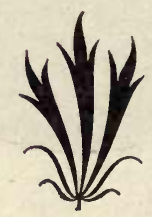




\section{CHAPTER XI.}

\section{CULTURE FOR EXHIBITION.}

THE interest centred in the potato at the present time is probably keener than it has been since its introduction into this country, owing; to a very great extent, to the increasing number of new varieties which are annually introduced . Unfortunately, many of the most handsome are practically useless except for appearance. In our opinion, though they are very taking on the exhibition table, the latter should not be encouraged, and in making awards we have always contended that judges should seriously take into consideration the quality of the varieties placed before them. This is generally done in the case of all other productions placed in competition, and why this should not be more rigidly enforced in respect of what is unquestionably on? of the most important necessaries of everyday life, we are at a loss to understand. Many entertain the erroneous opinion that high-class exhibition potatoes can only be procured on soil which is naturally most favourable to their growth. This, we assure the reader, is not the case, as by adopting somewhat artificial means, which necessarily entail a certain amount of labour, tubers of the highest quality can be ensured, if one is prepared to give the extra trouble required.

Preparing the "sets." - The first, and one of the most important, items is the selection of suitable varieties, a list of which we give at the end of this chapter. The next thing in importance is the preparation of the "sets." This unquestionably plays a most important part as to the 
final results. We prefer choice, medium-sized tubers planted whole. These should be selected in good time before they commence to sprout, be arranged in single layers on a little finely-sifted leaf-soil in suitable trays, and allowed to sprout away slowly in a low temperature, but, of course, proof against frost. The lighter the place assigned to them the better, as then no undue waste will take place previous to planting.

Preparation of the soil.-As above stated, much of the soil in many parts of this country is unsuited for naturally producing exhibition specimens, but we know of none, if properly prepared, and a suitable mixture added, that cannot be brought into such a condition that the difficulties may be overcome. In the first place, the site should be well drained, and as open as possible. The soil, too, should be well trenched during the winter or early spring. A thorough good layer of long stable litter should be placed in the bottom, and no attempt made to fine down the surface, which should be left for the time being to the influence of the weather. A good dressing of fresh soot should be strewn over the land after the trenching is completed, and if the soil be destitute of lime a good sprinkle of this should also be giver.

Compost for Planting.-This should also be got in readiness during the month of February, and we know of nothing better than old mushroom-bed manure and welldecayed leaf-mould in equal quantities, both of which should be passed through a coarse-meshed sieve. To every four barrow-loads add the fourth part of a peck of slacked lime and soot. The whole should be thoroughly turned over several times, so that each constituent becomes thoroughly incorporated. If this can be kept in the dry in an open shed till wanted, so much the better. About the middle of March the planting should be proceeded with. It is absolutely of the greatest importance that abundance of room should be provided both between 


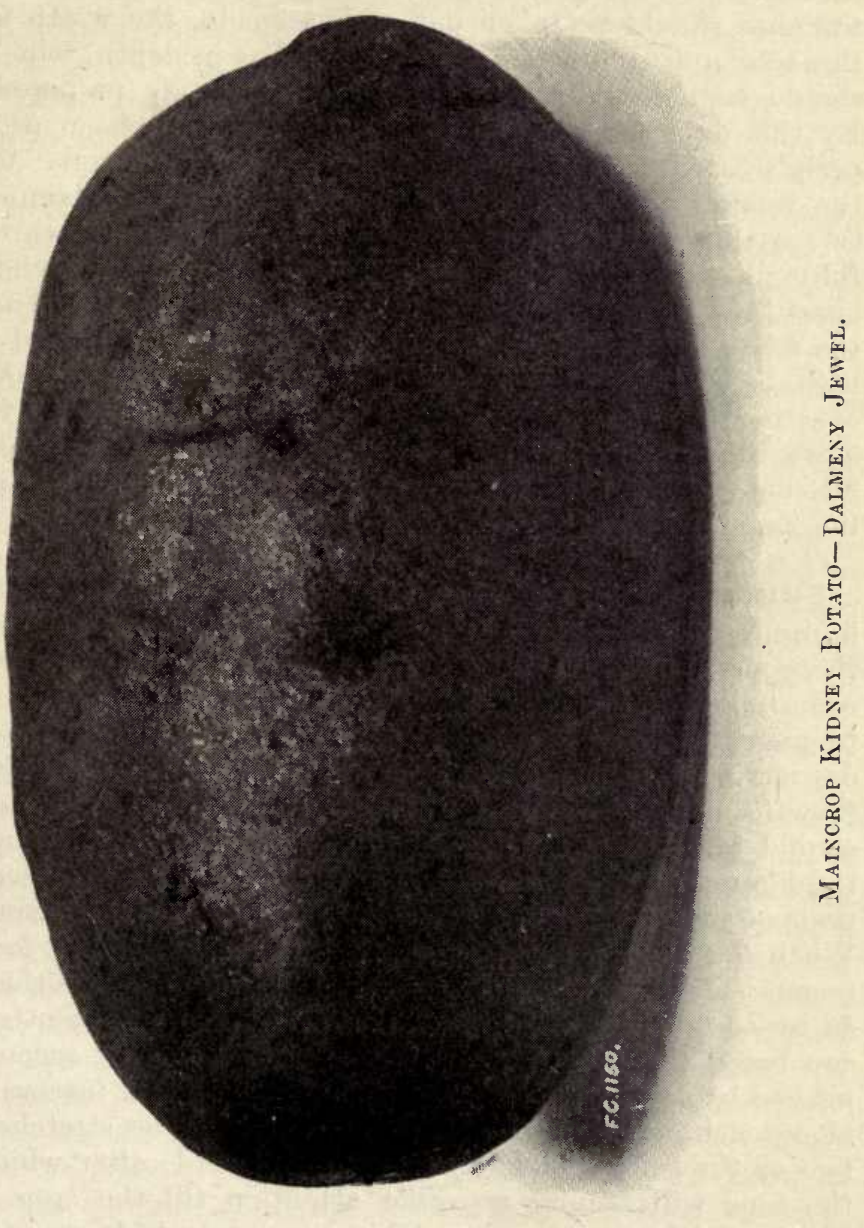


the rows and the "sets." Lightly fork over the surface this time, breaking it down as finely as possible. Good trenches should be taken out with a spade, the width of this tool and from a foot to fifteen inches in depth, which should be half filled with the mixture already prepared. By this date the selected tubers, if they have been properly treated, will have produced stout, sturdy shoots. All the weaker ones should be rubbed or cut out, retaining two or three of the strongest only. These should be carefully placed in the trenches at a distance of 24 inches apart, after which fill up the remainder of the trench with the same kind of mixture, over which should be placed a little of the finest soil which has been excavated. Rake over neatly and make a mark in the way of a small drill down the centre of the row. Allow a distance of at least $3 \mathrm{ft}$. $6 \mathrm{in}$. between the rows, and proceed with the work in the same manner.

Subsequent Culture.-Should late spring frosts be imminent, means of some kind must be taken to protect the young growth, as seldom, if ever, when the tops become crippled, do satisfactory results follow. Ply the hoe frequently after the growth can be seen, to keep down weeds and aerate and pulverise the soil. When the growths are about $4 \mathrm{in}$. in height, any small weak ones should be drawn out, which is easily accomplished, and the plants moulded in the ordinary way. Slight applications of soot should be applied during the growing season. When the growth has reached a height of about one foot means should be taken to keep it in an upright position, as by so doing both sun and air, which are so essential, can reach the soil uninterrupted. This is easily accomplished by driving in fairly stout stakes at regular intervals along each side of the row, to which should be stretched two or three lines of fairly stout tarred cord, after which the tops will require no other attention till the crop is lifted; and here, let us say, this precaution is frequently deferred too long. 
Lifting the Tubers. - Immediately the tubers have practically completed their growth, ne time should be lost in taking them up, or, in all probability, the dreaded disease will put in its appearance, and a large percentage of the crop will become affected and spoilt, which otherwise, by timely lifting, might have been saved. Cut off the whole of the tops close to the ground with a pair of hedge shears, and have everything in readiness. Proceed to dig them with a potato fork, choosing fine weather for the purpose. Every care should be taken not to damage the tubers, and all the most promising should be selected and placed in suitable boxes, covering them as speedily ats possible with some of the finely-sifted soil in which they have been growing.

Preserving the Tubers for Show.-It is of the utmost importance that both light and air be kept from the tubers. One layer only should be placed in a box, and the boxes stored away till required in a dark room or cellar. Some exhibitors wash and wrap the tubers in paper, covering them with fine sand until wanted, but we much prefer deferring this till the last moment, otherwise much of the fresh appearance will have left them. There are many methods adopted by way of washing and cleaning, but, after repeated experiments, we know of none better than placing them for about twenty minutes in a vessel of cold, soft water, after which thoroughly rub them as hard as the skin will allow without damaging with a very soft brush or a piece of sponge, and a lather of Sunlight soap. Thoroughly rinse the tubers in clear water, allow them to dry in a dark place, wrap up in soft tissue paper, and pack carefully. The required number of tubers should be as nearly alike as possible, free from all blemishes, and of medium size. Generally speaking, in my opinion, potatoes are shown much too large, and we hope the day is not far distant when this will be rectified. We know of no place where potatoes are better shown than in Scotland, and there is not the slightest doubt but what they set the southern growers a good example in this respect. 
Best Exhibition Varieties. - The following varieties are what we consider to be the very best both for exhibition and table use:

Round.-Windsor Castle, Cigarette, Carltonian, Snowball, General Buller, and Evergood.

Kinney.-Factor, Snowdrop, Sir John Llewelyn, Satisfaction, Royal Kidney, and Guardian.

Coloured Round.-Reading Russei, Vicar of Laleham, and The Dean.

Coloured Kidney.-Mr. Breese, Edgcote Purple, and King Edward VII.

\section{CHAPTER XII.}

\section{FORCING POTATOES.}

When we take into consideration the importance attached to this vegetable, one need not be surprised to find there is such a demand for the young tubers early in the year. While wealth increases, the public taste seems to grow with it; therefore, whatever seems to be most out of season there is usually the greatest demand for-in fact, it would appear that we have now arrived at a period when the taste for all things out of season seems to be the prevailing one. New potatoes in March and green peas in April are now quite common things, so, as the Americans say, we must " go one better," and have them all the year round. The flavour of the home-grown produce being so superior to those imported, it is not surprising that those who can afford the luxury of having them grown on their own establishments, even though the 
cost be greater, should do so. It was once the lot of the writer to serve an employer who was so fastidious about his young potatoes that he would not have them lifted out of the soil until it was time to cook them, as he was of opinion they lost much of their fine flavour unless they were cooked and eaten straight from the ground. Nows if the young tubers lose flavour during the time they are being transferred from the garden to the kitchen, what must be the quality of those brought from Malta, the Canary Isles, and elsewhere? Taking these things into consideration, is it not worth while malking an effort to have sweet home-grown tubers that are a credit to the host and producer alike? For a first erop special preparations are necessary, as it is useless to go to the store and take up a lot of seed, plant them in pots, pits, or frames, in the hope of lifting the crop of new tubers in the course of six or eight weeks; if so, the cultivator is doomed to disappointment.

Preparing the set:- - It has now become a recognised fact that if the finest results are to be obtained in growing potatoes, whether by early forcing or not, a start must be made at the time the crop is lifted in the autumn. Seed intended for planting early should be selected with care, being of even size, two to three ounces in weight. Those of much smaller size are not capable of producing the stout, robust growths, which are so necessary to the assurance of a heavy crop, while larger " sets " would be a waste of seed. Whole sets always produce heavier and more even crops than cut ones; therefore, the latter ought not to be resorted to in the case of forced potatoes. It is the greatest bulk that can be produced on a limited space that pays, not the heaviest weight from a given quantity of seed, as in the case of new varieties. Having selected the seed, this should be placed in shallow boxes or trays, with the broad or " rose" end upwards; or, if the sets are round ones, that part which possesses the most eyes. The boxes should be placed in a light, airy position, where 
frost can be excluded, and here they can remain until such times as they are required for planting, unless required for very early forcing, when it will be necessary to introduce them into a gentle heat to forward their growth previous to planting, as by so doing much time will be saved afterwards. At the time of planting, the young shoots should be from three-quarters to an inch in length -stout, green, plump growths, which will always grow rapidly when placed in the soil; and the little moisture afforded them is taken up readily, thus preventing any drawback.

Preparing the Soil.-As most varieties of early potatoes make but short haulm, they may be classed as dwarfs. This being the ease, it is necessary to have the soil in which they are grown as rich as possible, that the plant food may be readily assimilated by the young growths. It is not advisable to add stimulants, in the shape of liquid manure, to a great extent when the plants are growing, as too much moisture affects the quality of the tubers. The soil intended for the growth of this crop should have been prepared some time previously, and kept in readiness under cover till required. If that from a pasture be used, it ought to be thoroughly decayed. Old mushroom-bed or decayed manure should be added when the soil is mixed up. If artificial manure of any kind be employed, this should be rich in potash.

Potatoes in Pots. - It often happens in private establishments that space for forcing vegetables is very limited, and the most has to be made of every available foot of room. Still, ofttimes, there are vineries, peachhouses, and similar structures, where potatoes may be grown in pots to advantage. They will not interfere with the crop overhead in the least, and where the houses are of fair dimensions, paying crops may be taken off without the least injury to the roots. A few pots could be grown in almost any house of that description where space could 


$$
\text { A }
$$


be afforded. Pots that have been used for chrysanthemums will be just the thing. It will not be necessary to use many crocks for drainage, as some rough turfy loam or well-decayed manure will be far preferable. Place one large crock over the hole, then put in about six inches of soil, place one tuber in the centre, then fill up with soil to the rim. The pots should be stood in the house, the temperature of which is regulated according to the growth of the vines, peaches, etc. When, in the course of a few days, the young growths have pushed through the soil, a gentle watering may be given; this will cause the soil to sink, so as to allow room for earthing up, when the haulm is about six or eight inches high. Every possible care must be taken in watering; no more should be given than will keep the foliage in a healthy growing condition. The plants must, however, on no account be allowed to suffer for want of moisture, as this would cause a check to their growth, and the crop would be unsatisfactory as regards both quality and quantity.

Potatoes on Hotbeds.-Fermenting material in most country places is not difficult to obtain, and, though it requires some degree of knowledge to make the most of the material, there ought not to be much trouble in maintaining the requisite heat, provided due care be exercised in putting the bed together, and not starting it until the " sets" are ready for planting. The next thing is to prepare the material for the bed, which should consist of about two parts stable litter and one of leaves, previously mixed together by being thrown up in a heap and allowed to ferment for a short time, so as to pass off the violent heat. The size of the bed must depend on the quantity of material at command, and the measurements of the frame to be used, but it should be of sufficient depth to retain the heat for about two months. The soil having been prepared as previously noted, and the sets ready for planting, the material may be put together, allowing at least eighteen inches all round the frame for a lining, in 
case of severe weather, to maintain the requisite degree of warmth. The soil should be at least six inches deep at the time of planting, and another three or four inches may be added at the time of earthing. There should be at least a foot of space allowed between the soil and the glass

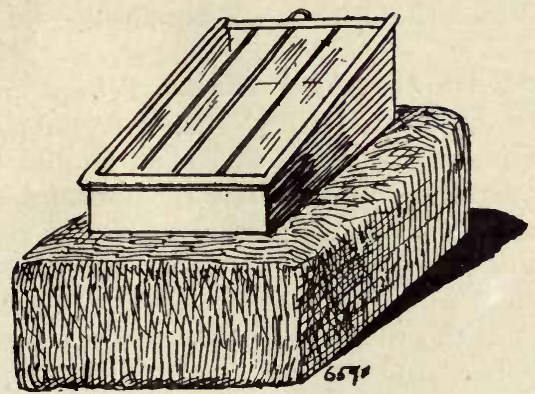

Hotbed and Frame.

for the foliage to develop. When the temperature of the bed is from 75 deg. to 80 deg., the sets may be planted, when in the course of a few days the young growth will appear through the soil. It will be necessary to cover the glass at night to protect the plants from frost, and prevent the temperature from falling too low. On all favourablo occasions air should be admitted at the top of the frame by tilting the lights, but care should be exercised to guard against cold draughts, as these would cause a serious check to the tender growth. Should the weather after planting be very severe, it may be necessary to add fresh fermenting material round the outsides of the frame to supply the requisite amount of warmth to promote a healthy, vigorous growth. Very little water will be required, as the evaporation is not great during the dull months of early spring; the soil, however, should on no account be allowed to get dry. As the days lengthen, the sun has more power, therefore evaporation will be greater, so that water may be needed, in which case choose fine 
weather, so that the lights may be removed in the mornings. After watering, close the lights for a time, unless the sun is very bright, in order that there may not be a serious fall in the temperature. If all goes well, the crop ought to be ready for lifting in about eight weeks from the time of planting, but, of course, much depends on the temperature and the amount of sunshine.

Potatoes in Heated Pits.-Where hot water is employed as the heating medium, new potatoes may be had from January onward. The beds should be prepared in the same manner as previously recommended by the aid of fermenting material, the difference being there will not be such a bulk required, as the whole will be placed inside the pit. When planting allow a distance of about fifteen inches between the rows and nine from one set to another in the row. If planted closer, the haulm is apt to become overcrowed, and the results are seldom satisfactory. There will be more evaporation in pits heated by hot water than in hotbeds, where the temperature is maintained by the heat of the fermenting material, therefore more water will be necessary. Choose a fine morning when the external temperature is favourable for watering, and always use water a little warmer than the temperature of the soil, say, from 75 to 80 deg. Fah. Ventilation will also need great care, as potatoes will not thrive in a close, dry atmosphere. When the haulm has grown about six inches long, earthing should be done, for if this be deferred too long, much injury will be caused to the foliage. In very cold weather, when it is most difficult to ventilate, do not allow the external air to come in contact with the young foliage, as this often causes a check to the growth, the foliage is attacked with aphis, and in a short time the whole plants become infested with this troublesome pest, causing the foliage to turn yellow and die off.

Potatoes in Cold Frames.-As early as February potatoes may be planted in these with safety, the sets 


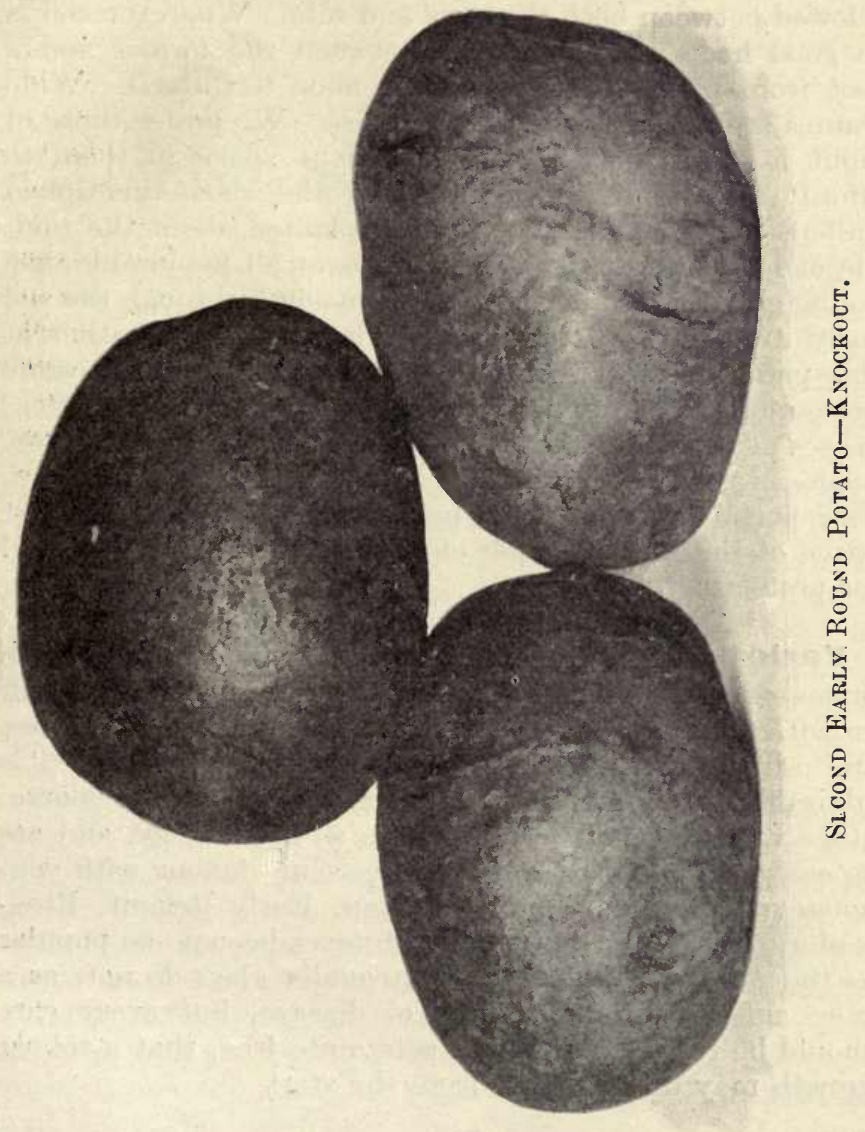


being prepared as previously explained, but as the days get longer and the sun gains more power, the haulm will grow more robust, therefore a greater distance should be allowed between both the rows and sets. When the soil is in good heart, fifteen inches between the former and a foot from plant to plant will be none too much. Wide frames are preferable to narrow ones. We prefer those of eight feet, as there is then sufficient space in them to afford the sets being planted at the above-mentioned dimensions to advantage. When planted about the middle of February, and the weather is at all favourable, the young growths will be showing themselves through the soil early in March. Sometimes we have severe weather at this period; it will therefore be necessary to afford some protection in addition to the glass. A couple of thicknesses of Russian mats, or, what is more preferable, straw made into frames the same size as the lights. These are very portable, and can be put on or removed in a short space of time by a couple of boys. They are also useful for protecting other crops.

Varieties.-As regards varieties, none command such prices as the Ashleaf, and they may be used when half grown. For early potatoes, cooks prefer them about one and a-half ounces in weight, being served up whole; it is advisable not to have them too large. There are, of course, other varieties that produce quite as good crops, and are as early, but they do not find the same favour with connoisseurs: Sharp's Victor, Puritan, Early Regent, Ringleader, and others, but they will never become so popular as the Ashleaf. Potatoes grown under glass do not, as a rule, suffer from the attack of disease, but every care should be taken to have the sets quite free, that a robust growth may be promoted from the start. 


\section{CHAPTER XIII.}

\section{NOVEL POTATO CULTURE.}

A Novel system of securing a supply of young tubers during the autumn and winter without the aid of artificial heat, was described in the " Gardeners' Magazine," dated February 14, 1903, by Mr. George Stanton, the talented head gardener to Mrs. Noble, of Park Place, Henley-onThames. He says: "We have been obtaining supplies of young potatoes of good quality all through the autumn and winter without glass or artificial heat. The system is so simple, and gives so little trouble, that it might, with much pleasure and profit, be practised extensively eren by those who have no gardens. The results of our trials have been so much appreciated, and the produce so much enjoyed, that in future they will not only be repeated, but will form a part of our routine work.

Best Sort to Grow.-We grow as a field crop enough potatoes for the suprly of a large establishment. For our main crop we find nothing better than the variety Windsor Castle. When lifted the tubers are taken and kept in some chalk caverns, of which we have several, and few places are better adapted for storage. These caverns are perfectly dark, and do not vary much in temperature. The potatoes are placed in heaps, and, of course, left uncovered, and can easily be examined by artificial light, as may be necessary through the season.

How the Tubers are Treated.-The crop of 1901 was a very good one, and about ten tons were stored. We 


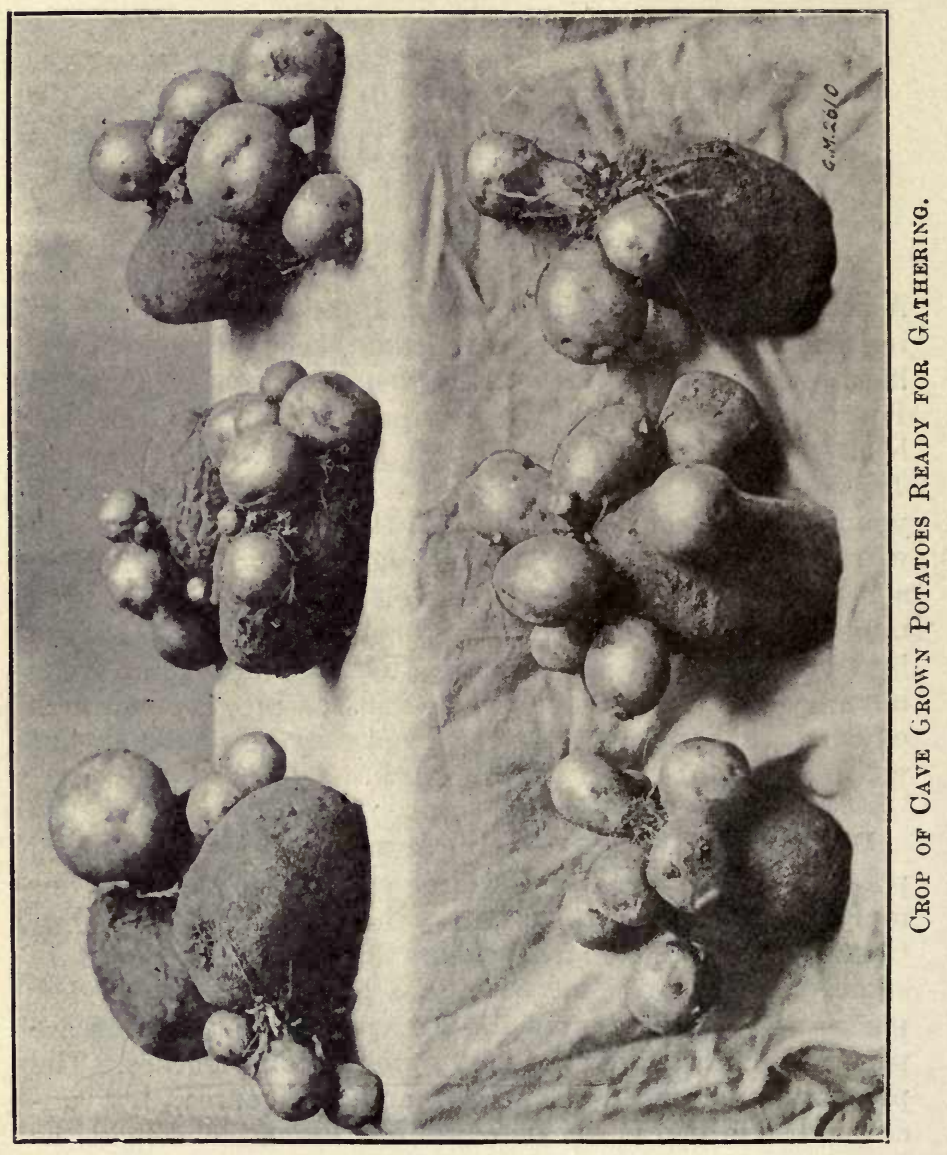


generally give any old potatoès away that may be left when the following season's crop is lifted. In doing this in 1902 , I saw that some of the old tubers of the 1901 crop on the chalk floor were forming small potatoes on their surfaces. On August 5 the more advanced and promising were arranged one thick in another part of the cave. Over these some finely-sifted potting shed soil was sprinkled, but not to quite cover them, so that they might be carefully watched. On September 5 the first dish of potatoes, of good size and excellent quality, was picked. As everything looked so encouraging we made frequent successions to follow on, with the result that we have been gathering (not digging) young potatoes throughout the autumn and winter.

Tubers Bear a second Crop.-Our practice has been to grow the earliest supply in pots, followed by frame culture. In these cases the plants have to be turned out, or dug up, and the very small ones are practically wasted. In our caves we pick off those that are ready, and leave the little ones to come on, so that the old tubers give a succession. Strange to say, some tubers that had borne a crop, after a short interval, showed signs of bearing a second time; we have tried them, with fairly good results. It is curious that very little root-action or leaf growth is made, I may almost say none at all.

In a Mushroom House.-We have, in addition to the caverns, tried them in our mushroom house, with satistory results. We also tried them in a frame with a little heat. In this case the tubers were covered with about two inches of the fine soil, to prevent the young potatoes becoming green. This also was very successful. In gathering from the frame, we draw away the fine soil with the hand, lift out the old tubers, pick off the young ones that are ready, and replace the old ones. This handling of the old tubers, which is necessary when gathering, does not seem to hurt them the least. Satisfactory crops have 


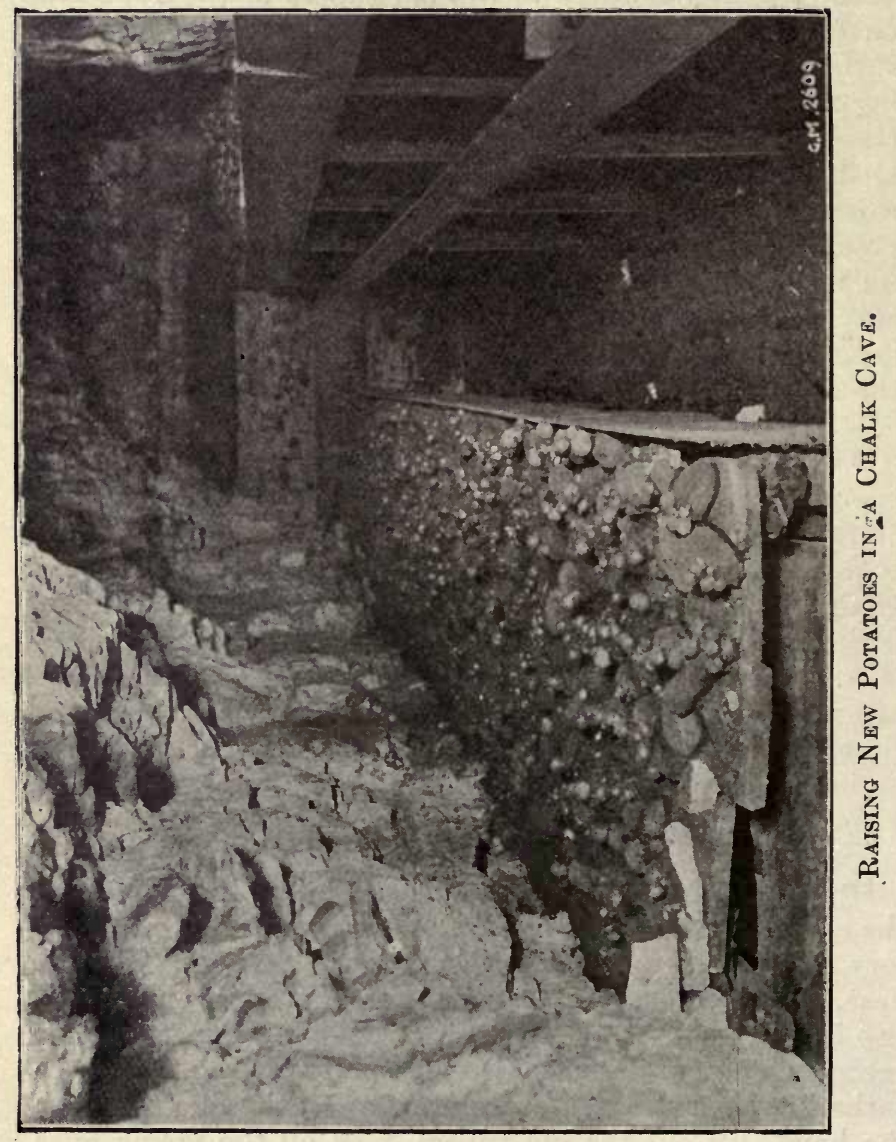


been obtained from beneath stages in the glasshouses, and from boxes. Underground cellars would be capital places for their culture.

Good Flavoured Tubers.-I am quite sure all who may adopt this system of potato culture will be delighted with the results. Windsor Castle is the only variety I have tried; probably other maincrop or late varieties would do as well. In all cases, large, firm tubers should be selected. I much prefer the young potatoes grown as I have described to those early forced in the usual way. They are less close and waxy.'

\section{CHAPTER XIV.}

\section{LIFTING, PACKING, AND MARKETING.}

When field crops of potatoes are to be marketed immediately after raising, as is the case with most early and second early crops, it is best to sort, weigh, and pack them in the field, as this reduces labour, and involves the least damage from moving and shaking about. Early potatoes, especially, are very tender, the skins rubbing off quite easily; so the less they are handled and shifted about before being finally packed the better. 1

Lifting the Crop.-Where there is a large area of potatoes to be harvested, it is quite worth while to use a potato plough of some sort to do the work of lifting, as this makes a great saving of time and labour. Particulars of such implements will be found in the chapter on "Im- 
plements and Appliances." But with less extensive crops, such as have to be dealt with on small holdings and in gardens, the raising is, of course, done by hand. For this purpose a broad-tined fork is the best implement; and with this a skilled hand will quickly and easily lift a large piece in a day, laying out the roots evenly and neatly along the rows, ready for the tubers to be shaken off and gathered by the pickers. An ordinary potato plough does not leave the tubers quite so handily; but if alternate rows are ploughed first burying is reduced to a minimum, and any tubers that are left in the soil can be picked up when the field has been cultivated after the clearing of the crop. This is well worth doing, as a surprising number are usually turned out by the cultivator, however carefully the crop has been lifted. The work of ploughing or digging is best done when the land is in a fairly dry and friable condition, as then the potatoes turn out clean, and the soil is improved in condition.

Picking up the Crop.-Either women or boys are employed for this work, the former usually being far preferable. Wooden baskets, such as are called "trugs" in Sussex and "bodges" in Kent, are as good as anything for collecting into; but any handy-sized baskets may be used. The potatoes should be sorted into three grades: ware or firsts, seconds or seed, and chats or tail ; and it is handy to sort into these sizes whilst gathering behind the diggers or plough. One woman or boy can collect ware only, another coming afterwards and taking seconds, and a third gathering the tail and any broken or diseased tubers that are left. If preferred, the ware can be collected separately, and the other two samples together, the tail and seconds being afterwards separated in a sieve or riddle of the correct gauge. There is often some trouble in getting the pickers to sort the sizes properly; but this can soon be corrected, especially if tho most reliable hands are set to gather the ware, and the least experienced the tail. In any case, a final picking over can be done when the 


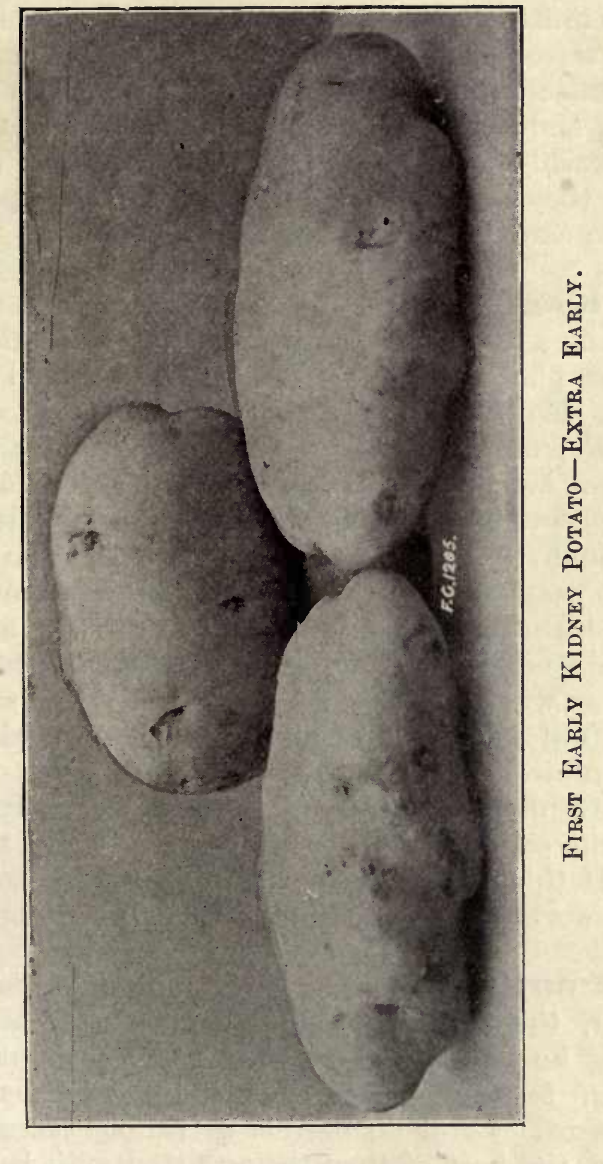


baskets are brought up to the weighing machine for the potatoes to be packed. In wet weather, or on heavy land, the potatoes are likely to be coated with dirt, in which case this must be rubbed off with the hands, or else thrown out in a sieve. It is best not to raise more potatoes than can be collected in a day, or the dirt may get hardened on to them, and a shower would make a mess of them, and of the freshly-turned soil. If the potatoes are to be clamped they may be either bagged up or simply thrown loose into carts for conveyance to the clamp.

Weighing. - It is a capital plan to have the weighing machine on a wooden platform, fitted with handles at each end-just like a hand-barrow, only without legs. Two men can then carry it about, so that it is always in the part of the field where the work of raising is going on. If it is not kept close to the pickers the work of carrying the baskets of potatoes to the weighing machine is very heavy, and time is lost unnecessarily. The platform makes it easy to keep the scales level. Without it they would work into the ground, and the packing and weighing would be more difficult. The weighing machine should be such as will support a good large barrel or sack. The empties, unless they are bags, are first weighed with any packing material that is to be used in the bottom. It is often convenient to weigh a number to start with, writing the weight on the label, or chalking it on to the empty itself. If this is not done it is no easy matter to cope with the work when the potatoes are being brought in fast.

The Empties.-If the grower is sending his crop to a salesman, the choice of empties does not concern him much, as he has to accept what the salesman supplies. However, for very early potatoes bushel baskets are usually sent. Later on barrels of various sizes are most in favour, the best of them being fitted with basket-work lids. The potatoes travel very well in either baskets or barrels, if they are sufficiently large to hold 
the proper quantity. Bags are used a great deal, especially late in the season. They are not as good as the barrels; but it is not of so much importance with the later crops, as the potatoes have then matured, and the skins do not rub and bruise so easily, being harder. Bags are at all times good enough for tail, but the best empties should be reserved for the ware when possible.

Packing.-When bags are used there is no great art about the packing. Nothing more can be done than to see that the tubers are clean and well sorted. The grading is most important, as an even sample will always obtain a better price in the market than a mixed one, even if composed of rather small tubers. The bags are simply filled until of the weight required; the mouth is tied up securely; and a label is attached, on which are written the destination, grade, and weight. All the bags should be made to contain the same weight if possible; at any rate, they should not contain odd pounds, but 1ewt., $1 \frac{1}{2}$ cwt., and so on. With barrels more care can be bestowed on the packing. A little packing material is placed at the bottom before the empty is weighed. Then, as the baskets of potatoes, ready sorted, are brought up to the scales by the pickers, the contents are emptied carefully into the barrels. When these are full they are lifted on to the scales, and if not of correct weight are made so by taking a few tubers out, or by putting in a few more, as the case may be. Allowance is, of course, made for the weight of the empty barrel. The top layer of potatoes is levelled off, but is not "topped up" with fine specimens. Finally a little more packing material is placed on the top, and is secured, either by the basket-work lids already mentioned, or by cords which are fixed round the rims of the barrels for the purpose. Most of the barrels contain 1cwt. of potatoes, though some are smaller, and a few larger. Early potatoes that are marketed in bushel baskets are packed in the same way as those in barrels, but with more care, as they are more delicate and valuable. Tubers 
forced under glass should be packed almost as carefully as apples. Stout paper is usually tied over the tops of baskets over the packing material; but " benders " may be used instead if preferred.

Packing Material.-It is a very common practice to use the potato haulm for packing purposes, as it is always handy. This does fairly well for barrels, though if too green and young, it is apt to become rather messy at the bottom. Rough hay, such as is cut from the bases of hedges, is a good deal better. It may be used green if preferred, straight away after eutting. Any litter that happens to be plentiful and cheap may be utilised for packing potatoes, the haulm being perhaps, the least desirable.

Packing Late Crops,-Crops that are stored in sheds or clamps are packed as already described for early crops. Bags are invariably used for these, the potatoes being shovelled into them with a wooden or open-work metal shovel (see "Implements and Appliances"). They may be graded by hand, in sieves, or in one of the larger sorting machines specially made for the purpose.

Miscellaneous Hints.-For small crops, or when sending to a local market, many kinds of empties often have to be used. This does not matter so long as the grading is good-this is the important point. Hampers, baskets, boxes, bags, or almost any receptacles may be pressed into the service. Great care must always be taken that no diseased tubers are included in a market sample, as these bring down the price immediately. The endeavour should always be to send up a clean, well-graded, evenly-packed sample, so that a name may be gained for fair packing and good quality. The tail are usually sold locally as pigs' potatoes; it would not pay to send these to the vegetable market. If a good variety is grown it often pays better to market only the firsts, disposing of the seconds for seed purposes. 


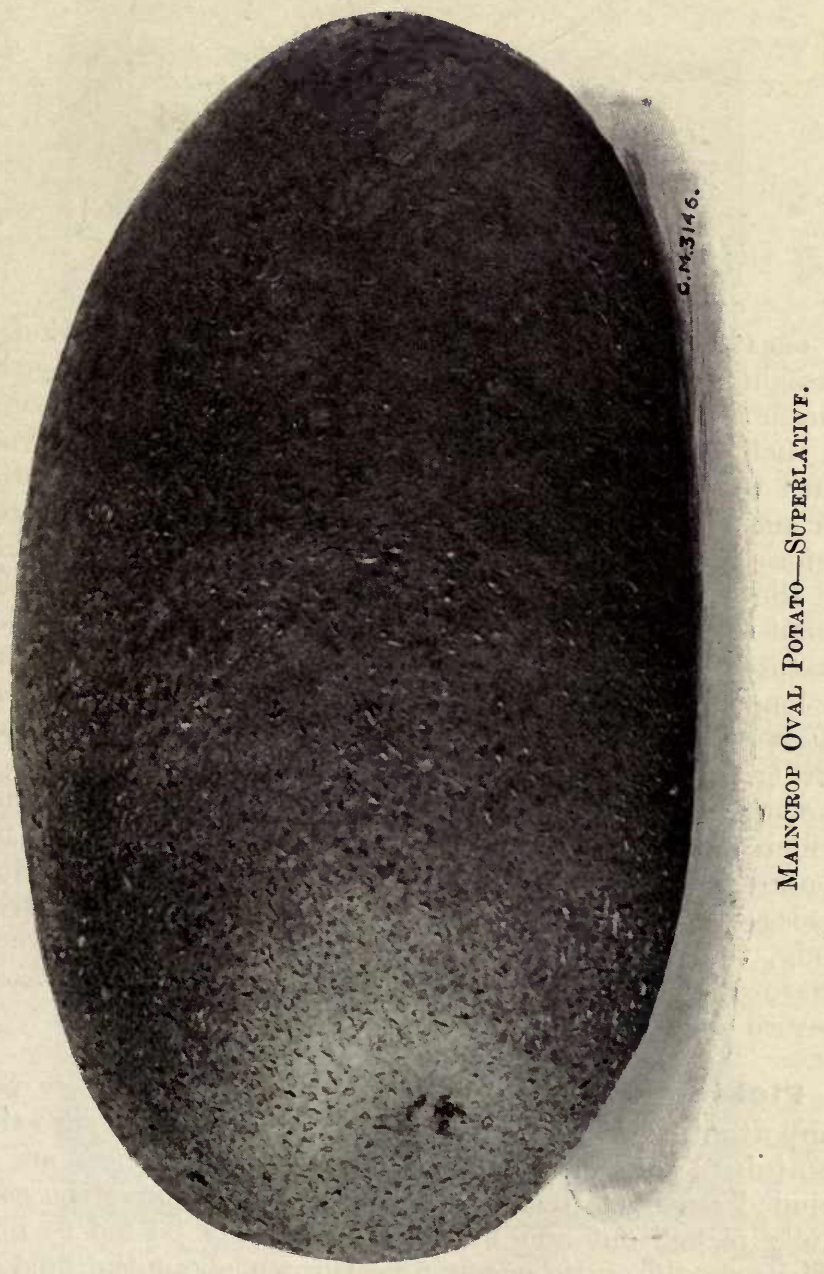




\section{CHAPTER XV.}

\section{STORING POTATOES.}

A GREAT bulk of the late potato crop is not marketed straight from the field, but is stored for disposal during the winter and spring. Seed potatoes, also, have to be stored in such a way as to keep them sound and safe from frost until they are wanted for planting. The chief essential for successful storing is that the potatoes be well matured before being lifted, as unripe tubers do not store well. In the southern parts of the country there is no difficulty about this, as the haulm dies off early, and the crop quickly matures or ripens; but further north the life of the crop is longer, and the haulm is often found green when the lateness of the season and the fear of frost necessitate lifting. In such cases, recourse is occasionally had to mowing or cutting the haulm a few weeks before lifting, which has the same effect in ripening the tubers as if the haulm had died down naturally. This plan is seldom necessary, however, as in most cases where the haulm lives long, the first frost kills it off in time for the tubers to mature and be lifted before there is a danger of frosts severe enough to injure them.

Picking out Unsound Potatoes..-Another very important point in successful storing is to make sure that no tubers showing signs of disease or unsoundness are included amongst those to be stored. These must be carefully picked out and burnt, or they may be fed to pigs. They should on no account be thrown about the field, or they may carry infection to future crops grown on the 


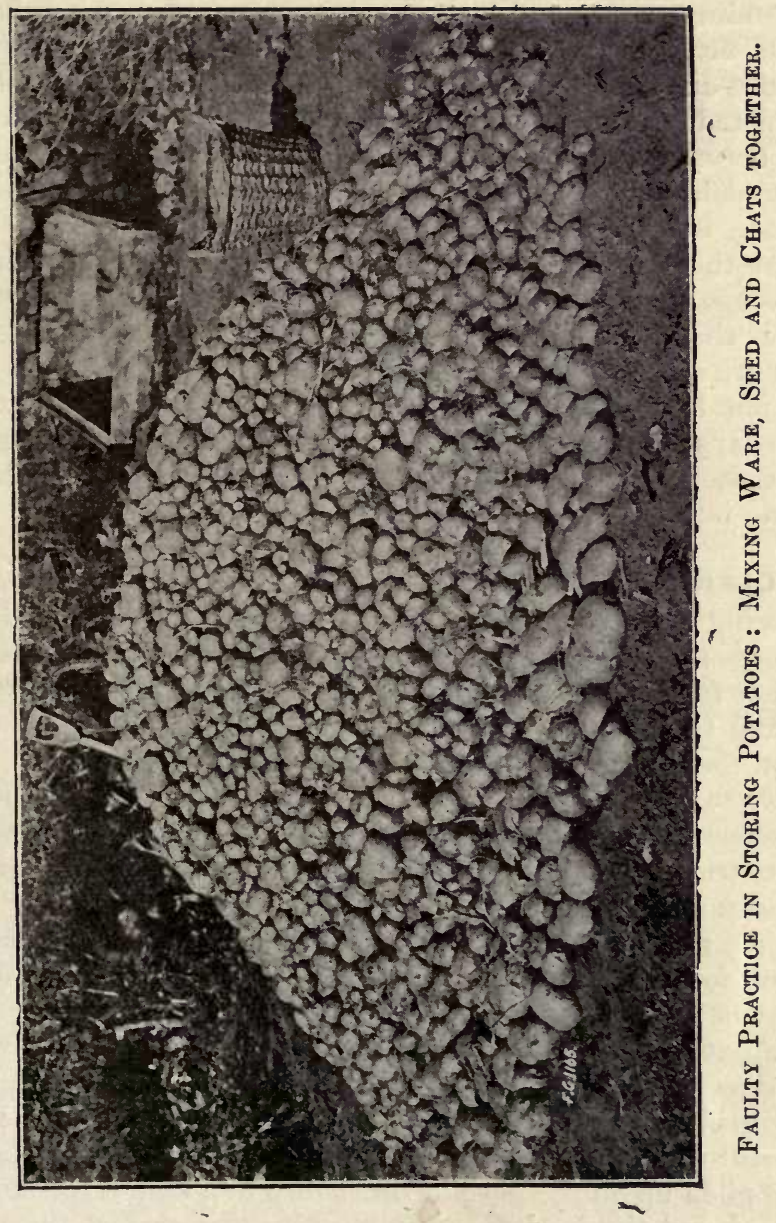


same ground. If they are included in a store they will quickly spread disease and rot to the sound tubers surrounding them; and in this way disease often spreads like wild-fire through large clamps or stores. In the case of a badly-diseased crop it is impossible to detect all that are affected, as the trouble is not always developed sufficiently to be externally visible; but it will develop afterwards in the clamp. To guard against this, experiments have been made in the use of various preparations with which to coat the potatoes, and considerable success has attended the use of quicklime for this purpose. The lime is dusted over the potatoes before storing, and carefully mixed with them, so that each tuber is coated. However, this plan is not likely to commend itself much to growers, except perhaps for seed, on account of the trouble of cleaning the potatoes before they can be fit for marketing, though the lime is said to shell off easily.

Clamps, Pits, or Graves.-The most usual way of storing potatoes is in clamps, pits, or graves, and the process is much the same as the clamping of mangolds and other farm roots. A glance at the illustration on p. 125 will make the appearance of a clamp fairly plain. The position for a clamp or pit should be a dry one, if possible, as a low, wet situation encourages rot and the spread of disease, besides which, where moisture or drainage water penetrates frost is likely to follow. For this reason the clamp should be made on the surface of the soil, the base being not more than nine inches below, just to make a good foundation, and to keep the tubers from rolling down whilst being heaped up. The first operation, then, is to dig out this foundation, making it about three feet wide, and as long as may be thought necessary. The width may be made five feet if preferred, and this is perhaps more useful when the clamp is to be a large one. The potatoes are piled up on the base of the clamp in a long ridge-shaped heap, and the height is regulated by the size of the base, the tubers being heaped as high as thay will lie naturally. 
The potatoes may be put into sacks for conveyance to the clamp, or simply be thrown into carts as raised, and brought loose. On wet soils the tubers should be placed on the surface and a trench dug round as per diagram to drain away the water.

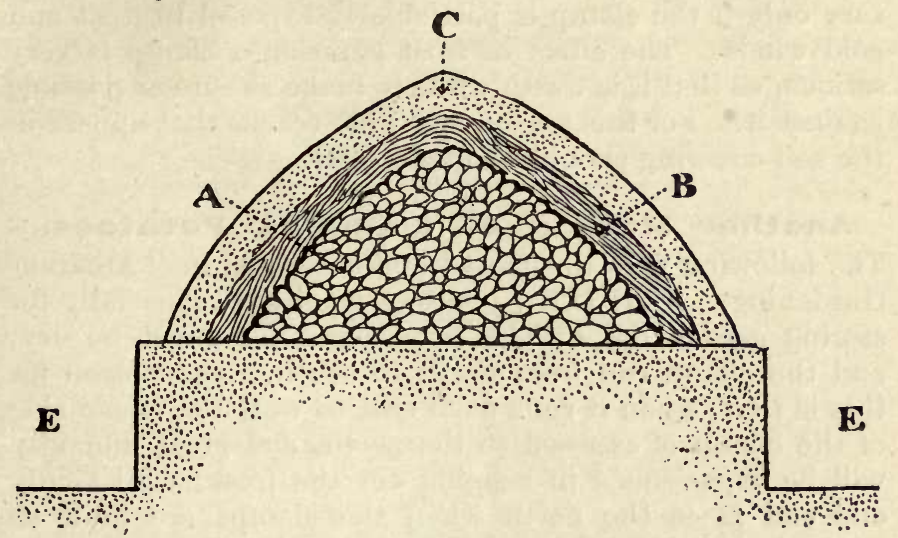

Section of a Potato Clamp.

A-The tubers. B-A layer of clean straw. C-Layer of soil. E-A trench dug round the clamp to drain away moisture. The soil removed is used to cover the clamp, as shown at $\mathrm{C}$.

Covering the Clamp.-As a first covering to the potatoes put a thick layer of dry straw, so thick that when pressed down by the soil it will still be six inches deep. Then give a six-inch layer of soil, making the surface firm with the spade. For convenience the soil for this is generally dug from close around the clamp, the spits or spadefuls being taken up solid, and built up round the clamp on the top of the straw. Chimneys or shafts must be left in the ridge for ventilation, at intervals of about six feet. The usual way of making these is by digging a hole through the soil of the ridge, and pulling through a handful of straw, leaving it sticking out from the top of the clamp. These chimneys are to allow the escape of heated air, generated by the fermentation which is sure to take place when the 
potatoes are first stored. After a week or two these chimneys may be closed, as there is some danger of severe frost entering through them; but they are often left open all the time without bad results. As already mentioned, a thatch of straw may be placed over the earth; but this is necessary only if the clamp is particularly exposed to frost and cold winds. The effect of frost entering a clamp is very serious, so that it is worth while to make as sure as possible against it. For this reason any wide cracks that appear in the soil covering should be made good.

\section{Another Method of Clamping Potatoes.-}

The following plan illustrated and described in " Amateur Gardening," by H.C.R., is also a good one, especially for storing garden crops: The site or position must be dry, and the clamp run from north to south. The reason for this is that, when it runs from east to west the whole side of the clamp is exposed to the north, and great difficulty will be experienced in keeping out the frost; whilst only one end faces the north when the clamps are built as advised. If the soil is sandy and dry the clamps may be sunk into the ground to a depth of about twelve inches, but when the soil is at all retentive or moist, the potatoes must be placed on the surface. When the tubers are not very dry, the clamp must not be more than two feet six inches wide at the bottom, but if they are thoroughly dry the width may be as much as four feet, whilst the length is, of course, unlimited; and the heap should be carried up from the base to the apex similar to the roof of a house, and as steep as practicable. A system of ventilation must be adopted. This is constructed of various materials, whichever is the handiest, in the following manner. Agricultural drainpipes, or inverted channel bricks may be used, sketches of these being given in Figs. 1 and 2 respectively, whilst a ventilation duct may be formed of ordinary bricks in a similar manner to Figs. 3 and 4 . These pipes, channel bricks, or common bricks, are fixed on the ground through the length of the clamp, side 
branches being put in every six feet, as shown in Fig 5 , the ends, of course, being open to the air. The ends of the

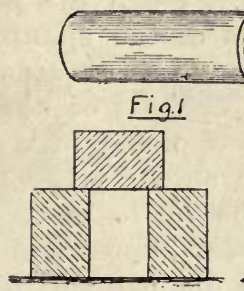

Fig 3

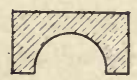

Fig 2.

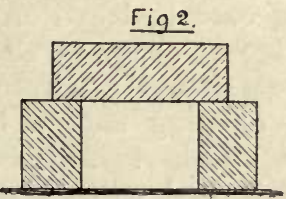

Fig 4.

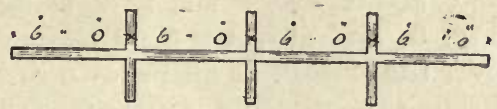

Fig 5.

Ventilating a Potato Clamp.

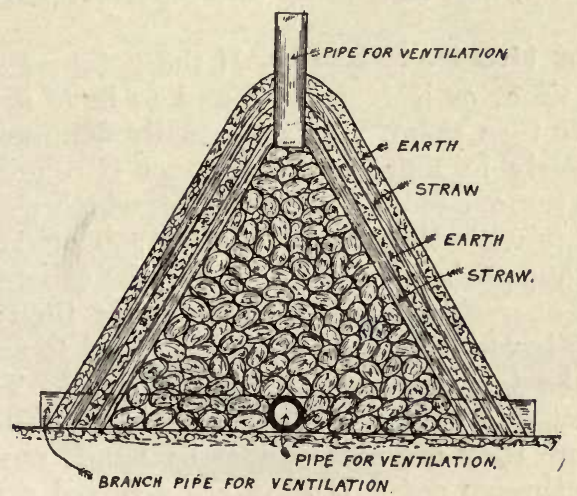

Fig 6.

Section of a Potato Clamp.

pipes or bricks should not butt close to each other, but a small space should be left between each, say one inch, 
to admit the air and allow it to circulate amongst the potatoes. Pipes should also be inserted in the apex of the clamp as afterwards described. When the potatoes are in position, the sides and ends of the clamp should be covered with a layer of straw, and afterwards a layer of earth, taking care to leave an opening or kind of gutter along the ridge or apex, to allow plenty of ventilation in case any heat should generate amongst the tubers. Of course, this opening should be made water-tight with straw in wet weather. As winter approaches this gutter should be dispensed with, and made up with straw and soil, pipes, extending from the potatoes to the outer air, being fixed about every six feet along the ridge, as shown in Fig. 6, and also a second layer of straw and earth placed over the clamp, as also shown in Fig. 6. The central and branch ventilating pipes are shown in the same sketch. When the weather becomes severe, all the ventilation openings, except those along the ridge, must be blocked up, and the clamp made perfectly frost-proof.

Turning the Potatoes.-If the potatoes are stored for a long time, or if decay is found to have set in, it is necessary to turn them. This is usually done as a matter of course early in February, or sooner if required. The object is to remove any decayed tubers, which would infect others if left with them, and also to rub off any shoots that may have pushed from the eyes of the tubers. Sometimes this operation requires doing more than once, as when decay is very bad, or shooting is found to occur again after the shoots have been rubbed off once. The clamp is opened at one end, and the potatoes shovelled into a riddle, where they are picked over by hand, any decayed ones being thrown out. If they are a mixed sample this is a good opportunity for sorting them, in either hand riddles or a sorting machine. The different grades can then be clamped separately. Any shoots that are found, and there is often quite a mat of them, must be rubbed off by hand. As the tubers are dealt with they are again 


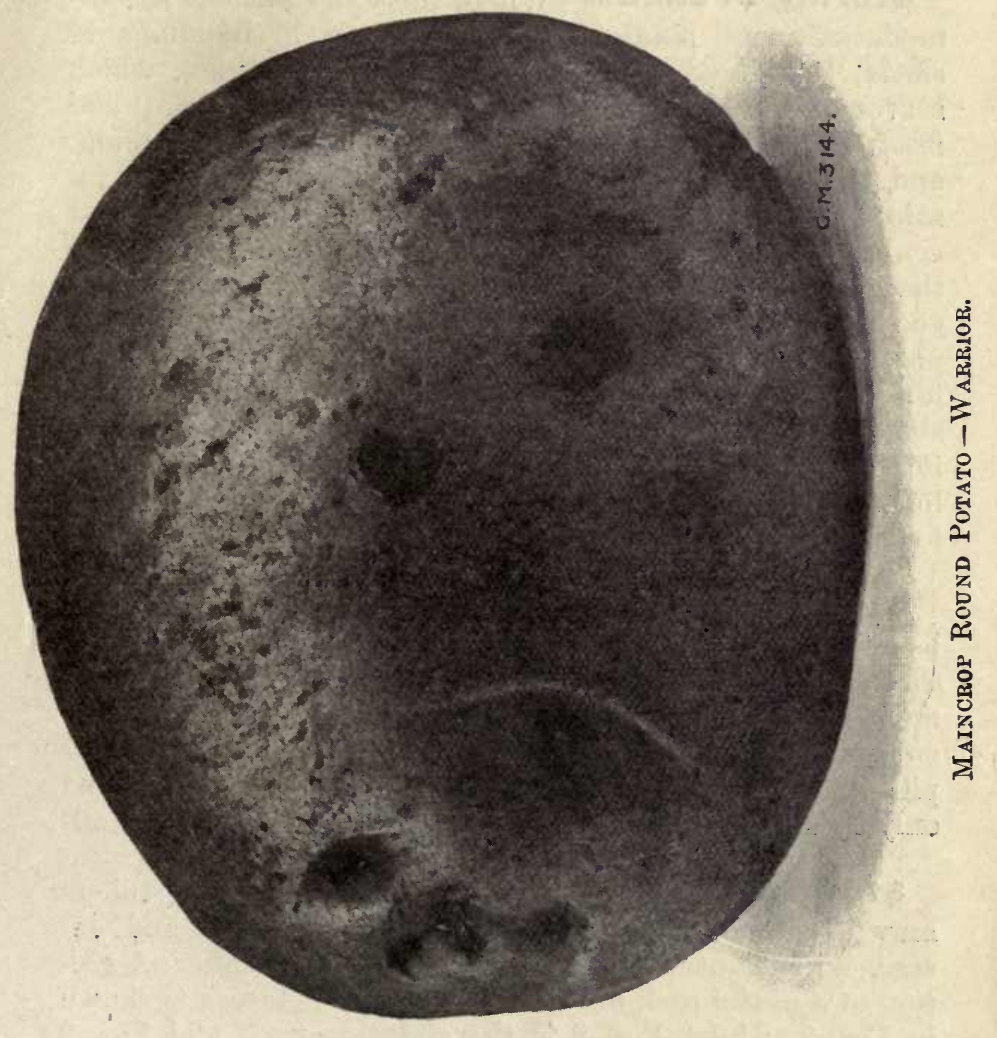


clamped, starting the new clamp opposite the open end of the old one, and so using the same foundation or base. Care must be taken not to open the pit during severe frost.

Storing in Sheds.-Where there is sufficient accommodation, ripe potatoes may be stored in buildings or sheds, if covered with a good thickness of straw, which serves to exclude both light (which would green them) and frost. This method involves less labour than clamping, and the tubers are more easily got at when wanted for sale. Care should be taken not to allow them to rest against the walls of the building, as frost is liable to injure them through the walls, unless these are very thick. A good thickness of straw or other litter makes all safe. The potatoes may be placed in heaps of almost any size; but if a very great depth is stored it is well to make ventilating shafts of straw at intervals of a few feet. Potatoes stored in this way are not likely to sprout to any great extent; but, should they do so, they may be turned as described for those stored in clamps.

Storing Green Potatoes.-Some growers are believers in green or unripe seed potatoes - that is, potatoes that are lifted before the crop is really mature. As already mentioned, such tubers do not keep so successfully as ripe ones in ordinary clamps, but they may be stored in shallow pits in the earth, not more than two feet deep, covered only by a good thickness of straw, and not by any soil at all.

\section{Storing Tubers for Planting. - "Seed" tubers} may be stored in the special boxes illustrated and described in Chapter VII., or in the following manner: A section of a usaful rask for storing " seed " potatoes is shown in Fig. 7, whilst Fig. 8 is the end elevation, and Fig. 9 shows how the potatoes are placed in it. This rack can be constructed by anyone with a little spare time, and will be found very handy and well worth the time and trouble spent on it. The size can he as desired, four feet six 


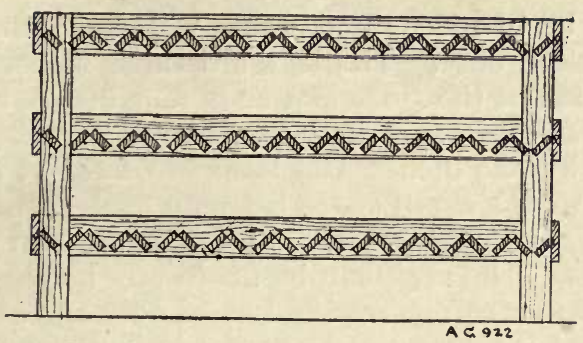

Fig 7
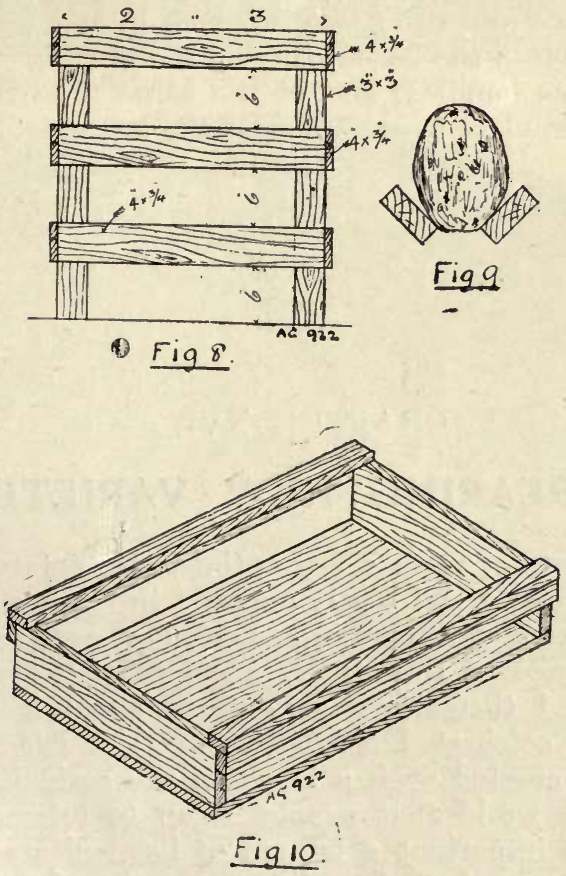

Storing Seed Potatoes. 
inches long by two feet three inches wide being mentioned as a suggestion only. The legs are three inches square, the boards round the sides and ends four inches by threequarters of an inch, and the laths forming the stays about two inches by one inch. The laths are fixed at an angle of 45 deg., with a small space between each, as shown on the sketch. Other necessary dimensions are also given on the sketches. The rack can be made any height desired, and the potatoes can be readily turned over and examined. Or the "seed" tubers can be stored in boxes, a good and simply made box being shown in Fig. 10 . It is similar to an ordinary box except that, instead of the sides being solid, they are formed of two two inch by one inch laths, fixed as shown in the accompanying sketch, Fig. 10. The laths serve as handles, and at the same time the air is allowed to circulate freely amongst the contents.

\section{CHAPTER XVI.}

\section{ON REARING NEW VARIETIES.}

For fifty years or more a few enthusiastic potato experts have been quietly and busily engaged in rearing new and improved forms of the potato. Few, however, recognised the importance of this quiet, unostentatious labour, or even troulled themselves very much about it. It was not till the celebrated Northern Star and Eldorado appeared and created such a boom in the agricultural and horticultural world that people began to interest themselves in so important a branch of horticultural science as the crossing and rearing of new varieties of the popular tuber. Workers like Robert Fenn, William Paterson, and 


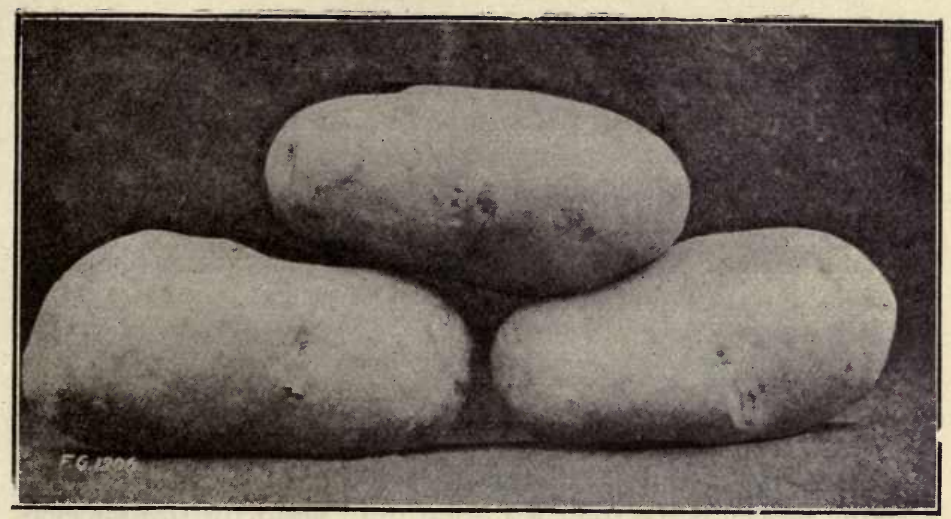

Maincrop Kidney Potato-Vermont Gold Coin.

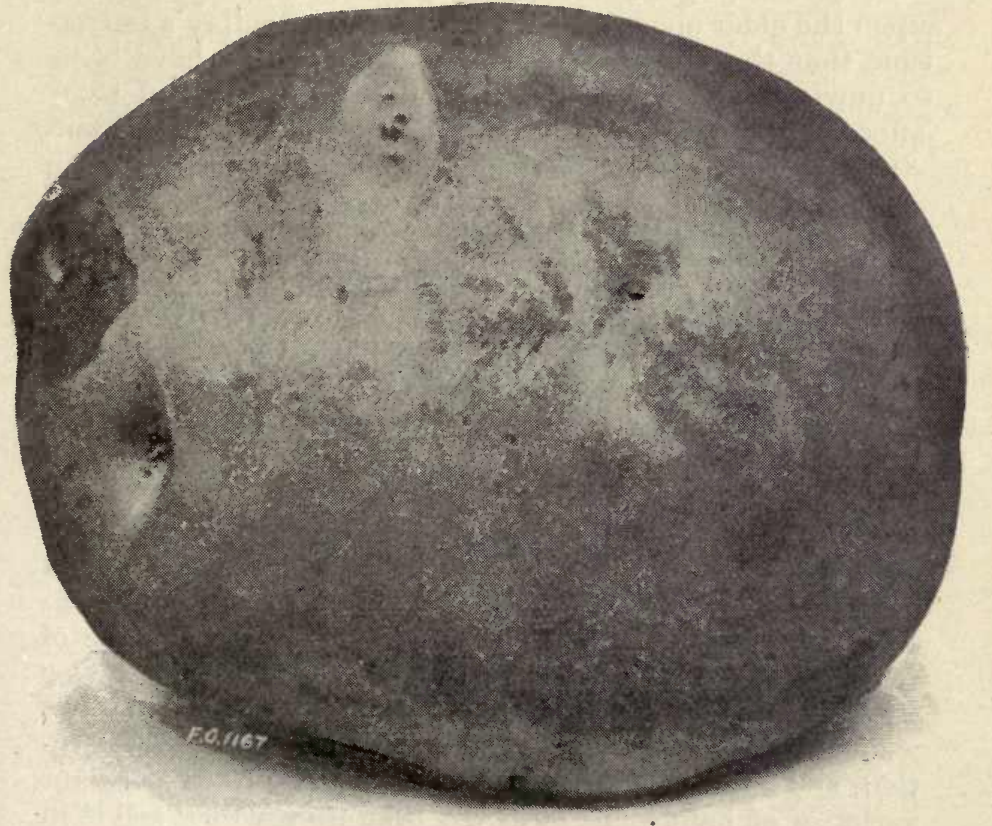

Mainchol RuUne Potato--Sik juhn Franklin. 
Messrs. Sutton and Sons, had, however, been working steadily for long years before the boom occurred in experimenting with the crossing and intercrossing of the potato, with a view to obtaining free cropping, high flavoured, and disease-resisting properties. And to-day we have as the result of their labours many really fine varieties of potatoes for field and garden culture. It is true, some of the earlier reared progeny have not, in the long vista of years, remained quite up to the standard of perfection they first possessed, but that is inevitable after many years of culture. In later times, Mr. A. Findlay has come to the rescue, and given us, as the result of patient toil and much skill, newer sorts that we hope may keep up the succession of really good varieties, if not materially improve upon the older ones. It is, perhaps, Mr. Findlay's misfortune that the varieties he has given us should have been so unwisely boomed before a good opportunity had been afforded of thoroughly testing their merits, so as to demonstrate that they were really a distinct improvement upon existing kinds, and worthy of the exceptional value set upon them. Still, we know Mr. Findlay to be a eonscientious, painstaking worker in this particular domain, which he has allocated to himself, and hence we look forward to the time when the present hysterical boom will be over, to see much real and lasting good coming from the varieties he and other genuine raisers are now giving forth to the world.

The Chief Aim in View.-The chief aim in view in the rearing of new varieties by crossing is, or should be, to obtain an improvement on existing sorts now in commerce. We want primarily varieties that are capable of resisting the fell disease which has wrought such havoc: among potato crops in this country. At the same time, we want varieties that will yield well, be of hardy constitition, and above all, possess good flavour. We do not want varieties of handsome form, so that they will " sell " in more seuses than one, but sorts that, while presentable 
in appearance, will cook well and be of good flavour. It is notorious that many of the sorts that are now grown largely, and which are put upon the market, are deficient in flavour. The British public, therefore, want those who take in hand the rearing of new varieties to bear in mind that flavour is a feature of as great an importance as disease-resisting powers and free cropping qualities. There is a fortune yet awaiting the man who ean turn out a really good flavoured variety in conjunction with the other attributes. The nearest approach, in our opinion, to this much-desired goa! of perfection is Sutton's Discovery. If it only retains its disease-resisting powers, and continues to crop freely, as well as retain its present excellent flavour and first-rate cooking qualities, its success will be assured.

Faults to Avoid. - The chief fault to avoid in the rearing of new varieties is, first of all, coarseness in size. Big tubers, however tempting they may be to the cottager for quickly filling his pot, are not wanted for ordinary use. They are wanting in flavour and ugly when served on the table. Neither do we, as previously intimated, want handsome-shaped tubers at the expense of flavour. Nor are varieties required with deep eyes; these mean a lot of waste when they are peeled for cooking. In selecting and growing seedlings year after year to test their cropping and disease-resisting powers, special attention should be paid to their cooking properties and flavour, and, if wanting in these essential features, they should be promptly discarded.

How New Varieties are Obtained.-Supposing the above points are clearly borne in mind, and the reader is anxious to try his skill in rearing a new variety by crossfertilisation, he must go to work as follows: His first care must be to have a definite object in his mind as to what he is going to try to achieve by the process-whether, for instance, he is going to aim at a heavier yield, a bettershaped tuber, or a better-flavoured variety. We will suppose, also, that one of the varieties possesses the good 
qualities of flavour and shape, but is lacking in vigour; and that the other is a free cropper, but more vigorous, and that it is desired to combine the two qualities or properties in one. The proper course to pursue, then, will be to cross the weaker with the stronger varicty and await the result. In some cases it may be well to make a reeiprocal cross, i.e., one with the other.

Act of Cross-fertilisation.- Each flower contains a stigma or female organ in the centre, and clustering round its base are the five anthers or male organs, which contain the pollen. (See p. 138.) Directly the flower

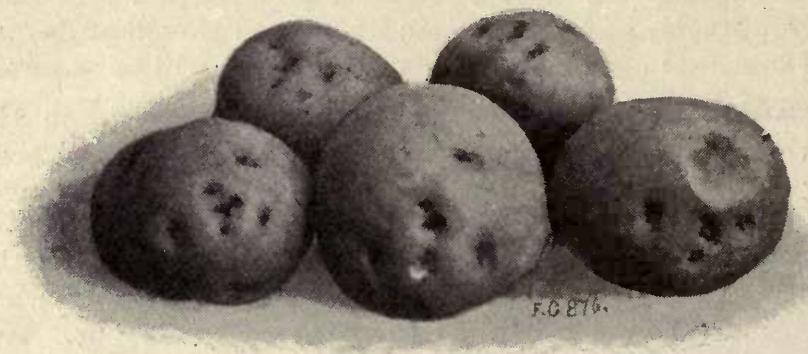

Maincrop Rodnd Potato-Lim Gray.

begins to open the anthers (6) must be removed carefully with a pair of fine-pointed scissors, as shown on p. 139. This is necessary to prevent its own pollen from falling on the stigma (7) and self-fertilising the ovary (5). It is well also to tie a piece of soft muslin round the emasculated flower. You have now to examine the flowers of the other variety which is to act as the male or husband. You may have to examine dozens of flowers before you will find one with its anthers bearing the precious pollen in a powdery form, as some varieties are exceedingly shy pollen-bearers, owing to the energies of the plant being occupied in producing tubers at the expense of full development of its maseuline attributes. When you do find the pollen dust, collect it earefully on 


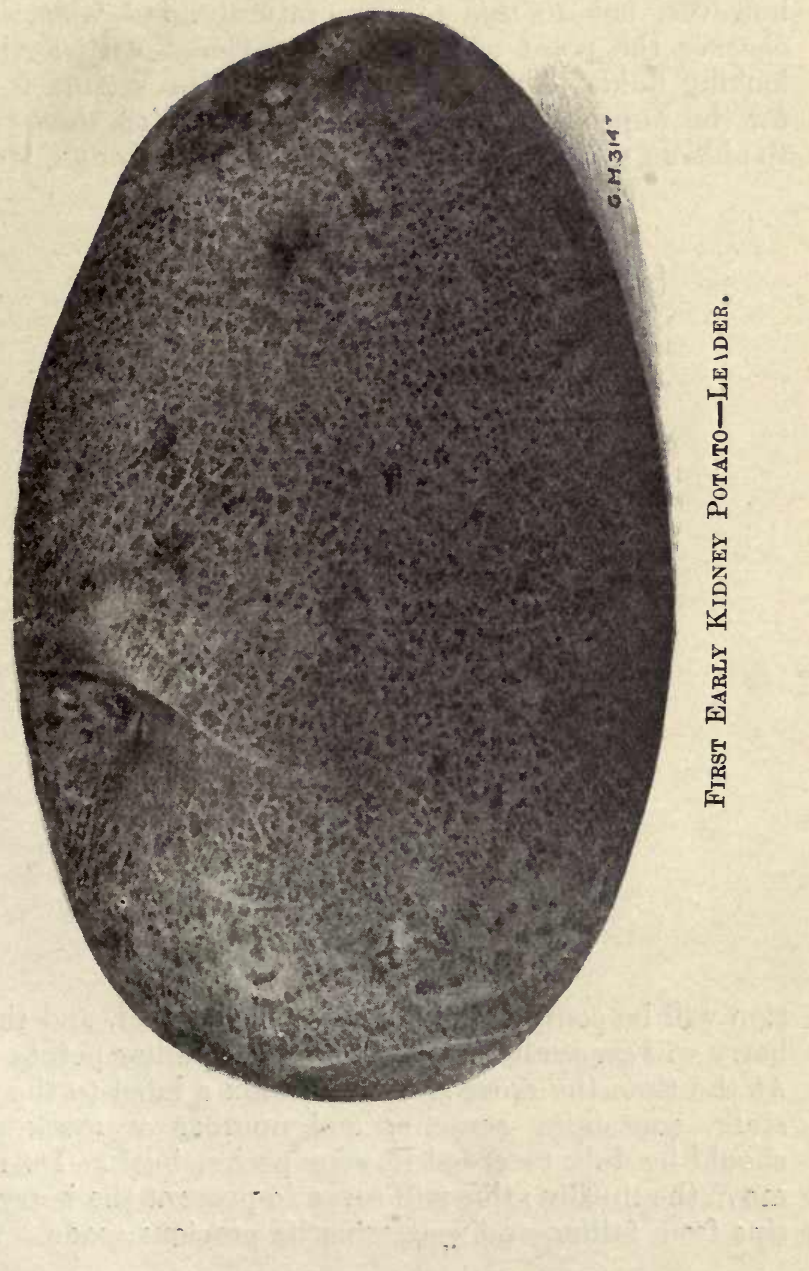


the point of a clean, dry camel-hair b:ush and gently brush it on the point of the stigma or female organ (7) that you had previously protected by means of muslin. You must, however, not do this too prematurely, but wait till you observe the point of the stigma covered with a viscouslooking fluid. Then, and then only, the stigma is ready for the nuptial rites to be performed. You then recover the bloom with the muslin, and, after a day or so, fertilisa-

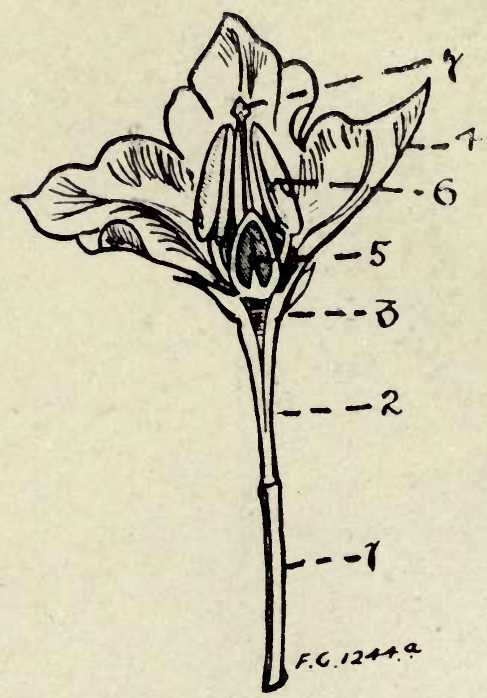

Section of Potato Flower.

tion will be complete, the petals will shrivel, and the tiny berry will gradually develop into the familiar potato apple. At the time the cross is effected affix a label to the flower stalk, containing some special number or mark, which should be duly recorded in your pocket book. Do not remove the muslin; this will serve to prevent the berry when ripe from falling and scattering its precious seeds. It will 
easily be ascertained when the berry is ripe, and then the latter should be gathered, placed in a box in a room to become thoroughly dry, after which remove the seeds, place them in a packet and store them away safely till spring, when sow as advised in Chapter VI.

A Word of Caution.- Simple as the process of crossfertilisation may appear, let no one entertain the idea that

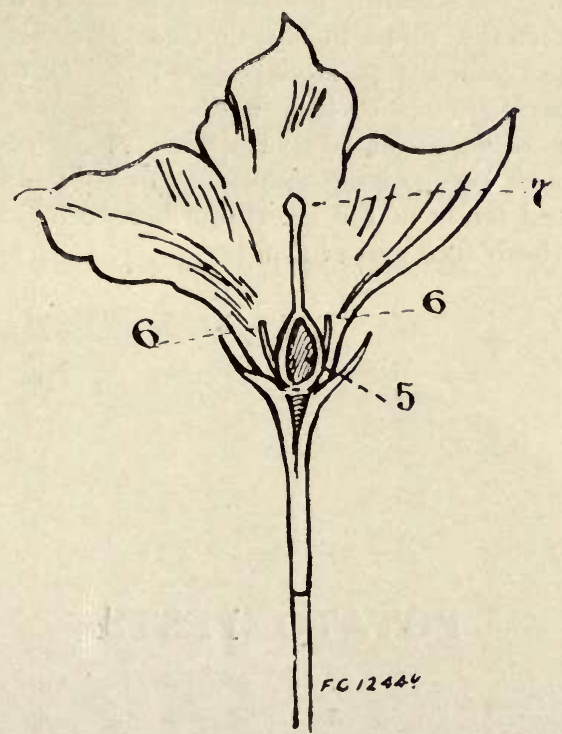

Section of Eimasculated Flowet.

the rearing of sterling new varieties is an easy task. It is one requiring very many years of patient toil and perseverance, as well as great skill, to attain even one success. You may get among your first year's seedlings a large number of very promising tubers, some that will astonish you as regards size and productiveness. Do not think for one moment that you have attained sucess. The next 
year, the next, and so on, your first-born seedlings will probably deteriorate instead of improving, and at the end of six to ten year's' trials, you may have to discard all of them. Messis. Sutton and Sons have often assured us that what looked like a promising, ideal potato, after years of trial, had finally to be discarded. It is sheer folly on the part of those growers who, since the boom in new potatoes started, have raised seedlings and begun to put them in commerce. No seedling potato can possibly claim to have its real character fixed in one or two years; it is a matter. of six to ten years' repeated trials, in order to thoroughly test the variety, before it is safe or honest to place it in commerce as a standard variety. The raiser of new sorts must therefore be prepared to devote many years to the repeated trials of his seedlings before he can honestly claim for them fixity of character.

\section{CHAPTER XVII.}

\section{POTATO PESTS.}

THE potato has many insect enemies, but the chief one is the wireworm. In light soils and in newly-broken-up pasture land, this pest is often a serious nuisance to potato growers. Fortunately, we are not troubled with another very serious pest which commits such havoc among American potato crops-the Colorado Beetle. It is true it has made its appearance in this country, but, thanks to prompt action, its career has been cut short. The remaining pests which occasionally attack the potato are not very numerous, but all that are known to inflict any serious injury will be dealt with in this chapter. 


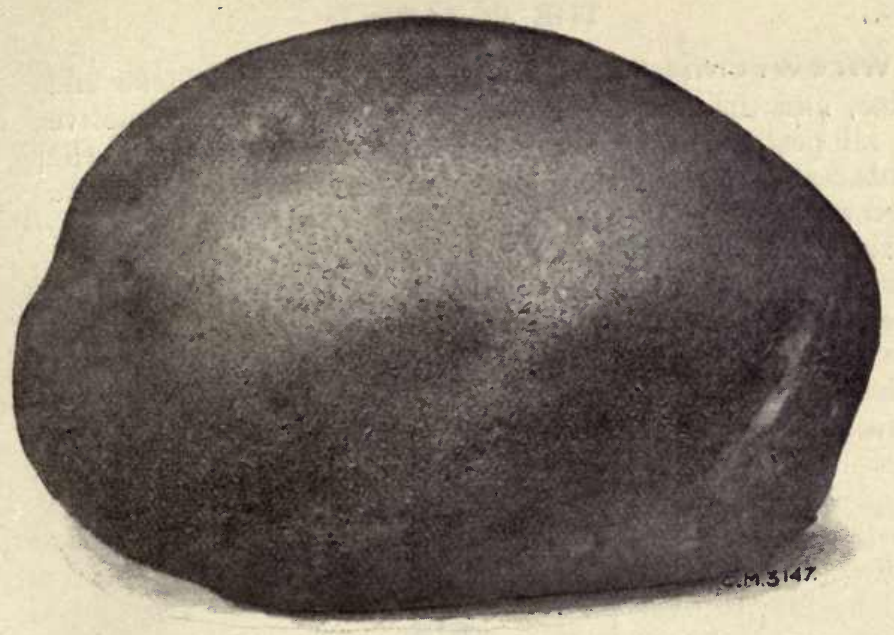

Maincrop Round Potato-Peckover.

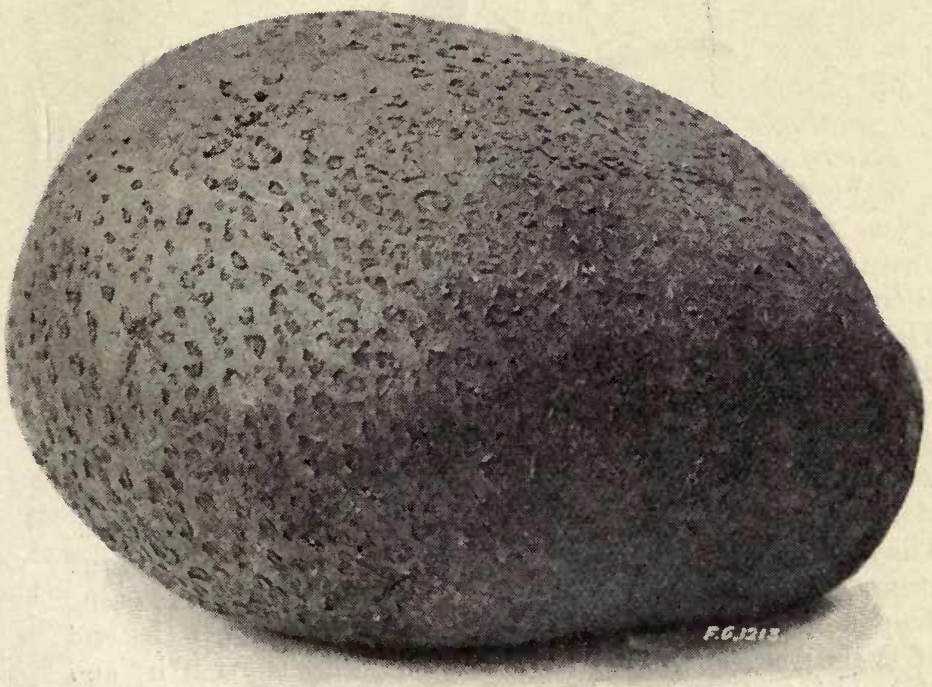

Maincrop Kidney_Potato-The Highuander 
Wireworm. - Wireworms are of two kinds, true and false, and the former are, perhaps, the most destructive of all pests that attack the potato. They exist in the grub state from three to five years, and during that time feed voraciously on the roots of farm crops, including the potato, not resting content with one, but passing from root to root, gnawing here and there, and inflicting very severe damage. True wireworms have six legs, whereas the false wireworms (millepedes) have many more. The Click Beetle, of which the wireworm is the grub, is well known, children often finding them dur.ng the surnmer in

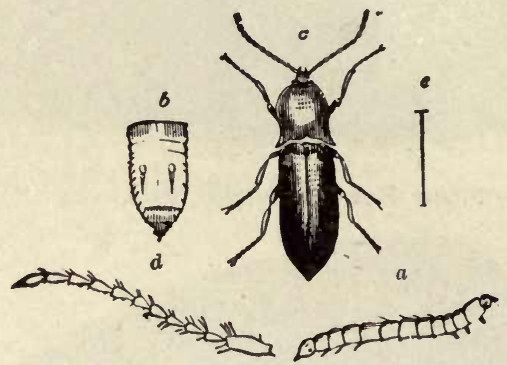

Click Beetre and Wireworm.

$a$-Wireworm ; $b$-tail joint; $c$-parent of wireworm ; $d$-antenna of beetle ; $e-$ natural size of click beetle.

grass fields, laying them on their backs, and watching them regain their position by giving a spring in the air. The noise which accompanies this movement is the origin of the name "Click." There are three species, the larvæ of which are harmful to the potato, namely, Agriotes lineatus, obscurus, and sputator. The grubs are hatched from eggs laid in the soil near the roots of plants, or occasionally in the lower leaves, where they envelop the stem. They start feeding at once, devouring the underground stems, continuing for a period of at least three years, going deeper into the soil during the winter months. At the end of their grub existence they descend into the earth, and change into beetles, which emerge in about three weeks. 
The beetles generally appear during August, but occasionally remain in the chrysalis state all the winter, and emerge in the spring.

REMEDIES.-There are a variety of measures calculated to lessen the prevalence of this pest, and the potato grower is advised thoroughly to test the efficacy of each. Profitable crops on land infested by wireworm are utterly impossible. Gas liming and harrowing will destroy numbers of insects, and in many cases benefit the land as well. Paring and burning may also be practised, though the grubs go down pretty deeply, and if only a few inches are removed many will remain untouched. Summer fallowing, and the collection into heaps and burning of all rubbish will also account for many of the pests, and by destroying many of the roots on which they feed others will be reduced to starvation. In cases of new infestation it would be best to leave the ground uncropped for some timé, putting on a heavy dressing of fresh gas-lime, which will kill everything, the grubs included. Of course, cropping will be delayed, but it is waste of time and money to keep on sowing afresh, simply to provide food for the hungry pests. It must be remembered that wireworms injure more than they actually destroy, and that the weaker the crop the more will this injury be felt. By good culture and the use of stimulating manures, such as potash and nitrates, the plants will often attain sufficient stamina to withstand partial attack. Among root crops, constant stirring with the hoes will annoy the pests, and encourage rapid growth at the same time. Moles, though undesirable in great numbers, certainly devour a great number of the pests, and the same may be said of rooks. It is said that wireworms have a great objection to White Mustard, and it might be well on newly-broken lands to sow this erop, so as to starve out the pests before planting with potatoes. Half measures are perfectly useless with this particular pest, and unless some decided steps are taken to clear the land of them, the same field may be infested for years. Next to gas-liming, the use of quick-acting manures to 
encourage strong growth, the frequent aeration of the soil, and the free use of soot, are measures best calculated to effect a clearance. In gardens dressing the soil with kainit at the rate of a pound per sq!ıre rod; with quicklime in February at the rate of three bushels per square rod; and nitrate of soda at the rate of one pound per square rod before earthing the potatoes up, will do much towards preventing injury to the potato crop.

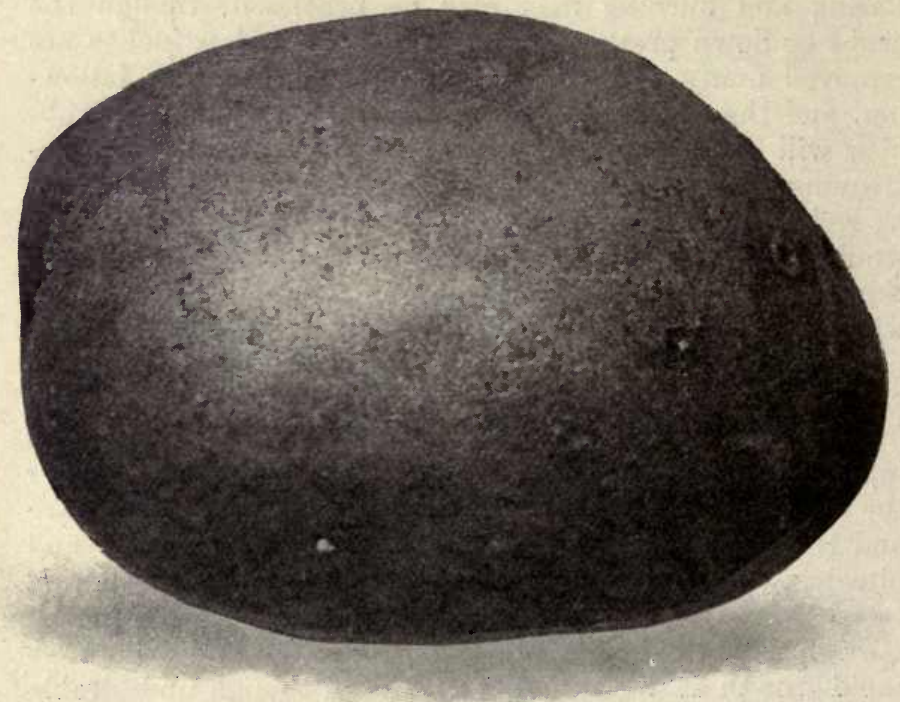

Maincrop Round Potato-syun House Prolific.

Millepedes or False Wireworms.-These are often confused with the true wireworm, although they are really distinct from the latter. They do not belong to the insect tribe, but to another closely allied tribe, the Myriopoda. Their bodies are composed of a number of rings, each furnished with one or two legs on each side. Owing 


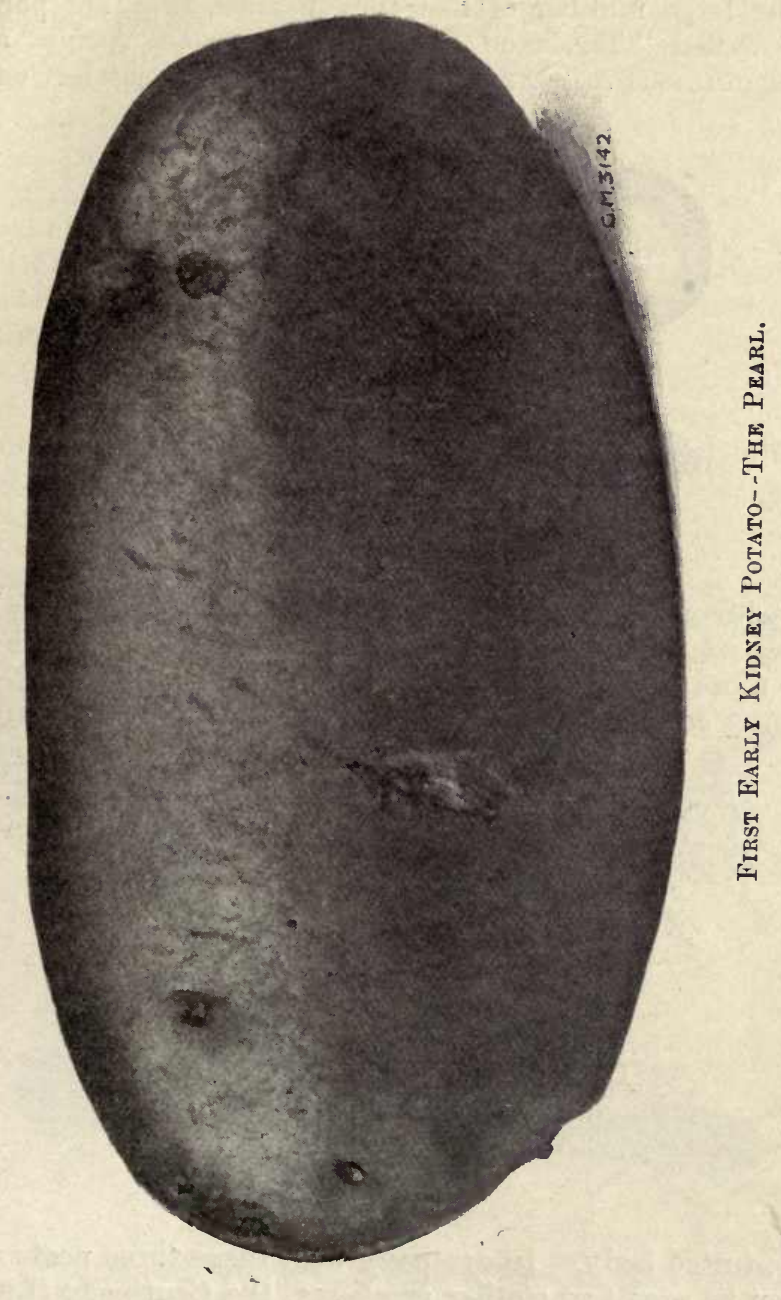

I 
to the large number of feet they possess they are popularly called "Thousand Feet." The hurtful species are Julus guttatus (Figs. 2 and 3), an inch long, slender, with

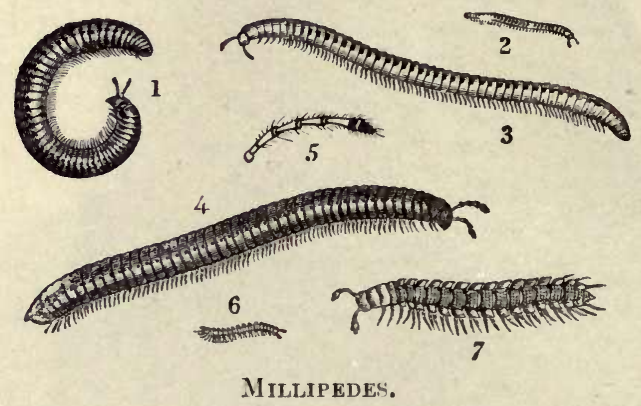

an ochreous-coloured body, spotted with crimson; Julus terrestris, about an inch long, of a pitchy or leaden hue, and more or less cylindrical in shape (Fig. 4); and Polydesmus complanatus (Fig. 7), a short, flat lind, with at

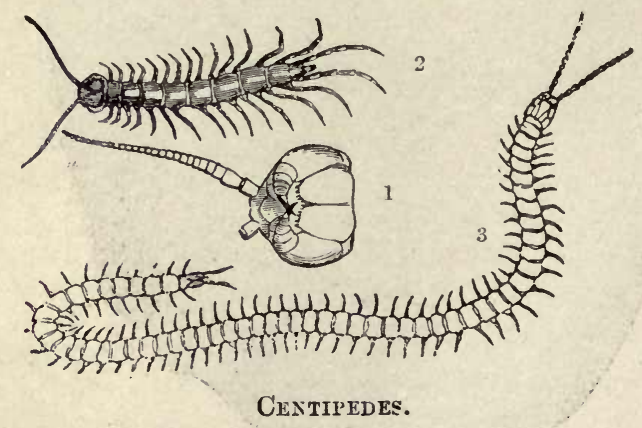

lilac-tinted body. In company with these three pests will often be sean two similar creatures, the Centipede (Lithobius forcipatus), a short, active little animal, with a 
smooth, shining, ochreous-coloured body, furnished with thirty feet (Fig. 2); and another long and slender creature - two to three inches long-with numerous legs and an ochreous-brown tinted body, named Geophilus longicornis (Fig. 3). The latter moves with a waving motion from right to left, and is very active. These two creatures are carnivorous in habit, and do no harm to vegetation. The millepedes, however, are very destructive, and attack the tubers with as much voracity as the wireworms.

Remevies.-Badly drained, wet or weed-infested lands are favourite haunts of these pests. Soil that is properly tilled, liept clean, and well limed occasionally is rarely much troubled with millepedes. The remedies advised for the eradication of the wireworm are equally applicable to the millepedes.

Colorado Beetle (Doryphora decemlineata).-This is an American pest, which has happily not established
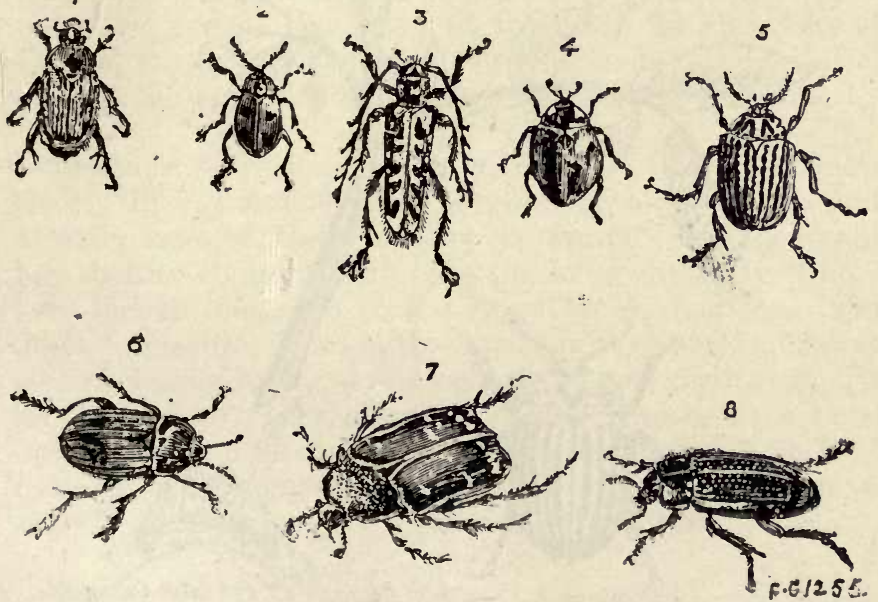

Colorado Potato Beetle any its Mimics.

1-Field Chafer. 2-False Lady Bird. 3-Spine Beetle. 4-Large Lady Bird. 5-Colorado Potato Beetle. 6-Brown Woodlouse Beetle. 7-Green Rose Beetle. S- Whert Beetle. 


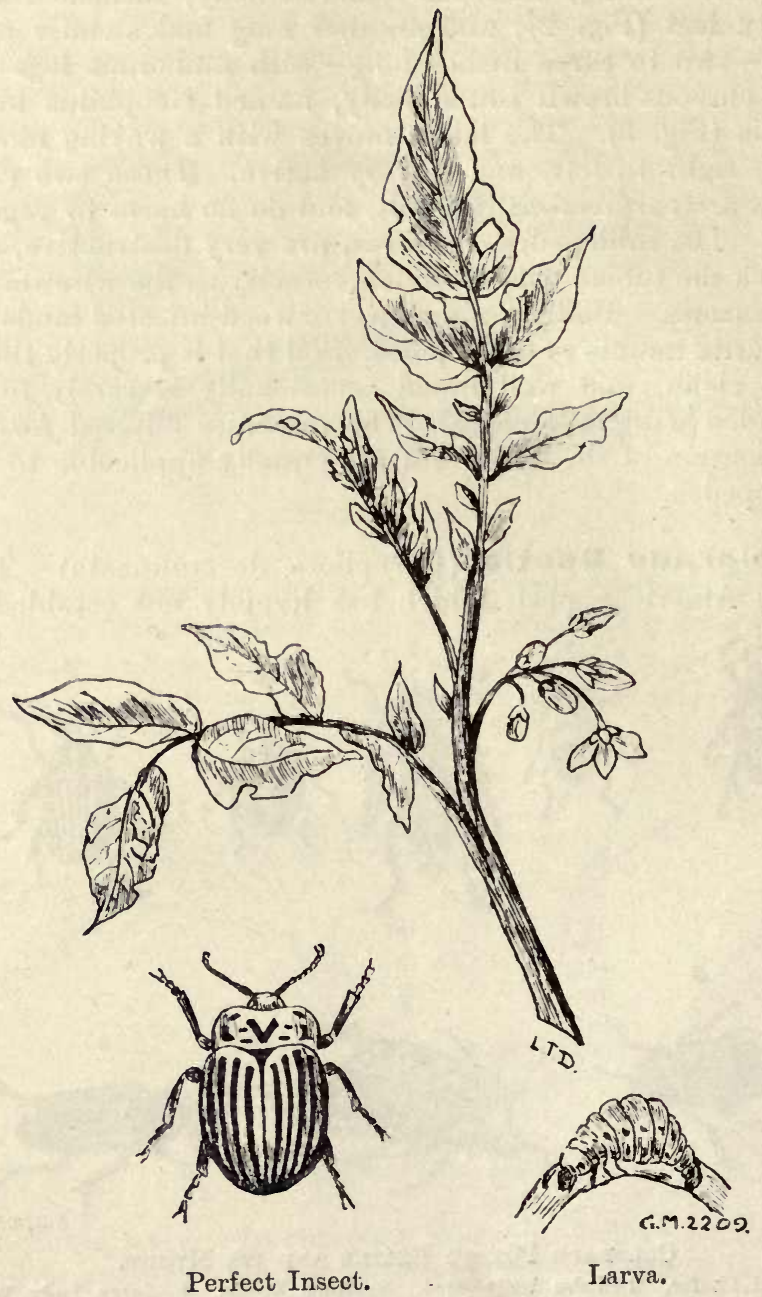

Colorado Potato BeEtle (Doryphora decemlineata). 
itself in this country, although it has made one or two futile attempts to do so. The female beetle is a little under half an inch in length, the male being slightly smaller. The colour of the beetle is yellow, with five longitudinal dark lines on each wing case. The legs are reddish, and the wings have a rosy hue. The eggs are oval in form, of an orange colour, and are deposited in clusters of nine to forty, mostly under one leaf. They are very similar to those of the Lady-bird Beetle, but are smaller in size. The larvæ are of a dull reddish brown colour, and not unlike those of the Lady-bird Beetle. When fully grown the larvæ are an inch long. They feed ravenously on the leaves and stalks, and when fully grown fall to the ground and pupate there in a few weeks. In America there are two to three broods in a season. On the approach of cold weather, the beetles descend to the earth, burying themselves a foot or more below the surface. The beetles are extremely hardy and do not seem to be affected by the cold or frost. There are numerous beetles which infest potatoes, and as they may be mistaken for the Colorado Beetle, we give illustrations of them, including the latter, so that the real culprit may be more readily recognised.

Remedies.-In accordance with the "Colorado Beetle Order, 1877," notice must be given to a police constable directly one of these beetles is found. The constable has then to communicate with the local authority, who in turn has to telegraph to the Board of Agriculture. This drastic measure, if promptly carried out, ensues immediate steps being taken for stamping out the pest forthwith. The larvæ feed on other plants than the potato, as a small colony of this pest was found at Tilbury, in Essex, in 1901, feasting upon nightshade, cabbages, etc. The recognized remedy is spraying with a Paris green solution.

Dart Moth (Noctua [Agrotis] segetum).-A surface caterpillar, the progeny of the above moth, is harmful to potatoes. The male moth has grey fore wings and white 
hind wings, and the abdomen and thorax are also grey. The hind wings of the female are white, while the fore wings as well as the abdomen and thorax are brown. The larvæ feed on the tubers, boring holes into them. They are about an inch long, and feed during the winter if circum-
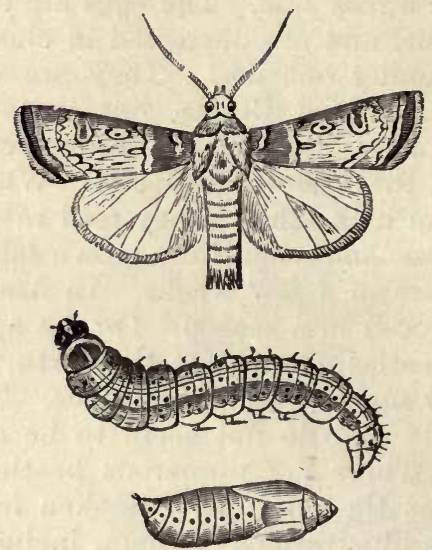

Dart Мотн (Noctua segetum).

stances are favourable (mild weather, etc); but if not, they hibernate in earth cells. In the following spring they are transformed into brown pupæ in the earth, where they remain for about a month, and are then transformed into the perfect inserts or moths.

Remedies.-The same as advised for the Heart and Dart Moth.

Heart and Dart Moth (Noctua [Agrotis] exclamationis). - The larva is known as a Surface Caterpillar. The Heart and Dart Moth is of an ochreous colour; the forewings are brown, while the hind-wings of the male are white, those of the female being brown. The larve are about an inch and a-half long, and furnished with tubercles, and when mature construct earth cells in which they 


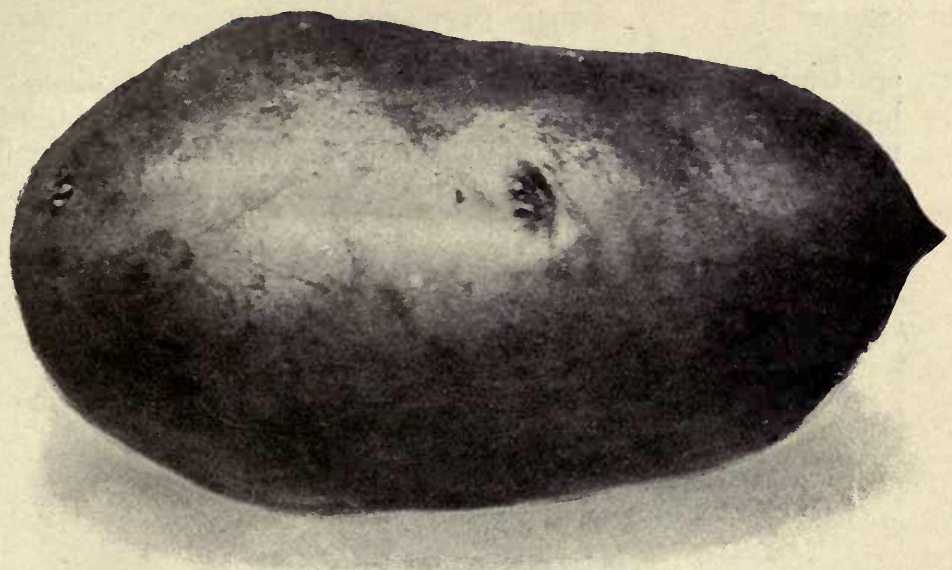

First Early Kidney Potato-Rivgleader.

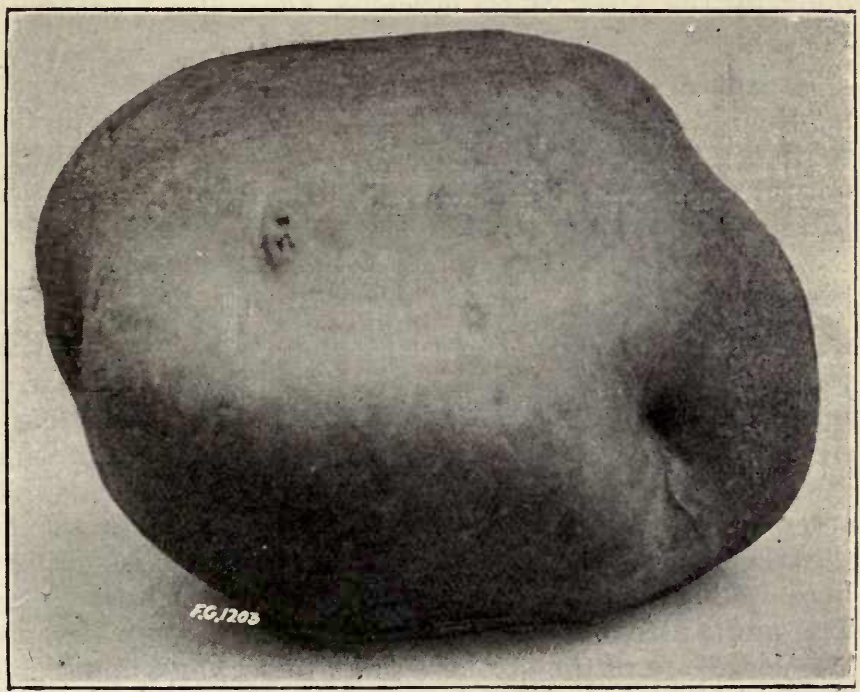

first farly Round Potato-Eureka Extra Fari,y, 
are transformed into pupæ. The latter are of a reddishbrown or chocolate colour, and hibernate in the earth-cells until the following season. These grubs do a lot of injury to the tubers, eating holes in them similarly to the injury
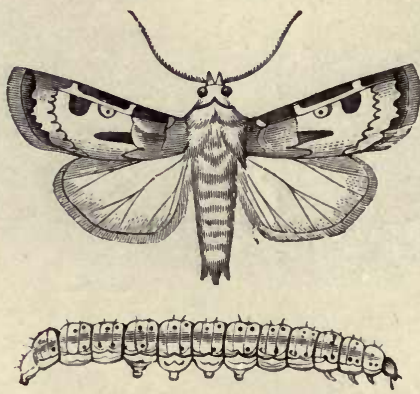

Heart and Dart Moti and Larva (Noctua exclamationis). done by the Dart Moth larva. They also feed on the foliage.

Remedies.-Experience has shown that the best remedy for this pest is to employ women or young folk to pick up the larva by hand. Dressings of lime, soot, and salt have not proved effectual. Thoroughly hoeing the soil between the rows will also prove effectual in killing these grubs.

Death's-Head Moth (Acherontia atropos).-The larva of this handsome moth feed upon the foliage of the potato, but are rarely present in sufficient numbers to do any serious harm. The moth is very large, measuring four to six inches across the spread of its wings. Its upper wings are black, with an ashy tint, and its lower ones bright orange; both wings are also marked with other tints. On the thorax is an orange-coloured figure representing a human skull, hence the common name of Death's Head. The moth utters a plaintive squeak like that of a mouse. The larvæ are of the size of a lad's finger, and upwards of three inches long. Their colour is a yellowish green, with 
seven oblique bands on each side, forming acute angles on the back. The stripes or bands are blue, lilac, and white. No one can possible mistake these handsome larvæ when seen. As they are never likely to be present in large numbers, no steps need be taken to exterminate them. Young entomologists would be only too glad to
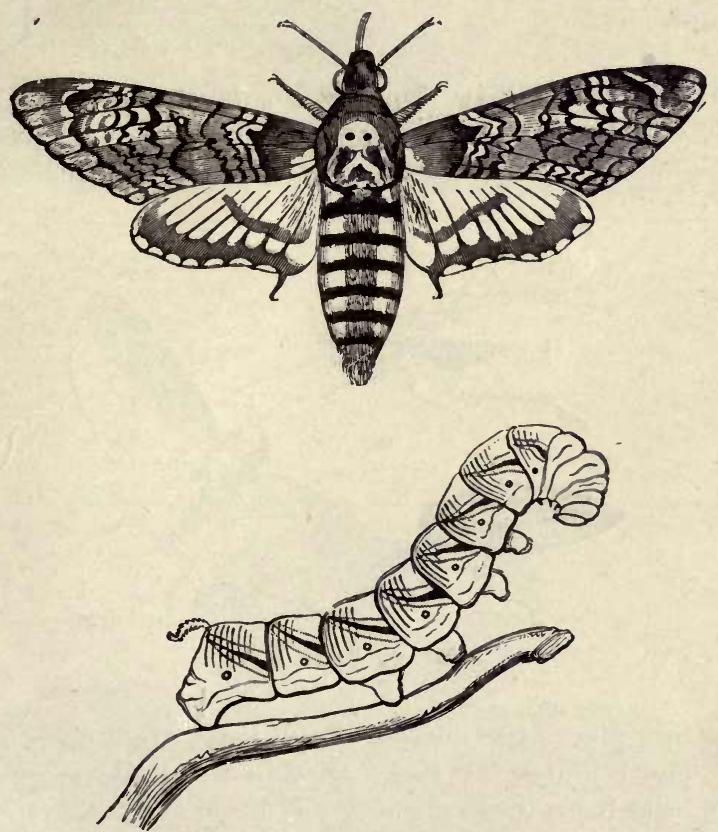

Death's-head Moth and Caterpillar (Revdced).

have all the larva they could find, so that, when found, they should be given to the former. The larve feed at night, therefore should be sought for on a moonlight night or by aid of a lamp. A few other larvæ of moths also feed upon the foliage of the potato, among which may be specially mentioned the caterpillar of the Frosted Orange Moth 
(Gortyna flavago), pale flesh colour, dotted with black and shining warts; the Dot Moth (Mamestra persicaria), green, pinkish brown, striped with white; the Rustic Shoulderknot (Apannea basilinea), brownish, with a yellow line, and black dots; and the Dark Brocade (Hadena adusta), green or purplish-green, smooth and waxy in appearance. These, however, do no serious damage.

Potato Frog Fiy (Eupteryx solani)._A small greenish fly which may be seen hopping about the potato foliage in August and September. By means of a beak or ros-

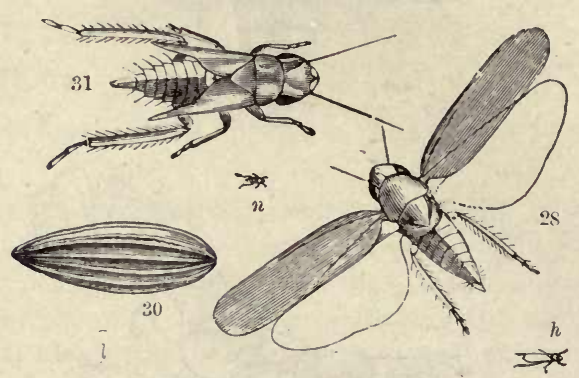

Potato Frog Fly.

trum they pierce the cuticle of the leaves and suck out the sap. The females lay their eggs on the undersides of the leaves, and from these are hatched little green larva, which also pierce the cuticles of the leaves, and feed upon the sap. By this means the cellular tissue becomes ruptured, and the growth of the plant severely checked. The flies have a habit of running to the opposite side of the leaf or stem when disturbed in dull weather, and of hopping away in sunny weather.

Remedies.-If very numerous, spray with an insecticide, otherwise do not bother about them. 


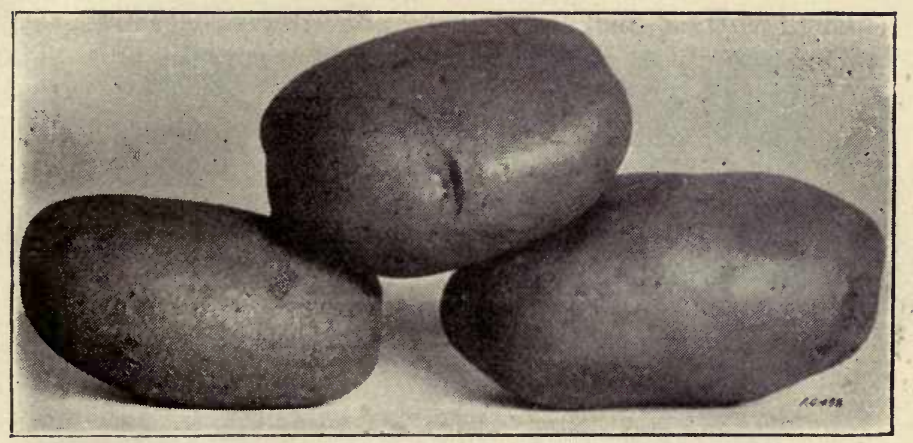

Maincrop_Kidney Potato-Evergood.

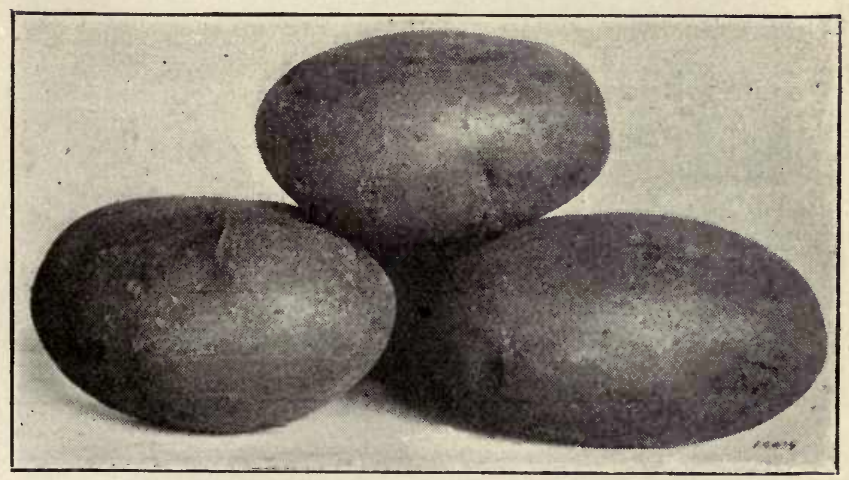

Second Early Oval Potato-Ruby Queex. 
Potato Bug (Lygus solani).-Active little insects furnished with a rostrum or beak, by means of which they pierce the cuticle of the leaves, and extract the sap. The
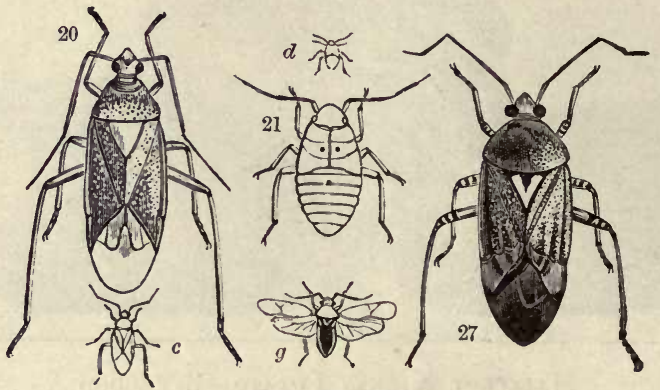

Ротато Bug.

perfect insects have green, shining bodies, and transparent wings. They are very agile, leaping away at the slightest touch. The insects are most abundant in August. The injuries they inflict upon the foliage are similar to those caused by the Potato Frog Fly, and the remedies are the same.

Potato Gnat (Sciara furcata).-Curtis, in his "Farm
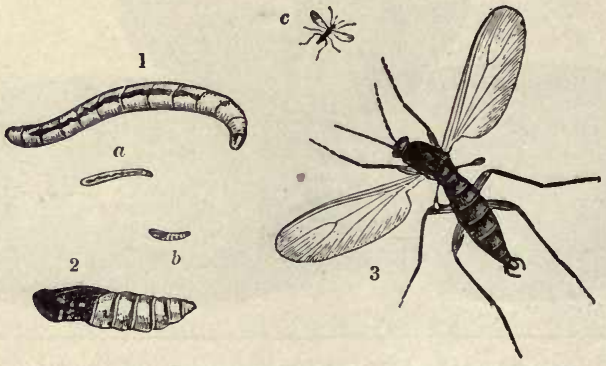

Potato GNat.

Insects," refers to this insect and its larva as feeding upon potato tubers. As, however, it is doubtful if they attack 


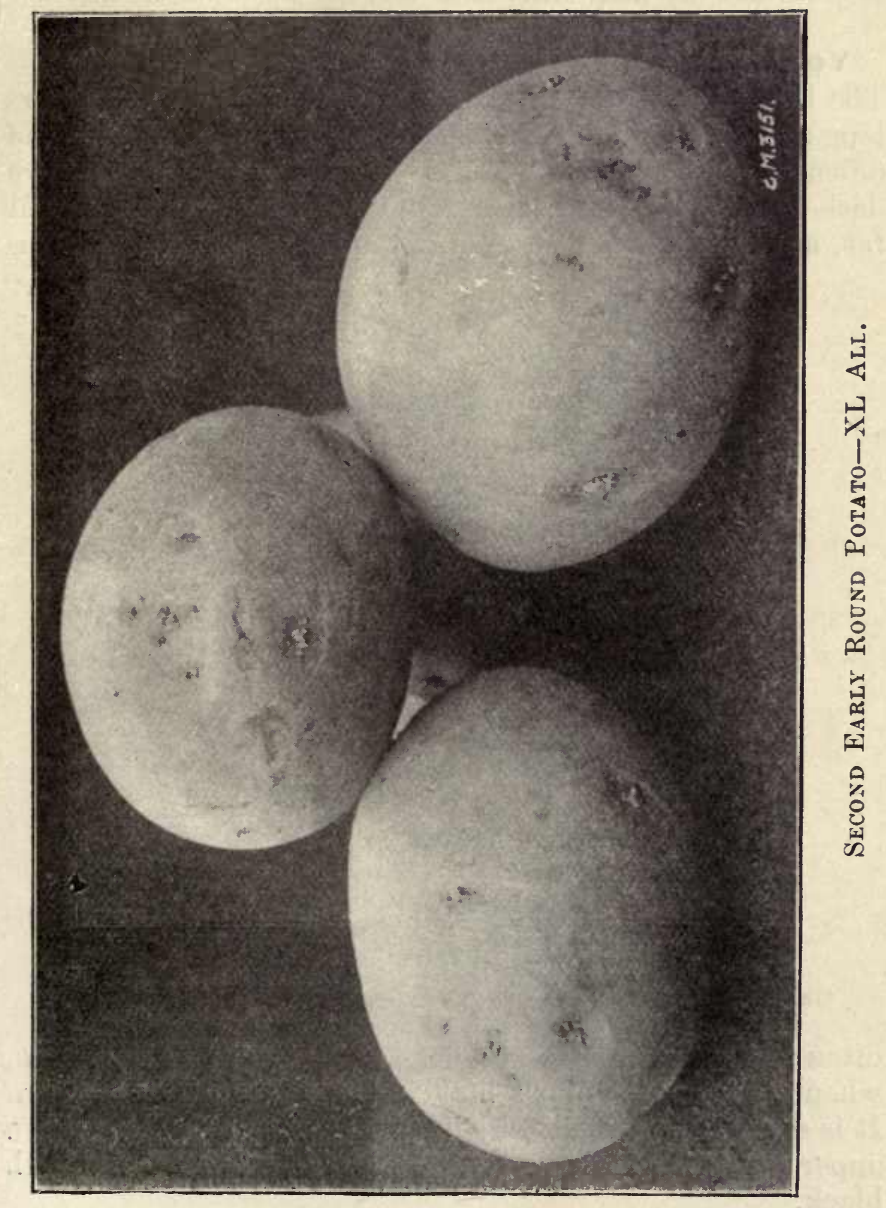


other than diseased or rotten tuberi, we need not äweil any further upon them.

Yellow Under.wing Moth ('Trypliana pronuba).The larva of this moth is about an inch and three-quarters long and of a pale, sickly green colour, with a brown band down the back, a pale line along the middle, and a line of dark spots along each side. They are generally somewhat fat, and, when touched, curl up into a ring. The moth is
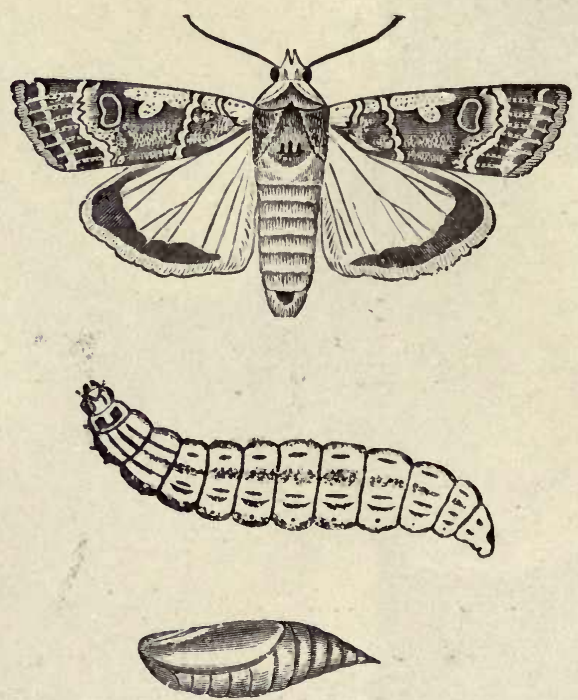

Great Yellow Under-wing Moth, Caterpillar and Puta.

often met with in pastures, etc., in June and July, where, when disturbed, it flies a little way and drops down again. It is easily distinguished by its ochreous or chestnut-brown upper wings, and orange-yellow under wings, bordered with black.

Remedies.-The same as advised for the Dart and Heart and Dart Moth larra. The larva feed chiefly by night. 
Slugs and Snails. - Both are rather partial to the young shoots of the potato, and, although the harm they

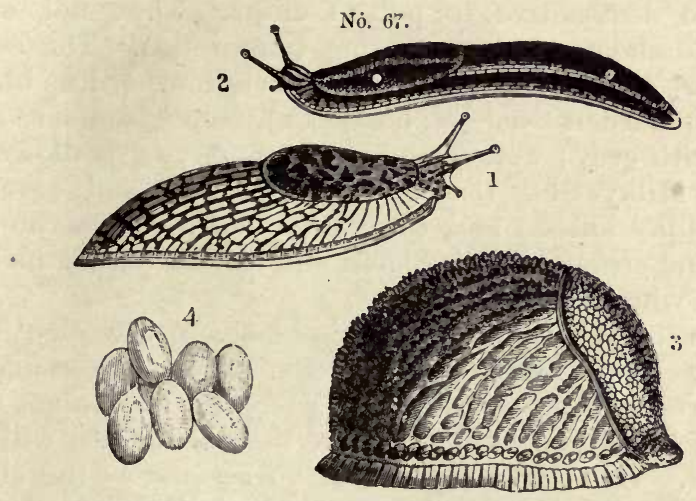

Fig. 1, Milky Slug; 2 and 3, Black Slugs.

do to ordinary potato crops is not of serious consequence, yet in the case of new and choice sorts, the injury to or

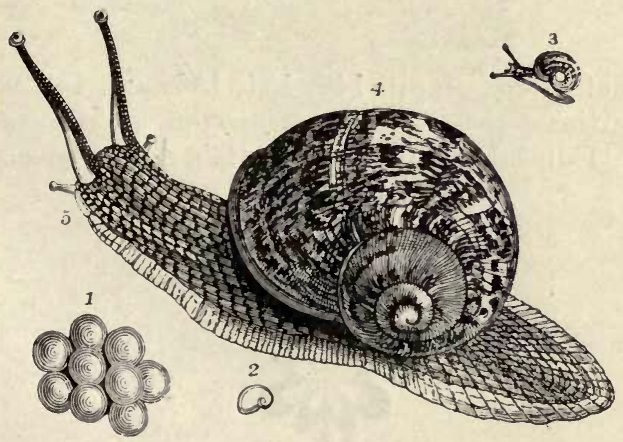

The Gardex Snail.

loss of a shoot is of some importance. The Common Snail (Helix aspera) and the Garden Snail (H. hortensis) 
are the chief culprits. An allied species named H. nemoralis also attacks potato shoots. Slugs, which are easily distinguished from snails by the absence of a shell, are still more destructive to potato crops. They not only attack the shoots, but the young tubers also. The chief culprits are the Black Slug (Arion ater), more or less black in colour; Garden Slug (A. hortensis), small, slender, and striped with grey; Yellow Slug (Limax flavus), yellowish; Field or Milky Slug (L. agrestis), greyish, and covered with a milky slime; and the Large Slug (L. maximus), spotted and streaked with black, and measuring six inches in length when stretched out.

Remedies.-Where both slugs and snails are plentiful, and likely to do harm to the crops, apply a dressing of equal parts of soot and lime on successive evenings and mornings for three or four times, then the pests will be destroyed. One application is of 110 service as the slugs can cast off the lime and soot with the slime. But if repeated as advised, it eventually penetrates the skin, and kills the pests. Guano, nitrate of soda, and sulphate of ammonia are also objectionable to slugs, so that where these artificials are used slugs and snails will not be very plentiful.

[The illustrations on pp. $146,154,156$, and 159 are reprodueed, by the courtesy and permission of Messis. Oliver and Boyd, Edinburgh, from “. Curtis's Farm Insects.' ]

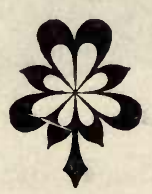




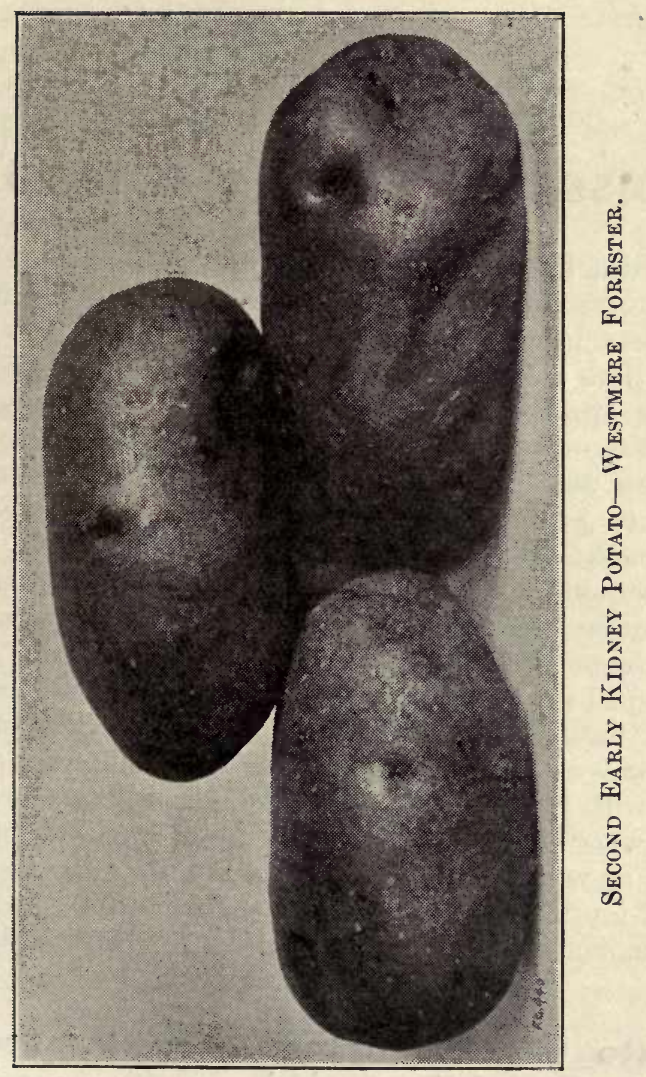




\section{CHAPTER XVIII.}

\section{DISEASES OF THE POTATO.}

The potato, like many other vegetables, has its enemies. Fortunately, in this country it is comparatively immune from insect pests, but not so in regard to diseases. One, at least, has proved a formidable enemy to the potato ever since its appearance was first noticed in Europe about 1845. From then onwards to the present time the disease known as the Potato Blight has been a source of great anxiety to potato growers. Science and skill, however, have clearly demonstrated its life history, made growers better acquainted with its manner of development, and taught them the wisdom of adopting preventive measures as a safeguard against attack. The up-to-date grower, therefore, does not run the risk of injury to his crops by disease, but uses his utmost endeavours first of all to plant disease-resisting varieties; and secondly, to spray the foliage with fungicides before the disease appears. The grower who plants diseased tubers, or varieties prone to disease, or waits till the disease is manifest in the foliage, is on all-fours with the hero of the fable who "locked the stable door after the horse was stolen." So much by the way.

\section{Potato Blight (Phytophthora Infestans).-} This is the dreaded disease which commits so much havoc among the potato crop in wet seasons. It first manifests itself in the form of brown patches on the leaves, followed by curling of the latter, and finally by their becoming black and decayed. The disease is caused by a fungus, the 
mycelium of which penetrates the tissues of the leaves and destroys them. In due course the mycelium develops what are technically known as conidiophores, or tiny stems which appear in the form of a mould on the surface. On the conidiophores are borne conidia, which give birth to zoospores. These, coming in contact with globules of water, emit germ tubes that penetrate the $\epsilon$ pidermis of the leaf or tuber, and eventually form the mycelium which does so much mischief to the tissues. The mycelium will often lie dormant in the tubers all the winter, and start into activity when new growth begins in the soil. The disease is mostly prevalent in rainy seasons.

Remedies. - First of all, let it be clearly understood that it is quite useless applying remedies, once the foliage is attacked by the blight. The mischief is done then. There is only one course to pursue in such a case, and that is to promptly cut off the diseased haulm and burn it. On no account ought it to be permitted to remain on the land to decay, otherwise the disease will attack crops in future years. Nor is it advisable to give diseased tubers to pigs, since the disease will be transported with the manure, and reconveyed to the land, ready to attack the next crop of potatoes grown thereon. Really, there should be no hesitation about burning both diseased haulm and tubers, as then the disease will be eradicated. Infested land should be liberally dressed with quicklime, and no potatoes grown thereon for at least two or three years.

Spraying with Fungicides.-Repeated experiments have demonstrated that it is possible to prevent an attack of the Potato Blight by one or more timely sprayings of the foliage with a fungicide. According to leaflet No. 14 issued by the Department of Agriculture and Technical Instruction for Ireland, the results of spraying potato crops have been of a most gratifying nature. Experiments have been made for three years with the following results: 
1900 .

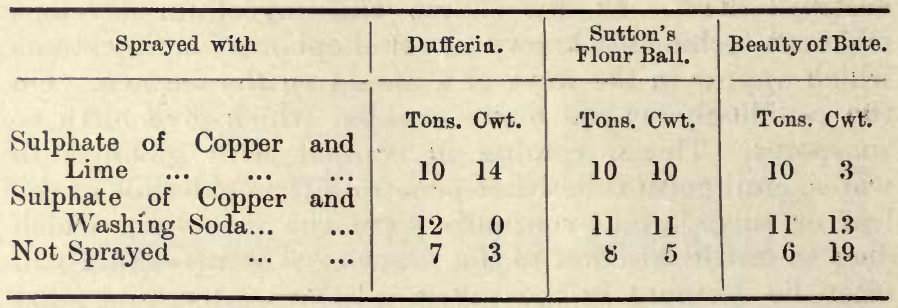

1901.

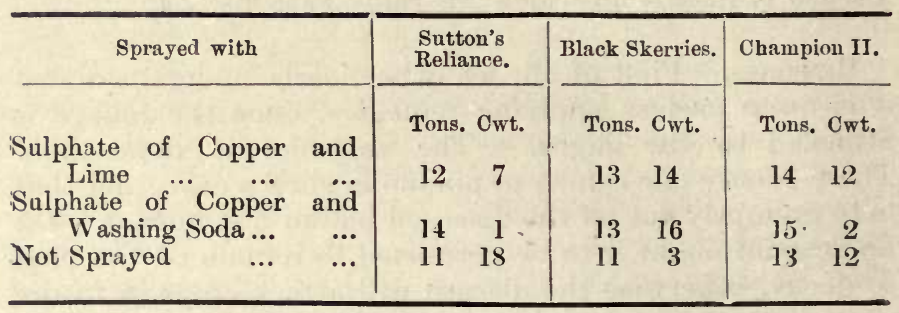

1902.

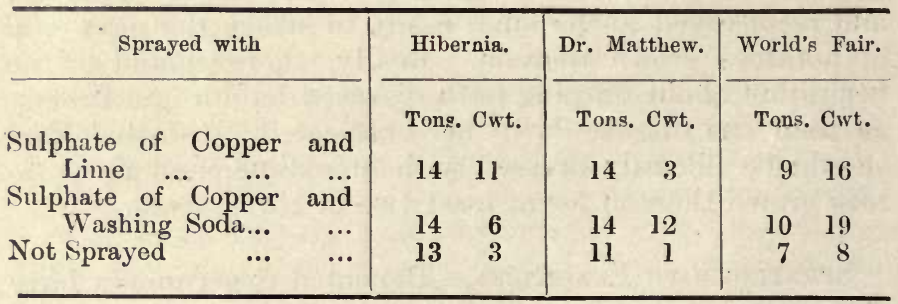

It will be observed that two fungicides were used, and of the two, the one composed of sulphate of copper and washing soda appears to have yielded the best results. Whichever mixture be decided upon, the first application should be given at the end of June or early in July, and a second spraying at the end of July. The spraying must be done in fine and dry weather, and the mixture applied as 


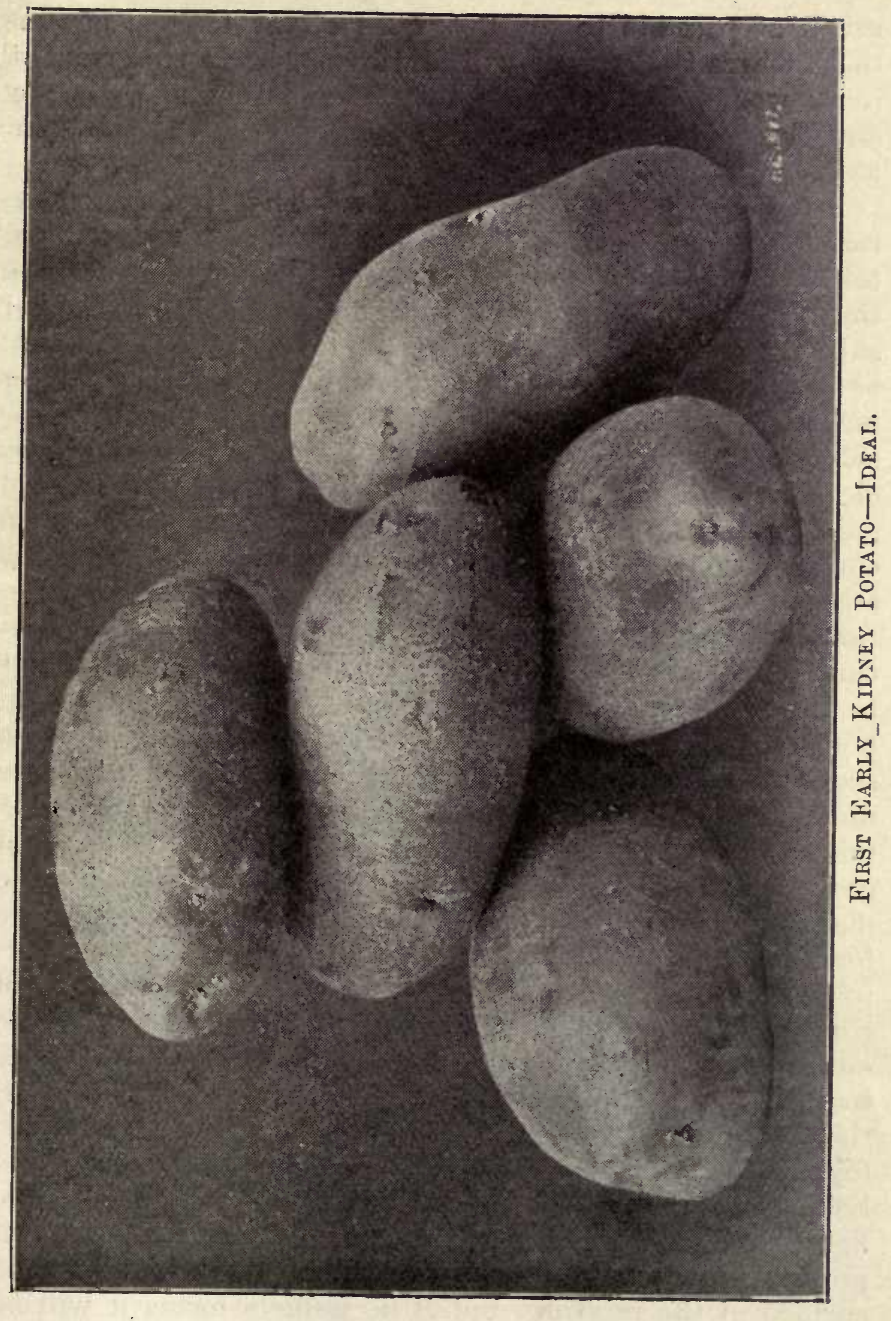


much as possible to the underside of the foliage, as it is there where the disease will first appear. In the event of rainy weather setting in soon after spraying, re-spray directly it is fine again. About 120 gallons are sufficient to spray a statute acre, or 194 gallons an Irish acre.

Bordeaux Mixture for Spraying.-The Bordeaux mixture should be sprayed on to the crop, not watered on, taking care to dew the underside of the leaves as well as the upper surface. The materials required are: Copper sulphate, 8lbs.; quicklime, 4lbs.; water, 40 gallons; or the quantities may be proportionately reduced or increased to suit the necessities of the case. Dissolve the copper sulphate by putting it in a bag of coarse cloth and hanging this in a vessel holding at least 4 gallons, so that it is just covered by the water. Use an earthen or wooden vessel. Slake the lime in an equal amount of water; then add this slowly to the copper solution, and enough water to makè 40 gallons. The mixture is then ready for immediate use. It should always be remembered that the lime must be fresh and quick, not old or air-slaked; it should be slaked gradually so as to secure a smooth paste, and then have water added to make milk of lime. A good test for acidity in Bordeaux mixture can be secured by means of a clean and good steel knife blade; when the mixture is ready for use insert the blade of a knife, and let it remain in the mixture for a minute or so; if copper is deposited on the steel, or, in other words, if the steel takes on the appearance of copperplate, one may conclude that the mixture is unsafe and likely to affect tender foliage, and more lime is required. If, however, the blade remains unaffected, the mixture is safe. Another test is made by pouring a little of the solution in an old saucer, and holding it up so as to get it between the eyes and the light, breathe upon it gently for about half a minute; if properly made, a thin skin or pellicle will form on the surface of the mixture, but if no pellicle forms it will be necessary to add more milk of lime. Yet another test 
is to dip a strip of blue litmus paper in the solution. If it turns red add more lime. . If it remains blue the solution is safe to use.

Copper and Soda Mixture for Spraying.-This mixture, as recommended by the Irish Board of Agriculture, consists of $2 \mathrm{lbs}$. of sulphate of copper of 98 per cent. purity; $2 \frac{1}{2} \mathrm{lbs}$. of pure washing soda; and 10 gallons of clean water. If a large quantity be desired, use 8lbs. of sulphate of copper; 10lbs. of washing soda; and 40 gallons of water. To make the 10-gallon mixture dissolve the sulphate of copper in 1 gallon of water, and the soda in another gallon of water, then add the two to 8 gallons of water.

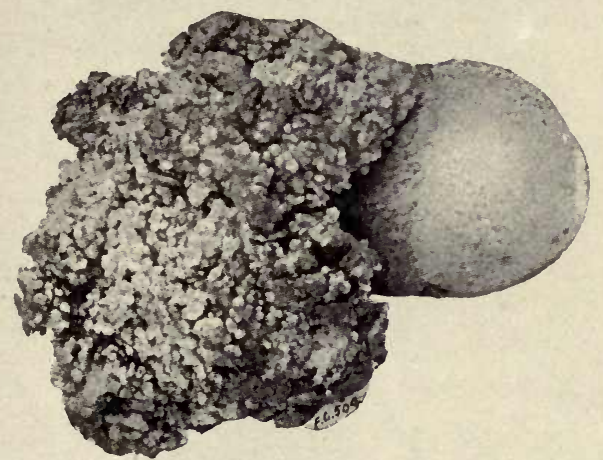

Potato Tobfr Infected with Blatk Scab or W: Rt Diseasf. (See p. 170.)

For the larger quantity place the copper in a canvas bag and steep it in 35 gallons of water till dissolved, then dissolve the soda in 5 gallons of water, and mix the two together. Add the soda solution slowly to the copper mixture, and stir continuously. To ascertain if the mixture is of the right strength test it with blue litmus paper. If the paper turns red, add more washing soda till, with further tests with the litmus paper, the latter remains blue. The vessels used for the solution should be of wood, and not of metal. Drain the solution through canvas be- 


\section{THE POTATO.}

fore putting it in the sprayer. See that the solution is kept well stirred, and bear in mind that sulphate of copper is a poison, and therefore the solution should not be put in pails or other receptacles that are to contain water for drinking purposes. On no account pour the sulphate of copper into the soda solution, but add the latter to the

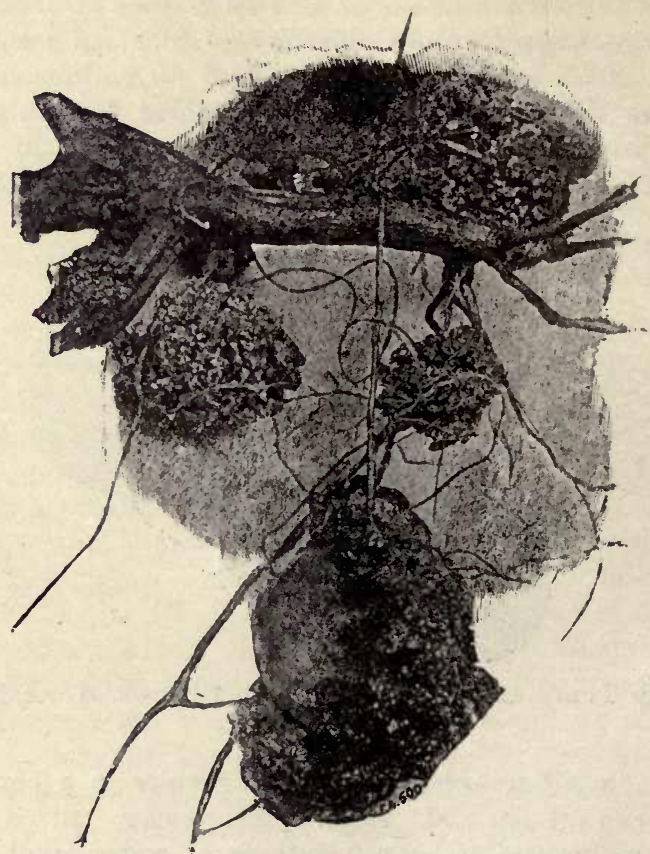

Potato:Root Infected with Black Scab or Wart Disease. (See p. 170.)

former, and that slowly. Spray for the first time at the end of June, again early in July, and lastly at the end of that month. Spray when the foliage is dry only. See that the undersides of the leaves are thoroughly moistened with the solution. Use 120 gallons per statute acre, of 194 


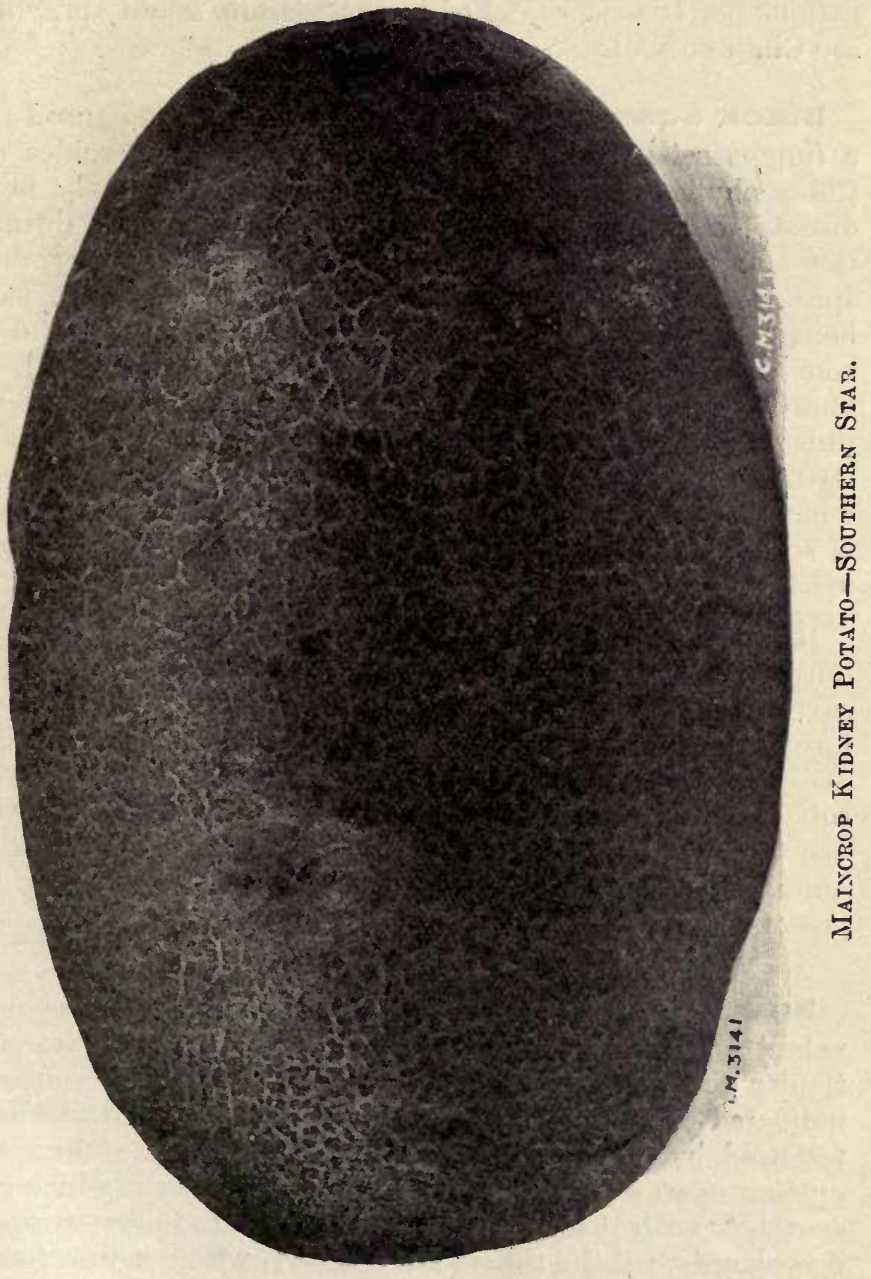


gallons per Irish acre. For further details about spraying see Chapter XVII.

Black Scab or Wart Disease.-This is caused by a fungus scientifically known as Oedomyces leproides or Chlorophylictis endobioticæ. It is a comparatively new disease, only having been noticed in this country during the last four or five years. It first attacks the young sprouts, causing them to assume a brownish tinge, this being followed by the formation of small warts. In due course the warts increase in size and grow into each other, almost enveloping the tuber, as shown in the specimens illustrated. The warts eventually become a black mass owing to the presence of resting spores. This new disease, which is said to have been introduced from the Continent, is so distinct in character that it cannot fail to be recognised. See illustrations on pp, 167 and 168.

Remedies.-All diseased tubers should be promptly burnt, and in the case of any apparently healthy tubers saved from an infected crop for " seed," they should, before storing, be well dusted with flowers of sulphur, taking care that the latter is well dusted into the "eyes " of the tuber. We think it equally advisable to be careful in the use of sacks that have contained infected tubers, as it is quite probable that the spores of the disease may be present in them.

Bacteriosis - $\mathrm{A}$ disease of bacterial origin is very prevalent in America, and may find its way here. The particular germ is Bacillus solanacearum, and its presence is indicated by the sudden drooping or wilting of the foliage, followed by discoloration and collapse of the stem. On cutting open a stem brown streaks will be seen which are crowded with bacteria. The disease gradually spreads downwards, till the tubers are reached, where it first forms a pale zone, followed by a black one just inside.

Remedies.-Burning all infected foliage and tubers seems 
to be the only way of stamping the disease out. Tubers with the brown ring inside should be avoided as sets.

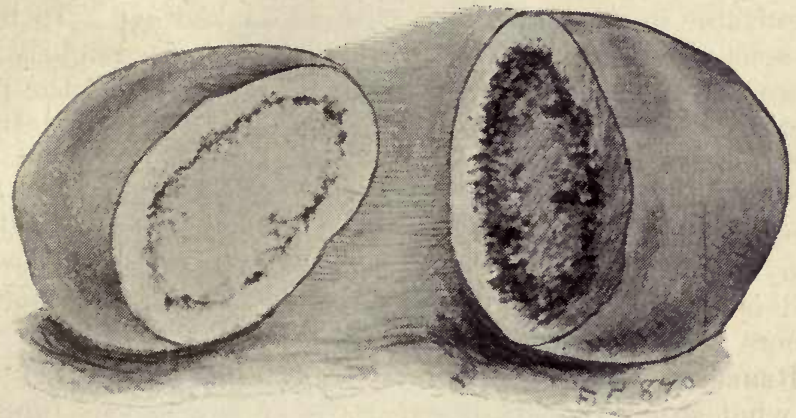

Bacterial Disease in Potatoes.

\section{Sclerotium Disease (Sclerotinia Sclero.} tiorum):-This is a fungoid disease which attacks the stems of potatoes just above the ground. It is in the form of a white mould, which gradually creeps up the stems and develops into small black bodies called sclerotia. When the latter stage is reached the stem becomes limp, withers and dies, seriously checking the growth of the tubers. In dry weather, the white mould is not apparent on the outer surface, the disease being more active within.

Remedies.-All foliage showing any indication of the disease should be burnt, otherwise the disease will attack a future crop. It appears that beans, peas, marrows, cucumbers and turnips are liable to be attacked also.

Potato Rot (Phellomyces sclerotiophorus):According to Professor Johnson, D.Sc., F.L.S., of Dublin, a new potato disease, caused by a fungus, has made its appearance in Ireland. It is reputed to form a scab on, and also dry rot in, the tubers. Professor Johnson first observed the fungus in several potato varieties grown in the west and other parts of Ireland in the autumn of 1901. 
Phellomyces causes the formation of discoloured patches in the skin of the tuber, in the midst of which are generally present the minute sclerotia $0.1 \mathrm{~mm}$. in diameter, just recognisable in washed tubers with the naked eye. In mild attacks, the fungus simply makes the tuber unsightly; in more severe cases it strips off layer after layer of the protecting skin of the tuber, and may ultimately penetrate through the skin into the flesh of the tuber, killing the protoplasm, sending the mycelial hyphx between and through the cells, and boring into the starin grains. Phellomyces can pass from seed tubers to the resulting crop, and is communicable from infected ground to healthy tubers grown in it.

Remedies.-Of course, but little is known at present as to what steps to take to arrest the spread of this fungus. Professor Johnson, however, found soaking the diseased tubers in 0.8 per cent. solution of formalin for one and a-half hours destroyed the fungus control, untreated tubers giving a diseased crop. Three varieties imported from France, planted in Connemara, gave crops showing Sclerotinia sclerotiorum, and Phellomyces sclerotiophorus, all unknown in France, on the potato up to the present. Frank first saw the fungus in various parts of Germany in 1894.

Potato Scab. - This is said by one authority to be a disease of bacterial origin, the germ being Micrococcus pellucidus. It causes scab-like eruptions to form on the surface of the tubers which render them unsightly. It has been found by experiment that tubers grown in sour soils, or where lime, cinder ashes, or farmyard manure has been lavishly used, are most susceptible to infection. Another authority describes the disease as being caused by a fungus, Sorosporium scabies. He says it forms large olive scabs or patches on the slin of fully-grown tubers. According to him, it is not very injurious, although depreciating the market value of the tubers.

Remedies-Seed which is not known to be all right 


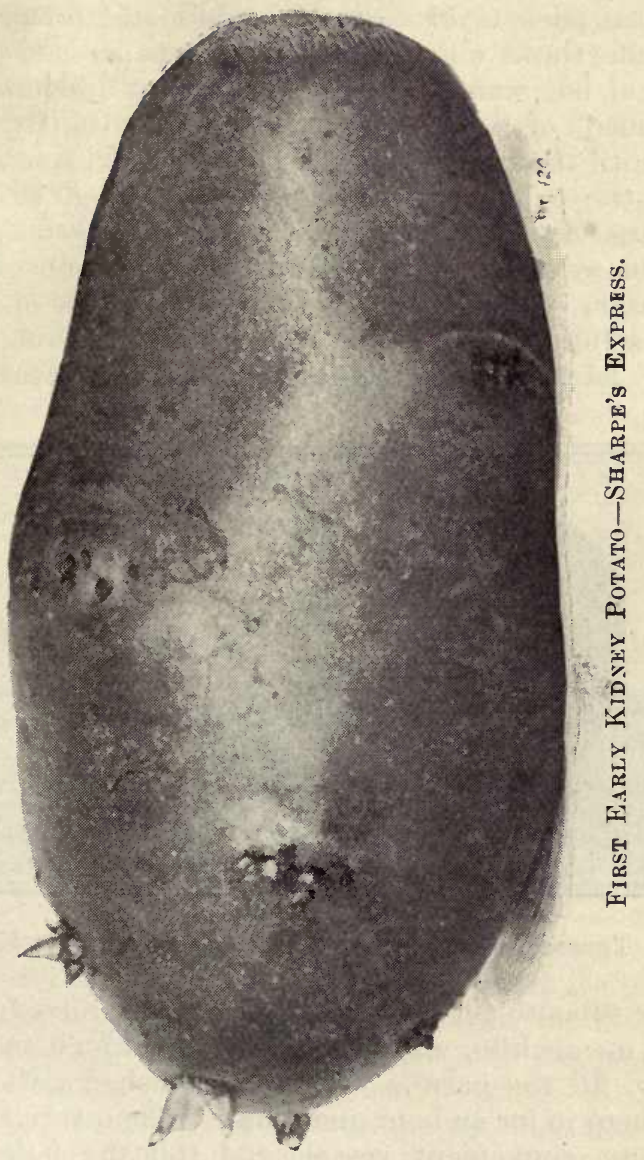


should be treated with a dressing of corrosive sublimate, which will effectually kill all germs. Obtain a number of two-ounce packets of corrosive sublimate, finely pulverised; take three wooden (not metal) pails, and put two gallons of hot water into each, and also add one packet (two ounce) of sublimate to each pail. Gently stir the water until the sublimate is dissolved, and leave the solution in the pails until next morning. Then have ready three large flour barrels, which have been soaked until they will hold water; put into each barrel thirteen gallons of cold water, and add to each one of the parts of the sublimate solution, which will make fifteen gallons in each barrel. Leave this for three or four hours, stirring occa-

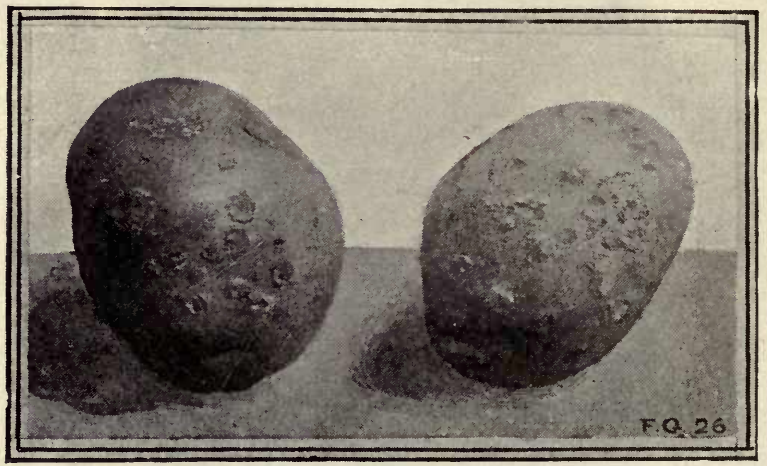

Tubers Infected with Potato Scab. (See p. 172.)

sionally so as to get the poison thoroughly mixed with the water; meanwhile, wash the potatoes through two waters in tubs, fill the barrels with these washed potatoes and leave them in for an hour and a-half. Then turn the liquid into some convenient vessel, and roll the potatoes out on to the ground. The barrels may then be again filled with fresh seed and the same water, which latter may be used for three or four times. Of course, any number of 
barrels, in reason, may be used, but we mention three as being a convenient number. Great care must be taken from beginning to end while the poison solution or the dressed potatoes are about. When the last of the solution is done with it should be emptied on to some bare piece of ground or on to the road, but not on to the grass.

Leaf Curl.-In some seasons and districts the leaves of the potato curl and pucker, then turn yellow. This condition is due to a fungus which first gains access to the tubers, and thence to the vessels of the shoots and foliage. Soon after attack the stems turn black and droop, a whitish mould appearing on the dark patches. The tubers, moreover, become stunted in growth, and although they appear sound when harvested will eventualy rot after storage. The particular fungus which causes the foregoing is supposed to be a species of pleospora.

Wet Rot.-Tubers are sometimes found quite rotten and putrefied, and having a decidely offensive smell. The cause is a bacteria called Clostridium, which, says Professor Marshall Ward, " consumes the cell walls, but leaves the starchy grains intact." In the February issue of the Board of Agriculture Journal it is stated that "Wet Rot" is due to the action of the fungi of the potato disease (Phytopthora infestans) and of Winter Rot (Nectria solani). The spores of the former infect the young tubers before lifting, and the mycelium of the same fungus passes down the stems into the tubers. If the season is wet and warm, the mycelium continues to grow, causing brown spots to appear, and ending in the rotting of the tuber. If the tubers are kept dry the mycelium remains stationary till the following spring, then commences growth, passes into the sprouts, and finally appears in the fruiting condition on the leaves. Then the Winter Rot fungus produces softening and swelling of the tubers, which are later attacked by bacteria, thus showing " Wet Rot." 
Remedies.-From experiments made at the farm belonging to the Agricultural Department of Leeds University it has been found that dressing the stored tubers with quick-not slaked-lime, at the rate of $7 \mathrm{lb}$. per cwt. has prevented healthy tubers being attacked by the "Wet Rot" disease. The lime quickly forms a thin shell over the tuber, which is afterwards easily removed, leaving the

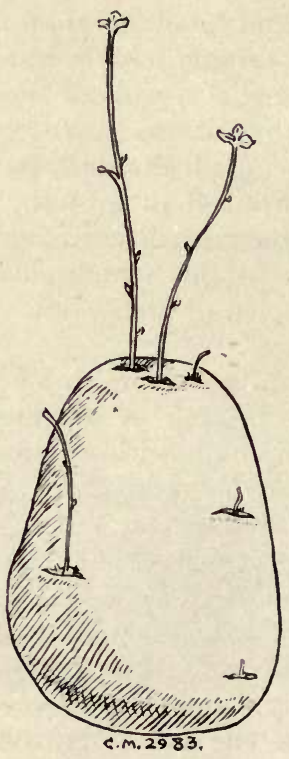

Potato Tuber Infected with Spindle Disease. (See p. 17i.)

skin clean and bright. It appears that when slaked lime is used, it forms a sticky, pasty mass, and is removed with difficulty from the tubers. The quicklime, on the other hand, in the process of hypation, expands and forms a thin, hard shell, which does not adhere to the tuber. By treating the tubers with lime the tubers are said to sprout quite a fortnight earlier than when no lime is used. 
Sea Blight.-Potato crops grown near the sea coast are often injured by the salt spray blown by the winds on the foliage. The saline matter causes the foliage to shrivel and become brown. Unfortunately there is no remedy for this.

Spindle Disease (Persola tomentosum).-A fungoid disease, which apparently attacks the eyes of the tubers, causing them to produce weak, spindly shoots. In many cases the shoots are mere thread-like growths. Tubers so attacked and planted frequently make no growth at all, and remain perfectly sound in the soil for months after planting. A correspondent informed us recently that he planted in March, 1904, a patch of apparently perfectly healthy tubers, which made no growth above the surface of the soil. In the autumn he examined the drills, and found the tubers sound. In the case of cut tubers the cut surface goes brown in a few days, and dry rot sets in. This disease is prevalent in France.

Remedies. - The only thing that can be done to guard against failure of the crop from this disease is to box the tubers early. This will enable the grower to determine whether the tubers are prone to produce the thread-like shoots characteristic of the disease. Tubers that do not sprout healthily should be burnt forthwith.

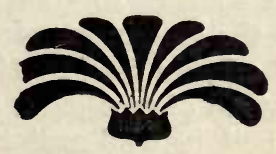




\section{CHAPTER XIX. \\ ON COOKING POTATOES.}

Ir is one thing to grow the potato, but quite another to cook it properly, so that the tubers shall be in the best possible condition for eating. It is said, with a certain amount of truth, that few people know how to cook the noble tuber properly. We are not referring here to the many fancy ways of " dressing " potatoes, but to the simple process of boiling or baking them. It is seldom in our public restaurants that one can obtain a really good boiled potato, and as for those cooked by the average servant, they are often worse, if anything. We consider it quite as important to instruct the readers of this Hand. book how to cook a potato, as it is to teach them how to grow it, and hence we shall describe what we consider to be the best methods of cooking the tubers in this short chapter.

The Wrong way is to peel off the rind very thickly, and throw the tubers into cold water to soak for an hour or so before cooking. The thick peeling is wasteful, and means the loss of a considerable amount of the best part of the potato, while the long immersion in water after peeling means a loss of soluble food matter, and a predisposition to waxiness instead of mealiness after cooking. Starting the tubers to boil in cold water is another common cause of waxiness, and the absence of that nice floury condition everyone appreciates in a well-cooked tuber.

The Right Way to cook the potato is to remove the 


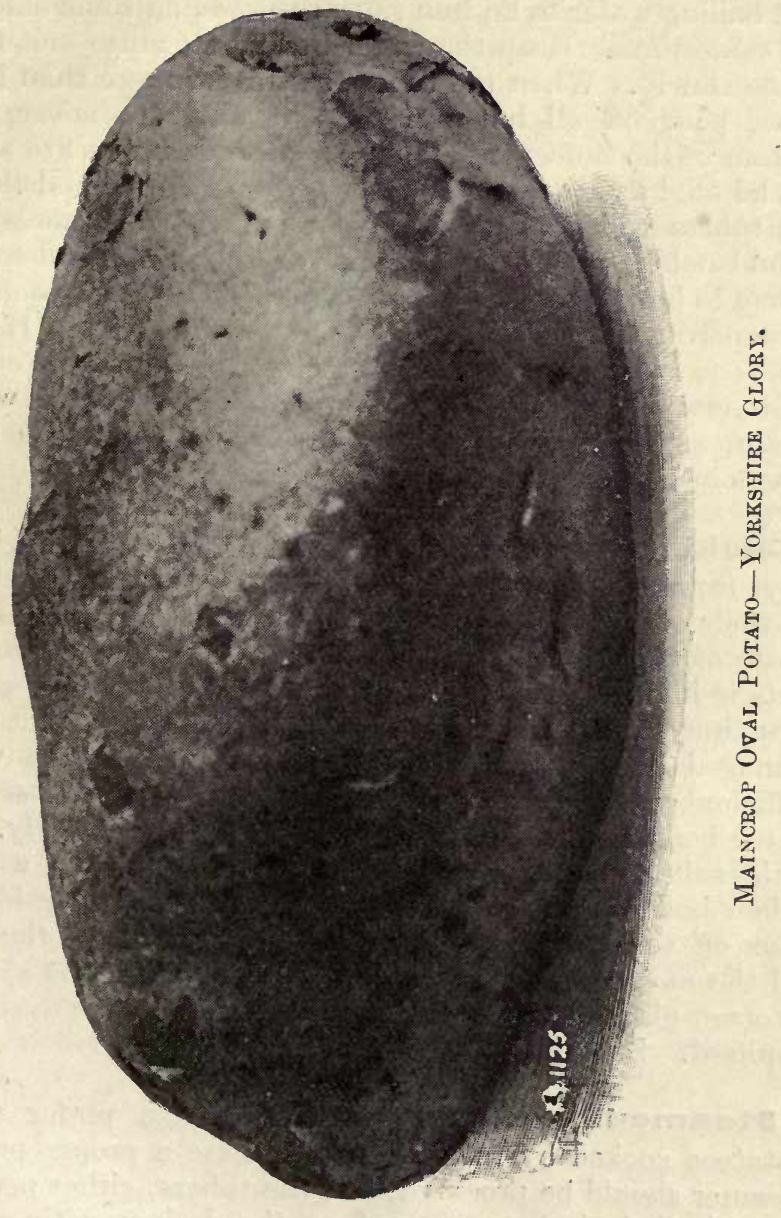


peel as thinly as possible, and to at once put the tubers into boiling water in an iron saucepan, adding some salt at the same time. Keep the water boiling steadily-not fast or too slowly. When the tubers are rather more than half done, pour off all but just enough water to cover the bottom of the saucepan, stand the latter near the fire with the lid slightly tilted to liberate the steam. Treated thus, the tubers will cook like balls of flour. The saucepan should not be placed near enough to the fire to cause the tubers to burn, but where there is a moderate heat to drive off superfluous moisture and leave the tubers dry. If the tubers cannot be eaten at once, cover them with a clean white cloth: this will prevent them becoming sodden with steam, and will preserve their flavour. Never place the tubers into the dish till ready to be served.

Cooking in their skins.-Unquestionably the best way, from a nutritive point of view, is to cook the tubers in their skins or "jackets." In this way there is no waste of food material, and, besides, the flavour of many sorts is infinitely better than when peeled. To cook potatoes thus, well wash them in cold water and cut out any damaged eyes or fractures. Put in the saucepan with sufficient water to not quite cover them. As soon as the water boils add a little more cold water occasionally. A little salt should be added with each supply of water. When boiled through-in about an hour, more or lesspour off the water, and hold the saucepan over the fire till the moisture is evaporated. If they cannot be served at once, place them in a thick white cloth in the oven till required. Serve with the skins on.

Steamed Potatoes.-Some persons prefer their potatoes cooked by steam. In this case a proper potato steamer should be procured, and the tubers, either peeled, or with their jackets on, put on the drainer with water beneath. When so cooked, the water should be poured off directly the tubers are cooked. 
Baked Potatoes are a delicious and nourishing vegetable when properly cooked. Select large tubers of such sorts as are known to be floury, wash their skins quite clean, and then place them in a moderately heated oven. Turn the tubers oceasionally. They will take from one and a-half to two hours to cook properly. Baked potatoes should be served in napkins. A capital way of baking potatoes is in a heap of smouldering ashes, the result of a bonfire of weeds and rubbish. Potatoes also bake splendidly in fresh lime during the process of slaking. We have often found otherwise bad cookers turn out well thus.

A French Method.-The eminent chef, Soyer, who, in his day, was considered the leading expert in culinary matters, says: "If boiled, the tubers may be put into boiling water, or into cold, and either boiled quickly or slowly, as the variety determines. Choose them all about the same size, with a smooth skin, and when they are boiled and begin to crack, throw off the water immediately, as it only damages the root. When dressed, let them stand near the fire, with a cloth over them, and serve them in the skins. Salt may be put in the water at the beginning. A watery potato will require quick boiling, and sometimes to be put into boiling water."

An Irish Method. - The same authority describes the Irish method of cooking the potato: " Put a gallon of water with two ounces of salt in a large iron pot, boil for about ten minutes till the skin is loose, then pour off the water, put a dry cloth over the tubers, and place the pot by the side of the fire for twenty minutes, then serve with their skins on. The boiling is of a gradual nature." 


\section{CHAPTER XX.}

\section{POTATOES AS POULTRY FOOD.}

A tтrough potatoes are, as generally used, not a good food for the feathered stock, as a supplementary vegetable diet they may be turned to good account by the intelligerit, poultry-keeper. The tuber, as everyone knows, is mainly composed of starch and water. Over fifty per cent. of its bulk consists of the latter, the remainder being starch, with just a trace of flesh-forming material, and no fat or oil. Starchy or carbonaceous foods, such as the potato, are mainly of use in maintaining the heat of the bodythey are the fuel necessary for the combustion that is ever going on in the processes of digestion and assimilation. Then there is that other group of foods termed nitrogenous, which exists in animal matter and albumen, and is present in the seeds and leaves of plants; but it is only to a very small extent contained in potatoes. This nitrogenous matter is mainly of use in the building up of muscle, bone, and tissue, and in repairing the waste that is ever going on in the body. The white of an egg is nearly pure albumen, or is nitrogenous in its composition. Now, a proper diet should consist of the right proportions of nitrogenous and carbonacenus foods, which has well been called a " nutritive ratio," and that proportion should be, under normal conditions, one part by weight of nitrogenous matter to four parts of carbonaceous. Much depends, of course, upon the condition of the birds, the weather or temperature, method of housing, extent of liberty allowed, and whether the birds are expected to produce eggs or to lay on fat and flesh. If a carbonaceous diet is fed to ex- 


\section{POTATOES «AS POULTRY FOOD.}

cess, that is, if we fed laying hens solely upon potatoes (perhaps adding some barley-meal or maize-meal), they would become inordinately fat, producing few, if any, eggs. The proportion of heat-producing material is too great. Then again, if the carbonaceous or fat-forming matter were to be stinted or not allowed in sufficient quantity, the heat of the body would be reduced, the reserves of internal fat drawn upon, and the albuminous food would, instead of going to produce eggs or flesh, be converted into the other channel to supply thə deficiency. Thus, without going further into the domain of chemistry, we may, with the knowledge before us of the general uses of the two broad classes of food constituents, discuss the practical application of the science of feeding, most particularly with regard to the potato.

How to Feed Potatoes. - The poultry-keeper must. always bear in mind that the potato is a fattening, heatproducing food, and it must be used as such in cornbination with flesh-forming materials. It is cheap, easy to prepare, and generally liked by all classes of poultry. The farmer whose laying hens are running at liberty in the winter tirce may use a larger proportion of potatoes in the morning meal than the poultry-keeper whose layers are enclosed in sheds or small runs, but the proportion of potato to the other ingredients of the mixture must always be regulated in accordance with the weather, no matter under what conditions the hens are kept. A cheap and good diet for layers that are at liberty may be composed of equal parts by weight of potatoes and bran. The former must be boiled, and the latter mashed into them while hot, the mixture being given warm. If the bran is good, it will supply the nitrogenous matter in which the tubers are deficient, and the diet will be a well-balanced one. If the weather is very cold, some linseed meal, or a littie animal fat, may be added.

Feeding Confined Birds.-In the case of layers that 
are more or less confined, the proportion of potato must be reduced, and the quantity made up with sharps or thirds. Pea or bean meal may also be added where the potato is in excess. When malt culms or malt sprouts can be obtained, the feeder need wish for nothing better to add to the potatoes. They are highly nitrogenous, and, what is equally important, have most valuable digestive properties. The quantity of bran in the mixture given above may be halved, and the weight made up with malt sprouts. Or we may take three pounds of the tubers and one of malt sprouts, mashing the latter into the former while boiling hot, and feeding when cool enough. Such foods as Indian meal, barley meal, and rice meal, which are deficient in nitrogenous matter, should, of course, not be used with potatoes; and when the tuber forms a large part of the morning meal the evening grain should be one that is deficient in starchy matter. Under such circumstances oats should be fed in preference to any other dry food.

For Fattening Poultry.-When it is required to fatten stock for table, potatoes are equally useful, and can be used to a larger extent than with layers. The usual mixture of ground oats and sour milk or buttermilk may be supplemented with well-mashed tubers to the proportion of one part of the vegetable to three of the other, in the case of chickens that are confined. Ducks, geese, and turkeys fatten well on a mixture of potato and middlings. Malt sprouts may be given also to aid digestibility and supply flesh-forming material, and in the case of such stock, wheat and oats may be fed as an evening meal. Chickens fattened at liberty, or in small runs, may also be supplied with the above mixture, but in cold weather some fat should be added to the meal, as well as to that of the larger stock. Many of our best home-fed Christmas poultry have been largely fattened with potatoes, and in Ireland the vegetable, used with buttermilk, is a favourite diet with turkey-feeders and chicken-raisers. In 


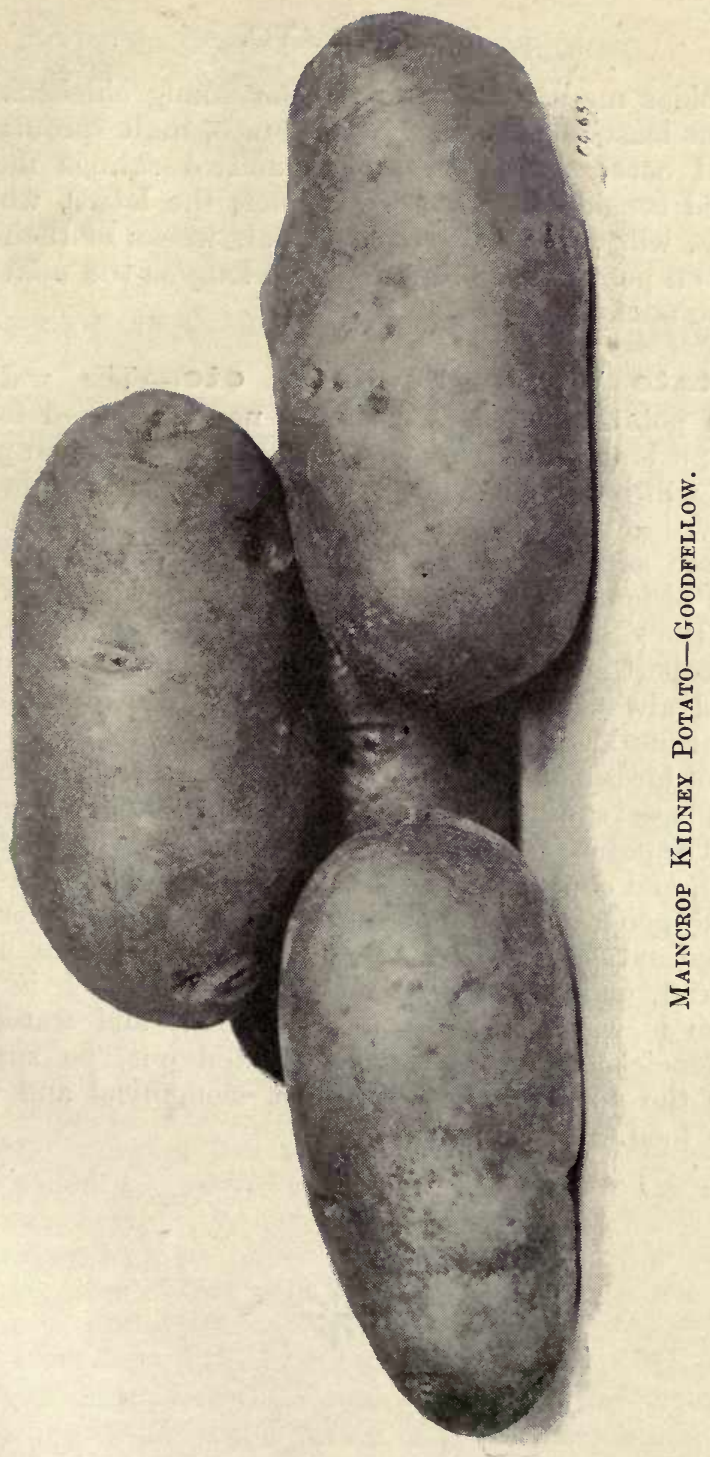


the colder months of the yea: the young chickens may have at least ons feed a day of potato, malt sprouts, and ground oats, mixed crumbly; and ducklings may be allowed considerably more. In fact, the latter, when at liberty, will do well for the first few weeks of their existence on potato and bran alone, so long as the mixture is not too sticky.

Potato Water, Peelings, etc.-The water in which potatoes are boiled should never be used for live stock; it is distinctly injurious to health, and when poured off, it will be found that the potatoes contain ample moisture within themselves for the proper mixing of the meals that are added to them. Householders who have small flocks of hens should never boil the potato peelings along with the other house scraps, but separately; and when the proportion of the former is large, bran or malt sprouts should always be used. In summer time fowls in confined runs are better without potatoes, excepting in the case of birds put up for fattening, and even then the proportion used should be less than that advised for winter feeding. The potato as a food for poultry is as little understood as maize, and consequently its value has seldom been realised by the general run of poultry-keepers. The latter must understand that it is deficient in flesh and bone-making material, and contains no fat or oil, but is rich in starch (which is warmth-giving and fattening) and water. Its deficiencies can, as we have pointed out, be supplied, when the potato becomes a most economical and wholesome food.

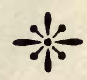




\section{CHAPTER XXI.}

\section{POTATOES FOR STOCK FEEDING.}

The value of potatoes as stock food is not generally understood any more than is the proper way to serve them. It is not going too far to say that they are useful for all farm animals, lest it be for sheep, and we are not sure but that, prudently served, they might be very wholesome for ewes in the lambing yard. Seeing the interest now evinced in the cultivation of the tubers, it will be both instructive and profitable to point out their value for different stock, and how to serve them.

For Horse Feeding.--Potatoes exceed in value all other roots, even the esteemed carrot, for horses doing heavy and not too fast work. Take team horses, for instance, or even dray or van horses. Cook the tubers and serve them judiciously, so that there is not too much relaxation of the bowels as a result, and you may withhold a portion of the corn. Walker Watson, M.R.C.V.S., in revising Youatt's book, "The Horse," observes: "Potatoes have been given, and with advantage, in their raw state, sliced with the chaff, but where it has been convenient to boil or steam them, the benefit has been far more evident. Purging has then rarely ensued. Some have given boiled potatoes alone, and horses, instead of rejecting them, have soon preferred them even to the oat; but it is better to mix them with the usual manger feed, in the proportion of one pound of potatoes to two and a-half pounds of the other ingredients. The use of the potato must depend on its cheapness, and the facility for boiling it. Half-a-dozen horses would soon repay the expense of a steaming boiler in the saving of provender, without tak- 
ing into the account their improved condition and capability for work. Professor Lamb says that $15 \mathrm{lbs}$. of potatoes yield as much nourishment as four pounds and a-half of oats. Von Thayer asserts that three bushels are equal to $112 \mathrm{lb}$. of hay; and Curwen, who tried potatoes extensively in the feeding or horses, says that an acre goes as far as four acres of hay. A horse fed on potatoes should have his quantity of water materially curtailed." But the tubers nowadays are far cheaper than when these eminent authorities wrote, and the steaming apparatus is cheaper too. Personally, we consider cooking almost essential, for reasons we will show by and by.

For Cattle Feeding.-We find in South Lancashire, in the great potato-growing districts, that potatoes are used a good deal for dairy cows, particularly by farmers who serve milk to the important towns there studded so thickly about-at least that is so in plentiful seasons. And food that is good enough for such stock undoubtedly contains value for other bovines. Again, in the fen districts and in Devon and Cornwall, we find that the crops are in certain seasons largely used for milling cows, say when the average price on the farm does not run to above $£ 2$ per ton for the heavier yields and coarser sorts.

How to Serve to Horses and Cattle.-The tubers should be cleaned and steamed or boiled, and served whole while warm with chaff to cows. A peck, or, say, three gallons is a fair daily allowance for an average dairy cow, but more is often served if the supply be not limited. Lots of farmers feed the tubers raw, probably more than cooked, but in such cases the starch therein is less digestible; and this starsh is not only the principal constituent of the tuber, even to the tune of 60 per cent., but it is the most nutritious. So you may serve raw, and the potato will be no more useful than turnips; but when steamed or boiled it is more than doubly as nutritious as any other root. 
For Calf Feeding.-A few potatoes nicely cooked and served in sweet hay chaff make excellent first solid food for calves, i.e., for the youngsters after they are, say, six weeks or two months old. The line to draw as regards quantity is to stop at any signs of over-looseness in the bowels. Potatoes are hardly good enough for fattening cattle, which need something more concentrated and rich. In fact, swedes answer better for oxen in stalls, as they form a better accompaniment to rich cakes and meals. But, as regards calves, why, by using potatoes judiciously a good deal of milk may be saved, and all cakes. Crushed oats really go best with the tubers; and by serving the two, not only may the young herds be brought nicely on, but that at a reasonable cost.

For Pig Feeding.-Here probably potatoes are more profitably fed than to any other stock. Yet, thrown about carelessly in the yard, raw and uncleaned, the animals appexr little the better for them. Still, we have nearly fattened porkers on the tubers, nicely cooked, and a milky wash, and soon finished them off with the addition of a little barley meal. Milk and potatoes go well together. The former is astringent if served fresh, and the latter sightly laxative; so they work together for good. Probably pork fattened on milk, potatoes, and barley meal is of the highest quality made. There is no other root that can be used for porking purposes, save potatoes, although carrots, swedes, and mangold wurzel have been tried over and over again, both uncooked and cooked. For sows with farrows, for farrows as soon as they take solid food or thereabouts, or for strong stores the tubers are most wholesome, and are cheap enough in plentiful seasons.

Potato Liquor.--Singularly enough, the liquor potatoes are cooked in is not wholesome for any animals. It not only upsets the bowels, but sometimes appears to act in a pronouncedly poisonous manner. Again, if they are not well washed before being boiled, the liquor contains 
a quantity of grit, that has ere now caused purging to the horse as well as to other animals. There are men worth listening to who have declared that it is the diseased roots, or such as have been exposed to sun and turned green, that cause the liquor to be so unwholesome; it may be so; at all events it is not wholesome, and it is folly indeed to try serving it-all the more so because there is very little nutriment in vegetable broth at the best. We believe it has been conclusively proved that potatoes grěened by exposure above the ground are in a degree poisonous to man. Why, then, should not they be bad for the lower animals? They, however, make the best seed, and hence need not be wasted.

Potato Parings.-Even potato parings are wholesome and useful pig food. This, peasants' wives show us. The farm labourer buys his small pig a little after it is weaned, and his wife rears it on potato peelings, waste potatoes, and other vegetables with broths, all cooked up together. A little meal is, of course, thrown in, but half a sack has to go a long way. And so, the youngster grows and waxes strong, and eventually is fattened up with meal into a substantial baconer. Without potato waste the cost would be considerably greater, and the carcass probably not so heavy, nor of so good a quality. Then, how cheap potatoes on the farm are sometimes. We have known any amount offered at $35 \mathrm{~s}$. per ton. Then is the time to get cheap pig food, and feed for other stock, too, for that matter.

Steaming v. Boiling Potatoes,-Although we have once or twice touched on cooking the tubers, a few more words on the subject will not be out of place. The better plan of cooking is to steam. The majority of potatoes brought to our own tables are spoiled for want of cooking properly-in short, for want of steaming or baking. The latter plan is not practical for farm stock, but steaming is. In steaming, the tubers are saved from being 
overcharged with water, of which they already contain too much-over 70 per cent., as we have shown. In the steamed article a maximum percentage of nutriment is served with a minimum of water. Not that the vegetable cannot be cooked in a nice mealy state by boiling; but, we repeat, it very often is not, and, seeing that such is the case with the dish brought to our own tables, it is not likely that Giles, with his hundred and one jobs to do, is likely hardly ever to boil the tubers well. In steaming there is practically no trouble, very little attention being needed, because the vegetable does not come into immediate contact with the water. Thirdly, cooked potatoes should be served promptly, and made to warm up a lot of other feed, which is all the better not taken into the stomach in a chilly state on a cold winter's day. In fact, by this warming up of other foods the value of the cooked potato is considerably enhanced as stock food.

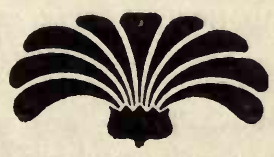




\section{CHAPTER XXII.}

\section{POTATO IMPLEMENTS, ETC.}

Besides the ordinary farm implements used in preparing and cultivating the soil, there are many of special construction employed in connection with the potato crop. In fact, considering how backward we are in inventing and adopting agricultural implements in general, potatogrowers are very well provided with labour-saving machinery. The latest efforts of inventors have been towards the production of a machine capable of raising, sorting, and packing the potatoes in consecutive movements; but, so far, these attempts have not resulted in practical success, though some of the implements produced are extremely ingenious. The chicf obstacle to success is that no machine can separate potatoes and stones or hard clods, which are graded and packed with the tubers. Should this objection ever be overcome, such an implement would be of the greatest use where large areas of potatoes are grown; and it might well go on circuit, as threshing and reaping machines do now, raising crops at a piece-work rate of payment.

Potato Diggers.-There are numbers of excellent potato diggers on the market, which raise the crop without grading or bagging it. Many of these do the work very well indeed, and, of course, far more quickly than can be done by hand digging. The tubers are more liable to be buried; but this may be disregarded on account of the saving in labour and expense. The fault is, however, constantly receiving the attention of implement makers, and improvements are frequently effected; so special attention 
should be given to this point when choosing a machine. An implement that has been very successful when exhibited in operation at agricultural shows is the Caledonian potato raiser made by Messrs. A. Jack and Sons, Maybole, N.B. This is simple and strong in construction, and is of light draught, two horses drawing it easily on any soil. A curved share at the rear of the machine passes underneath and loosens the roots, which are immediately caught up by revolving forked tines. The potatoes are deposited on the surface of the ground without being spread much, so that they are handy for gathering. The land is left almost level, and it is not easy for any tubers to get buried. The share can be lowered to any required depth, or raised so as to clear the ground. A somewhat similar machine is the patent rotary digger made by Messrs. Ransomes, Sims, and Jefferies, Orwell Works, Ipswich. This can be fitted with feathering or self-clearing tines. These are well hooked to pass under and raise the roots, and on coming out of the soil gradually turn down and backwards, so that the potatoes are delivered on the surface of the soil, and the tines freed from haulm. A machine of different construction from the foregoing is the potato digger, made by Messrs. A. Newlands and Son, Linlithgow, N.B. This differs from the others in not having a rotary action. The potatoes are raised by a flat share, and pass over some steel tines on to the surface of the ground, without being scattered widely. It is claimed for this machine that the tubers are not bruised or rubbed, and that therefore it is very suitable for raising early crops of green potatoes.

Potato Ploughs. -. Where the acreage grown is not sufficient to warrant the purchase of one of the potato diggers described above, an ordinary potato plough is often employed. The best known of these is that made by Messrs. J. and F. Howard, Britannia Works, Bedford. In appearance it is much like an ordinary plough, except that two sets of steel tines are substituted for the breast, 
the potatoes being raised by a share which passes under the roots, and lifted to the surface over these tines, which partly free them from earth. Such ploughs work very well, except that they bury a good many tubers, and are rather seriously impeded where the haulm is abundant and green, as in early crops. However, with a pair of horses three or four acres of potatoes can be raised in a day, and a boy walking beside the plough with a hooked stick can do much to keep the tines free from haulm. One advantage of the plough mentioned is that breasts and shares can be substituted for the tines, when the implement is changed into a serviceable ridging plough.

A Potato Planter. - The Jervis potato planter, made by Messrs. Battla, Maltby, and Bower, Victoria Chemical Works, Lincoln, is a simple and useful contrivance, and has the merit of being quite inexpensive. By its means the tedious, stooping job of potato-planting is brought breast hign; and when proficiency has been gained in its use, it is said that cne man can plant at least two acres in a day, dropping the tubers with great exactness. The implement consists of three metal tubes, which are brought together at the tops, but spread out fan-wise towards the bottoms, which can be set at various distances according to the space required between the seed tubers. This contrivance is carried along the furrow, and the seed dropped down the tubes by a sweeping motion of the hand, and thus deposited at equal distances in the row. When the operator has dropped thr se he takes a step forward, the exact distance being shown by a measure at the bottom of the tubes.

Saddle Harrows.- For cultivating the potato ridges before the crop is above the ground it would be difficult to equal the work done by the saddle harrows made by Messrs. A. Jack and Sons, Maybole, N.B. These fit over two of the ridges at one time, and are easily drawn by one horse. Both the tops and the sides are thus cultivated, 
and weeds are kept down, or prevented from making an appearance. The benefit to the crsp from the stirring of the soil is considerable.

Potato Sorters.-The work of grading large bulks of potatoes, as when a clamp is opened, is very heavy if done in hand riddles, and to avoid this many clever contrivances have been placed on the market. Probably the most elaborate and perfect of these is the Wilson-Dobbie potatodressing machine, made by Mr. David Wilson, Riccarton, Linlithgow, N.B. In this the potatoes pass down a revolving sieve of hexagonal shape, which separates the tubers into three sizes, as they pass along. The "seed" and "ware " drop on to a carrier, running at a sufficiently slow speed to allow time for picking out any diseased or damaged tubers before they pass into baskets or bags placed at one end of the machine. The motion is easily lrept up by hand, and the capacity of the sorter is such that a man is constantly kept at work feeding it. Most of the other sorters separate the tubers into three sizes into flat riddles, which are kept in motion either by pushing to and fro with the hand, or by means of a crank worked by turning a wheel. Mr. Henry Cooch, Commercial Street, Northampton, sells a machine which may be had to work by either of these methods. Messrs. Penney and Co., Lincoln, also make a very similar machine, in which the riddles are actuated by a crank.

Sorters for Small Crops.-Growers of small crops would not, of course, think of investing in a large potato sorter, but will find ordinary round hand-riddles of suitable meshes quite efficient. When these are used, the work is made much less arduous by the provision of a stand on which to work the riddles. An excellent one is sold by Messrs.. A. Jack and Sons, Maybole, N.B.; but anyone at all handy at carpentering can soon construct such a stand as is shown in the illustration. The construction of the apparatus can be clearly seen. The dimensions 
are three feet square and three feet high. Four stout posts, $3 \mathrm{ft}$. high, are cut out of $3 \mathrm{in}$. by $3 \mathrm{in}$. quartering, and are joined at top and bottom by pieces of $6 \mathrm{in}$. by 1in. floor board. Strips are nailed across three of the sides from corner to corner, to make the framework quite

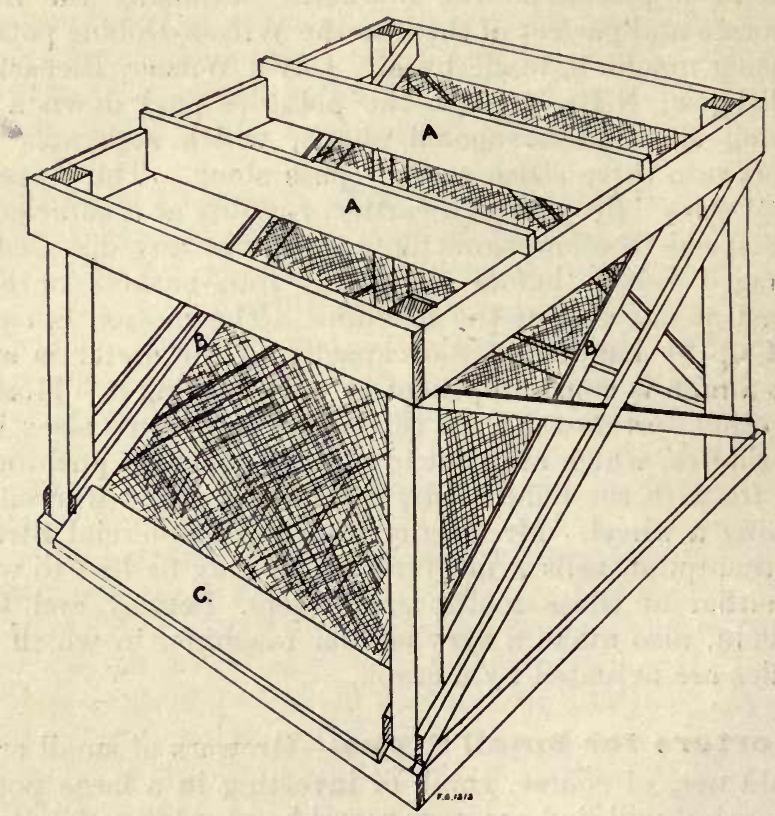

A Potato Dresser.

rigid. Now two pieces of hard wood, such as oak, are fitted across the top, as at A A. A framework, B, B, C, is next fitted in, sloping from the top of the back to the bottom of the front of the framework. To the lower side 
of this a piece of $\frac{1}{2} \mathrm{in}$. wire netting is nailed, and the dresser is complete. A riddle of $1 \frac{1}{4}$ in. or $1 \frac{1}{2} \mathrm{in}$. mesh is set across the two pieces $\mathrm{A} \mathrm{A}$, the potatoes are put into this, and the riddle is slid backwards and forwards till all small tubers have fallen through on to the wire netting sieve. Here the loose dirt falls through, and the chats roll down the sieve on to the ground in front of the dresser. This dresser is so simple that anyone can make it, and it also lias the advantage of being very cheap. It will be found especially useful where the chats and seconds are picked up together and clamped till winter.

Weighing Machines.-For weighing potatoes any machine that will support a sack or barrel is suitable. A simple and inexpensive one is the garden machine made by Messrs. H. Pooley and Son, 89, Fleet Street, London; and another almost identical with it is sold by Messrs. W. and T. Avery, Soho Foundry, Birmingham. Both of these firms make other machines which are still more suitable, though more expensive, having supports against which full sacks may rest whilst being weighed.

Potato Shovels.-The best shovel to use for potatoes when bagging or clamping is one specially made of thin steel or iron bars, which hold the potatoes, but allow any dirt to fall through. For shifting potatoes on a wooden floor a wooden shovel, such as is used for grain, will be found handy.

Potato Hoes.-For covering in the seed of small crops, or when a ridging plough is not available for this work, the large potato hoes used in Lincolnshire are very useful. These are about 16in. wide and $4 \frac{3}{4}$ in. deep, and have the handles fitted into straight necks about $2 \mathrm{in}$. long. If two men with these hoes work down opposite sides of a row, one immediately behind the other, the work of covering in the sets is rapidly and well done. 


\section{WORK PRICES.}

Cutting tubers for seed, per cwt., 2d. and $3 \mathrm{~d}$.

Planting in ploughed furrows by dibble, per acre, 6s. (Labour: Man dibbling, woman dropping seed and boy covering in, 1 acre per day.)

Hoeing, per acre, 3s. 6d. to 6s.

Earthing up, by hand, per acre, 6s.

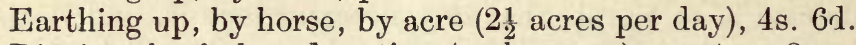

Digging, by fork and sorting (early crops), per ton, 8s.

Ditto (late crops), 6s. 8d.

Lifting by machine digger ( 4 acres per day, with 12 pickers), per day, 10 s.

Cecil H. Hooper.

\section{POTATO MEASURES.}

LoAD.-A northern measure weighing 18 stones, or 2 cwt. $28 \mathrm{lb}$, used in the Sheffield and Manchester markets.

Half Load.-Ditto, weighing 9 stones, or 1 cwt. $14 \mathrm{lb}$.

Рот.-A Worcestershire measure weighing 80 lb., used in the Birmingham market.

Stone.-Weight, $14 \mathrm{lb}$.

Hundredweight.-Clean, 112 lb.; uncleaned, $120 \mathrm{lb}$.

Ton. -20 cwt. ; 2,240 lb. ; 49 bushels.

Barrel.-Weight $200 \mathrm{lb}$.

SACK (London). - $168 \mathrm{lb}$.

Strike (Nottingham measure). $-84 \mathrm{lb}$.

BAG. $-112 \mathrm{lb}$.

\section{YIELD PER ACRE.}

The average yield per statute acre is 6 to 12 tons. Some varieties, like Evergood, have yielded over 18 tons; Northern Stars, 13 to 20 tons ; Recorder, 12 to 13 tons ; Up-toDate, 22 tons, and Dalmeny Beauty, 24 tons, per acre.

\section{MISCELLANEOUS DATA.}

A peck of potatoes weighs $20 \mathrm{lb}$.

Potato seeds take 16 to 24 days to germinate.

Number of seeds in a potato berry, 200 to 300 .

Early potatoes take 10 to 12 weeks from date of planting to arrive at maturity; late crops 18 to 24 weeks. 
Heaviest yield from $1 \mathrm{lb}$. of Eldorado potatoes was 43 cwt.

In 1875 it is recorded that a Kentish gardener reared $647 \mathrm{lb}$. of tubers from $1 \mathrm{lb}$. of cut tubers of the variety Eureka.

Potatoes may be propagated by grafting a portion of a tuber of one variety on to that of another. All the eyes must be removed from the tuber which is to be used as the stock. Out of this tuber cut a wedge-shaped slice, then cut a piece of exactly the same size, furnished with one good shoot an inch or so long, and fit this into the wedge-like cleft. See that the rinds fit exactly, and then bind firmly with bass matting and plant in the soil at once. If a coloured tuber be grafted on a white one, the yield will include both coloured and white, as well as mottled tubers. The old variety Yorkshire Hєro was said to be reared in this way.

A tomato shoot may be grafted on the shoot of a potato, and vice versâ. In the latter case tubers will be borne in the axils of the leaves in the air, and not in the soil as usual.

SOIL CULTIVATION.

\begin{tabular}{|c|c|c|c|c|c|c|c|c|c|}
\hline & & \multicolumn{2}{|l|}{ How Cultivat $d$. } & $\begin{array}{l}\text { Cost } \\
\text { p. r } \\
\text { rod } \\
\end{array}$ & \multicolumn{3}{|c|}{$\begin{array}{l}\text { Oost per } \\
\text { acre. }\end{array}$} & \multicolumn{2}{|c|}{ Time Required. } \\
\hline Light & & Dug 1 spit deep & & $\begin{array}{ll}\text { s. } & d . \\
0 & 2\end{array}$ & & 6 & & 14 days $p$ & er acre \\
\hline Uitto &.. & Trenching 2 spits de & & 010 & & & & 28 days & , \\
\hline Ditto & $\ldots$ & Bastard Trenching & $\ldots$ & 06 & & & & I days & ,", \\
\hline Ditto & .. & Ploughing $\quad \ldots$ & $\ldots$ & & 01 & 2 & 0 & 1 day & ," \\
\hline Heavy & & Dug 1 spit deep & .. & 3 & & 0 & & 8 days & ," \\
\hline Ditto & ... & Trenching 2 spits de & & 0 & & 0 & & 30 days & $"$ \\
\hline Ditto & .. & Bastard 'I'renching & $\ldots$ & 0 & & & & 4 days & ," \\
\hline Ditto & $\ldots$ & Ploughing $\quad \ldots$ & .. & & 01 & & & $\frac{1}{4}$ days & \\
\hline Ordinary & & steam Ploughing & & & 01 & & & a:res pe & $r$ day \\
\hline Ditto & & Steam Cultivating & .. & & 01 & & & to $10 \mathrm{ac}$ & \\
\hline Ditto & . & Steam Digging & $\ldots$ & & 01 & & & 0 acres $p$ & er day \\
\hline Ditto & & Harrowing $\ldots$ & ... & & 0 & 1 & & Jitto & \\
\hline Ditto & & Cultivating ... & ... & & $\mathbf{0}$ & 3 & & to $5 \mathrm{ac}$ & es per day \\
\hline Ditto & & Rolling $\quad \ldots$ & .. & & 0 & & & to $10 \mathrm{acr}$ & es per day \\
\hline
\end{tabular}




\section{WEIGH'T OF POTATO CROPS.}

TO ASCertaIn, BY WeIghINg TWENTY, THE WEIGII PER ACRE OF POTATOES :-

\begin{tabular}{|c|c|c|c|c|c|}
\hline $\begin{array}{l}\text { Inches } \\
\text { hetween } \\
\text { Plants. }\end{array}$ & $\begin{array}{l}\text { Number of } \\
\text { Plants } \\
\text { per acre. }\end{array}$ & $\begin{array}{c}1,400 \text { lbs: } \\
\text { per } \\
\text { acre. }\end{array}$ & $\begin{array}{c}2,800 \mathrm{lbs} . \\
\text { per } \\
\text { aere. }\end{array}$ & $\begin{array}{c}4,200 \text { lbs. } \\
\text { per } \\
\text { acre. }\end{array}$ & $\begin{array}{c}5,600 \text { lbs. } \\
\text { per } \\
\text { aore. }\end{array}$ \\
\hline 6 & 174,240 & $\begin{array}{l}\text { lbs. } \\
0 \cdot 16 \text { ) }\end{array}$ & $\begin{array}{l}\text { lbs. } \\
0 \cdot 320\end{array}$ & $\begin{array}{l}\text { lbs. } \\
0 * 4 \div 2\end{array}$ & $\begin{array}{l}\text { lbs. } \\
0.642\end{array}$ \\
\hline 7 & 123,013 & 0.218 & 0.437 & $0 \cdot 65 j$ & 0.574 \\
\hline 8 & 98,010 & 0.255 & 0.571 & $0 \cdot 8 \tilde{6} 6$ & $1 \cdot 142$ \\
\hline 9 & 77,440 & $0 \cdot 361$ & 3.723 & $1 \cdot 048$ & $1 \cdot 446$ \\
\hline 10 & 62,726 & 0.419 & $0 \cdot 892$ & 1.389 & $1 \cdot 785$ \\
\hline 11 & 51,840 & 0.540 & $1 \cdot 080$ & $1 \cdot 620$ & $2 \cdot 160$ \\
\hline 12 & 43,560 & 0.612 & $1 \cdot 285$ & $1 \cdot 9 \cdot 27$ & $2 \cdot 571$ \\
\hline 13 & 36,116 & $0 \cdot 754$ & 1.503 & $2 \cdot 262$ & 3.017 \\
\hline 14 & 32,003 & $0.87 t$ & $1 \cdot 749$ & 2624 & $3 \cdot 449$ \\
\hline 15 & 27,878 & $1 \cdot 005$ & $2 \cdot 010$ & $3 \cdot 015$ & $4 \cdot 021$ \\
\hline 16 & 24,502 & $1 \cdot 142$ & 2285 & $3 \cdot 427$ & $4 \cdot 571$ \\
\hline 17 & 21,704 & $1 \cdot 290$ & $2 \cdot 580$ & 3.870 & $5^{4} 160$ \\
\hline 18 & 19,360 & $1 \cdot 445$ & $2 \cdot 891$ & $4 \cdot 386$ & $5 \cdot 782$ \\
\hline 19 & 17,375 & $1 \cdot 611$ & $3 \cdot 223$ & $4 \cdot 83 t$ & 6446 \\
\hline 20 & 12,581 & $1 \cdot 785$ & $3 \cdot 571$ & $5 \cdot 356$ & $7 \cdot 142$ \\
\hline
\end{tabular}

ExAMPLE. - If the produce of 20 Potato stools, or of 20 Turnips, growing 12 inches apart from each other, weigh 0.642 of a $1 \mathrm{lb}$., then the produce per acre is $1,400 \mathrm{lbs}$; if $1 \cdot 285$, theil $2,800 \mathrm{lbs}$ per acre; and so on. The second column shows the number of plants per acre; at 12 inches distant each way, the number is 43,560

DRAINAGE,

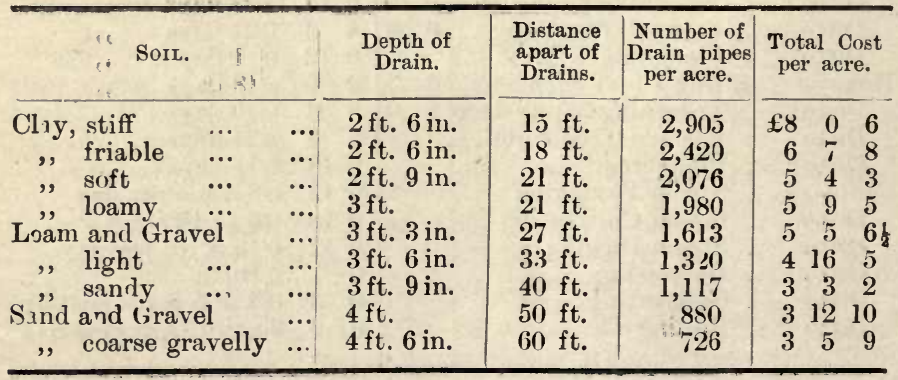


ANALYSIS OF POTATOES (ASH).

$\begin{array}{llllllll}\text { Carbonic acid } & \ldots & \ldots & \ldots & \ldots & \ldots & \ldots & 13.4\end{array}$

$\begin{array}{llllllll}\text { Sulphuric acid } & \ldots & \ldots & \ldots & \ldots & \ldots & \ldots & 7.1\end{array}$

$\begin{array}{llllllll}\text { Phosphoric acid } & \ldots & \ldots & \ldots & \ldots & \ldots & \ldots & 11.3\end{array}$

$\begin{array}{lllllllll}\text { Chlorine } & \ldots & \ldots & \ldots & \ldots & \ldots & \ldots & \ldots & 2.7\end{array}$

$\begin{array}{lllllllll}\text { Magnesia } & \ldots & \ldots & \ldots & \ldots & \ldots & \ldots & \ldots & 5.4\end{array}$

$\begin{array}{llllllllll}\text { Lime } & \ldots & \ldots & \ldots & \ldots & \ldots & \ldots & \ldots & \ldots & 1.8\end{array}$

$\begin{array}{llllllllll}\text { Potash } & \ldots & \ldots & \ldots & \ldots & \ldots & \ldots & \ldots & \ldots & 51.5\end{array}$

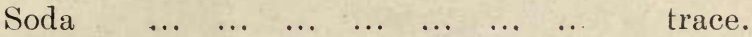

$\begin{array}{llllllllll}\text { Silica } & \ldots & \ldots & \ldots & \ldots & \ldots & \ldots & \ldots & \ldots & 5.6\end{array}$

Oxide of iron and aluminia $\ldots \begin{array}{lllll}\ldots & \ldots & \ldots & \ldots & .5\end{array}$

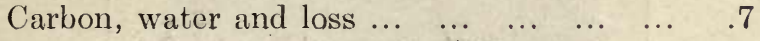

100.0

\section{CHAPTER XXIII.}

\section{POTATO MONSTROSITIES.}

Tiu tubers of the potato vary a great deal in their shape, no two being exactly alike. This tendency to variation in the case of the potato occasionally lends itself to the production of odd shapes, and to the exhibition of great powers of mimicry. 'Thus, as in the few examples of tubers illustrated, one tuber mimics a dog, another a cottage loaf of bread, and another an ape or depraved human being. In the course of our long practical and editorial experience, we have seen a wonderful diversity of forms which potato tubers have assumed, and had we only photographed them all, they would have made a most interesting colleetion. 
The Cottage Loaf Tuber.-This illustration shows a perfect counterfeit presentment of a cottage loaf. Either the larger or lower portion supertuberated, and thus produced a second smaller tuber on its upper

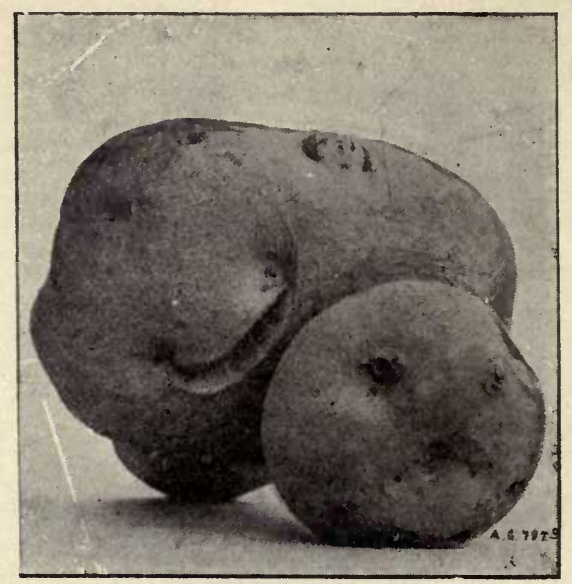

The Cottage Loaf Tuber.

surface; or the two tubers must have been brought into such close contact with each other in an earlier period of their growth as to unite by fission.

The Doggie Tuber.-Here we have a fairly good representation of a small dog. It has at least two legs, a truncated tail, and a head replete with ears and eyes. It is the best example of a doggie tuber we have seen. This monstrosity doubtless owes its origin to some check to growth, which prevented the tuber making its normal growth; or to wet weather following a dry period, thus causing supertuberating to supervene. It is a very interesting example of mimicry. 


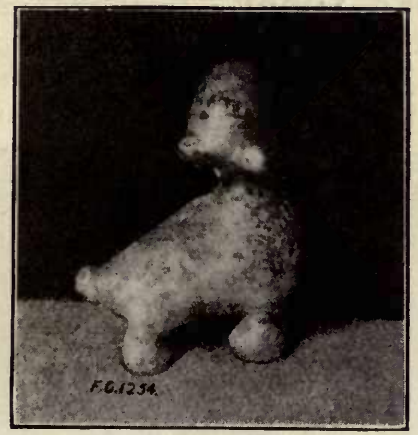

The Doggie Tuber.

A Marine Animal Mimic.-This, again, is a very peculiar form of tuber. It appears to be furnished with fins like those of a seal, to have a kind of rostrum or beak, and a pair of feelers or horns on its head. It is suggestive of some denizen of the ocean. Really, it is an in.

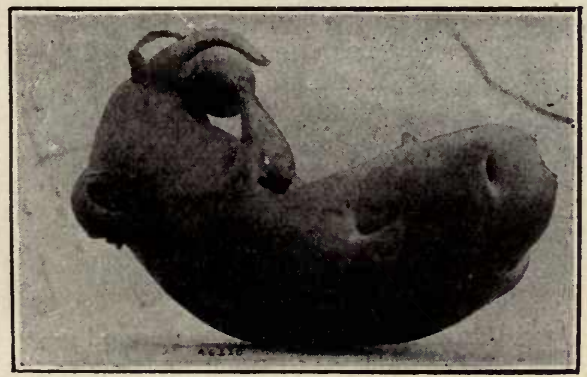

MaRine Animal Mimic.

stance of a tuber anxious to strike out a new line for itself by forming a modified form of stem, furnished with leaf scales - the projecting parts-and buds in their axils. Had this tuber remained in the soil it would, no doubt, have borne tubers like an ordinary potato stem. 
The Ape-like Tuber.-In this example we have a monstrous likeness of an ape or depraved human creature. It is true the head has been slightly and ingeniously manipulated by the original discoverer of the tubev, a facetious

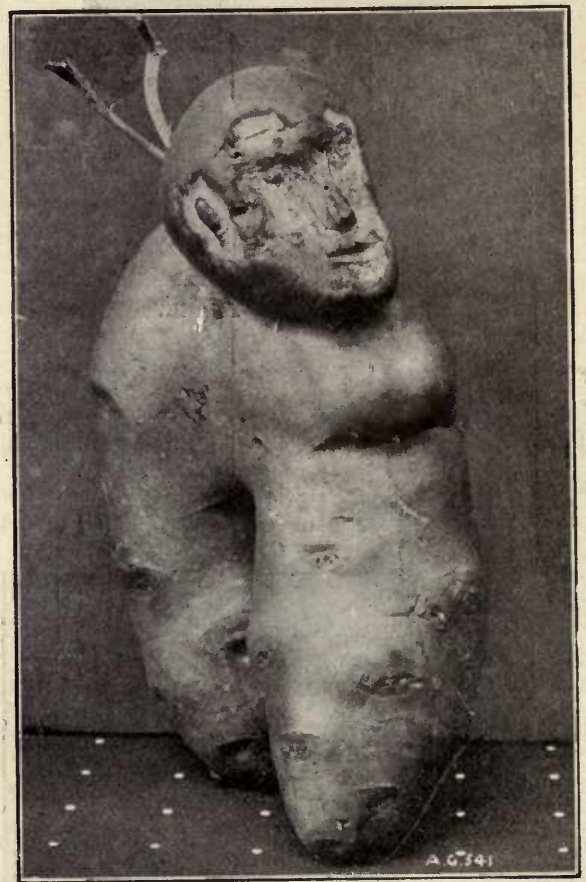

"The Monarch of the Modld."

(Grown by S. Johnson, Oroca Vale, Ireland. Photo by J. H. Rnssgll.)]

Irishman, who favoured us with the photograph. Apart from this, there are the two legs, a short body, minus arms, and a good imitation of a head. It will be observerd that the back of the head is furnished with a dual kind of pigtail, in the shape of the roots which originally connected the tuber with the plant. The sender of the photo 
assured us that there were distinct traces of the ears, eyes, nose and mouth, before he artificially intensified these organs by the use of the knife.

Tuber-in-Tuber.-Tubers are occasionally met with where one is growing inside the other. The larger tuber is the original "set," which was planted in the ground,

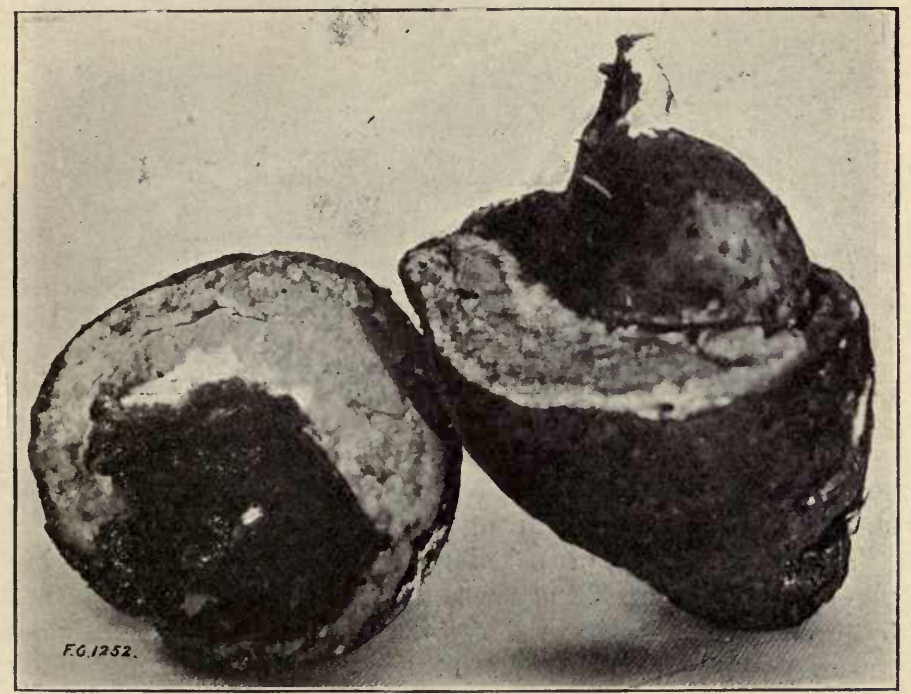

Tuber-in-Tuber Freak.

and by some means an underground stem penetrated it and in due course gave birth to a young tuber, which developed within its parent. 9

Tuber Perforated by Twitch.-This is a very interesting example of the power of roots to force their way through objects which resist their onward progress. Kerner, in his " Natural History of Plants," affirms that 
the roots of the Twitsh or Couch grass wiil bore their way through the roots of trees, and especially so through the tubers of the potato. He further says that the roots will force their, way through dises of tinfoil. The roots of the Couch grass are furnished at their tips with hard

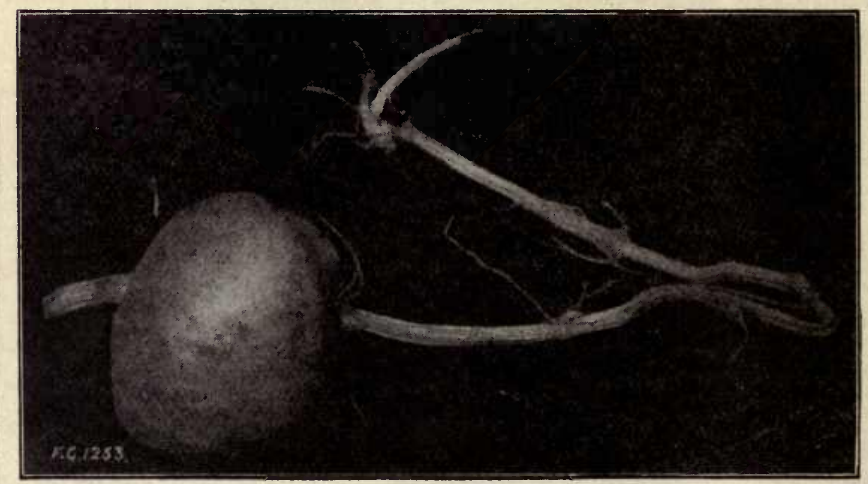

Tuber Pierced by Couch.

scales, hence their power of penetration. The illustration shows a tuber pierced through with a Couch root.

These examples of mimicry, etc., in the potato are given in this work to show that there is, apart from the food value and cultural details, much also of general interest connected with the "Monarch of the Mould."

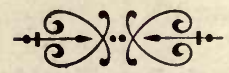




\section{CHAPTER XXIV.

\section{BEST VARIETIES TO, GROW.}

In the following pages we give classified selections of up-todate First-Early, Second-Early, and Maincrop varieties, subdivided into sections, according to the shape and colour of the tubers - as white and coloured kidneys, also white and coloured rounds. The varieties described have been chosen for their good cooking qualities, their productiveness, and their more or less immunity from disease attacks. The selection includes some of the latest as well as a few of the older and well-tried sorts, the aim being to give a limited number rather than a lengthy list, and thus avoid causing embarrassment to the beginner in making a choice of what kinds to grow. Further on, brief selections for light and heavy soils; floury (when cooked); yellow-fleshed varieties; remarkable for their size; also those suitable for exhibition purposes. For southern districts it is advisable to procure and plant north-grown seed tubers.

\section{FIRST EARLY VARIETIES.}

\section{A.-WHITE KIDNEYS.}

Asfileaf Kidney (Myatt's Early Prolific).-Tubers, medium. sized, long and tapering; skin, smooth, straw coloured; flesh, pale straw-yellow ; excellent cropper, very early; cooks well; haulm, dwarf; flowers, pale lavender, tipped white.

BEAUTY OF HEBRON.-Tubers, medium size, handsome in shape ; good cropper ; flesh, white ; cooks floury ; skin, pink tinted; an old variety

CARISBROOKE CASTLE (Sutton's).-Tubers, large, handsome shape; shallow eyes; very heavy cropper; cooking quality, first rate; white flesh; haulm, dwarf ; flowers, pale lilac. 
DOBBIE'S RESISTANT SNOWDROP.-Tubers of handsome shape; shallow eyes; white flesh; free cropper and wart disease resister; quality and flavour excellent; flowers, creamywhite.

DUKE OF YORK.-Tubers, oval-shaped; flesh, yellow ; excellent cooker; prolific cropper; good keeper and disease resister; flowers white.

DUNNOTAR CASTLE (Sutton's).-Tubers, large and handsome in shape; clean skin; flesh, white; heavy cropper; resists wart disease; cooks splendidly; flowers, lilac; haulm, dwarf.

FIRST CROP (Carter's).-Tubers, large and of handsome shape ; yellow flesh; cooks floury; an enormous cropper.

HARBINGER (Sutton's).-Tubers, large and of perfect shape ; shallow eyes; extraordinarily prolific cropper; flesh, white ; good cooker; ripens very early; flowers, white.

MAY QUEEN (Sutton's).-Tubers, large ; flesh, white; haulm, dwarf; an immense cropper; matures in May and early June; delicious flavour when cooked as lifted; good keeper; flowers, lilac.

MIDLOTHIAN EARLY.-Tubers, large, handsomely shaped; shallow eyes; tremendous cropper; yellow flesh; matures early; splendid cooker; strong grower; flowers, white.

NEW COLONIST (Webbs').-Tubers, large ; skin, smooth; shallow eyes; very heavy cropper; disease resister; flesh, white; cooks mealy; haulm, dwarf.

NINETYFOLD.-Tubers, very large and uniform in size ; exceedingly heavy cropper; flesh, white; splendid cooker; haulm, erect and very dwarf; flowers, white.

RINGLEADER.-Tubers, large ; flesh, white ; crops freely ; cooks splendidly; matures early; haulm, moderate; flowers, pale lilac.

ST. Malo.-Tubers, medium size; very prolific; flesh, white; good cooker; haulm, dwarf ; wart disease resister; largely grown in Channel Islands.

SHARPE'S EXPRESS.-Tubers, medium size; heavy cropper; flesh, white; good cooker; matures very early; haulm, dwarf; good sort for frame culture; flowers, heliotrope.

SHARPE'S 'VICTOR.-Tubers, flattened oval in shape; skin, clear; eyes, shallow ; most prolific cropper; yellow flesh; cooks beautifully; matures very early; suitable for frame culture ; flowers, lavender, tipped white.

SIR JOHN LLEWELYN.- Tubers, large and of handsome shape; flesh, white; shallow eyes; an excellent cooker; heavy cropper; resists disease; flowers, white.

WiTcH HILL.-Tubers, large, long, beautifully shaped; skin, smooth ; flesh, white; excellent cooker; very heavy cropper; eyes, shallow; discase resister; flowers, creamywhite. 


\section{B.-COLOURED KIDNEYS.}

DOBBIE's ExHIBITION RED KIDNEY.-Tubers, large and of splendid shape; skin, bright red; shallow eyes; flowers, heliotrope; an ideal exhibition kidney potato.

EARLY ROSE.-Tubers, medium size; skin, pink; flesh, white ; eyes, few ; cooks floury; moderate cropper; flowers, white. RED KIDNEY (Fidler's).- T Tubers, large ; skin, bright red; flesh, yellow; splendid cooker.

\section{C.-WHITE ROUNDS.}

Edzell BLUE.-Tubers numerous, medium in size, inclining

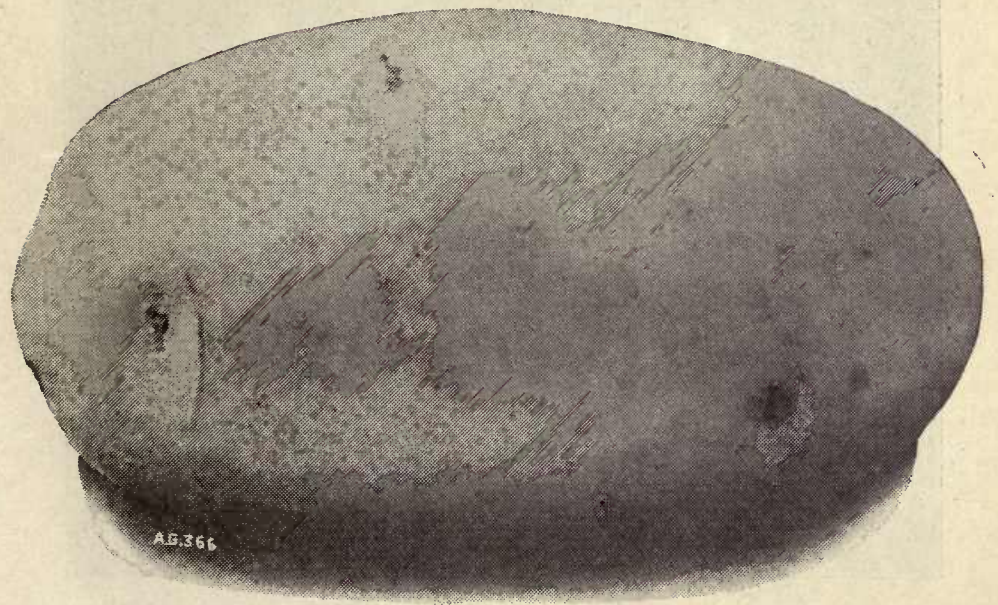

Potato, Webis' "New Colonist."

to round in shape. Though the skin is blue, the flesh is perfectly white, and of fine flavour when cooked. It is one of the few earlies which is immune to wart disease.

A.r. (Sutton's).-Tubers, large, and firm in texture; flesh, white ; very heavy cropper; haulm, dwarf and erect; cooks floury; wart disease resister; good for frame or outdoor culture.

EARLY REGENT (Sutton's).-Tubers, large; flesh, white; very productive; matures early; cooks floury; good sort for early use. 


\section{SECOND EARLY VARIETIES.}

\section{A.-WHITE ROUNDS.}

BALMORAL CASTlE (Sutton's).-Tubers, very large, round; skin, white; eyes, shallow; exceedingly heavy cropper; flesh, white; cooks well ; flowers, lilac.

BRITISH QUEEN.-Tubers, large, oval, or pebble shape; fleshwhite; splendid cooker; heavy cropper and disease resister; flowers, white.

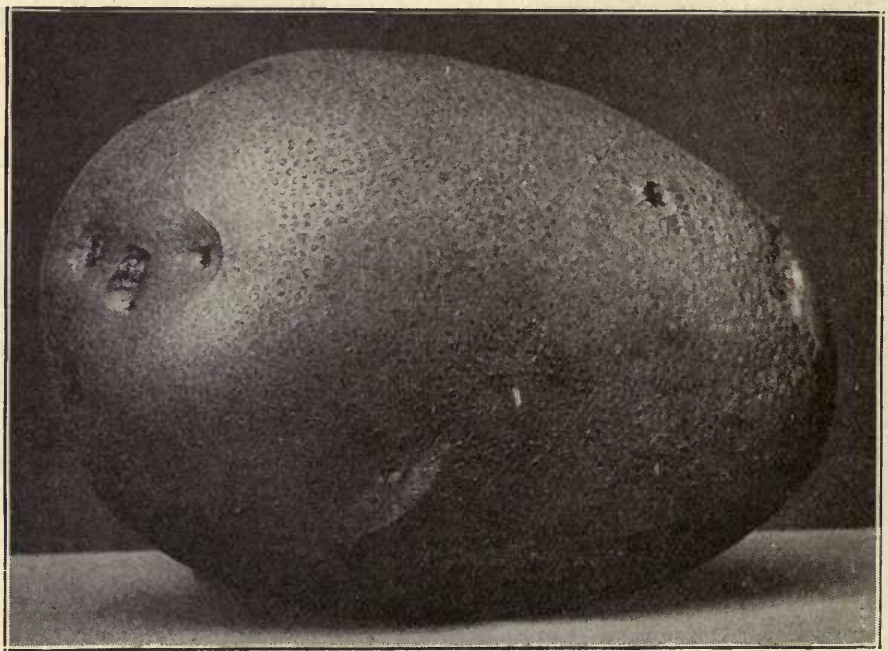

Maincrop Potato. - “The Chapman."

BURNHOUSE BEAUTY (Dobbie's).-Tubers, flattish-round, large ; flesh, white; very heavy cropper, yielding 20 to 24 tubers to each root; first-rate cooker and good keeper; haulm, vigorous; resists the wart disease; flowers, lavender and white.

CENTENARY (Sutton's).-Tubers, large and of handsome shape ; flesh, white; good cropper; excellent cooker; resists disease ; flowers, white.

COMMODORE (Fidler's).--Tubers, large ; skin, thin and russety ; shallow eyes; very heavy cropper; good cooker; haulm, vigorous. 
DOBBIE'S FAVOURITE.- Tubers, medium size and of good shape ; shallow eyes; cooks beautifully; heavy cropper and good keeper; resists wart disease; flowers, white.

Duchess OF NORFOLK (1)aniels').- Tubers, very large and of handsome contour; shallow eyes; flesh, white; cooks floury; Howers, lavender and white.

THE DuCHESs (Dobbie's).- Tubers, oval to round, large; a prolific cropper; splendid cooker; flesh, white; wart disease resister; haulm, medium ; flowers, white.

EARLY REGENT.-Tubers, oval-round, medium size; good cropper; flesh, white; cooks floury; good market variety.

EPICURE (Sutton's).-Tubers, oval, and of good form; prodigious cropper; flesh, white; cooks beautifully; haulm, robust ; flowers, white ; a popular North of England variety.

GREAT SCOT. - Tubers, large, round, and of good shape; very heavy cropper ; flesh, white; cooks floury; resists the wart disease ; growth, robust ; good exhibition or general variety.

SECuNDUS (Dobbie's).- - Tubers, oval in shape and handsome in appearance; heavy cropping variety; white flower.

THE ALLY.- Tubers, numerous, oval in shape; a good keeper ; resistant to wart disease.

StIRLING CASTLE (Sutton's).--Tubers, large, round ; eyes, shallow; enormous cropper; flesh, white; splendid cooker; thoroughly resists disease; flowers, pale lilac.

WARWICK CASTLE (Sutton's).- Tubers, large, round, and of handsome shape; skin, rough; immense cropper; flesh, white; cooks mealy; reliable disease resister; flowers, pale lilac.

WiNDSOR CASTLE ('Sutton's).--Tubers, very large, often weighing over a pound each; exceedingly heavy cropper; flesh, white; cooks floury; disease resister; flowers, lavender.

\section{B.-COLOURED ROUNDS.}

LORD TENNYSON.-Tubers, large. and of handsome shape; skin, purplish; flesh, white; good cooker; suitable for exhibition.

READING RUSSET (Sutton's).-Tubers, large, flattish-round; skin, red and russety; flesh, lemon-white; cooks floury; good keeper; flowers, white.

\section{C.-WHITE KIDNEYS.}

KING GEORGE V.-Tubers, large, and of handsome shape; free cropper; flesh, white; good cooker; resistant to wart disease ; flowers, white.

NEw GUARDiAN (Webbs'). - Tubers, large, handsome shape; splendid cropper; flesh, white; good cooker; keeps well. 
ROYAL KIDNEY.-Tubers, medium size; a heavy cropper; flesh, white; firm and dry; cooks beautifully; good keeper; disease resister; a good sort.

WhITE BEAUTY OF HEBRON.-Tubers, large, handsome in shape; flesh, white; cooks well; free cropper; flowers, white.

WORDSLEY PRIDE (Webbs').-Tubers, large; eyes, shallow and few ; very heavy cropper ; flesh, white, fine-grained, and of excellent quality; good cooker; resists disease.

\section{D.-COLOURED KIDNEYS.}

CRIMSON BEAUTY.-Tubers, large and of good shape; skin, bright red; free cropper; good cooker; excellent exhibition variety.

MR. BREESE.-Tubers, large and of handsome contour; skin, rose-coloured; crops freely; cooks well; suitable for exhibition ; flowers, creamy-white.

PINK BEAUTY (Webbs'). - Tubers, large and of handsome shape ; skin, pinkish; good exhibition variety; flowers, creamywhite.

PURPLE EYES.-Tubers, large and of good shape; skin, white, with purple eyes; flesh, white; cooks well ; flowers, white ; splendid exhibition variety.

\section{MAINCROP VARIETIES.}

\section{A.-WHITE ROUNDS.}

ABUNDANCE (Sutton's).-Tubers, flattish-round or pebbleshaped; an immense cropper; flesh, white; wart disease resister; cooking qualities excellent; flowers white.

AJAX (Jack's).- Tubers, flattish-round ; shallow eyes; a great cropper; strong grower and disease resister; white flower.

THE ADMIRAL (Dobbie's).- Tubers, very large, oval-shaped; very heavy cropper; flesh, white ; an excellent cooker; resists the wart disease; flowers, white.

ARRAN CHIEF.- Tubers, large and oval-shaped; a prolific cropper; splendid cooker and keeper; resists disease; strong grower; a profitable variety for allotment culture.

THE CROFTER (Dobbie's).--Tubers, large and oval-shaped; skin, netted; very heavy cropper; flesh, white; cooks floury; wart disease resister; flowers, white.

DALMENY. HERO. -Tubers, large, oblong-oval; skin, netted; eves, shallow ; very prolific cropper; disease resister ; flesh, white; excellent cooker; robust grower.

DOBBIE'S PROLIFIC. - Tubers, large, long-oval in shape; very heavy cropper; cooks and keeps well; robust grower. 
DOMinion (Poad's).-Tubers, handsome, nearly round; excellent cooking quality; immune to wart disease; white flower.

THE FACTOR (Dobbie's).- Tubers, exceedingly large and ovalshaped; skin, netted; an enormous cropper ; cooks floury; good keeper; disease resister; flowers, mauve.

GoLDFINDER (Webbs').-Tubers, large, flattened, and uniform in size; heavy cropper; flesh, white and fine-grained; cooks floury; disease resister; robust grower; flowers, white.

GORDON CASTLE (Sutton's).- Tubers, large and oval in shape; skin, russety; eyes, shallow; flesh, white; cooks floury; heavy cropper; disease resister; flowers, pale lilac.

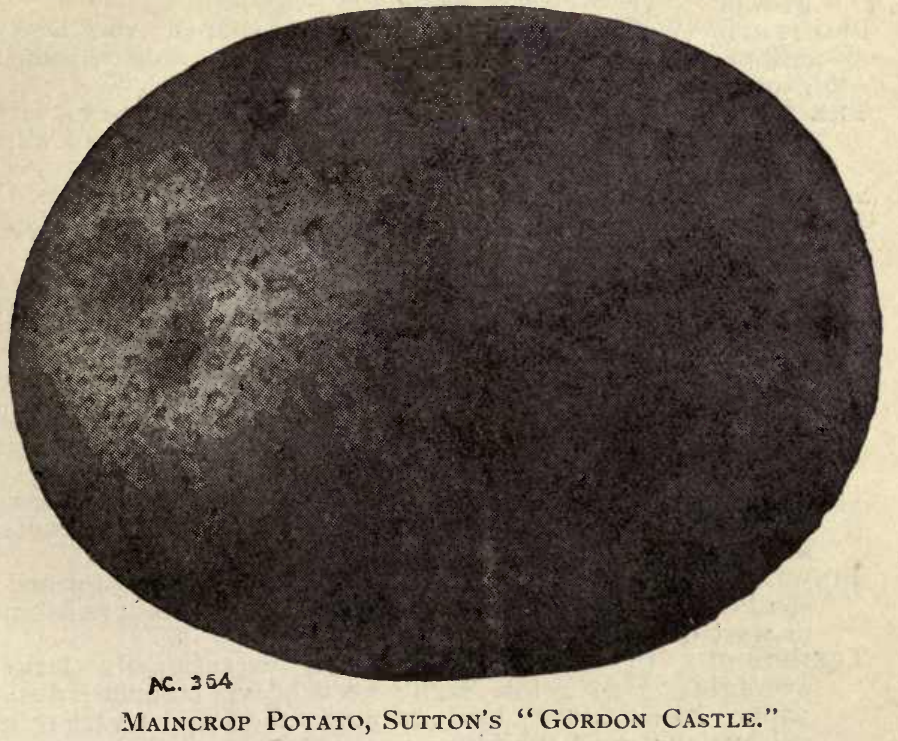

IRISH QUEEN.-Tubers, large and of uniform shape; skin, pink; very prolific cropper; flesh, white; cooks floury; resists wart disease; a popular Irish variety.

MighTy ATOM (Webbs').-Tubers, very large, oval-shaped ; skin, beautifully netted; eyes, shallow; haulm, strong, upright; cooks floury; good keeper; immense cropper ; disease-proof; flowers. white. 
MAJESTIC (Findlay's).-Tubers, oval-shaped; hardy, strong grower; enormous cropper; fine quality and appearance.

New ChIEFTAIN (Webbs'). - Tubers, large, oval; skin, white ; heavy cropper; good cooker and keeper; general culture or exhibition; Howers, mauve.

NEW PROVIDER (Webbs')._'l'ubers, large, oval-round; eyes, shallow; a prolific cropper; flesh, white; cooks floury; disease resister; good keeper; flowers, white.

NEW TABLE KING (Webbs').- Tubers, large, oval ; skin, white ; heavy cropper; flesh, white; good cooker; flowers, lilac.

PROGRESS (Webbs').- - Tubers, very large, oval-shaped; crops heavily, tubers averaging upwards of a pound each; eyes, few and shallow; flesh, white; cooks floury; robust grower.

PROSPERITY (Webbs').-Tubers, large, oval-shaped; very heavy cropper; eyes, shallow; flesh, white; good cooker; robust grower and disease resister; flowers, mauve.

The PRovost (Dobbie's).--Tubers, large, oval-shaped; very heavy cropper; flesh, white; cooks splendidly; resists wart disease; haulm, medium; flowers, white.

SATISFAC'TION (Sutton's). - Tubers, very large, pebble-shaped; eyes, shallow; very heavy cropper; flesh, white; cooks floury; disease resister; flowers, lilac.

THE SCOT (Dobbie's). - Tubers, large, oval-shaped; heavy cropper; flesh, white; good cooker; suitable for exhibition or general use; flowers, lavender, tipped white.

SCOTTISH TRIUMPH.-Tubers, large, oval; very heavy cropper ; flesh, white; good cooker; flowers, mauve.

STOURBRIDGE GLORY (Webbs').-Tubers, very large, ovalshaped; an enormous cropper; flesh, white; cooks floury; good keeper; disease resister; flowers, lilac.

TABLE TALK. - Tubers, large, good shape; skin, netted; very heavy cropper; flesh, white; disease resister; flowers, mauve, tipped white.

TINWALD PERFECTION (Farish's).-Tubers, kidney formed; shallow eyes; yields large crop of uniform tubers; resistant to wart disease.

TREmEnDOUS (Toogood's). - Tubers, exceptionally large, averaging 3 to $4 \mathrm{lbs}$. each; very heavy cropper; flesh, white; cooks floury; haulm, dwarf; the largest variety in cultivation; good exhibition variety.

UP-TO-DATE. - Tubers, very large, oval; skin, netted; prolific cropper; flesh, white; cooks dry and mealy; shallow eyes ; flowers, mauve.

\section{B.-COLOURED ROUNDS.}

The DeAn.-Tubers, large ; skin, deep violet ; flesh, white ; cooks well; heavy cropper; an exhibition variety; flowers, blue, tipped white. 
KERR'S PINK.-Tubers, large, oval-round; skin, pale pink; good cropper ; flesh, white; excellent cooker; resists wart disease; strong grower; flowers, white.

RUSSET RED (Webbs').- Tubers, medium size; skin, red and russety; flesh, white; cooks floury; crops freely; good keeper; flowers, white.

SUTTON FLOURBALL (Sutton's).-Tubers, large and of good shape; skin, dark red; flesh, white; cooks like a ball of flour; flavour excellent; wart disease resister.

TOWSER.- Tubers, large, handsome; skin, red, netted; free cropper; flesh, white; good cooker; resists wart disease.

\section{C.-WHITE KIDNEYS.}

Dover CaStle (Sutton's). - Tubers, large, handsomelyshaped; eyes, shallow; very heavy cropper ; flesh, white; first-rate cooker ; haulm, robust ; disease resister ; flowers, white.

DREADNOUGHT (Fidler's).--Tubers, very large, good shape; shallow eyes; flesh, yellowish; cooks mealy; a free cropper.

GOLDEN WONDER.-Tubers, large, good shape; skin, netted; very heavy cropper; resists the wart disease; flesh, white ; cooks floury; good sort for general use; flowers, lilac.

LANGWORTHY.- Tubers, large; light cropper; flesh, white; good cooker; excellent keeper; immune to wart disease.

RECORD (Webbs').--Tubers, very large, averaging nearly a pound each; heavy cropper; flesh, white; cooks well; keeps well; haulm, vigorous.

WHAT'S WANTED.-Tubers, large ; very prolific cropper; flesh, white; splendid cooker; resists wart disease.

WHITE CITY (Sutton's).-Tubers, large and of handsome contour; eyes, few and shallow; tremendous cropper; flesh, white; cooks dry and floury; haulm, sturdy and erect; resists wart disease; fine exhibition or general variety; flowers, lilac.

\section{D. - COLOURED KIDNEYS.}

Edgecote PURPLE.-Tubers, medium size and of handsome shape; skin, purple; prolific cropper; flesh, white; good cooker; an exhibition variety; flowers, white.

KING EDWARD VII.-Tubers, large, and of good shape; eyes, tinged with pink; flesh, white ; good cooker; heavy cropper; disease resister; flowers, mauve.

ROYAL PURPLE.-Tubers, large and of handsome contour; skin, crimson-purple; free cropper; white flesh; cooks well; robust growth; good exhibition variety; flowers, white. 


\section{VARIETIES IMMUNE FROM THE WART DISEASE.}

The following varieties are recommended by the Board of Agriculture as resistant to the Wart or Black Scab Disease (Synchytrium endoboticum). The Board also warn occupiers of land that it is illegal to plant the following or any other varieties in soils that have been declared to be infected with the Wart Disease without previously having obtained their licence to do so. Penalty-£10.

Abundance (Maincrop white round).

Adirondack (Maincrop coloured round).

Burnhouse Beauty (Seccnd-early white round)

Conquest (Second-early white round).

Crofter (Maincrop white round).

Dobbie's Resistant Snowdrop (First-early white kidney).

Edzell Blue (First-early coloured round).

Favourite (Second-early white round).

Great Scot (Second-early white round).

Golden Wonder (First-early white kidney).

Irish Queen (Maincrop white round).

Kerr's Pink (Maincrop coloured round).

King George (Second-early white oval).

Langworthy (Maincrop white kidney).

Leinster Wonder (Maincrop white round).

Mr. Breese (Second-early coloured kidney).

Rob Roy (Maincrop white oval).

Shamrock (Maincrop coloured round).

Sir Douglas Haig (similar to Great Scot).

Southampton Wonder (ditto).

Sutton Flourball (Maincrop coloured round).

Sutton's Supreme (Maincrop white oval).

The Admiral (Maincrop coloured round).

The Ally (Second-early white oval).

The Duchess (Second-early white round).

The Laird (Maincrop white round).

The Rector (Maincrop coloured round).

The Templar (Maincrop white oval).

What's Wanted (Maincrop white kidney).

White City (Maincrop white kidney). 


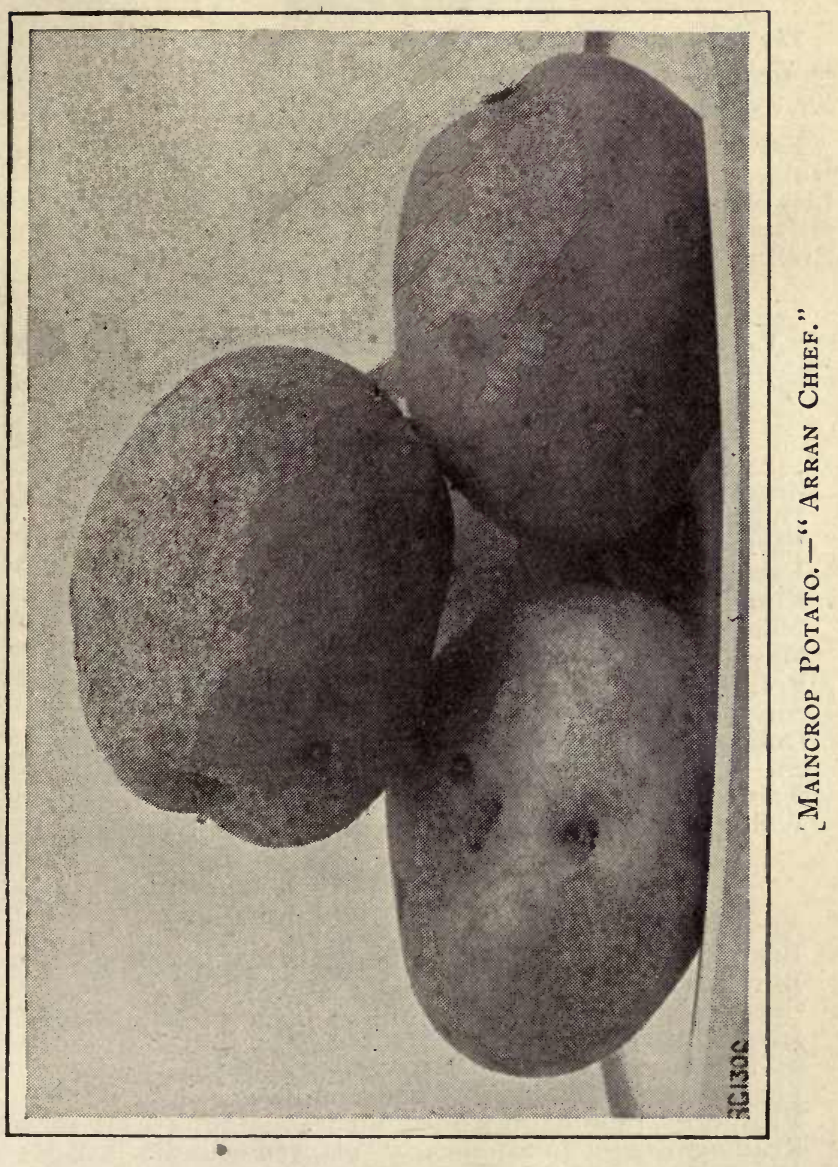




\section{VARIETIES SUSCEPTIBLE TO WART DISEASE.}

The following varieties are declared by the Board of Agriculture to be highly susceptible to Wart Disease, so MUST NOT BE PLANTED ON INFECTED LAND:-

Early Puritan, Epicure, Midlothian Early, British Queen, Duke of York, Sharpe's Express, Sharpe's Victor, Sir John Llewelyn, Evergood, Cora, Cigarette, King Edward VII., Upto-Date, Dalhousie, Duchess of Cornwall, Arran Chief, and Prolific.

\section{VARIETIES FOR LIGHT AND HEAVY SOILS.}

\section{LIGHT SOILS.}

Beauty of Hebron (Second-early coloured round).

Duke of York (First-early white round).

Early Regent (Second-early white round)

Factor (Maincrop white round).

King Edward (Maincrop coloured kidney).

Ninetyfold (First-early white kidney).

May Queen (First-early white kidney).

Progress (Maincrop white round).

Sir John Llewelyn (First-early white kidney).

Dobbie's Resistant Snowdrop (First-early white kidney).

St. Malo (First-early white kidney).

Table Talk (Maincrop white round).

White Beauty of Hebron (Second-early white kidney).

\section{HEAVY SOILS.}

Arran Chief (Maincrop white round).

British Queen (Second-early white kidney).

Burnhouse Beauty (Second-early white round).

Great Scot (Second-early white round).

Irish Queen (Maincrop coloured round).

Midlothian Early (First-early white kidney).

Mighty Atom (Maincrop oval-round).

Prosperity (Maincrop white round).

Reading Russet (Second-early coloured round).

Royal Kidney (Second-early white kidney).

Sharpe's Express (First-early white kidney).

What's Wanted (Maincrop coloured kidney).

Windsor Castle (Second-early white round). 


\section{VARIETIES FOR EXHIBITION.}

Duke of York (First-early).

\section{WHITE KIDNEYS.}

Midlothian Early (First-early).

New Colonist (First-early).

Royal Kidney (Second-early).

Sir John Llewelyn (First-early).

Snowdrop (First-early).

White City (Maincrop).

Wordsley Pride (Second-early).

\section{WHITE ROUNDS.}

Abundance (Maincrop).

Arran Chief (Maincrop).

Chieftain (Maincrop).

Duchess of Norfolk (Second-early).

Goldfinder (Maincrop).

The Scot (Maincrop).

Windsor Castle (Second-early).

\section{COLOURED KIDNEYS.}

Crimson Beauty, (First-early).

Edgecote Purple (Maincrop).

King Edward (Maincrop).

Mr. Breese (Second-early).

Pink Beauty (Second-early)

Red Kidney (First-early).

Royal Purple (Maincrop).

\section{COLOURED ROUNDS.}

Kerr's Pink (Maincrop).

Lord Tennyson (Second-early).

Reading Russet (Second-early).

Russet Red (Maincrop).

Sutton's Flourball (Maincrop).

The Dean (Main-crop).

\section{VARIETIES THAT COOK FLOURY.}

Chieftain (Maincrop).

Dobbie's Prolific (Maincrop white round).

Duchess of Norfolk (Second-early white round).

Goldfinder (Maincrop white round).

Gordon Castle (Maincrop white round).

Great Scot (Second-early white round).

Irish Queen (Maincrop white round).

Kerr's Pink (Maincrop coloured round).

Mighty Atom (Maincrop).

New Provider (Maincrop white round). 
Progress (Maincrop white round).

Prosperity (Maincrop).

Russet Red (Maincrop coloured round).

Satisfaction (Maincrop white round).

Sutton Flourball (Maincrop coloured round).

Sutton's A.r. (First-early white round).

The Provost (Maincrop white round).

Toogood's Tremendous (maincrop white kidney).

Warwick Castle (Second-early white round).

White City (Maincrop white kidney).

\section{YELLOW-FLESHED VARIETIES.}

Duke of York (First-early white kidney).

First Crop (First-early white kidney).

Midlothian Early (First-early white kidney).

Myatt's Ashleaf Kidney (First-early white kidney).

Red Kidney (First-early coloured round.

Sharpe's Victor (First-early white kidney).

\section{VARIETIES FOR SIZE AND WEIGHT.}

Dreadnought (Maincrop white kidney).

Factor (Maincrop white round).

Great Scot (Maincrop white round).

New Guardian (Second-early white kidney).

New Provider (Maincrop white round).

Toogood's Tremendous (Maincrop kidney).

Stourbridge Glory (white round).

Stourbridge Glory (Maincrop white round).

\section{VARIETIES FOR ALLOIMENTS.}

FIRST EARLY-

Duke of York (white kidney).

May Queen (white kidney).

Midlothian Early (white kidney).

Sir John Llewelyn (white kidney).

SECOND EARLY-

Burnhouse Beauty (white round).

Great Scot (White round).

New Guardian (white kidney).

Warwick Castle (white round).

Wordsley Pride (white kidney).

MAINCROP-

Arran Chief (white round).

Chieftain (white round).

King Edward VII. (coloured kidney).

Mighty Atom (white round).

The Factor (white round). 


\section{FIDLERS' GARDEN SEEDS}

ARE NOTED FOR THEIR

\section{PURITY, VITALITY, and CHEAPNESS}

50 per cent. less cost than some Houses in the Trade.

Our Illustrated List, giving full particulars of the best Vegetable and Flower Seeds and Seed Potatoes will be sent Gratis and Post Free to any address upon application. Send for a copy, and note the prices for yourself

\section{COLLECTIONS OF FLOWER AND VEGETABLE SEEDS to suit any sized Garden.}

\section{FIDLERS' GIANT FLOWERED SWEET PEAS} in liberal packets at popular prices. SEED POTATOES A SPECIALITY FIDLER \& SONS ( $\left.\begin{array}{c}\text { Establihbed } \\ 1856\end{array}\right)$ Royal Berkshire Seed Stores, REA D I N G. 


\section{N D E X.}

PAGE

PAGE

$\begin{array}{llllll}\text { Blacklands } & \ldots & \ldots & \ldots & \ldots & 28\end{array}$

Diseases of Potatoes-

Bordeaux Mixture $\quad . . \quad \ldots 166$ Spindle Disease $\quad \ldots \quad \ldots 177$

Botanical Features ... ... 16

$\begin{array}{llllll}\text { Wet Rot } & \ldots & \ldots & \ldots & \ldots & 175\end{array}$

$\begin{array}{lllllll}\text { Name } & . . & \ldots & \ldots & \ldots & \ldots & 16\end{array}$

Distances for Planting $\quad$.. 76

Botany of the Potato ... $\quad \ldots \quad 15$

Drainage, Cost of $\quad$... $\quad$... 200

Boxing and Sprouting

$\begin{array}{llllll}\text { Tubers } & \ldots & \ldots & \ldots & \ldots & 62\end{array}$

Irish Experiments in $\quad \ldots \quad 70$

Catch Crops in Gardens ... 93

Drill System of Planting $\quad \ldots \quad 75$

Cattle, Potatoes for Feeding 188

Chalk Caves, Culture in ... 111

Channel Islands, Culture in 12

Clamping and Pitting Pota-

$\begin{array}{llllll}\text { toes } \ldots & \ldots & \ldots & \ldots & \ldots & 124\end{array}$

Cooking Potatoes... $\quad \ldots \quad \ldots \quad 178$

Copper and Soda Mixture ... 166

Crops, Estimating Weight of 200

Cross-Fertilisation $\quad$... $\quad \ldots \quad 136$

Cultivation, Cost of $\ldots . .198$

Diseases of Potatoes ... $\quad \ldots \quad 162$

Bacteriosis... $\quad \ldots \quad \ldots \quad \ldots \quad 170$

Black Scab or Wart Dis$\begin{array}{lllllll}\text { ease } \ldots & \ldots & \ldots & \ldots & \ldots & 170\end{array}$

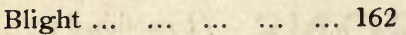

$\begin{array}{llllll}\text { Leaf Curl } & \ldots & \ldots & \ldots & \ldots & 175\end{array}$

$\begin{array}{lllllll}\text { Rot } & \ldots & \ldots & \ldots & \ldots & \ldots & 171\end{array}$

$\begin{array}{lllllll}\text { Scab } & \ldots & \ldots & \ldots & \ldots & \ldots & 17_{2}\end{array}$

Sclerotium Disease ... $\quad \ldots \quad 171$

Sea Blight ... $\quad \ldots \quad \ldots \quad \ldots \quad \ldots 177$

Exhibition, Culture for $\quad \ldots \quad 97$

Varieties for $\quad \ldots \quad \ldots \quad \ldots 102$

Expenses and Returns _.. 23

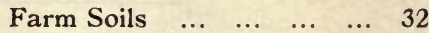

Farms, Acreage on ... $\quad \ldots \quad 78$

$\begin{array}{llllll}\text { Culture on ... } & \ldots & \ldots & \ldots & 78\end{array}$

$\begin{array}{lllll}\text { Field Culture } \ldots & \ldots & \ldots & \ldots & 78\end{array}$

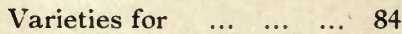

Flat System of Planting $\quad \ldots \quad 75$

Forcing Potatoes... ... ... 102

Foreign Names of the Potato 16

Frames, Culture in Cold ... 108

$\begin{array}{llllll}\text { Fungicides } & \ldots & \ldots & \ldots & \ldots & 166\end{array}$

$\begin{array}{lllll}\text { Garden Soils ... } & \ldots & \ldots & \ldots & 29\end{array}$

Gardens, Culture in $\quad \ldots \quad \ldots \quad 88$

Early Crops in ... $\quad \ldots \quad$... 90

Second Early Crops in ... 91

Maincrops in $\quad \ldots \quad \ldots . \quad \ldots \quad 92$

History of the Potato ... ... 1

IHorses, Potatoes for Feeding 188

Hotbeds, Culture on ... ... 106 


\section{INDEX.}

PAGE

PAGE

Implements for Potato Cul$\begin{array}{llllll}\text { ture } \ldots & \ldots & \ldots & \ldots & \ldots & 192\end{array}$

$\begin{array}{llllll}\text { Diggers } & \ldots & \ldots & \ldots & \ldots & 192\end{array}$

$\begin{array}{llllll}\text { Harrows } & \ldots & \ldots & \ldots & \ldots & \ldots 4\end{array}$

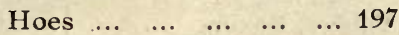

$\begin{array}{llllll}\text { Planter } & \ldots & \ldots & \ldots & \ldots & 194\end{array}$

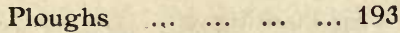

$\begin{array}{llllll}\text { Shovels } & \ldots & \ldots & \ldots & \ldots & 197\end{array}$

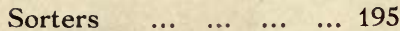

Weighing Machines... ... 197

Ireland, Potato First Introduced to... $\quad \ldots \quad$...

John Evelyn's Advice ... $\quad . . \quad 7$

Lazybed System of Planting $\mathbf{7 5}$ Lifting the Crop ... $\quad \ldots \quad \ldots \quad 115$

Lord Bacon on Potatoes ... 7

Manures and Manuring $\quad \ldots \quad 36$

$\begin{array}{llllll}\text { Basic Slag ... } & \ldots & \ldots & \ldots & 37\end{array}$

$\begin{array}{lllll}\text { Bone Meal ... } & \ldots & \ldots & \ldots & 37\end{array}$

$\begin{array}{llllll}\text { Farmyard } & \ldots & \ldots & \ldots & \ldots & 36\end{array}$

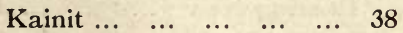

$\begin{array}{llllllll}\text { Lime } & \ldots & \ldots & \ldots & \ldots & \ldots & 42\end{array}$

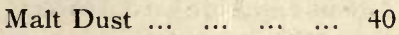

Nitrate of Soda $\quad \ldots \quad$... 40

Nitrogenous $\quad \ldots \quad \ldots \quad \ldots 40$

$\begin{array}{llll}\text { Muriate of Potash ... } & \ldots & 38\end{array}$

Phosphates for Heavy $\begin{array}{llllll}\text { Soils... } & \ldots & \ldots & \ldots & \ldots & 37\end{array}$

Phosphates for Light Soils 37

$\begin{array}{lllll}\text { Phosphatic... } & \ldots & \ldots & \ldots & 37\end{array}$

$\begin{array}{llllll}\text { Potash... } & \ldots & \ldots & \ldots & \ldots & 37\end{array}$

$\begin{array}{llllll}\text { Seaweed } & \ldots & \ldots & \ldots & \ldots & 42\end{array}$

$\begin{array}{lllllll}\text { Soot } & \ldots & \ldots & \ldots & \ldots & \ldots & 40\end{array}$

Special, for Field Crops ... 40

Special, for Garden Crops 40

Sulphate of Ammonia ... 40
Manures-Sulphate of Iron 38

Sulphate of Potash ... ... 38

Manuring Experiments, Eng-

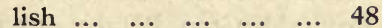

$\begin{array}{lllllll}\text { Irish } & \ldots & \ldots & \ldots & \ldots & \ldots & 44\end{array}$

$\begin{array}{llllll}\text { Scottish } & \ldots & \ldots & \ldots & \ldots & 46\end{array}$

Marketing the Crop $\quad \ldots \quad \ldots 115$

Measures $\quad \ldots \quad \ldots \quad \ldots \quad \ldots 198$

Monstrosities... $\quad \ldots \quad \ldots \quad \ldots 201$

Novel Potato Culture ... . .. 111

Packing for Market ... ... 119

Pasture Land, Broken up ... 33

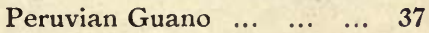

$\begin{array}{lllllll}\text { Pests } & \ldots & \ldots & \ldots & \ldots & \ldots & 140\end{array}$

$\begin{array}{lllllll}\text { Bug } & \ldots & \ldots & \ldots & \ldots & \ldots & 156\end{array}$

$\begin{array}{llllll}\text { Centipedes... } & \ldots & \ldots & \ldots & 146\end{array}$

Colorado Beetle ... ... 147

Dart Moth Caterpillars ... 149

Death's Head Moth... ... 152

$\begin{array}{lllllll}\text { Frog Fly } & \ldots & \ldots & \ldots & \ldots & 154\end{array}$

Heart and Dart Moth $\begin{array}{lllll}\text { and Larva } & \ldots & \ldots & \ldots & 150\end{array}$

$\begin{array}{llllll}\text { Millepedes ... } & \ldots & \ldots & \ldots & 144\end{array}$

Potato Gnat $\quad \ldots \quad$... $\quad \ldots \quad 156$

Slugs and Snails $\quad \ldots \quad \ldots 159$

Wireworms $\quad \ldots \quad \ldots . .142$

Yellow Underwing Moth and Larva $\quad \ldots \quad \ldots \quad \ldots 158$

Pigs, Potatoes for Feeding 189

Pits, Culture in Heated ... 108

Planting, Distances for $\quad \ldots \quad 76$

$\begin{array}{lllll}\text { Drill System } & \ldots & \ldots & \ldots & 74\end{array}$

Field Crops $\quad \ldots \quad \ldots \quad \ldots \quad 82$

$\begin{array}{lllll}\text { Flat System } \quad \ldots & \ldots & \ldots & 75\end{array}$

Lazybed System $\quad \ldots \quad \ldots \quad 75$

Ploughing-in System _.. 76

$\begin{array}{llllll}\text { System } \text { of } & \ldots & \ldots & \ldots & \ldots & 74\end{array}$ 
PAGE

Pot Culture of Potatoes ... 104

Poultry Food, Potatoes as... 182

Prices Obtained ... $\quad \ldots \quad$... 22

Profitable Crop, Potatoes as a 20

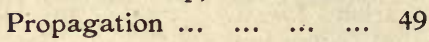

by Cuttings $\quad \ldots \quad \ldots \quad \ldots \quad 55$

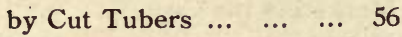

$\begin{array}{llllll}\text { by Eyes } & \ldots & \ldots & \ldots & \ldots & 54\end{array}$

by Grafting $\quad \ldots \quad \ldots \quad \ldots \quad 199$

$\begin{array}{llllll}\text { by Seeds } & \ldots & \ldots & \ldots & \ldots & 52\end{array}$

Puritan Times, the Potato in 7

Rearing New l'arieties _.. 132

Scotland, Introduction of

$\begin{array}{lllll}\text { Potato into } & \ldots & \ldots & \ldots & 8\end{array}$

" "Seed," Change of ... $\quad \ldots \quad 61$

for Planting $\quad$...

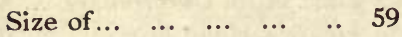

Whole, Cut, and Cuttings 50

Soil Cultivation, Cost of ... 199

Soils and their Treatment ... 27

$\begin{array}{lllllll}\text { Farm } & \ldots & \ldots & \ldots & \ldots & \ldots & 32\end{array}$

for Early Crops... $\quad \ldots \quad \ldots \quad 34$

$\begin{array}{llllll}\text { Garden } & \ldots & \ldots & \ldots & \ldots & 29\end{array}$

in Relation to Acreage ... 28

$\begin{array}{llllll}\text { Ridging } & \ldots & \ldots & \ldots & \ldots & 31\end{array}$

$\begin{array}{llllll}\text { Trenching } & \ldots & \ldots & \ldots & \ldots & 30\end{array}$

Spraying Field Crops ... $\quad \ldots \quad 86$

Stock Feeding, Potatoes for 187
PAGE

Storing Potatoes $\ldots . \quad \ldots \quad \ldots \quad 122$

$\begin{array}{llllll}\text { for Planting } & \ldots & \ldots & \ldots & 130\end{array}$

$\begin{array}{lllllll}\text { Green } & . . & \ldots & \ldots & \ldots & \ldots & 130\end{array}$

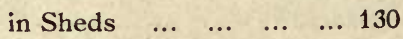

Tubers, Boxing $\quad \ldots \quad$...

$\begin{array}{lllll}\text { Constituents of } & \ldots & \ldots & \ldots & 16\end{array}$

$\begin{array}{lllll}\text { for Planting } & \ldots & \ldots & \ldots & 59\end{array}$

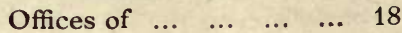

Varieties, First Early ... ... 207

for Allotments ... $\quad \ldots \quad$... 220

for Exhibition $\quad \ldots \quad$...

for Field Culture $\quad \ldots \quad$... 84

for Forcing $\quad \ldots \quad \ldots \quad \ldots 110$

for Garden Culture ... ... 93

for Light and Heavy Soils 218

for Size and Weight... .... 220

grown Sixty Years Ago ... 8

Immune from the Wart

$\begin{array}{llllll}\text { Disease } & \ldots & \ldots & \ldots & \ldots & 216\end{array}$

Best to Grow ... ... ... 207

$\begin{array}{llllll}\text { Maincrop } & \ldots & \ldots & \ldots & \ldots & 212\end{array}$

$\begin{array}{lllll}\text { Rearing New } & \ldots & \ldots & \ldots & 132\end{array}$

Second Early $\quad \ldots \quad \ldots \quad \ldots 210$

Susceptible to Wart

$\begin{array}{lllll}\text { Disease } & \ldots & \ldots & \ldots & 218\end{array}$

that Cook Floury ... $\quad \ldots \quad 219$

Yellow-fleshed $\quad \ldots \quad$... 220

Yield per Acre $\quad \ldots \quad \ldots \quad 20,198$

Yields, Heaviest $\ldots . \quad \ldots \quad$... 199 


\section{THE POTATO PROBLEM!}

\section{Two points of urgent importance}

1. The National Food Supply.

At the present time, when the production of Food Crops is of such great national importance, Growers would be well repaid to give a trial to the "Castle" Strain of Pedigree Seedling Potatoes.

Noted for its

Vigorous Constitution,

High Table Quality,

Heavy Cropping Properties, Freedom from Disease.

\section{The Destructive Wart Disease.}

Highly contagious in its nature and very destructive in its effects. Experiments, however, have shown that certain Potatoes are resistant to the disease, and have been declared by the Board of Agriculture and Fisheries to be immuned from the pest.

Full List of Varieties post free on application From

SUTTON \& SONS, Seed Potato READING 


\section{SCOTCH
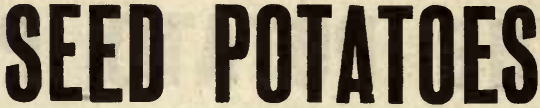

(FROM FORFARSHIRE.)

\section{CANNOT BE BEATEN}

YOU MAY FULLY RELY UPON OB'TAINING true, clean and healthy Seed of all the varieties recommended in this book, for Early, Mid-season or Main Crop.

I shall be pleased to quote for the whole or part of any of the selections for special purposes, or to supply planting stock for Private Gardens, Allotments or Small Holdings, at Lowest Prices for QUALITY.

Send for Free Lists and Testimonials.

\section{JAS. MILNE, York Place, Monlfieth, SEOTLAND}

\section{SEND A POST CARD FOR \\ COMPLETE CATALOGUE OF HORTICULTURAL BOOKS}

Published by

W. H. \& L. COLLINGRIDGE, 148-9, Aldersgate Street, London, E.C.

\section{SCOTCH \\ GROWN SEED \\ POTATOES}

I will be pleased to quote prices for above on receiving particulars of kinds and quantities wanted. WRITE FOR CATALOGUE.

WILLIAM DAVIE, Sead Potate Grover HADDINGTON, SCOTLAND. 


\section{LINCOLHSHIRE SEED POTATOES}

ARE

JUSTLY FAMOUS

For Highest Quality and Productiveness.

The First Essential to Successful

$\because$ Culture is GOOD SEED $\because$

THE BEST LINCOLNSHIRE SEED

IS OBTTANABLE FROM

AMBRose LICHTON,

KIRTON, Nr. BOSTON, LINCS.

SHARPE'S EXPRESS,

\section{ARRAN CHIEF, \\ GREAT SCOTT,}

ECLIPSE, SIR JOHN LLEWELLYN, MYATTS, DUKE OF YORK, EARLY ROSE, FACTOR,

and all the finest and most productive varieties in commerce are carefully and extensively grown, and constantly re-selected on my oivn grounds for Seed purposes.

We have satisfied thousands of Gardeners and Allotment Holders, and can supply clean vigorous stock at fair prices. Write, stating requirements, quotation, and Catalogue will be sent gratis.

Bargain Lists of Seeds, Seed Potatoes, Roses. Bulbs, Hardy Plants and Fruit Trees, FREE.

AMBROSE LIGHTON, KIRTON, Nr. BOSTON, LINGS. 


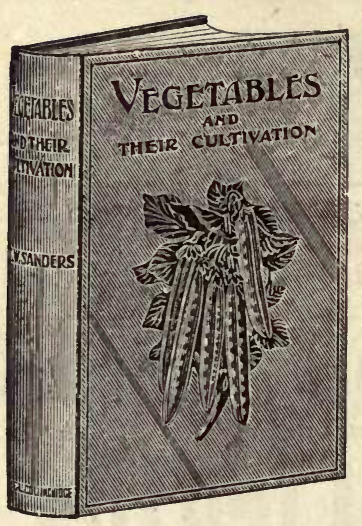

\section{The Art of Kitchen : : Gardening.}

AN UP-TO-DATE AND PRACTICAL WORK ON GROWING VEGETABLES, SALADINGS AND HERBS, IS THE SECOND EDIIION :: $:: \quad:$ OF $\quad$ :: $:: \quad$ ::

\section{VEGETABLES}

AND THEIR CULTIVATION

\section{By T. W. SANDERS,}

PRICE

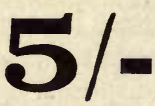

NET.
F.L.S, F.R.H.S., Editor of "Amateur Gardening."

There is no better work on the Formation and Successful Upkeep of the Kitchen Garden.

Cloth. 500 Pages, and 150 Illustrations in Colour and Black - and - White.

(By Post, 5/6)
W. H. \& L. COLLINGRIDGE, "Amateur Gardening" Office, 148-9, ALDERSGATE STREET, E.C. 


\section{WORLD-RENOWNED.}

THE

\section{Encyclopadia of Gardening.}

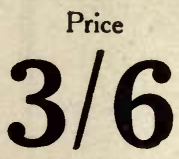

By Post, 3/11

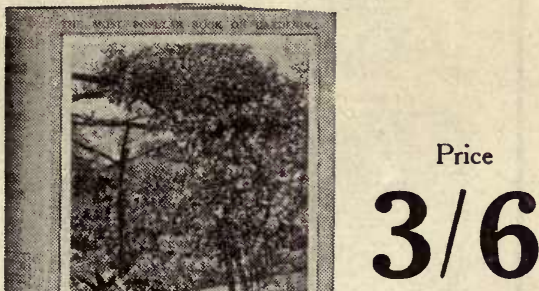

The Encyclopredia of GARDENING $3 / 6$

7 Here is NO OTHER GARDENING BOOK that has met with such continuou suc:ess and appreciation. Its merits have called forth edition after edition.

THE REASON IS that it tells AT A GLANCE all one wants to know about the CULTURE, PROPAGATION, and DESCRIPTION of FRUIT, FLOWERS, VEGETABLES, PLANTS, TREES, and SHRUBS, including TIME OF PLANTING, COLOUR, HEIGHT, and FLOWERING PERIOD. It includes their LATIN and COMMON NAMES.

\section{The Busy Man's Garden Guide.}

W. H. \& L. COLLINGRIDGE,

"Amateur Gardening" Office,

148-9. ALDERSGATE STREET, LONDON, E.C. 


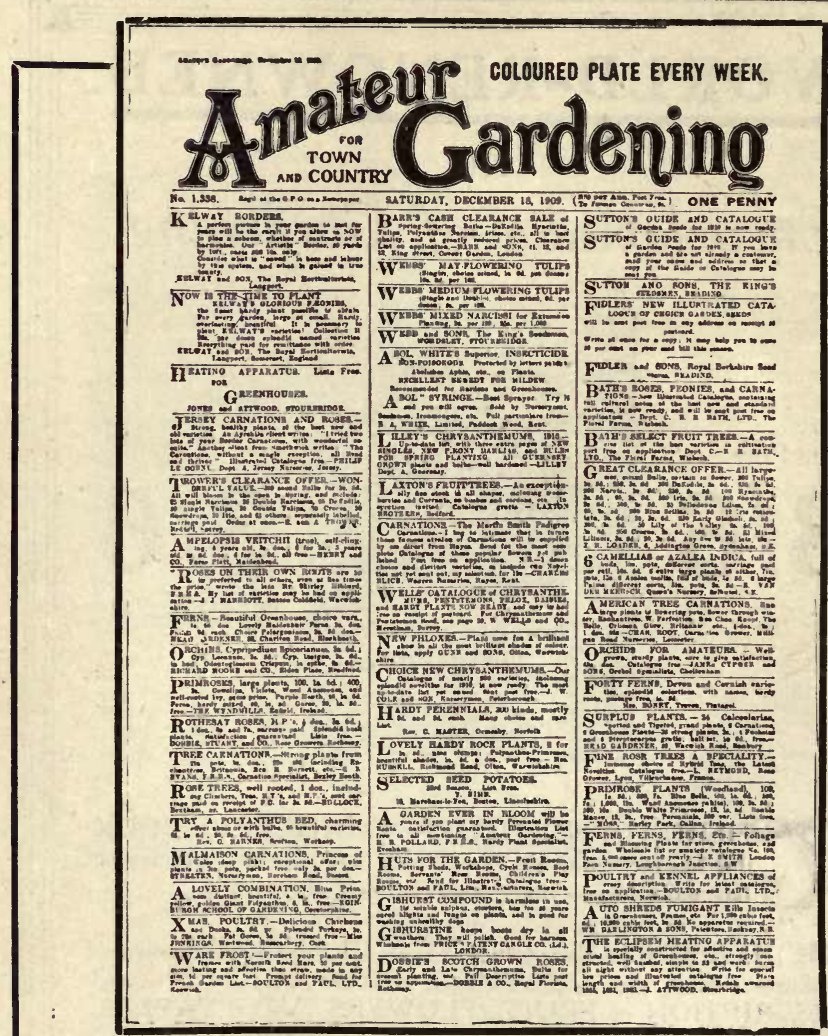

\section{The LARGEST and BEST PAPER for AMATEUR GARDENERS * *}

A Coloured Plate is Presented Gratis Every Week.

THERE is no other journal so eagerly sought by all classes of

Gardeners. The bright, crisp, and intensely practical manner in which it deals with all phases of gardening has made it pre-eminent. Every Newsagent stocks it. $\therefore \quad \therefore \quad \therefore \quad \therefore$ Price One Penny.

London: 148=9, Aldersgate Street, E.C. 

THIS BOOK IS DUE ON THE LAST DATE STAMPED BELOW

AN INITIAL FIN OF 25 CENTS WILL BE ASSESSED FOR FAILURE TO RETURN THIS BOOK ON THE DATE DUE. THE PENALTY WILL INCREASE TO 50 CENTS ON THE FOURTH DAY AND TO \$1.00 ON THE SEVENTH DAY 3*: OYERTYUE.

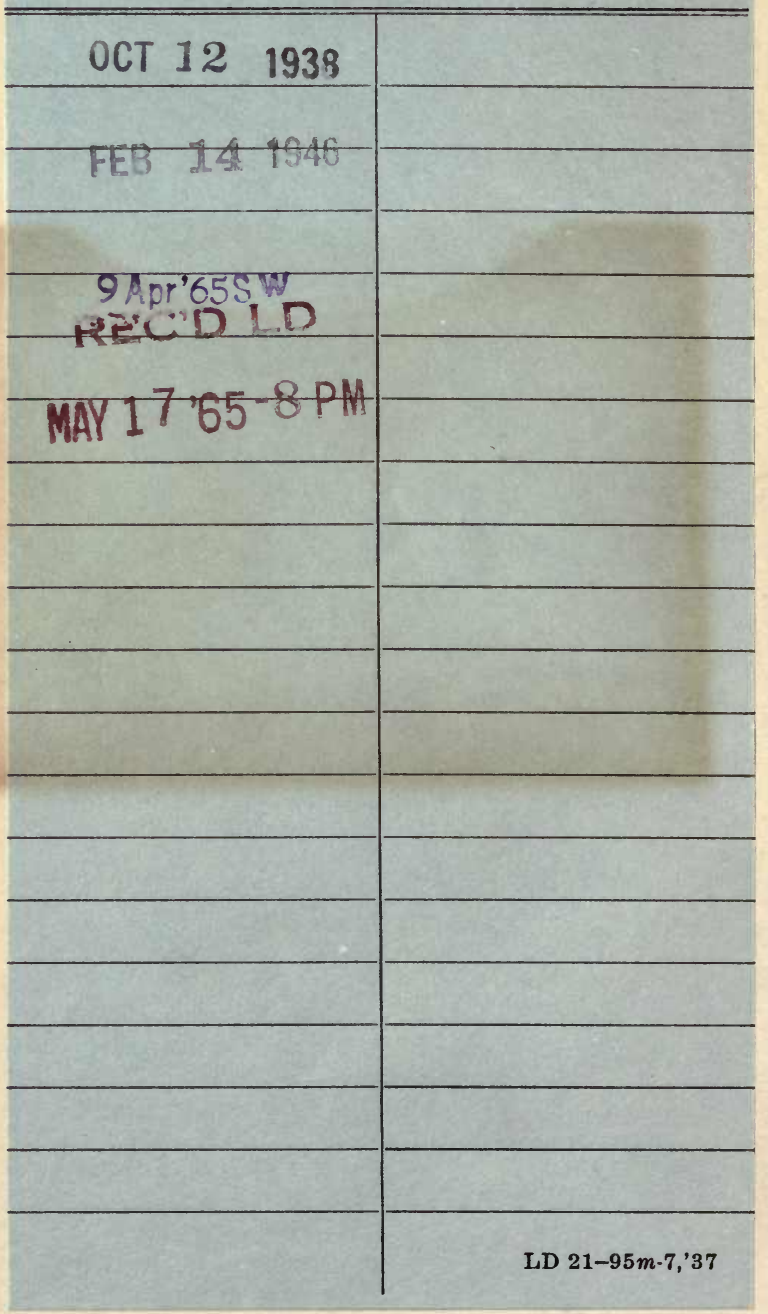


